\title{
MESOESTRUCTURA, COMPORTAMIENTO MECÁNICO Y PROPIEDADES DE TRANSPORTE EN HORMIGÓN.
}

Aplicación a hormigones dañados y hormigones especiales.

\author{
María Celeste Torrijos
}

Tesis presentada para el grado de

$$
\text { DOCTOR EN INGENIERÍA }
$$

Departamento de Construcciones, Facultad de Ingeniería, Universidad Nacional de La Plata, Diciembre, 2008

Director: Raúl L. Zerbino 


\section{AGRADECIMIENTOS}

Quisiera agradecer en primer lugar a mi director el Dr. Raúl Zerbino por sus valiosos aportes, dedicación y apoyo.

A la Ing. Graciela Giaccio por sus contribuciones.

A las autoridades del LEMIT por permitirme realizar la mayor parte de los trabajos de esta tesis, al personal del LEMIT por la ayuda brindada para la realización de los ensayos y a mis compañeros por los años compartidos.

Al Departamento de Construcciones de la Facultad de Ingeniería de la UNLP donde se realizaron los trabajos sobre fluencia en hormigones dañados por temperatura.

Al Dr. Bryan Barragán y al Laboratorio de Tecnología de Estructuras de la Universitat Politècnica de Catalunya donde se realizaron los estudios de hormigones autocompactantes reforzados con fibras.

Finalmente quisiera agradecer a mi familia, especialmente a mi mamá por el apoyo y la confianza constante y a Flavio por la paciencia y comprensión. 


\section{RESUMEN}

El hormigón es un material compuesto a distintos niveles. A nivel mesoestructural se puede distinguir una matriz porosa de mortero que rodea a los agregados gruesos y las interfaces matriz-agregado, además se pueden observar diferentes tipos de defectos como defectos de compactación o fisuras de diverso origen. En el caso de hormigones reforzados con fibras se consideran las fibras como elementos distintivos de la mesoestructura.

Si bien se ha reconocido la influencia de la estructura interna sobre las propiedades del hormigón son contados los trabajos que lo hacen en función de los parámetros medidos a nivel mesoestructural. En esta tesis se analiza la mesoestructura del hormigón y su vinculación con la respuesta mecánica y las propiedades de transporte. En primer lugar se buscó una metodología para cuantificar el cuadro de fisuración (ancho y densidad de fisuras) y la distribución de los agregados de mayor tamaño y sus interfaces, como elementos característicos de la mesoestructura del hormigón. Para el caso particular de los hormigones con fibras se evaluaron la distribución y orientación del refuerzo.

Como casos de aplicación se analizaron hormigones dañados por altas temperaturas, por contracción por secado y por reacción álcali-sílice. Se evaluaron fisuras en muestras de hormigón expuestas a distintas temperaturas o a secado en un ambiente con baja humedad, los diferentes niveles de daño se vincularon con la respuesta mecánica en compresión y tracción y con las propiedades de transporte (absorción capilar y permeabilidad). Estudios similares se realizaron sobre otras muestras de hormigón dañadas por altas temperaturas sometidas a cargas de larga duración. Se encontró que los distintos niveles de daño afectan en forma diferenciada a las propiedades de transporte, mientras la permeabilidad aumentó en forma continua con el aumento del ancho de fisuras, se observó que la absorción capilar tuvo un máximo para anchos intermedios de fisuras. Finalmente se estudiaron hormigones dañados por reacción álcali-sílice, abordando en este caso un aspecto original, considerando el desarrollo de las fisuras bajo cargas de larga duración así como sobre muestras libres de cargas. Se encontró un marcado efecto de las tensiones aplicadas sobre la propagación de las fisuras, las medidas de la orientación de las fisuras mostraron una clara relación con las propiedades mecánicas. 
El estudio de la mesoestructura también se aplicó para analizar hormigones reforzados con fibras y hormigones autocompactantes. Se estudiaron la orientación de fibras de acero y fibras de polipropileno en hormigón convencional vibrado y su influencia sobre los parámetros post fisuración obtenidos en ensayos de flexión sobre vigas entalladas. Además se analizó la orientación y distribución que adquieren las fibras de acero y la influencia de la forma de moldeo en hormigón autocompactante. Se encontró que en hormigones autocompactantes las fibras tienden a orientarse en planos horizontales, siendo fuertemente afectadas por el flujo de hormigón y el efecto pared del molde. Finalmente se evaluó la homogeneidad en base a la distribución de agregados en elementos esbeltos de hormigones autocompactantes con y sin refuerzo de fibras y elaborados con distintos tipos de agregados. 


\section{ABSTRACT}

Concrete is a composite material at different levels. At the mesostructural level it can be seen as a porous mortar matrix that surrounds coarse aggregates and matrixaggregates interfaces, also different types of defects such as cracks or compaction defects can be distinguished. In the case of fibre reinforced concrete the fibres can be considered as distinct elements from the mesostructure.

Although the influence of the internal structure of concrete over its properties had been recognized, there are few works where it was related with mesostructurals parameters. In this thesis the concrete mesostructure and its relationship with the mechanical response and transport properties in damaged, fibre reinforced and self compacting concretes are analysed. First of all, a method to characterize mainly the crack pattern (fibre width and density) and aggregates distribution in concrete was sought, as characteristics elements of concrete mesostructure. For the particular case of fibre reinforced concrete the reinforce distribution and orientation was studied.

The adopted method was used for evaluating damages in concrete caused by high temperatures, drying shrinkage and alkali-silica reaction. Cracks were studied on specimens damaged by exposure to high temperatures and drying in a low humidity environment, and the different levels of damage were related to the mechanical response in compression and tension and with the transport properties (sorptivity and permeability). The influence of long term loads on other concrete specimens damaged by high temperature was evaluated. It was found that the different levels of damage doesn't affect the transport properties in the same way, as the permeability increased with cracks width increments, the sorptivity had a maximum for intermediate crack width. Finally, concretes damaged by alkali-silica reaction were studied, considering the crack development under long term loads. It was found that the loads applied had a great influence over crack propagation, the cracks orientation measurement showed a direct relationship with the mechanical response.

The mesostructure study was also carried out on fibre reinforced concretes and self compacting concretes. In the former case, the orientation of steel and polypropylene fibres and its influence in the post peak behaviour in conventional vibrated concrete was studied; in self compacting concrete the orientation and distribution that steel fibres acquire and the influence of the casting procedure was analysed. It was found that the fibres were oriented on horizontals planes also in self compacting concretes, 
being the wall effect and the flow through the moulds the main factors that oriented fibres. Finally the homogeneity on slender elements made of self compacting concrete with and without fibre reinforce and with different types of aggregates was evaluated through the aggregate distribution analysis. 


\section{Índice}

Índice de Figuras

Índice de Tablas

Capítulo I: Introducción 1

1.1 Estructura y propiedades del hormigón 1

1.2 Objetivos 3

1.3 Estructura 4

Capítulo II: Estructura y Propiedades del hormigón 6

$\begin{array}{ll}2.1 \text { Mesoestructura del hormigón } & 7\end{array}$

2.2.1 Estructura y respuesta mecánica 12

2.2.2 Estructura y mecanismos de transporte 14

$\begin{array}{ll}\text { 2.2.3 Evaluación de la mesoestructura } & 17\end{array}$

$\begin{array}{ll}2.2 \text { Mesoestructura en hormigones dañados } & 19\end{array}$

2.2.1 Procesos de daño en hormigón por exposición a alta temperatura 20

2.2.2 Procesos de daño en hormigón por contracción por secado 26

2.2.3 Procesos de daño en hormigón por reacción álcali-sílice 27

2.3 Mesoestructura en hormigones especiales $\quad 30$

2.3.1 Hormigón Autocompactante $\quad 30$

2.3.2 Hormigón Reforzado con Fibras 33

2.3.2.1 Hormigón Vibrado Reforzado con Fibras (HVRF) 35

2.3.2.2 Hormigón Autocompactante Reforzado con Fibras (HACRF) 36

2.3.3 Métodos de relevamiento de fibras $\quad 37$

2.3.4 Determinación analítica de la orientación de las fibras 38

2.4 Consideraciones finales $\quad 40$

Capítulo III: Programa experimental $\quad 42$

3.1 Introducción $\quad 42$

3.2 Plan de trabajos expermientales 43

3.2.1 Estudios sobre hormigones dañados 43

3.2.2 Estudios sobre hormigones especiales 45

3.3 Técnicas experimentales 47 
3.3.1 Caracterización del cuadro de fisuración y de la distribución de agregados 47

3.3.1.1 Descripción del método

3.3.1.2 Evaluación del método

3.3.2 Análisis de la densidad de fibras

3.3.3 Evaluación de las propiedades macroscópicas

3.3.3.1 Velocidad de pulso ultrasónico

3.3.3.2 Variación de longitud

3.3.3.3 Frecuencia de resonancia

3.3.3.4 Absorción de agua 24 horas y Densidad (ASTM C 642-90) 54

3.3.3.5 Absorción capilar (IRAM 1871) 55

3.3.3.6 Penetración de agua a presión (IRAM 1554) y Permeabilidad 56

3.3.3.7 Caracterización del comportamiento mecánico en compresión uniaxial 58

3.3.3.8 Flexión sobre hormigón convencional (RILEM TC50-FMC) 60

3.3.3.9 Tracción por compresión diametral (IRAM 1658) 61

3.3.3.10 Flexión sobre hormigones con fibras (RILEM TC162-TDF-EN 14651) 61

3.3.3.11 Fluencia bajo cargas de compresión de larga duración 64

3.3.4 Acondicionamiento para el desarrollo de los procesos de degradación 65

3.3.4.1 Exposición a alta temperatura 65

3.3.4.2 Contracción por secado 66

3.3.4.3 Reacción álcali-sílice $\quad 66$

Capítulo IV: Estudios sobre hormigones dañados $\quad 67$

$\begin{array}{ll}4.1 \text { Introducción } & 67\end{array}$

4.2 Variabilidad de la mesoestructura en hormigones dañados por temperatura 68

$\begin{array}{ll}4.2 .1 \text { Materiales y mezclas } & 69\end{array}$

4.2.2 Detalles experimentales $\quad 69$

$\begin{array}{ll}4.2 .3 \text { Resultados y discusión } & 71\end{array}$

4.2.3.1 Evaluación de la mesoestructura 71

4.2.3.2 Mesoestructura y propiedades del hormigón 81

4.2.4 Conclusiones 85

4.3 Mesoestructura y propiedades macroscópicas en hormigones dañados 86 por alta temperatura y por contracción por secado

4.3.1 Materiales y mezclas 86

4.3.2 Detalles experimentales 86

4.3.3 Resultados y discusión $\quad 87$

$\begin{array}{ll}\text { 4.3.4 Conclusiones } & 101\end{array}$

4.4 Mesoestructura y propiedades residuales en hormigones dañados 102 
por exposición a alta temperatura y sometidos a cargas de larga duración

$\begin{array}{ll}\text { 4.4.1 Materiales y mezclas } & 102\end{array}$

4.4.2 Detalles experimentales 102

$\begin{array}{ll}\text { 4.4.3 Resultados y discusión } & 104\end{array}$

4.4.4 Conclusiones 115

4.5 Mesoestructura y propiedades residuales en hormigones dañados $\quad 117$ por reacción álcali sílice sometidos a cargas de larga duración

$\begin{array}{ll}\text { 4.5.1 Materiales y mezclas } & 117\end{array}$

$\begin{array}{ll}\text { 4.5.2 Detalles experimentales } & 118\end{array}$

$\begin{array}{ll}\text { 4.5.3 Resultados y discusión } & 119\end{array}$

$\begin{array}{ll}\text { 4.5.4 Conclusiones } & 138\end{array}$

4.6 Análisis comparativo de la influencia del cuadro de fisuración 139

sobre las propiedades de hormigones dañados

Capítulo V: Estudios sobre hormigones reforzados con fibras y hormigones autocompactantes

5.1 Introducción

5.2 Estudio de la orientación del refuerzo y sus efectos sobre las propiedades mecánicas en hormigón convencional vibrado reforzado con fibras de acero

5.2.1 Materiales y mezclas

$\begin{array}{ll}\text { 5.2.2 Detalles experimentales } & 145\end{array}$

$\begin{array}{ll}5.2 .3 \text { Resultados y discusión } & 147\end{array}$

5.2.3.1 Influencia de la dosis y tipo de fibras y de las dimensiones 148

del molde sobre la orientación del refuerzo

5.2.3.2 Vinculación entre mesoestructura y comportamiento mecánico en flexión

5.2.4 Conclusiones

5.3 Estudio comparativo de la orientación de fibras en hormigón convencional 155 reforzado con fibras sintéticas y de acero, de uso corriente en el mercado local

5.3.1 Materiales y mezclas

5.3.2 Detalles experimentales 156

$\begin{array}{ll}\text { 5.3.3 Resultados y discusión } & 157\end{array}$

$\begin{array}{ll}\text { 5.3.4 Conclusiones } & 158\end{array}$

5.4 Efecto del método de llenado sobre la orientación y distribución 159 de fibras en HACRF

$\begin{array}{ll}\text { 5.4.1 Materiales y mezclas } & 159\end{array}$

$\begin{array}{ll}\text { 5.4.2 Detalles experimentales } & 160\end{array}$ 
5.4.3 Resultados y discusión

$\begin{array}{ll}\text { 5.4.3.1 Propiedades en estado fresco } & 164\end{array}$

5.4.3.2 Propiedades mecánicas 164

$\begin{array}{ll}\text { 5.4.3.3 Estudio de la orientación de las fibras } & 171\end{array}$

5.4.3.4 Estudio de la distribución de las fibras 173

$\begin{array}{ll}\text { 5.4.4 Conclusiones } & 177\end{array}$

5.5 Aplicación de un modelo teórico para el estudio de la orientación de las 179 fibras de acero

5.6 Estudio de la homogeneidad en hormigón autocompactante (HAC) 182 y hormigón autocompactante reforzado con fibras (HACRF)

$\begin{array}{ll}\text { 5.6.1 Materiales y mezclas } & 182\end{array}$

5.6.2 Detalles experimentales 183

5.6.3 Resultados y discusión 186

$\begin{array}{ll}\text { 5.6.4 Conclusiones } & 192\end{array}$

5.7 Análisis comparativo de las variables que inciden sobre la orientación 194 de las fibras en HRF y HACRF

5.8 Influencia del tipo de agregado en la homogeneidad de un hormigón 195 autocompactante

$\begin{array}{ll}\text { 5.8.1 Materiales y mezclas } & 195\end{array}$

5.8.2 Detalles experimentales 196

$\begin{array}{ll}\text { 5.8.3 Resultados y discusión } & 197\end{array}$

$\begin{array}{ll}\text { 5.8.4 Conclusiones } & 201\end{array}$

Capítulo VI: Conclusiones $\quad 202$

$\begin{array}{ll}6.1 \text { Conclusiones de la tesis } & 202\end{array}$

6.2 Recomendaciones de estudio futuro 206

$\begin{array}{ll}\text { Capítulo VII: Referencias } & 208\end{array}$

Anexo I - Capítulo IV

Anexo II - Capítulo V

Nomenclatura 


\section{ÍNDICE DE FIGURAS}

Figura 2.1.1. Escalas y métodos de observación del hormigón. 19

Figura 2.1.2. Densidad de fisuras en función de la escala de observación. $\quad 19$

Figura 2.3.1 Estado tensional en la cercanía de una fisura. 34

Figura 2.3.2. Ensayo SegBox. 38

Figura 3.3.1.1. Sección de hormigón, imagen escaneada 48 y posterior acondicionamiento.

Figura 3.3.1.2. Programa utilizado en el cálculo de las características de las fisuras 49 y agregados.

Figura 3.3.1.3. Fotografías de los cortes y zoom de los agregados relevados. $\quad 50$

Figura 3.3.2.1. Superficies fracturadas de vigas entalladas ensayadas a flexión. $\quad 52$

Figura 3.3.2.2. Superficie cortada de probeta de HRF con fibras de acero. 52

Figura 3.3.3.1. Equipo para la medición de la velocidad de pulso ultrasónico. $\quad 53$

Figura 3.3.3.2. Comparador de longitudes. 53

Figura 3.3.3.3. Equipo para la determinación del módulo de elasticidad dinámico. $\quad 54$

Figura 3.3.3.4. Ensayo de absorción capilar. 56

Figura 3.3.3.5. Equipo utilizado para los ensayos de permeabilidad y penetración $\quad 58$ de agua a presión.

Figura 3.3.3.6. Disposición del ensayo de compresión. 59

Figura 3.3.3.7. Curvas tensión-deformación longitudinal, transversal y volumétrica. 60

Figura 3.3.3.8. Disposición del ensayo de tracción por compresión diametral. $\quad 61$

Figura 3.3.3.9. Disposición del ensayo de flexión y detalle del clip utilizado 62 para medir el CMOD.

Figura 3.3.3.10. Curvas Carga-CMOD y modelo para delimitar la tensión de primera fisura $\left(\mathrm{f}_{\mathrm{L}}\right)$.

Figura 3.3.3.11. Disposición del marco para el LVDT utilizado para medir las flechas.63 Figura 3.3.3.12. Diagramas Carga-Flecha (RILEM TC 162).

Figura 3.3.3.13. Pórticos con resortes y detalle de las probetas con los pernos de acero inoxidable. $\quad 65$

Figura 4.2.1. Cortes transversales para el análisis de la densidad de fisuras. $\quad 70$

Figura 4.2.2. Interfaces. 
Figura 4.2.3. Densidad de fisuras en cada corte $\left(\mathrm{cm} / \mathrm{cm}^{2}\right)$. 77

Figura 4.2.4. Relación entre ancho de fisuras y coeficiente de permeabilidad. $\quad 83$

Figura 4.2.5. Relación entre densidad de fisuras y coeficiente de permeabilidad. 83

Figura 4.2.6. Relación entre densidad de agregados y coeficiente de permeabilidad. 84

Figura 4.2.7. Relación entre perímetro de agregados y coeficiente de permeabilidad.84

Figura 4.3.1. Variación de la permeabilidad en el tiempo. 93

Figura 4.3.2. Variación del coeficiente de permeabilidad con la densidad 94

de fisuras mayores a $10 \mathrm{~mm}$ y la densidad total de fisuras.

Figura 4.3.3. Variación de la velocidad de absorción capilar

con la densidad de fisuras.

Figura 4.3.4. Variación de la velocidad de pulso ultrasónico

con la densidad total de fisuras.

Figura 4.3.5. Variación de la velocidad de pulso ultrasónico con el coeficiente permeabilidad.

Figura 4.3.6. a- Curvas Tensión-Deformación específica

longitudinal, transversal y volumétrica para cada grupo.

Figura 4.3.6. b- Curvas Tensión-Deformación específica longitudinal. 98

Figura 4.3.7. Variación de la VPU con el módulo de elasticidad. 99

Figura 4.3.8. Variación de la VPU con la resistencia a compresión. 99

Figura 4.3.9. Tensiones Máxima y Crítica en función de la densidad de fisuras. $\quad 100$

Figura 4.4.1. Deformaciones totales bajo carga sostenida. 108

Figura 4.4.2. Cuadro de fisuración relevado sobre cortes de probetas cilíndricas $\quad 108$ preparados para ensayos de permeabilidad.

Figura 4.4.3. Cortes delgados de los hormigones luego de ser sometidos al proceso de degradación.

Figura 4.4.4. Variación de la resistencia a compresión, módulo de elasticidad y coeficiente de Poisson en función de los diferentes tipos de exposición.

Figura 4.4.5. Curvas tensión-deformación (longitudinal, transversal y volumétrica) 112 obtenidas sobre las probetas que permanecieron 1 año en cámara seca sin cargar.

Figura 4.4.6. Curvas tensión-deformación (longitudinal, transversal y volumétrica) 112 obtenidas sobre las probetas que permanecieron 1 año cargadas.

Figura 4.4.7. Curvas promedio obtenidas a partir del ensayo de absorción capilar. 114 Figura 4.5.1. Curvas tensión-deformación (longitudinal, axial y volumétrica) $\quad 120$ medidas a la edad de 7 días.

Figura 4.5.2. Deformaciones totales bajo carga y deformaciones libres (sin cargar) 122 medidas durante 14 meses. 
Figura 4.5.3. Cuadro de fisuración en la superficie de los cilindros del hormigón C. 123 Figura 4.5.4. Esquema del criterio adoptado para evaluar la orientación de las fisuras.

Figura 4.5.5. Variación de la densidad de fisuras con el número de agregados 127 reactivos evaluados sobre las rodajas utilizadas en el ensayo de permeabilidad.

Figura 4.5.6. Efectos de la reacción álcali-sílice sobre la estructura del hormigón C.127 Figura 4.5.7. Relación entre la velocidad de pulso ultrasónico y la densidad de fisuras en el perímetro.

Figura 4.5.8. a- Curvas tensión-deformación para los hormigones T.

Figura 4.5.8. b- Curvas tensión-deformación para los hormigones $\mathrm{C}$.

Figura 4.5.9. Curvas típicas del ensayo de permeabilidad.

Figura 4.5.10. Fotografías de cortes transversales luego de ser sometidos al ensayo de permeabilidad (Hormigón $\mathrm{C}$ ).

Figura 4.5.11. Relación entre el coeficiente de permeabilidad máximo y la densidad de fisuras.

Figura 4.5.12. Relación entre el coeficiente de permeabilidad a las 24 horas y la densidad de fisuras.

Figura 4.5.13. Perfiles de penetración.

Figura 5.2.1. Fibras de acero tipo hooked-end (30 y $60 \mathrm{~mm}$ ).

Figura 5.2.2. Planos de corte.

Figura 5.2.3. Relación entre fibras eficaces y fibras totales.

Figura 5.2.4. Efecto de la densidad de fibras totales sobre las propiedades mecánicas.

Figura 5.2.5. a- Efecto de la densidad de fibras totales sobre la resistencia $f_{R 3}$.

Figura 5.2.5. b- Efecto de la densidad de fibras eficaces sobre la resistencia $f_{R 3}$.

Figura 5.3.1. Fibras utilizadas.

Figura 5.4.1. Tipos de vertido.

Figura 5.4.2. Direcciones de corte y esquema de relevamiento de fibras.

Figura 5.4.3. Gráficos carga-CMOD correspondientes a las vigas elaboradas con HACRF1.

Figura 5.4.4. Variación de los parámetros resistentes con la densidad de fibras HACRF1.

Figura 5.4.5. Fibras eficaces vs fibras totales en HACRF1.

Figura 5.4.6. a- Densidad de fibras eficaces vs $f_{R 2}$ HACRF1.

Figura 5.4.6. b- Densidad de fibras totales vs $\mathrm{f}_{\mathrm{R} 2} \mathrm{HACRF1.}$ 
con HACRF2.

Figura 5.4.8. Variación de los parámetros resistentes con la densidad de fibras 170 HACRF 2.

Figura 5.4.9. Gráficos carga-CMOD correspondientes a las vigas elaboradas 170 con HACRF3.

Figura 5.4.10. Esquema de la superficie de fractura.

Figura 5.4.11. Densidad de fibras $\left(\mathrm{N} / \mathrm{cm}^{2}\right)$ a lo largo de los plano $\beta$ y $\gamma$. y a lo alto del plano $\alpha$.

Figura 5.6.1. Esquema de aserrado de los tubos.

Figura 5.6.2. Distribución de agregados sobre un corte de $20 \mathrm{~mm}$ de espesor.

Figura 5.6.3. Esquema de la distribución de fibras en una sección de HAC-25. 185

Figura 5.6.4. Aspecto superficial de los tubos. 188

Figura 5.6.5. Variación con la altura de las propiedades fisicomecánicas. $\quad 189$

Figura 5.6.6. Variación con la altura de la densidad y número de agregados. 191

Figura 5.6.7. Relevamiento de agregados sobre cortes a diferentes a alturas. 191

Figura 5.6.8. Variación con la altura de la densidad de fibras. 192

Figura 5.7.1. Esquema del tubo en U. 197

Figura 5.7.2. Cortes transversales de tubos de HAC preparados con 197 diferentes tipos de agregado grueso.

Figura 5.7.3. Relevamiento de agregados a lo largo de los tubos en U. 198

Figura 5.7.4. Variación de la densidad de agregados a lo largo de los tubos en U. 200

Figura 5.7.5. Aspecto superficial de tres sectores de los tubos en U. 201 


\section{ÍNDICE DE TABLAS}

Tabla 3.3.1.1. Densidad y perímetro de fisuras obtenidos mediante diferentes métodos.

Tabla 4.2.1. Proporciones $\left(\mathrm{kg} / \mathrm{m}^{3}\right)$ de los hormigones.

69

Tabla 4.2.2. Relevamiento de fisuras, probetas de hormigón CR. 72

Tabla 4.2.2. (continuación) Relevamiento de fisuras, probetas de hormigón PP. $\quad 73$

Tabla 4.2.3. Relevamiento de agregados, hormigón CR.

Tabla 4.2.3. (continuación) Relevamiento de agregados, hormigón PP. $\quad 75$

Tabla 4.2.4. Densidad y número de fisuras. Valores promedios. 77

Tabla 4.2.5. Promedios de densidad de fisuras $\left(\mathrm{cm} / \mathrm{cm}^{2}\right)$ a partir 79 de combinación de diversos cortes.

Tabla 4.2.6. Promedios de la densidad de fisuras $\left(\mathrm{cm} / \mathrm{cm}^{2}\right)$ en relevamientos $\quad 79$ de caras opuestas del mismo corte.

Tabla 4.2.7. Variabilidad en la densidad de fisuras entre probetas 80 de un mismo grupo.

Tabla 4.2.8. Parámetros de caracterización de la mesoestructura y 82 coeficientes de permeabilidad.

Tabla 4.3.1. Ensayos no destructivos sobre cilindros. 88

Tabla 4.3.2. Detalle de fotografías de los cortes analizados y cuadro de fisuración. 89

Tabla 4.3.3. Cuadro de fisuración. 90

Tabla 4.3.4. Densidad y propiedades de transporte. 91

Tabla 4.3.5. Respuesta mecánica. 96

Tabla 4.4.1. Pérdida de peso y variación de longitud medida sobre prismas. $\quad 105$

Tabla 4.4.2. Propiedades físicas y mecánicas determinadas sobre cilindros $\quad 105$ luego de la exposición a altas temperaturas.

$\begin{array}{ll}\text { Tabla 4.4.3. Resultados ensayos de larga duración. } & 107\end{array}$

Tabla 4.4.4. Relevamiento de fisuras y agregados sobre cilindros. 109

Tabla 4.4.5. Relevamiento de fisuras sobre cilindros. 109

Tabla 4.4.6. Ensayos no destructivos sobre cilindros al cabo de un año en 110 cámara seca.

Tabla 4.4.7. Propiedades mecánicas medidas sobre cilindros y prismas $\quad 111$ al cabo de un año en cámara seca.

Tabla 4.4.8. Propiedades físicas y de transporte. 
Tabla 4.5.1. Proporciones de los hormigones. 118

Tabla 4.5.2. Propiedades mecánicas medidas a los 7 días en los 120 hormigones $\mathrm{C}$ y $\mathrm{T}$.

Tabla 4.5.3. Caracterización del cuadro de fisuración del perímetro de los cilindros. 124

Tabla 4.5.4. Relevamiento de fisuras y poros con gel en cortes del hormigón C. $\quad 125$

Tabla 4.5.5. Relevamiento de agregados. 126

Tabla 4.5.6. Ensayos no destructivos y propiedades mecánicas medidas $\quad 129$

sobre los hormigones $\mathrm{C}$ y $\mathrm{T}$ una vez finalizados los ensayos de fluencia.

Tabla 4.5.7. Coeficientes de permeabilidad obtenidos sobre muestras 135 del hormigón $\mathrm{C}$.

Tabla 4.6.1. Influencia del tamaño de las fisuras (densidad y ancho) sobre la $\quad 140$ resistencia y rigidez en compresión, el coeficiente de permeabilidad y la absorción capilar.

Tabla 4.6.2. Influencia del tamaño (densidad y ancho) y orientación de las fisuras 141 sobre la resistencia y rigidez en compresión, el coeficiente de permeabilidad y la penetración de agua a presión.

Tabla 5.2.1. Características de las fibras utilizadas.

Tabla 5.2.2. Dimensiones de las probetas estudiadas. 145

Tabla 5.2.3. Densidad de fibras en $\mathrm{N} / \mathrm{cm}^{2}$. 147

Tabla 5.2.4. Densidad de fibras eficaces (Fe) y fibras totales (Ft) 149

en el plano de fractura y resultados del ensayo de flexión.

Tabla 5.3.1. Características de las fibras y HRF elaborados. 155

Tabla 5.3.2. Densidad de fibras $\left(\mathrm{N} / \mathrm{cm}^{2}\right)$ según el plano relevado. 157

Tabla 5.4.1. Proporciones $\left(\mathrm{kg} / \mathrm{m}^{3}\right)$ de los materiales componentes. 160

Tabla 5.4.2. Características de los hormigones en estado fresco. 164

Tabla 5.4.3. Resultados del ensayo de flexión y densidad de fibras en HACRF1. 165

Tabla 5.4.4. Resultados del ensayo de flexión y densidad de fibras en HACRF2. 169

Tabla 5.4.5. Resultados del ensayo de flexión y densidad de fibras en HACRF3. 171

Tabla 5.4.6. Densidad de fibras (fibras $/ \mathrm{cm}^{2}$ ) HACRF1. 172

Tabla 5.4.7. Densidad de fibras (fibras $/ \mathrm{cm}^{2}$ ) HACRF2. 173

Tabla 5.4.8. Distribución del número de fibras en distintos sectores de las vigas. $\quad 176$

Tabla 5.5.1. Coeficiente de orientación (CO) obtenido a partir 180

de las ecuaciones (1) y (2) para el HACRF 1 (sección 5.4).

Tabla 5.5.2. Coeficiente de orientación (CO) obtenido a partir 180

de las ecuaciones (1) y (2) para el HACRF 2 (sección 5.4).

Tabla 5.5.3. Coeficiente de orientación (CO) obtenido a partir 
de las ecuaciones (1) y (2) para los HRF1, 2 y 3 (sección 5.2).

Tabla 5.6.1. Dosificación de los HACs estudiados $\left(\mathrm{kg} / \mathrm{m}^{3}\right)$.

182

Tabla 5.6.2. Resultados de los ensayos sobre el hormigón fresco.

186

Tabla 5.7.1. Cuantificación del grado de influencia que ejercen distintas variables sobre la orientación de las fibras.

Tabla 5.8.1. Propiedades del agregado grueso.

Tabla 5.8.2. Proporciones de los materiales componentes.

Tabla 5.8.3. Relevamiento de la densidad y número de agregados en los tubos U. 199 


\section{CAPÍTULO I}

\section{INTRODUCCIÓN}

\subsection{ESTRUCTURA Y PROPIEDADES DEL HORMIGÓN}

El estudio de la microestructura de los materiales en ingeniería ha dado lugar a notables avances en el conocimiento de sus propiedades y durabilidad, posibilitando además el diseño de productos con propiedades particulares o incluso nuevos materiales.

El hormigón es uno de los materiales de construcción de mayor uso a nivel mundial. A diferencia de otros materiales que emplea la ingeniería civil, posee una estructura sumamente compleja que dista de ser la de un material homogéneo, tanto a nivel microscópico como en el mesonivel. En este compuesto una matriz porosa rodea a un conjunto de inclusiones de distinta rigidez y tamaño; poros e inclusiones se distribuyen de manera aleatoria junto con una serie de defectos principalmente constituidos por micro y macrofisuras.

Aunque en el hormigón muchas propiedades se relacionan con las características microestructurales (Jacobsen et al, 1995, Soroushian y Elzafraney, 2004, Cwirzen y Penttala, 2005), la respuesta del material depende estrechamente de aspectos característicos de la mesoestructura como la presencia de defectos, poros de diversos tamaños, y principalmente de los agregados de mayor tamaño y sus interfaces. En el caso de hormigones reforzados con fibras, el tipo, contenido y orientación de estas últimas es determinante.

La relación entre la estructura interna del hormigón a nivel mesoestructural y sus propiedades físicas y mecánicas ha sido ampliamente documentada (Zhang, 1998, 
Gowripalana et al, 2000, Leeman et al, 2006) pero no se han propuesto métodos sencillos de caracterización de la primera.

Diversos trabajos han tratado el efecto de las interfaces sobre las propiedades y el mecanismo de fractura del hormigón (Shah y Chandra, 1968, Giaccio y Giovambattista, 1986), otros trabajos consideran también la incidencia de la presencia de defectos sobre la resistencia y deformabilidad (Giaccio y Zerbino, 1997, 1998a y b).

Algunos procesos de daño del hormigón (corrosión, reacción álcali sílice, etc.) se encuentran directamente vinculados con las propiedades de transporte y con las características del hormigón de recubrimiento, en particular.

Aunque su efecto es evidente, pocos trabajos tratan sobre la incidencia de la existencia de micro y macrofisuración y otros tipos de defectos sobre las propiedades de transporte en el hormigón (Wang et al, 1997, Aldea et al, 1999a y b). Mas aún en la mayoría de los códigos se caracteriza a las fisuras sólo por su ancho y al momento de realizar consideraciones desde el punto de vista de la durabilidad se lo limita entre 0.1 y $0.4 \mathrm{~mm}$. Existen estudios que muestran que en ese rango de fisuras las diferencias en permeabilidad pueden ser hasta de 4 órdenes de magnitud con respecto a un hormigón no fisurado, poniendo de manifiesto la importancia que adquiere la caracterización de las fisuras.

Cabe agregar que la eliminación del nivel de defectos en la estructura del material en orden a mejorar la durabilidad, fue una de las principales motivaciones para la más reciente innovación en la especialidad, los hormigones autocompactantes (HAC).

Otros hormigones especiales sobre los que existe gran interés son los reforzados con fibras (HRF). En este caso se introducen fibras de diverso tipo dispersas en la matriz frágil del hormigón con el fin de mejorar la capacidad de absorción de energía y controlar el desarrollo de fisuras. De este modo se aumenta la vida en servicio de las estructuras en especial cuando se ven expuestas a acciones dinámicas. Es evidente que las propiedades de los HRF dependen directamente del tipo, contenido, orientación y distribución de las fibras, elementos que se consideran en el nivel mesoestructural. 


\subsection{OBJETIVOS}

Esta tesis tiene como objetivo general la caracterización de la mesoestructura del hormigón a través de la cuantificación de determinados parámetros a fin de alcanzar una mayor comprensión de su influencia sobre el comportamiento del material. Se plantean como elementos distintivos de la mesoestructura la distribución de agregados e interfaces, la densidad y tamaño de fisuras, y en el caso particular de los hormigones con fibras, la distribución y orientación del refuerzo. Estos parámetros de la mesoestructura se analizan junto con el comportamiento macroscópico del hormigón, considerando tanto la respuesta mecánica bajo distintas solicitaciones como las propiedades de transporte (absorción y permeabilidad) asociadas a la durabilidad.

Como casos de aplicación se estudia la vinculación entre la mesoestructura y la respuesta macroscópica de hormigones dañados por diversas patologías (exposición a alta temperatura, secado al aire y expansiones internas por desarrollo de la reacción álcali-sílice), en estos casos se destacan como parámetros las características de las interfaces y la densidad y ancho de fisuras. También se aplica la caracterización de la estructura para explicar la influencia de la distribución y orientación de las fibras en el hormigón reforzado con fibras y para analizar la homogeneidad en la distribución de agregados en elementos estructurales elaborados con hormigón autocompactante.

En cuanto al aporte original y significado del estudio cabe notar que si bien existen antecedentes donde se ha vinculado la estructura interna del hormigón con sus propiedades macroscópicas, principalmente las mecánicas, en general sólo se ha hecho de una forma cualitativa. Entre los objetivos específicos y metas a alcanzar en esta tesis se destacan:

- Desarrollar métodos y criterios para la evaluación de la mesoestructura y cuantificación del nivel de defectos.

- Estudiar las relaciones entre diferentes tipos de defectos y la respuesta del hormigón, considerando las propiedades mecánicas (resistencia y rigidez) y de transporte (permeabilidad y absorción) del material.

- Analizar la influencia de la distribución de agregados gruesos e interfaces considerando los casos de hormigón vibrado convencional y hormigón autocompactante. 
- Analizar, para el caso específico de hormigones reforzados con fibras la relación entre el contenido de fibras incorporado al hormigón fresco y la distribución de fibras en diferentes secciones de los elementos estructurales así como la distribución de fibras en hormigón autocompactante.

\subsection{ESTRUCTURA}

En cuanto a la estructura de la tesis, en primer lugar se desarrolla el estado del conocimiento (Capítulo II) sobre los temas abordados, incluye el concepto de nivel mesoestructural en hormigón, antecedentes relativos a formas de evaluación de la estructura interna y una descripción de las alteraciones típicas que producen la exposición a alta temperatura, la contracción por secado y la reacción álcali-sílice. Además se precisan aspectos distintivos de la mesoestructura y propiedades de hormigones autocompactantes y reforzados con fibras. También se muestran ejemplos salientes de la vinculación entre la mesoestructura y la respuesta mecánica y las propiedades de transporte del hormigón para hormigones convencionales y especiales.

En el Capítulo III se explican los objetivos del programa experimental y el método desarrollado para evaluar la mesoestructura, este método fue utilizado para caracterizar los hormigones del Capítulo IV. Asimismo se precisan los métodos de ensayo utilizados para la evaluación de las propiedades mecánicas y de transporte.

Luego se desarrolla el programa experimental considerando los dos casos de aplicación elegidos: Hormigones dañados y Hormigones especiales. En el Capítulo IV se incluyen los resultados de hormigones dañados por exposición a altas temperaturas, contracción por secado y reacción álcali-sílice. Entre los aportes originales realizados en este Capítulo se destacan la evaluación de la influencia de las cargas de larga duración sobre el desarrollo del daño en hormigones afectados por temperatura y en hormigones afectados por la reacción álcali-sílice. A su vez la evaluación de los niveles de daño a través de la cuantificación de las fisuras constituyó una herramienta eficaz y permitió verificar la incidencia dispar de los distintos niveles de daño sobre las propiedades mecánicas y de transporte. Asimismo y como contribución se destaca que los defectos afectan de modo desigual a los mecanismos de transporte. 
En el Capítulo V se presentan las experiencias sobre hormigón convencional vibrado con fibras de acero y fibras sintéticas, y sobre hormigón autocompactante simple y reforzado con fibras de acero; en forma complementaria se aplicó un modelo teórico para analizar la distribución de fibras. En cuanto a las contribuciones originales en el tema de hormigones con fibras, se destacan la relación existente entre la cantidad de fibras en el plano de fractura considerando distintas dosis de refuerzo y dimensiones de los moldes y la respuesta post pico del hormigón así como la realización de mediciones en hormigones reforzados con fibras sintéticas. En el hormigón vibrado convencional es conocido que las fibras se orientan en planos horizontales, sin embargo no ha sido tan estudiada la orientación en el hormigón autocompactante reforzado con fibras, en esta tesis se destaca la influencia del flujo y el efecto pared sobre la orientación de las fibras. En el caso de hormigones autocompactantes los estudios encontrados en la literatura se centran en el diseño y la evaluación de las propiedades en estado fresco, pero se han encontrado pocos trabajos donde se evalúe la resistencia a la segregación, un aporte original realizado lo constituye la evaluación de la homogeneidad en estado endurecido en elementos estructurales elaborados con HAC.

Finalmente en el Capítulo VI se presentan las conclusiones y recomendaciones de estudio futuro y en el Capítulo VII las referencias. 


\section{CAPÍTULO II}

\section{ESTRUCTURA Y PROPIEDADES DEL HORMIGÓN}

En este Capítulo se desarrolla el estado del conocimiento relativo a la estructura interna del hormigón y su vinculación con las propiedades macroscópicas del material.

En primer lugar se describen los elementos distintivos de su mesoestructura (poros, agregados, interfaces, fisuras, fibras), luego se destacan las propiedades mecánicas y de transporte más importantes desde el punto de vista de la aplicación y los factores que las modifican.

Dado que entre las contribuciones de esta tesis se destaca la caracterización y cuantificación de fisuras como elementos de la estructura interna del hormigón que resultan determinantes de sus propiedades macroscópicas, en este Capítulo se citan algunas técnicas de evaluación de fisuras y las limitaciones que poseen, (la bibliografía indica que la caracterización de fisuras se ha realizado fundamentalmente a nivel microestructural y en forma cualitativa).

Más adelante y teniendo en cuenta que uno de las campos de mayor impacto del tema abordado será el análisis de la durabilidad de estructuras de hormigón, se desarrolla una breve síntesis del estado de conocimiento sobre las tres patologías que han sido seleccionadas para los estudios experimentales: la exposición a altas temperaturas, los procesos de contracción por secado y la reacción álcali-sílice. Se realiza una breve introducción sobre el mecanismo de daño del hormigón producto de las altas temperaturas, de los niveles de alteración que éstas producen conforme el tiempo de exposición y composición del hormigón, y se presentan experiencias que evalúan las propiedades mecánicas residuales en hormigones afectados. En cuanto a los procesos por contracción por secado también se introducen brevemente las 
causas y los factores que afectan la contracción y se presentan algunos aportes sobre la influencia del secado en el mecanismo de fractura del hormigón y la permeabilidad de morteros. Finalmente se describe la reacción álcali-sílice, los factores que inciden en su desarrollo y el daño que produce.

Teniendo en cuenta que otros casos de aplicación de la vinculación entre estructura y propiedades abordados en esta tesis involucran al hormigón con fibras y al hormigón autocompactante, se presentan brevemente estos hormigones especiales destacando las características particulares de su mesoestructura como así también algunos de los trabajos recientes vinculados. En el caso de los hormigones reforzados con fibras se muestra el estado del conocimiento acerca de la distribución de fibras en hormigón vibrado convencional, propuestas para el relevamiento de fibras y modelos teóricos de distribución y orientación.

\subsection{MESOESTRUCTURA DEL HORMIGÓN}

El hormigón es un material compuesto formado por una matriz porosa y un conjunto de inclusiones de distinta naturaleza insertas en ella. La idea del hormigón como un material continuo y homogéneo resulta insuficiente para llevar a cabo un análisis y justificación de su comportamiento.

Este material puede ser clasificado en tres niveles estructurales el nivel micro $(<1 \mu \mathrm{m})$, el nivel meso (entre $1 \mu \mathrm{m}$ y $1 \mathrm{~cm}$ ) y el nivel macro $(>1 \mathrm{~cm})$ (Zhang, 1998). En el nivel micro el hormigón es un material discontinuo donde se pueden distinguir los productos altamente cristalinos, geles (silicatos hidratados) y poros de la pasta. En el meso nivel el hormigón puede ser considerado como un material continuo pero carente de homogeneidad, donde una matriz de mortero rodea un conjunto de inclusiones de diferente tipo y tamaño. En el macro nivel se puede ver al hormigón como un material continuo y homogéneo.

Las propiedades del hormigón a nivel macro estructural como la resistencia, elasticidad, contracción, durabilidad, etc. están relacionadas con el comportamiento en los niveles micro y meso estructural (Mehta y Aitcin, 1990, Sicard et al, 1992, Wang et al, 1997, Giaccio y Zerbino, 1998a y b, Aldea et al, 1999a y b, Lepech y Li, 2001, Lu et al, 2006, Gonen y Yazicioglu, 2007). 
A nivel micro estructural se estudia fundamentalmente la pasta de cemento, varios efectos a escala macroscópica vinculados con variaciones en el contenido de humedad o la temperatura pueden ser explicados a partir de procesos desarrollados en este nivel. Pero el comportamiento del hormigón es más complejo, tanto los efectos de los poros de mayor tamaño, las interfaces, los agregados, la matriz, las fisuras, los defectos de compactación o incluso las fibras en el caso de los hormigones reforzados con fibras, se consideran en el mesonivel, constituyendo aspectos característicos de la estructura del hormigón.

En la pasta de cemento existe una gran variedad de tamaño de poros, con diámetros que van desde $10 \mu \mathrm{m}$ hasta menos de $0.5 \mathrm{~nm}$ (Mindess et al, 2003), en función del tamaño serán los efectos sobre el comportamiento del material. Los diámetros mayores corresponden a los poros capilares, que son los espacios ocupados originalmente por el agua en la pasta de cemento y que no fueron llenados por los productos de hidratación, los tamaños menores corresponden a los poros del gel de cemento hidratado. En los poros del gel de silicato de calcio hidratado existe agua adsorbida y también agua combinada químicamente. Los poros capilares siguen formas tortuosas, se encuentran interconectados y orientados al azar (Pradhana et al, 2005); el agua dentro de los poros capilares se comporta como agua libre, a medida que disminuye el tamaño de poro se generan fuerzas capilares sobre el agua. Los poros capilares de tamaño mayor a $50 \mathrm{~nm}$ se denominan macroporos y afectan la resistencia y la permeabilidad y los más pequeños, llamados microporos, junto con los poros del gel adquieren un rol más importante en la contracción por secado y la fluencia bajo carga. Además, durante el mezclado frecuentemente queda aire atrapado en la pasta de cemento, estos huecos pueden tener hasta $3 \mathrm{~mm}$ de diámetro afectando la resistencia y la permeabilidad. También existen aditivos que incorporan burbujas de aire en forma intencional, estas burbujas tienen diámetros entre 50 y $200 \mu \mathrm{m}$ (Mindess y Young, 1981, Mehta y Monteiro, 1993).

Asimismo la presencia del agregado grueso origina una zona de transición más débil, que es la interfaz matriz-agregado, donde existen diferencias importantes en la microestructura y la morfología de los productos de hidratación con respecto al interior de la pasta. Debido al efecto pared se produce una menor concentración de partículas de cemento en las interfaces, que limita el desarrollo del silicato de calcio hidratado, lo que trae aparejado una mayor porosidad. Además alrededor del agregado grueso se puede acumular agua, ya sea por exudación o por intercambio con el agregado, 
modificando la razón agua-cemento en esta zona. A su vez el espacio disponible brinda la posibilidad de crecimiento a los productos de mayor cristalinidad y de menor aporte resistente como el hidróxido de calcio y la etringita. Es habitual encontrar en las interfaces cristales de mayor tamaño. Además los cristales de hidróxido de calcio se orientan creando planos preferenciales de clivaje. Favorecida por la mayor porosidad y debilidad, y los diferentes cambios dimensionales por expansión térmica o secado, es frecuente la aparición de fisuras en las zonas de transición aún antes de la aplicación de cargas exteriores.

Las interfaces matriz-agregado pueden conectarse en función de su espesor y del contenido de agregados, esta unión favorece el flujo de fluidos dentro del hormigón. La compactación tiene una influencia significativa sobre la porosidad y el espesor de la interfaz, en este sentido se encontró una mayor porosidad en las interfaces del hormigón convencional vibrado que en las de un hormigón autocompactante (Leeman et al, 2006). Estos autores realizaron estudios en hormigones autocompactante y convencional vibrado valorando la resistencia a compresión, la permeabilidad al oxígeno y la conductividad del agua, y notaron que la menor porosidad en las interfaces del primero, favorecía su comportamiento. Sin embargo en sus experiencias encontraron que el menor contenido de pasta y los mayores tamaños de agregados utilizados en el hormigón convencional reducían el efecto de la mayor porosidad.

En lo referente al mecanismo de rotura del hormigón, los agregados controlan la propagación de fisuras a través de la matriz, favoreciendo su ramificación, en función de las características del agregado, su textura superficial, forma y la diferencia de resistencia entre la matriz y el agregado principalmente. Una superficie triturada, áspera y angulosa como la de una piedra partida resulta más favorable que una superficie lisa como la del canto rodado, ya que mejora la adherencia mecánica. Además los agregados tienen un efecto favorable respecto a la contracción plástica y por secado ya que restringen los cambios de volumen que se producen en la pasta. Para una dada razón a/c al aumentar el porcentaje de agregados disminuye la contracción. El contenido y tipo de agregado influyen de la misma forma en la fluencia lenta del hormigón.

Como fuera anticipado el hormigón también posee defectos y fisuras antes de estar sometido a cargas, son producidos principalmente por contracción plástica, exudación, diferencias en el coeficiente de expansión térmica entre la pasta y los 
agregados, contracción por secado y deficiencias de compactación. La mayoría de estos defectos se acumulan en las zonas de transición.

La estructura del hormigón sufre modificaciones considerables, simplemente con el paso del tiempo, al ser expuesto frente a distintas condiciones ambientales o sometido a diversas solicitaciones. Como es sabido la falla del material comienza en alguna imperfección como poros, defectos de compactación o microfisuras, y luego se produce la propagación de las fisuras.

En experiencias realizadas en columnas de $2 \mathrm{~m}$ de altura y $0.60 \mathrm{~m}$ de ancho con tres razones agua/cemento distintas, se observó cómo los defectos provocados por exudación afectan las propiedades del hormigón. Se extrajeron testigos verticales y horizontales de las zonas superior e inferior de las columnas. En los niveles altos, donde tanto la razón agua/cemento como la porosidad aumentaron, disminuyeron la resistencia a compresión (alrededor de un 30 \%) y a tracción. En las curvas tensióndeformación se observó un incremento en la deformabilidad. La anisotropía fue mayor en tracción que en compresión lo que se atribuyó a la presencia de canales en los planos de máxima tensión de tracción; de la misma manera la anisotropía horizontal fue alrededor de un $30 \%$ mayor que la vertical, dado que el agua de exudación se acumula debajo de los agregados dando origen a fisuras horizontales. Las columnas con bajas razones agua/cemento no presentaron este comportamiento anisotrópico entre las zonas superior e inferior (Giaccio y Giovambattista, 1986).

En experiencias realizadas con columnas de hormigón armadas con barras dispuestas en forma horizontal se observó que el agua de exudación se acumuló debajo de las armaduras creando defectos en las interfaces acero-hormigón. Estos defectos alteraron la adherencia y propiciaron la corrosión de las barras de acero. La magnitud de estos defectos fue incrementándose a medida que los testigos provenían de partes más elevadas de las columnas y de hormigones con mayor razón agua/cemento. En hormigones de razón agua/cemento 0.75 se observó un incremento de la porosidad con la altura producto de una mayor exudación (Soylev y François, 2003).

La durabilidad de las estructuras de hormigón es uno de los mayores desafíos con los que se enfrenta hoy la industria de la construcción. Las propiedades de transporte, especialmente la permeabilidad, afectan la durabilidad y por lo tanto la integridad de las estructuras. El transporte de fluidos dentro del hormigón está 
controlado por el volumen de pasta, la estructura porosa de la matriz y las zonas de interfaz. Por ejemplo la permeabilidad del hormigón es mayor que la de la pasta de cemento, a pesar que la permeabilidad de los agregados es menor, debido principalmente a la mayor porosidad de las interfaces. La presencia de poros y fisuras incrementan la permeabilidad del material favoreciendo el ingreso de agentes agresivos que contribuyen a la degradación de la estructura (Wang et al, 1997, Aldea et al, 1999a y b). También se debe tener en cuenta que existen procesos de microfisuración que no afectan la resistencia pero resultan definitorios al momento de ponderar la durabilidad del hormigón (Barragán et al, 2000).

La caracterización de la mesoestructura también adquiere una importancia fundamental y tiene características y aplicaciones particulares en hormigones especiales como el Hormigón Reforzado con Fibras (HRF) o el Hormigón Autocompactante (HAC).

El comportamiento del HRF y la variación en sus propiedades post-fisuración están directamente relacionados con el tipo, orientación y número de fibras (Edgington y Hannant, 1972, Redon et al, 1999, Gettu et al, 2005, Woo et al, 2005, Ferrara y Meda, 2006, Ozyurt et al, 2006, Stähli y van Mier, 2007). En el proceso de fisuración del hormigón bajo carga, aparecen en primer lugar microfisuras que se van uniendo formando macrofisuras. Las fibras actúan interceptando las fisuras y retardando su propagación, si hay suficiente cantidad y están uniformemente distribuidas evitan que las microfisuras se unan. La presencia de fibras favorece el desarrollo de múltiples fisuras de menor tamaño (Lepech y Li, 2001, Rapoport et al, 2002). La incorporación de fibras no sólo es beneficiosa en el control de las fisuras bajo carga sino que también es interesante evaluar su uso como alternativa para mejorar la permeabilidad y otras propiedades de transporte en estructuras de hormigón.

Por lo expuesto la orientación y la densidad de fibras aparecen como parámetros de interés en la caracterización de la mesoestructura del HRF. Más adelante se presentarán mayores detalles sobre este tema.

En HAC los procesos de llenado y compactación están regulados únicamente por las propiedades reológicas del hormigón fresco. La calidad final será función de dichas propiedades y por ello además de los materiales componentes, la temperatura, el tiempo que demore el llenado y las condiciones de mezclado aparecen como factores que contribuyen a la variabilidad. La matriz del HAC debe ser suficientemente 
viscosa para evitar la segregación de los áridos gruesos pero poseer suficiente movilidad para asegurar el llenado. Es por ello que la evaluación de la homogeneidad de su mesoestructura adquiere más trascendencia que en un hormigón convencional (Bonen y Shah, 2005). La distribución de agregados gruesos representa un parámetro de la mesoestructura relevante para dicha evaluación.

\subsubsection{Estructura y respuesta mecánica}

Las características de los agregados, la naturaleza de las interfaces y la resistencia relativa entre la matriz y los agregados están fuertemente relacionadas con la respuesta mecánica del hormigón. La resistencia del hormigón es función de la resistencia de la pasta de cemento, de los agregados y de la interacción entre ambos. Tanto el comportamiento frente a cargas de los agregados como el de la pasta de cemento son esencialmente lineales, pero al diferir sus módulos de elasticidad el hormigón se comporta de forma inelástica. Además es sabido que la resistencia y módulo de elasticidad del hormigón se encuentran directamente relacionados con la porosidad de la pasta.

En el proceso de fractura la propagación de fisuras se inicia generalmente en las interfaces, la zona más débil, y luego las fisuras crecen a través de la matriz. Un hormigón sometido a cargas de compresión uniaxial presenta un comportamiento prácticamente lineal hasta el $30 \%$ de la carga última. Entre el 30 y el $50 \%$ de la carga última las fisuras, principalmente de interfaz, comienzan a incrementar su longitud, ancho y número, es en este rango de cargas donde la curva tensión-deformación se desvía de la linealidad. La propagación de las fisuras de interfaz en el mortero está relacionada con el aumento del coeficiente de Poisson, la tensión de iniciación se corresponde con el inicio de un marcado crecimiento de la relación entre deformaciones laterales y axiales. A mayores cargas las fisuras comienzan a unirse, conectarse y propagarse en la matriz. Entre el 70 y el $90 \%$ de la carga última las fisuras se propagan muy rápidamente y el volumen de hormigón alcanza un mínimo a partir del cual comienza a aumentar, producto del gran aumento en la fisuración de la matriz; este mínimo de deformaciones volumétricas se identifica como tensión crítica (Hsu et al, 1963, Mindess y Young, 1981). A partir de la tensión crítica se verifica un incremento pronunciado en la longitud de fisuras, siendo un indicador del comienzo del proceso que culmina en la falla macroscópica. 
El tamaño de los agregados tiene gran influencia en el comportamiento inelástico, a menor tamaño de agregado el hormigón se comporta en forma más homogénea para un mayor rango de cargas. Las tensiones críticas y de iniciación disminuyen respecto a la tensión máxima de 98 a $74 \%$ y de 60 a $50 \%$, respectivamente, al pasar de tamaños entre 0.59-1.19 mm a $6.4-9.5 \mathrm{~mm}$. El predominio de las fisuras de interfaz sobre las de matriz explica la gran influencia que poseen la cantidad y tamaño de agregados sobre el comportamiento inelástico del material (Shah y Chandra, 1968).

El módulo de elasticidad depende del tipo y cantidad de agregados y del progreso de la microfisuración en las interfaces. En el caso de los agregados livianos, que poseen un módulo de elasticidad bajo, la concentración de tensiones en la interfaz es menor y por lo tanto la curva tensión-deformación presenta una zona de comportamiento lineal más extensa.

Un hormigón con fisuras preexistentes se comporta en forma diferente al ser ensayado. No sólo disminuye la resistencia a compresión sino que varía la relación entre cargas y deformaciones, siendo la magnitud de estos cambios función del nivel y tipo de daño. Si el material es sometido a altas temperaturas, por ejemplo, además de fisuras puede presentar alteraciones en los productos de hidratación que también se ven reflejadas en la caída de la resistencia. En general la existencia de defectos trae aparejado una mayor deformabilidad, disminución de la linealidad en el inicio de las curvas tensión-deformación y una disminución de la tensión crítica. Si el hormigón es sometido durante el ensayo a ciclos de carga y descarga se puede observar que luego del primer ciclo quedan deformaciones remanentes debido al cierre de algunas fisuras preexistentes.

Dada la vinculación existente entre mesoestructura y respuesta mecánica, es de interés caracterizar los defectos y valorar el grado en que afectan a estas propiedades. Más adelante se estudiarán casos particulares de hormigones dañados por contracción por secado, alta temperatura y reacción álcali-sílice.

Cabe reiterar que existen particularidades en cuanto a la influencia de la mesoestructura en la respuesta mecánica de algunos hormigones especiales, en especial la orientación de las fibras es un factor determinante en la respuesta post fisuración del HRF, más adelante se abordará este tema con más detalle. 


\subsubsection{Estructura y mecanismos de transporte}

En tecnología del hormigón el término durabilidad se puede definir como la habilidad que posee el hormigón de resistir las acciones del medio ambiente en el que está emplazado, el comité ACl 201 la define como la capacidad para resistir la acción del tiempo, los ataques químicos, la abrasión o cualquier otro proceso de deterioro, es decir para ser durable el hormigón deberá retener su forma original, su calidad y su servicio al ser expuesto al medio ambiente.

Para controlar la velocidad de deterioro del hormigón es esencial diseñar por durabilidad restringiendo los mecanismos de deterioro cerca de la superficie. A través de una superficie deteriorada ingresan más fácilmente agentes agresivos del medio que a su vez incrementan el daño favoreciendo la continuidad del proceso. Tal vez la propiedad más importante del hormigón para asegurar su durabilidad sea la de resistir el flujo de fluidos a través de él, esta propiedad se conoce como permeabilidad.

La durabilidad del hormigón está relacionada con la velocidad con que el agua y los agentes agresivos que ésta transporta ingresan en el material. El movimiento de la humedad dentro del hormigón es bastante complejo debido al amplio rango de tamaño de poros, los cambios en la estructura de poros en el tiempo y la interacción entre el agua, el vapor de agua y el sistema de poros. El mecanismo de ingreso dominante en períodos cortos de tiempo (horas) especialmente en superficies no saturadas o parcialmente saturadas, es la absorción capilar, el transporte a través de los poros capilares. En cambio el transporte de humedad en períodos largos de tiempo está dominado por el transporte a través de los poros del gel y por difusión (Neithalath, 2006).

Se analizan a continuación las propiedades de transporte vinculadas con la durabilidad.

La Permeabilidad es la propiedad que describe el movimiento de fluidos a través de la estructura de poros saturados del hormigón bajo una presión externa. La permeabilidad al agua está definida por la ley de Darcy como: 


$$
\begin{aligned}
& \mathrm{Q}=-\mathrm{KA}(\Delta \mathrm{P} / \Delta \mathrm{l}) \quad \text { siendo } \mathrm{K}=\text { coeficiente de permeabilidad al agua } \text {. } \\
& Q=\text { caudal. } \\
& \Delta \mathrm{P}=\text { variación de presión. } \\
& \Delta \mathrm{l}=\text { trayectoria del flujo. } \\
& \mathrm{A}=\text { área sobre la que está aplicado el flujo. }
\end{aligned}
$$

En el caso del hormigón la permeabilidad depende de la estructura interna, el contenido de humedad y las características del fluido que se infiltra (agua, gases). Dado que la resistencia y la permeabilidad están relacionadas a través de la porosidad capilar muchos de los factores que afectan la resistencia del hormigón también afectan la permeabilidad. La permeabilidad comienza y continúa incrementándose en la medida que exista una trayectoria de flujo continua, por esta razón es más perjudicial la existencia de una gran cantidad de poros interconectados que el tamaño de los mismos.

El coeficiente de permeabilidad puede ser un buen índice para evaluar la durabilidad del hormigón (De Schutter y Audenaert, 2004). En cuanto a órdenes de magnitud el coeficiente de permeabilidad de un hormigón de resistencia moderada $(a / c=0.50)$ es del orden de $1 \times 10^{-12} \mathrm{~m} / \mathrm{s}$ mientras que en un hormigón de baja resistencia $(a / c=0.75)$ crece significativamente y alcanza cerca de $30 \times 10^{-12} \mathrm{~m} / \mathrm{s}$.

Las cargas a las que se encuentra sometida una estructura durante su vida en servicio no son, en general, suficientemente importantes como para causar un daño grave. Sin embargo con el tiempo la degradación puede crecer, formándose microfisuras. En estructuras de retención de agua, estas variaciones en la estructura interna del material son de gran interés ya que dan lugar a grandes diferencias en la permeabilidad. En general, en todo tipo de estructuras de hormigón armado las fisuras aumentan significativamente la permeabilidad del hormigón, acelerando los procesos de deterioro.

La caracterización en el mesonivel adquiere interés ya que los cambios dependen del tipo de fisuras. Se ha observado que cuando las fisuras poseen un ancho mayor a $100 \mu \mathrm{m}$ aproximadamente la permeabilidad se incrementa sustancialmente (Wang et al, 1997, Aldea et al, 1999a y b). Wang et al (1997) presentaron ensayos de permeabilidad sobre muestras prefisuradas, las fisuras se generaron en el centro de cada probeta a través de tracción por compresión diametral; 
se encontró que para aperturas de fisuras menores a $50 \mu \mathrm{m}$ no se observaron variaciones con respecto a la permeabilidad, para aperturas entre 50 y $200 \mu \mathrm{m}$ se producía un rápido incremento y para aperturas mayores a $200 \mu \mathrm{m}$ la velocidad de incremento de la permeabilidad se tornaba más estable.

Varios estudios han demostrado que el hormigón reforzado con fibras mejora la permeabilidad ya que las fibras actúan de manera tal que favorecen la formación de múltiples fisuras de menor magnitud (Persson, 2004, Bhargava y Banthia, 2008). Rapoport et al (2002) observaron que para anchos de fisura mayores a $100 \mu \mathrm{m}$ la inclusión de fibras reducía la permeabilidad del hormigón, pero no tendría mayor influencia en anchos menores.

El proceso a través del cual los líquidos, gases o iones se mueven a través de los poros del material bajo la acción de un gradiente de concentración se denomina Difusión. Se puede definir un coeficiente de difusión como:

$\mathrm{J}=-\mathrm{D} \Delta \mathrm{c} / \Delta \mathrm{x} \quad$ siendo $\mathrm{J}=$ velocidad de transferencia de la masa a través de una sección unitaria.

$\Delta c / \Delta x=$ gradiente de concentración .

$\mathrm{D}=$ coeficiente de difusión.

Este mecanismo puede ocurrir en hormigones parcial o completamente saturados y es importante en estructuras expuestas a la acción de agentes agresivos. En particular la difusión de cloruros es altamente peligrosa para las estructuras de hormigón armado ya que el ingreso de éstos produce la despasivación de las armaduras. La velocidad de difusión depende de la temperatura, la humedad interna, el tipo de difusor y de la difusividad inherente del material.

Según Gerard y Marchand (2000) la presencia de fisuras continuas dentro del hormigón incrementa la difusividad del material entre 2 y 10 veces. Los mismos autores observaron que su influencia se hace más notoria a medida que aumenta la relación $D_{1} / D_{0}$ siendo $D_{1}$ el coeficiente de difusión de iones en solución libre y $D_{0}$ el coeficiente de difusión de iones en el material homogéneo es decir sin fisuración, esto esencialmente significa que el efecto de las fisuras es más importante en materiales densos como los hormigones de alta performance en los cuales el coeficiente de transporte inicial (sin fisuración) es pequeño (Gerard y Marchand, 2000). 
La Absorción Capilar es el mecanismo por el cual un fluido ingresa por acción de fuerzas capilares a un material poroso que no se encuentra saturado. La absorción de agua por capilaridad es inversamente proporcional al radio de poros. También depende de la geometría del poro y del nivel de saturación del material (este fenómeno no ocurre en un material completamente saturado), evidentemente a mayor cantidad de poros interconectados mayor será el ingreso de agua y de agentes agresivos.

La absorción capilar es el mecanismo de transporte que habitualmente se presenta en aquellas estructuras en las que el hormigón se encuentra sujeto a ciclos de humedecimiento y secado. El mecanismo es cuantificado a través de la velocidad de succión capilar que representa la velocidad de penetración del líquido por capilaridad.

$A=C+s t^{1 / 2}$

siendo $A=$ masa de agua absorbida por unidad de área de la sección mojada.

C = perturbación inicial (según algunos investigadores es dependiente de la terminación de la superficie).

$\mathrm{s}=$ velocidad de succión.

$\mathrm{t}=$ tiempo.

La absorción capilar es muy sensible al tipo de curado, curados prolongados disminuyen la absorción capilar en forma considerable, el efecto es más notorio en hormigones de razones agua/cemento bajas (Tasdemir, 2003, Taus et al, 2005).

\subsubsection{Evaluación de la mesoestructura}

La caracterización de la mesoestructura resulta una necesidad tanto para evaluar el deterioro en estructuras sometidas a diferentes procesos de degradación como para diversos casos de aplicación y desarrollos recientes, adquiriendo interés contar con herramientas sencillas de valoración. Por ejemplo el estudio de la distribución de agregados permite valorar la homogeneidad del hormigón o la tendencia a la segregación en hormigones autocompactantes (HAC), por otro lado la densidad, ancho y distribución de fisuras representa un parámetro fundamental para caracterizar hormigones afectados por diferentes patologías, como la exposición a alta temperatura, la fisuración por secado o por reacciones deletéreas de los agregados. 
El estudio de la fisuración abarca desde estudios macroscópicos sobre el comportamiento del hormigón fisurado hasta estudios microscópicos de la fisura en sí misma. La presencia de microfisuras puede ser predicha por el comportamiento macroscópico y verificada a través de estudios microscópicos. Se han aplicado diversas técnicas para estudiar la estructura interna del hormigón como por ejemplo técnicas de impregnación, emisión acústica, rayos X, microscopía óptica y electrónica, tomografía o porosimetría de mercurio (Jacobsen et al, 1995, Ammouche et al, 2000, Nemati y Stroeven, 2001, Chen et al, 2006, Hutchinson y Chen, 2006, Kurumisawa y Tanaka, 2006, Lu et al, 2006). Algunas de estas técnicas presentan limitaciones en la resolución, en la sensibilidad en detectar las fisuras, o en la posibilidad de realizar observaciones sobre grandes áreas, otras requieren de una preparación especial de la muestra la cual puede alterar su estructura (Nemati, 2000).

En la Fig. 2.1.1 se resumen los distintos niveles en los cuales el hormigón puede ser evaluado, los elementos característicos de su estructura (como productos de hidratación, interfaces, agregados, fisuras) y los métodos de observación correspondientes a cada escala.

Las técnicas más utilizadas para la observación de defectos se basan en la adquisición de imágenes y su posterior análisis en el microscopio. Las imágenes sólo dan información localizada dentro del material, la densidad de fisuras depende de la resolución con la que se realice la observación. En primer lugar a mayor resolución se tiene un mayor nivel de detalle, por lo tanto es posible observar una mayor cantidad de fisuras. Pero se debe tener en cuenta que en función del grado de resolución varía el tamaño de la muestra a analizar, a mayor resolución menor es el tamaño de la zona observable y es necesario analizar una mayor cantidad de muestras en el caso de un material tan heterogéneo como el hormigón. Como se ve en la Fig. 2.1.2 las fisuras no están distribuidas uniformemente y en función del tamaño de la superficie analizada variará la densidad obtenida para cada rango de tamaños de fisuras (Ringot y Bascoul, 2001). Estas técnicas requieren de equipos costosos (microscopio, cámara, software de procesamiento de imágenes, en algunos casos es necesario realizar cortes delgados) y tiempo de procesamiento ya que las muestras llevan una preparación previa para poder ser observadas en el microscopio (pulido, técnicas de impregnación). 
Porosidad

Molecular

Porosidad Capilar

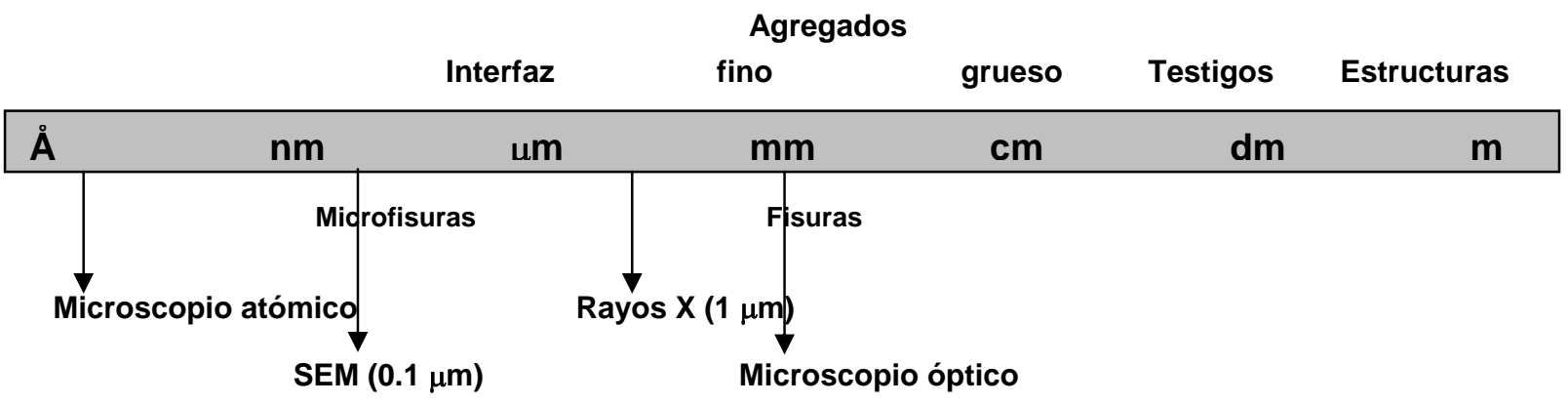

Figura 2.1.1. Escalas y métodos de observación del hormigón.

(Adaptado de Ringot y Bascoul, 2001)

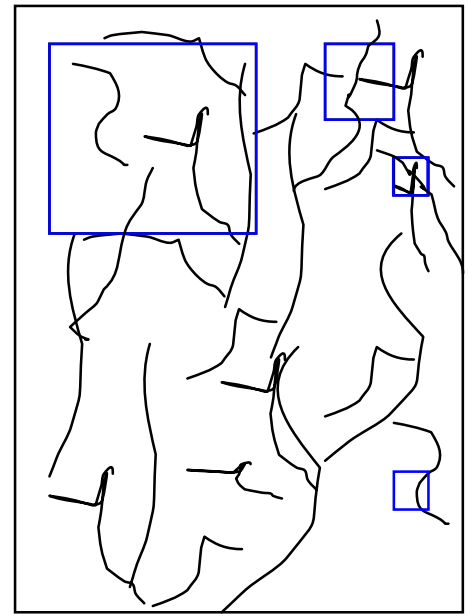

Figura 2.1.2. Densidad de fisuras en función de la escala de observación.

(Adaptado de Ringot y Bascoul, 2001)

\subsection{MESOESTRUCTURA EN HORMIGONES DAÑADOS}

Como ya fue comentado la mayoría de las estructuras de hormigón se fisuran durante su vida en servicio, ya sea por cargas mecánicas, térmicas, contracción plástica o por secado, reacciones deletéreas de los agregados, degradación por ingreso de agentes agresivos, entre otras causas. El deterioro de determinadas obras civiles como presas o plantas nucleares puede llegar a ser inadmisible si su funcionamiento es ineficaz poniendo en riesgo a la comunidad. A su vez las pérdidas generadas por el deterioro de caminos, puentes, ductos y los costos de reparación derivados también representan montos de dinero muy elevados. En este sentido es 
evidente la importancia de la caracterización y evaluación de las fisuras para controlar y predecir el funcionamiento de las estructuras de hormigón y el desarrollo de nuevas tecnologías para lograr estructuras más durables con un menor mantenimiento. En los últimos años se han llevado a cabo investigaciones para mejorar los métodos de diseño, de inspección y mantenimiento de las estructuras de hormigón y asegurar que operen en forma segura y económica (Sarja, 2003).

\subsubsection{Procesos de daño en hormigón por exposición a alta temperatura}

El daño en el hormigón por temperatura puede ser causado por: diferencia entre el coeficiente de expansión térmica de los agregados y la pasta, presión de poros y descomposición de los hidratos. Los primeros dos mecanismos inducen tensiones en la pasta y los agregados y el último debilita la resistencia de los hidratos. Con el aumento de la temperatura disminuyen la resistencia y el módulo de elasticidad del hormigón debido al desarrollo de micro y macro defectos y a la descomposición de la pasta. Consecuentemente disminuye también la durabilidad debido al aumento de las vías de ingreso de agua y agentes agresivos.

Por lo tanto el efecto producido por el aumento de la temperatura depende del grado de hidratación de la pasta, del contenido de humedad y de las características de los agregados. A su vez los defectos generados por temperatura varían significativamente conforme la temperatura, el tiempo de exposición y la forma de enfriamiento, pudiendo consistir en simples microfisuras a nivel de la pasta de cemento hasta grandes fisuras o desprendimientos de pasta o agregados por estallido del hormigón superficial.

El agua en la pasta de cemento se encuentra como agua evaporable en poros del gel y capilares y como agua ligada químicamente en los hidratos del cemento. Al incrementar la temperatura en primer lugar se evapora el agua presente en los poros capilares cercanos a la superficie. Luego el contenido de humedad se transfiere por difusión superficial, debido al gradiente de presión de poros, el agua del gel migra hacia los poros capilares y luego se evapora. A temperaturas superiores a $100^{\circ} \mathrm{C}$ aumenta la velocidad de transferencia de humedad, esto podría deberse a una variación en el modo de transferencia en lugar de fluir en capas adsorbidas la transferencia se lleva a cabo en forma de vapor, lo cual sólo es posible si hay un incremento en el tamaño de poros. La deshidratación producto del aumento de temperatura conlleva a la progresiva ruptura de la estructura del silicato de calcio 
hidratado $(\mathrm{SCH})$ (alrededor de los $500^{\circ} \mathrm{C}$ ) y del hidróxido de calcio aumentando el tamaño promedio de poros y la superficie específica de poros interna. Harmathy (en Bazant y Kaplan, 1996) encontró que la porosidad para pastas de cemento de razón a/c 0.63 a temperaturas de 105,500 y $900{ }^{\circ} \mathrm{C}$ era igual a $44 \%, 54 \%$ y $59 \%$ respectivamente. Al calentar hasta una temperatura de $600^{\circ} \mathrm{C}$ existe un incremento del volumen de poros debido al aumento en la cantidad de poros mayores a $5 \mu \mathrm{m}$ y a la formación de microfisuras. La deshidratación completa del gel de $\mathrm{SCH}$ se produce alrededor de los $850^{\circ} \mathrm{C}$.

Durante el calentamiento existe una competencia entre expansión y contracción de la pasta que afecta su microestructura y por lo tanto sus propiedades físicas y mecánicas. Hasta los $105^{\circ} \mathrm{C}$ se producen expansiones en la pasta (máxima expansión aproximadamente igual a $0.2 \%$ ), entre 150 y $300^{\circ} \mathrm{C}$ no hay expansiones y a partir de los $300^{\circ} \mathrm{C}$ comienza a contraerse (a los $800^{\circ} \mathrm{C}$ la contracción se encuentra aproximadamente entre 1.6 y $2.2 \%$ ). Dettling atribuyó la expansión inicial de la pasta a movimientos cinéticos de las moléculas y a presiones de hinchamiento causadas por la disminución de la tensión capilar del agua a medida que aumenta la temperatura. Según Lanckard la contracción de la pasta es producida por la pérdida de agua evaporable y químicamente combinada principalmente. A menor velocidad de calentamiento (considerando como lenta $0.2^{\circ} \mathrm{C} / \mathrm{min}$ y rápida $1^{\circ} \mathrm{C} / \mathrm{min}$ ) mayor es la pérdida de humedad y, por lo tanto, es mayor la contracción (Bazant y Kaplan, 1996).

Fu et al (2004) realizaron observaciones con un microscopio electrónico en pastas y morteros calentados hasta $500^{\circ} \mathrm{C}$ bajo carga constante y luego cargados hasta la rotura. Indicaron que el daño producido en la pasta no fue sólo debido a la descomposición de los hidratos sino también a fisuras causadas por la disparidad entre expansión y contracción de los distintos tipos de productos de hidratación. La mayoría de las fisuras se desarrollan entre los 300 y los $500^{\circ} \mathrm{C}$. Piasta observó que el desarrollo de microfisuras en la pasta sufre un incremento significativo a partir de los $300^{\circ} \mathrm{C}$, generándose primero fisuras alrededor de los cristales de hidróxido de calcio y luego alrededor de los mayores granos de cemento anhidro, alrededor de los $400^{\circ} \mathrm{C}$ (Bazant y Kaplan, 1996).

En morteros calentados a $300^{\circ} \mathrm{C}$ y sometidos a carga constante, Fu et al (2004) describieron tres tipos de fisuras alrededor de la arena, de tipo radial, tangencial y de inclusión. Comparando las deformaciones térmicas de la pasta y el mortero apreciaron que hasta temperaturas de aproximadamente $100^{\circ} \mathrm{C}$ la pasta se 
expandió pero a temperaturas mayores comenzó a contraerse hasta que al llegar a los $500^{\circ} \mathrm{C}$ la contracción fue del $2.3 \%$; en cambio el mortero presentó una continua expansión a medida que aumentó la temperatura debido a la expansión de la arena y a $500{ }^{\circ} \mathrm{C}$ la expansión fue igual al $0.9 \%$. Las fisuras radiales ocurrieron a temperaturas entre 200 y $300^{\circ} \mathrm{C}$ al ser el coeficiente de expansión térmica de la pasta menor que el del agregado. Las fisuras tangenciales y de inclusión en los agregados en cambio pudieron formarse a temperaturas menores a $100^{\circ} \mathrm{C}$ cuando el coeficiente de expansión térmica de la pasta es mayor que el de los agregados. La fisuración superficial se debió a la pérdida del agua libre que comienza a los $100^{\circ} \mathrm{C}$ y finaliza a los $540^{\circ} \mathrm{C}$. El coeficiente de expansión térmica de los agregados varía entre $5.5 \times 10^{-6} \mathrm{y}$ $11.8 \times 10^{-6}{ }^{\circ} \mathrm{C}^{-1}$ en función del contenido de minerales cristalinos o amorfos, la orientación de los cristales, el porcentaje de humedad y el contenido de sílice (mayor coeficiente de expansión).

En general los agregados se descomponen con temperaturas mayores a $500{ }^{\circ} \mathrm{C}$ en función de su origen. Los agregados silíceos a $500-600^{\circ} \mathrm{C}$ sufren la transformación del cuarzo $\alpha$ en cuarzo $\beta$ con una expansión del $0.85 \%$, los agregados calcáreos entre los 600 y $900^{\circ} \mathrm{C}$ sufren una reacción de descarbonatación, el carbonato de calcio se disocia en óxido de calcio y dióxido de carbono, el óxido de calcio al enfriarse se combina con la humedad atmosférica y forma hidróxido de calcio con un aumento de volumen del $44 \%$ que puede causar fisuras en el hormigón. Los agregados livianos poseen mayor estabilidad química a elevada temperatura.

En consecuencia hasta temperaturas de aproximadamente $700^{\circ} \mathrm{C}$ el hormigón se expande, ya que la expansión de los agregados es mayor que la contracción de la pasta. Para temperaturas mayores a $700^{\circ} \mathrm{C}$ el hormigón se contrae por deshidratación y descomposición del gel de silicato de calcio hidratado de la pasta.

Durante el enfriamiento también se producen alteraciones tanto más cuanto mayor es la velocidad de descenso de la temperatura. El hormigón una vez frío no conserva su longitud inicial debido a los cambios químicos y físicos sufridos durante la exposición a alta temperatura. La estabilidad dimensional depende de las propiedades de los agregados y la matriz, contenido de la mezcla y temperatura máxima de exposición. En experiencias con hormigones calentados a $1000^{\circ} \mathrm{C}$ y enfriados al aire se observó que los elaborados con agregado silíceo al enfriarse presentaban una expansión residual mientras que los elaborados con escoria una contracción residual. Las deformaciones residuales dependen del tipo de alteraciones internas, en el primer 
caso a los $570^{\circ} \mathrm{C}$ el hormigón se expandió fisurándose, al enfriar estas fisuras no se cerraron completamente quedando una expansión residual; en el segundo caso las elevadas temperaturas disminuyeron las tensiones entre los agregados y la matriz disminuyendo de esta forma la microfisuración y la expansión irreversible. En otro estudio se observó que luego de calentar hasta $300{ }^{\circ} \mathrm{C}$ probetas de hormigones con distintos agregados, al enfriarlas aparecía una contracción residual, exceptuando las que contenían grava, pero si se las llevaba a $700^{\circ} \mathrm{C}$ al enfriarlas sufrían una expansión residual con excepción de las de escoria (Bazant y Kaplan, 1996).

En lo referente al aspecto de los hormigones dañados por temperatura, se ha observado que hasta unos $200^{\circ} \mathrm{C}$ no aparecen cambios de color en el hormigón, en cambio para temperaturas de 400,800 y $1000^{\circ} \mathrm{C}$ el hormigón pasa por distintas tonalidades desde amarillenta a blanco apagado hasta finalmente un color rojizo ( $\mathrm{Li}$ et al, 2004).

La evaluación de la resistencia mecánica a altas temperaturas se puede realizar en distintas condiciones: calentar primero la probeta y ensayarla mientras está caliente, cargarla hasta un $55 \%$ de la resistencia a compresión como máximo, luego elevar la temperatura y cargarla nuevamente hasta la rotura y el tercer procedimiento consiste en calentar primero la probeta y ensayarla una vez fría, esta última resistencia se identifica como resistencia residual. En ensayos donde la carga se aplica durante el calentamiento se observan menores pérdidas en la resistencia, debido a que los esfuerzos aplicados retardan la fisuración. Si las probetas se encuentran selladas evitando la pérdida de humedad, la disminución de resistencia es mucho mayor.

La pérdida de resistencia a compresión se puede deber a daño de los agregados, al debilitamiento de las interfaces y disminución de la resistencia por aumento de la porosidad, degradación de los silicatos de calcio hidratados, transformaciones químicas por reacciones hidrotérmicas y desarrollo de micro y macro fisuras. Además se encuentra influenciada por la temperatura máxima alcanzada y por el tiempo de exposición. Para temperaturas de $100^{\circ} \mathrm{C}$ y tiempos de exposición entre 45 y 90 minutos se encontró una ganancia de resistencia de entre el 10 y el $23 \%$, las mayores pérdidas en resistencia se registraron para temperaturas mayores a $400{ }^{\circ} \mathrm{C}$ (Chiang y Yang, 2005). Se ha observado que hasta temperaturas de $200^{\circ} \mathrm{C}$ la resistencia puede aumentar porque el hormigón se seca rápidamente y aumenta la 
hidratación, esto equipara la disminución de resistencia por microfisuración debido a la incompatibilidad térmica entre la pasta y los agregados.

El tipo de agregados es uno de los principales factores que afectan la resistencia, a temperaturas menores a $600^{\circ} \mathrm{C}$ los hormigones elaborados con dolomitas y piedras calizas se encuentran menos afectados que los preparados con agregados silíceos. También tiene influencia la relación agregado/cemento, en general a mayor contenido unitario de cemento (pastas más ricas) mayor será la reducción en resistencia.

El valor de la resistencia a compresión también se ve influida por el tamaño de la probeta ya que la zona más afectada la constituye el hormigón de recubrimiento. La pérdida de resistencia es mayor en probetas de menor tamaño dado que el hormigón es un pobre conductor (Li et al, 2004).

Los hormigones de alta resistencia poseen una pobre resistencia al fuego, al ser sometidos a temperaturas mayores a $400^{\circ} \mathrm{C}$ son proclives al descascaramiento producto de su menor permeabilidad y mayor fragilidad. Este hecho está en gran medida relacionado con las posibilidades de movimiento del agua en el interior de los poros. El estado de saturación previo al proceso de calentamiento tiene una incidencia determinante en la degradación del hormigón por exposición a alta temperatura.

La incorporación de fibras reduce y hasta elimina el descascaramiento que puede presentar el hormigón. Experiencias realizadas con HRF expuestos a $800^{\circ} \mathrm{C}$ mostraron que mientras los hormigones con fibras de carbono y acero presentaron explosiones esto no ocurrió cuando se incorporaron fibras de polipropileno. Las fibras de polipropileno se funden durante el calentamiento y se evaporan dejando microcanales que actúan aliviando las tensiones de vapor en los capilares. Se observó también que la pérdida en la resistencia al calentar hasta una temperatura de $400^{\circ} \mathrm{C}$, incorporando fibras de carbono y acero, fue menor debido a que las fibras bloquean la iniciación y propagación de los microdefectos en el hormigón, a $800^{\circ} \mathrm{C}$ de temperatura la resistencia residual fue del $30 \%$ (Chen y Liu, 2004).

Debido al desarrollo de fisuras por efecto de las altas temperaturas la respuesta del hormigón en la rama ascendente de la curva tensión - deformación es no lineal. Se observó además una disminución en los valores de la tensión de iniciación $\left(\mathrm{f}_{\text {inic }}\right) \mathrm{y}$ de la tensión crítica $\left(\mathrm{f}_{\text {crit }}\right)$. También se demostró que las alteraciones 
provocan una reducción en el período de propagación estable de fisuras (diferencia entre $f_{\text {crit }} y f_{\text {inic }}$ ) y una extensión del período de crecimiento inestable de fisuras (dado por $f^{\prime}{ }_{c}-f_{\text {crit }}$ ) (Giaccio y Zerbino, 2003).

El módulo de elasticidad es la propiedad más afectada por la exposición a altas temperaturas (Barragán et al, 1998, 2000, 2001, Di Maio et al, 1999, 2002). En cuanto al comportamiento en tracción, la mayoría de los estudios (Bazant y Kaplan, 1996) concluyen que las pérdidas en resistencia son mayores que para compresión. Influyen el tipo de agregado y la razón agregado/cemento (a medida que disminuye la razón es mayor la reducción), mientras que la velocidad de calentamiento parece no ser un factor a tener en cuenta. Sin embargo algunas experiencias realizadas con hormigones de alta resistencia con y sin refuerzo de fibras mostraron pérdidas con el aumento de la temperatura en tracción y compresión similares (Chen y Liu, 2004).

Considerando el efecto de cargas de larga duración, por debajo de los $100^{\circ} \mathrm{C}$ la fluencia se intensifica por la difusión de humedad entre los microporos del gel y la alta difusión a través de los poros capilares mientras se está secando el hormigón. A temperaturas por encima de $105^{\circ} \mathrm{C}$ ocurre un proceso de deshidratación que probablemente acelera el creep. La forma y tamaño de las probetas afecta los resultados de los ensayos ya que influye en la pérdida de humedad.

Más reducida es la información en lo referente a las propiedades de transporte. De acuerdo a un estudio reciente de permeabilidad realizado sobre hormigones mientras eran simultáneamente expuestos a cargas de compresión y altas temperaturas $\left(105\right.$ y $\left.150^{\circ} \mathrm{C}\right)$ se encontró que las cargas en una primera instancia disminuyeron la permeabilidad por cierre de las microfisuras preexistentes. Luego, a medida que el hormigón se fue fisurando por efecto de las cargas la permeabilidad aumentó. Al descargar las fisuras no se cerraron completamente y la permeabilidad continuó aumentando. Con respecto a la temperatura, la permeabilidad se incrementó a medida que aumentó la temperatura, a $105^{\circ} \mathrm{C}$ el aumento se debió al incremento del tamaño de poros por efecto de la expansión térmica del hormigón. A $150^{\circ} \mathrm{C}$ el aumento fue más importante dado por el incremento del tamaño de poros y la fisuración por temperatura (Choinska et al, 2007). 


\subsubsection{Procesos de daño en hormigón por contracción por secado}

La contracción por secado es uno de los principales fenómenos que generan cambios dimensionales y microfisuración dentro del hormigón. El proceso se produce por la pérdida de humedad, principalmente la pérdida de agua de los poros capilares y a baja humedad relativa también por la pérdida del agua adsorbida en los silicatos hidratados.

Por efecto de los gradientes hídricos entre el interior y el exterior de un elemento de hormigón se generan contracciones diferenciales que inducen tensiones de tracción en la superficie. Si estas tensiones superan la resistencia a tracción del hormigón se producen fisuras. De esta forma la contracción por secado induce micro y macro fisuras que tendrán influencia sobre las propiedades elásticas y en la resistencia del material. Los elementos estructurales adyacentes causan también restricciones que incrementan las tensiones de tracción generadas por efecto de la contracción por secado.

Entre los factores que modifican la contracción se encuentran la composición del hormigón, las condiciones de exposición (humedad y temperatura), las dimensiones y forma de las probetas o elementos estructurales (inciden en la pérdida de agua afectando la velocidad de contracción) y la cantidad y distribución de las armaduras (poseen un efecto restrictivo en la contracción).

En cuanto a los factores mesoestructurales que influyen en la contracción, un hormigón con mayor volumen de agregados o con agregados más rígidos presenta menor contracción ya que son los agregados los que restringen los cambios volumétricos.

En un estudio realizado sobre morteros se observó la influencia de la contracción por secado sobre el comportamiento bajo cargas de compresión uniaxial. Las probetas fueron mantenidas durante 6 meses bajo agua y luego diferenciadas en 3 series, un grupo protegido con láminas de aluminio para mantenerlas saturadas, otro grupo fue secado en estufa a $60^{\circ} \mathrm{C}$ y luego cubierto con aluminio constituyendo las muestras secas y al tercer grupo se lo dejó secar en atmósfera controlada. Además de los ensayos de compresión se realizaron mediciones de permeabilidad al aire y porosidad. Los resultados obtenidos con respecto a la permeabilidad y la porosidad mostraron que estas propiedades no presentaron grandes variaciones entre probetas 
pudiéndose considerar los morteros como homogéneos y su proceso de secado idéntico. El secado produjo un aumento en la resistencia del mortero de un $20 \%$. En cambio el módulo de elasticidad y el coeficiente de Poisson disminuyeron un 10 y un $25 \%$ respectivamente, este fenómeno se puede deber a la depresión capilar que causa el secado como también a la microfisuración producto de la contracción diferencial entre el centro y los bordes de las probetas y por la presencia de los agregados (Yurtdas et al, 2004).

En experiencias (Giaccio y Zerbino, 1997 y 1998b) con canto rodado y piedra partida se analizó la influencia de la fisuración por contracción por secado sobre la respuesta mecánica y particularmente sobre el mecanismo de fractura. Se asume que la mayoría de las fisuras producidas por secado se concentran en las interfaces por ser la zona más débil, de ahí la influencia del tipo de agregado utilizado. En el caso del hormigón elaborado con rodados cuando las muestras sin alterar fueron sometidas a compresión, las fisuras recorrían la superficie de los agregados, por el contrario, en las muestras prefisuradas por contracción por secado, las fisuras se alejaban de los agregados y se propagaban por la matriz, sin embargo el período de propagación de fisuras fue similar en ambos casos. En los hormigones con piedra partida se observó que en el caso de las muestras alteradas, la capacidad de los agregados de frenar o desviar las fisuras disminuyó, ya que la presencia de las fisuras preexistentes facilitó el camino para su propagación, dando lugar a un aumento del período de propagación inestable de fisuras, disminución de la tensión crítica y una mayor pérdida de resistencia.

\subsubsection{Procesos de daño en hormigón por Reacción Álcali-Sílice}

La reacción álcali-sílice (RAS) es una reacción deletérea que se produce entre los álcalis del cemento y la sílice del agregado. Para que se desarrolle se deben cumplir como condiciones que el hormigón posea agregados reactivos que contengan sílice metaestable, que exista una concentración mínima de iones alcalinos ( $\mathrm{Na}, \mathrm{K}, \mathrm{Ca}$ y $\mathrm{HO}$ ) en el fluido de poros, elevada humedad (humedad interna superior al 80-85\%), temperatura normal y un tiempo necesario para que se inicie la reacción. Por el contenido de álcalis el $\mathrm{PH}$ del cemento se mantiene entre 12.5 y 13.5 , con estos valores las rocas ácidas (con minerales de sílice) no se mantienen estables ante largas exposiciones. En las rocas que tienen minerales de sílice pobremente cristalina o metaestable (como ópalo, tridimita, cristobalita y vidrio volcánico) los signos de deterioro se observan rápidamente en un año o menos mientras que las rocas 
compuestas por cuarzo microcristalino, tensionado o deformado presentan una reacción más lenta con signos externos de deterioro visibles al cabo de 8 a 25 años. Los iones álcalis se pueden encontrar en el cemento y en aditivos, agregados contaminados con sales, penetración de agua de mar, sales deshielantes, etc. Si el contenido total de álcali es menor que $3 \mathrm{~kg} / \mathrm{m}^{3}$ no se producirán daños, igualmente el umbral de álcali necesario para iniciar y mantener la reacción varía según el tipo de agregado.

El mecanismo de expansión se inicia cuando los iones hidroxilos rompen la estructura de sílice amorfa (atacan la ligadura de Si-O de la sílice presente en los agregados) de los agregados reactivos y seguidamente se adsorben, los iones de metal alcalino, en la superficie recientemente creada de los productos de la reacción. Los geles de silicato alcalino en contacto con agua se hinchan absorbiendo gran cantidad de agua por ósmosis. La presión hidráulica lleva al agrietamiento del agregado afectado y la pasta de cemento que lo rodea. La solubilidad de estos geles hace que se muevan desde el interior del agregado y se localicen en las fisuras de los agregados y la pasta de cemento, formando anillos alrededor de las partículas de agregado, llenando vacíos en la pasta y reemplazando al silicato de calcio hidratado. La disponibilidad de agua favorece el crecimiento y la extensión de las microgrietas hasta que alcanzan la superficie externa del hormigón, por desarrollarse en forma irregular se lo denomina agrietamiento de mapeo.

La reacción se manifiesta en fisuras y poros llenos con productos de la reacción o formando aureolas rodeando los agregados reactivos con presencia de humedad a su alrededor, también se puede observar un aumento de volumen y fisuras en la interfaz pasta agregado, en la pasta de cemento o en los agregados. La aparición de estos signos depende de las características de los agregados reactivos y de la cinética de la reacción. La reacción en los pavimentos se caracteriza por la ondulación y superposición de las losas y el cerrado de las juntas de contracción. La abertura de las fisuras sobre la superficie exterior varía desde décimas de milímetro hasta 2 o $3 \mathrm{~cm}$. Al extraer testigos de estructuras afectadas se puede observar que la reacción se produce en toda la masa. En estructuras de hormigón armado las fisuras se ubican paralelas a las armaduras, las armaduras y otras restricciones de borde reducen y controlan las tensiones producidas por la expansión, sin embargo las fisuras superficiales no son reducidas por las restricciones. 
La temperatura afecta el momento de iniciación y el desarrollo de la reacción. También la cinética de la reacción incide sobre el proceso de daño en el hormigón. Si la velocidad de reacción es rápida se generan tensiones en las interfaces y en la pasta de cemento produciendo micro y macro fisuras. Si los agregados contienen cuarzo tensionado la reacción se localiza en zonas dentro de los agregados, es un proceso lento y no se produce un daño generalizado alrededor de los agregados, en otro tipo de agregados la reacción se desarrolla en las interfaces, la presión del gel genera fisuras que se extienden por la matriz y también se van llenando con gel (Giaccio et al, 2008).

El desarrollo de esfuerzos internos también depende de la cantidad y tamaño de agregado reactivo. Agregados reactivos de tamaño menor a $75 \mu \mathrm{m}$ no producen expansión, las partículas de tamaño intermedio entre 0.85 y $0.07 \mathrm{~mm}$ son las que producen las mayores expansiones. Según (Zhang et al, 1999) para agregados silíceos con tamaños entre 0.15 y $10 \mathrm{~mm}$ cuanto menor es el tamaño de agregado mayor es la expansión y la razón cemento/agregado que se corresponde con el máximo de expansión disminuye a medida que aumenta el tamaño de los agregados.

En un estudio realizado en hormigones reforzados con microfibras se encontró que la acción de las fibras impidiendo la propagación de las fisuras no sólo impuso un confinamiento mecánico a la expansión del gel sino también uno de tipo químico. El confinamiento impidió al gel expandirse por la matriz produciendo un aumento en la concentración de los iones $\mathrm{Si}$ y $\mathrm{Na}$. Esta alta concentración aumentó la viscosidad del gel dificultando, a su vez, su migración. Además la mayor concentración de iones Si retardó la disolución de los agregados reactivos (Ostertag et al, 2007).

En cuanto al comportamiento mecánico se ha observado que la RAS afecta la resistencia y en mayor medida el módulo de elasticidad y el coeficiente de Poisson (Batic et al, 2004). Al analizar las curvas tensión - deformación se observó que el comienzo y crecimiento de las fisuras se iniciaba antes en el hormigón dañado y que el período de propagación inestable de fisuras se encontraba más afectado que el de propagación estable. En lo que respecta al comportamiento en tracción de hormigones dañados por RAS, se observaron diferencias en las curvas carga - desplazamiento, mostrando mayores deformaciones inelásticas lo que pone de manifiesto la mayor ramificación en la formación de las fisuras. El estudio concluyó que la RAS afecta en mayor proporción la resistencia a tracción y el módulo de elasticidad que la resistencia a compresión. Este hecho así como las consideraciones relativas al mecanismo de 
rotura en compresión constituyen efectos comparables a los observados sobre las propiedades residuales de hormigones dañados por alta temperatura.

Un estudio reciente donde el hormigón fue sometido a estados de confinamiento uniaxial y triaxial, concluye que la deformación volumétrica es similar independientemente del estado tensional (Saouma y Perotti, 2006), variando el desarrollo de la reacción si el hormigón se encuentra tensionado.

\subsection{MESOESTRUCTURA EN HORMIGONES ESPECIALES}

El estudio de la mesoestructura también resulta de interés para la evaluación de hormigones especiales. En especial se destaca la aplicación en hormigón reforzado con fibras (HRF). La relación entre la orientación y distribución de fibras dentro del hormigón con los métodos de elaboración y el posterior comportamiento del material en estado endurecido resultan de utilidad para el diseño de elementos estructurales así como también para caracterizar al material y como parte del control de calidad. Asimismo el análisis de la homogeneidad en un hormigón autocompactante (HAC), cuantificada a través de la distribución de agregados, puede ser una forma de controlar la calidad del material.

Por este motivo se han planteado dentro del trabajo experimental varias aplicaciones para HRF y HAC. Se realiza a continuación una breve discusión sobre las características mesoestructurales y propiedades de estos dos hormigones.

\subsubsection{Hormigón autocompactante}

El hormigón autocompactante (HAC) fue desarrollado en Japón con el fin de eliminar la vibración y disminuir los defectos causados por prácticas constructivas deficientes. Su desarrollo fue posible gracias al progreso de los superfluidificantes.

Un HAC posee la capacidad de llenar el interior de los encofrados y pasar a través de las barras de armaduras, logrando la compactación por la acción de su propio peso, sin presentar signos de segregación (Gettu y Agulló, 2004a y b). De esta forma se elimina el trabajo de compactación con las reducciones en ruido y mano de obra que esto conlleva y se obtiene una mejora en el tiempo y la facilidad de construcción, apariencia superficial y características en estado endurecido. 
Entre las principales ventajas de un HAC se destacan la reducción en la mano de obra, mejoras en la terminación superficial, mayor facilidad de colocación, mejoras en la durabilidad; a la vez permite unạ mayor libertad de diseño, reducir las secciones de hormigón, reducir los niveles de ruido por la ausencia de vibración y por lo tanto otorga mayor seguridad en el trabajo.

La fluidez, la capacidad de pasaje y la resistencia a la segregación son fundamentales en HAC, pero en general las dos primeras se oponen a la última (Koyata y Comman, 2005). Estudios reológicos de HAC en estado fresco mostraron cómo para lograr las condiciones de autocompactabilidad se requiere una cooperación entre la tensión umbral de cizallamiento y la viscosidad plástica del hormigón, si la viscosidad es muy baja, es recomendable que el umbral de cizallamiento aumente para evitar la segregación en el hormigón; por otro lado si la viscosidad es elevada se necesita una tensión umbral muy pequeña (Nielsson y Wallevik, 2003). La matriz del HAC debe ser suficientemente viscosa para evitar la segregación de los áridos pero poseer suficiente movilidad para asegurar el llenado. Se ha observado que los parámetros reológicos se modifican cuando se adicionan fibras al hormigón convencional (Pasini et al, 2004).

Se han desarrollado métodos para optimizar su diseño y para evaluar sus propiedades. Las investigaciones sobre el diseño se centran principalmente en reducir el contenido de pasta, ya que representa los mayores costos. Para ello se debe optimizar el esqueleto granular a fin de obtener la máxima compacidad, reduciendo el contenido de agregado grueso, limitando el tamaño máximo de agregado y tratando de utilizar agregados redondeados.

Para obtener una buena capacidad de pasaje se debe reducir la fricción entre partículas y aumentar la deformabilidad de la pasta. Lo primero se logra reduciendo el volumen de agregados y combinando el cemento con adiciones de forma tal de obtener una distribución homogénea de tamaños. La utilización de aditivos superplastificantes aumenta la fluidez de la pasta sin pérdida de viscosidad.

Para evitar la segregación de los sólidos se debe reducir el contenido de agua libre a través de la disminución de la razón a/c, utilización de aditivos modificadores de viscosidad e incorporación de adiciones con elevada superficie específica. 
En definitiva un HAC en relación a un hormigón convencional contiene menor contenido de agregado grueso, mayor contenido de pasta, baja razón agua/ligante, aumento de superplastificante y en algunos casos contiene un aditivo modificador de viscosidad.

Por tanto el estudio de la homogeneidad en un HAC adquiere una gran trascendencia, ya que el llenado y compacidad dependerán básicamente de las características del material en estado fresco. La calidad final será función de las propiedades reológicas del HAC y por ello además de los materiales componentes, la temperatura, el tiempo que demore el llenado y las condiciones de mezclado. Por estos motivos el estudio de la distribución de agregados y la existencia de grandes defectos son aspectos a evaluar de la mesoestructura de un HAC.

En cuanto a sus propiedades mecánicas la resistencia a compresión de un HAC con la misma razón a/c que un hormigón convencional vibrado puede ser levemente mayor, la ausencia de vibración mejora la interfaz matriz-agregado (SCCEPG Guidelines, 2005). El módulo de elasticidad podría ser menor ya que el HAC posee un mayor volumen de pasta.

Zhu et al (2001) moldearon columnas y vigas de tamaños normalmente utilizados en la práctica para evaluar la calidad de un HAC y compararla con un hormigón vibrado. No encontraron diferencias ni en la resistencia ni en la calidad del hormigón superficial a lo largo de las vigas elaboradas con HAC y las de referencia. En cambio en el caso de las columnas encontraron que la resistencia a compresión se incrementaba de arriba hacia abajo en ambas mezclas. En todos los casos encontraron que el HAC se comportaba de manera similar al hormigón vibrado e incluso presentaba una mayor homogeneidad en sus propiedades.

En cuanto a las propiedades de transporte se encontró que el HAC al tener menor tamaño promedio de poros que el hormigón vibrado, posee un coeficiente de absorción capilar ligeramente mayor (Assié et al, 2007). Pero a pesar de ser un hormigón con una microestructura densa, los mismos autores no observaron mejoras en la resistencia al ingreso de cloruros, ratificando que las propiedades de transporte además del tamaño y la dimensión de los poros, también dependen de la tortuosidad e interconexión entre los mismos. 


\subsubsection{Hormigón reforzado con fibras}

Los beneficios que brindan las fibras al hormigón reduciendo su fragilidad, otorgando capacidad resistente residual y controlando el desarrollo de la fisuración, han sido ampliamente documentados. Las fibras actúan interceptando las fisuras y retardando así su propagación, si hay suficiente cantidad y están uniformemente distribuidas evitan la unión de las microfisuras aumentando la resistencia aparente de la matriz (Shah, 1991). Disminuyen también el ancho de las fisuras lo cual es muy favorable para la durabilidad del hormigón.

Además de disminuir la fragilidad del hormigón también se las utiliza en el control de la fisuración por contracción, para aumentar la resistencia a impacto y fatiga y para aumentar la resistencia al fuego en hormigones de alta resistencia.

En relación al mecanismo de acción de las fibras cabe notar que la resistencia a tracción es una acción conjunta entre la resistencia de la matriz y la de las fibras que atraviesan las fisuras. La adherencia entre las fibras y la matriz posee varios componentes: la adhesión física y/o química entre ambas, la resistencia friccional, el componente mecánico asociado con la geometría de la fibra, y la trabazón (interlock) de las fibras entre sí. Si se toma como ejemplo una fisura en una viga sometida a flexión, la zona fisurada puede ser representada por tres subzonas: una zona de trabazón de agregados, debida a la microfisuración de la matriz que se inicia con la falla en la adherencia entre la matriz y las fibras, la zona de puenteo de la fisura, donde la fibras se encuentran parcialmente desprendidas (pull-out) de la matriz y finalmente la zona de tracción "libre" donde las fibras están totalmente desprendidas de la matriz (Fig. 2.3.1, Prudencio et al, 2006). En la mayoría de los casos las fibras son arrancadas, en lugar de romperse, una vez que perdieron la adherencia con la matriz. Por lo tanto cuanto más largas sean las fibras mayor será la capacidad de resistir las fuerzas de arrancamiento. 


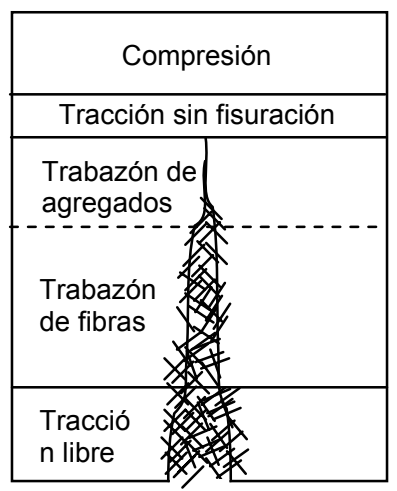

Figura 2.3.1. Estado tensional en la cercanía de una fisura (adaptado de Prudencio et al, 2006).

Existe un límite en la relación de aspecto (longitud/diámetro) de las fibras que está asociado con el mezclado (a menor relación de aspecto mayor trabajabilidad), la distribución de las fibras y que su incorporación sea económicamente competente (Choi y Lee, 2003). El tipo de fibra, la composición de la mezcla, el proceso de mezclado y la técnica de compactación utilizada determinan el máximo contenido de fibras que es posible incorporar en el hormigón.

La contribución de las fibras en la tenacidad depende de las características, cantidad, distribución y orientación con respecto a las máximas tensiones de tracción de las fibras dentro del hormigón.

Diversos estudios han demostrado que existe un alto grado de proporcionalidad entre la cantidad de fibras presentes en la sección fracturada y la tenacidad (Kooiman, 2000, Barr, 2003b). Kooiman (2000) observó que la variabilidad en los parámetros post pico, obtenidos en el ensayo de flexión, estaba relacionada con la distribución de fibras en la sección transversal. En estudios sobre HRF (Barragán, 2002, Barragán et al, 2003, Giaccio y Zerbino, 2004) también se observó que la variabilidad de los resultados del ensayo de tracción directa podía ser justificado considerando el efecto del número de fibras en los planos de fisuración. A medida que disminuye la dosis de fibras aumenta la variabilidad en los resultados de los ensayos sobre vigas (Barr, 2003b).

También se encontró una fuerte dependencia entre los parámetros del postpico y el número de fibras eficaces (en las fibras con ganchos en los extremos se 
denominan eficaces aquellas que finalizado el ensayo presentan los ganchos deformados (Barragán, 2002, Barr, 2003a). Por el contrario tanto para la tensión máxima como para la tensión de primera fisura no surgía un efecto de la cantidad de fibras eficaces, hecho que confirma que este parámetro principalmente depende del comportamiento de la matriz. Si se tiene en cuenta que en las probetas el área de fractura es relativamente pequeña, las tendencias observadas permiten inferir que en un elemento estructural (con un área más grande) la dispersión debería ser mayor. En el citado estudio (Barragán, 2002) la relación entre fibras eficaces y totales fue 0.63.

Aunque en estado fresco las fibras puedan presentar una distribución homogénea el proceso de colocación, el efecto pared y el tipo de compactación favorecerán su orientación en determinadas direcciones (Kooiman, 2000, Grünewald, 2004, Stähli y van Mier, 2007). En algunos casos la orientación preferencial de las fibras puede ser favorable. Asimismo pueden darse diferencias entre un hormigón con fibras convencional compactado mediante vibración $y$ un hormigón fluido o autocompactante reforzado con fibras. En este sentido la aplicación de estudios de mesoestructura representa una contribución directa para la caracterización y evaluación de HRF. Se destacan a continuación algunos antecedentes al respecto.

\subsubsection{Hormigón Vibrado Reforzado con Fibras (HVRF)}

La respuesta postpico del hormigón con fibras está relacionada con el tipo, contenido y orientación de las fibras (Kooiman, 2000, Dupont y Vandewalle, 2005). Muchos autores (Edgington y Hannant, 1972, Soroushian y Lee, 1990, Kooiman, 2000, Gettu et al, 2005, Ozyurt et al, 2007) coinciden en que la compactación a través del vibrado externo favorece una orientación preferencial en dos dimensiones a lo largo de planos.

Según Gettu et al (2005) las probetas cilíndricas compactadas adecuadamente poseen en su parte central una distribución de fibras homogénea e isótropa, sin embargo si la vibración es excesiva las fibras adquieren una orientación preferencial. En el caso de las probetas prismáticas, la vibración externa también induce una alineación preferencial de las fibras, favorecida a su vez por el efecto pared que induce una mayor concentración de fibras junto a los bordes del molde. La compactación tanto mediante varilleo como con vibradores sumergidos parece no alterar la distribución isótropa de las fibras, si bien al utilizar éstos últimos los autores encontraron menores concentraciones de fibras en el centro de la sección. 
Por lo dicho anteriormente, el comportamiento a flexión está fuertemente influenciado por la dirección de ensayo, según Toutanji y Bayasi (1998) si el ensayo se realiza cargando en forma perpendicular a la dirección de moldeo la resistencia a flexión y la tenacidad disminuyen en comparación con el caso en que ambas son paralelas.

Los mismos autores observaron que a medida que aumenta la trabajabilidad de la mezcla aumenta la tendencia de las fibras a asentarse, las probetas elaboradas con mezclas de relativamente alta fluidez y ensayadas en dirección paralela al llenado mostraron mayores valores de resistencia a primera fisura, resistencia última y tenacidad comparados con los resultados de las probetas ensayadas en dirección perpendicular al llenado. Por lo tanto las propiedades en estado fresco también tienen influencia en la segregación de las fibras y en el comportamiento mecánico del hormigón (Ozyurt et al, 2007).

\subsubsection{Hormigón Autocompactante Reforzado con Fibras (HACRF)}

En un HAC la incorporación de fibras modifica la trabajabilidad y, a su vez, las características del hormigón en estado fresco pueden afectar la distribución de fibras. Por lo tanto es interesante observar qué pasa con la distribución de fibras en un HACRF. En este sentido la resistencia a la segregación es una característica muy importante en estos hormigones, si poseen alta viscosidad tendrán una mayor resistencia a la segregación y por lo tanto las fibras se distribuirán de manera más uniforme.

En algunos estudios se encontró que el HACRF presenta menor segregación de fibras que el hormigón vibrado reforzado con fibras (HVRF) (Ferrara y Meda, 2006, Ozyurt, 2007) como así también un mejor comportamiento mecánico (Grünewald, 2004). Se ha encontrado que las fibras en un HACRF son más propensas a orientarse en la dirección del flujo que en un HVRF (Grünewald, 2004), siendo mayor la alineación de las fibras dentro de la masa de hormigón cuanto más fluido es el material (Stähli y van Mier, 2007). Por otro lado Ferrara y Meda (2006) observaron que un HACRF más fluido posee mayor segregación de fibras y mayor dispersión en los resultados. 
Por otro lado si se sobrepasa un contenido crítico de fibras el material no puede fluir bajo la acción de su propio peso siendo la composición de la mezcla de referencia la que establece el máximo contenido de fibras a incorporar (Grünewald y Walraven, 2001). Por lo tanto en el análisis de resultados se debe relacionar tanto la distribución de fibras, la trabajabilidad y las propiedades mecánicas (Ferrara y Meda, 2006).

\subsubsection{Métodos de relevamiento de fibras}

Durante los últimos años se han sugerido y aplicado distintas formas para analizar la distribución y orientación de las fibras en el hormigón.

Ferrara y Meda (2006) evaluaron la distribución de fibras determinando el contenido de fibras en testigos. Para ello los testigos fueron triturados mediante una carga de compresión, y se separaron las fibras del hormigón con un imán, el peso de las fibras extraídas fue referido al volumen del testigo. Se estableció como diámetro óptimo de los testigos un diámetro de $70 \mathrm{~mm}$, ya que testigos de diámetros menores no resultaban representativos de la estructura y presentaron gran dispersión en los resultados, mientras que diámetros excesivamente grandes dejarían huecos para reparar. Complementariamente analizaron otros testigos con rayos $\mathrm{X}$ contando las fibras en 2 secciones transversales para obtener información adicional sobre la segregación.

Otros autores también utilizaron la observación mediante rayos $\mathrm{X}$ para detectar la orientación de las fibras (Redon et al, 1999). La imagen 2D obtenida con los rayos X es el resultado de la proyección en la dirección de la cámara de las fibras que se encuentran en el volumen de hormigón. En este caso cortaron probetas cúbicas en forma transversal y longitudinal obteniendo rodajas de $15 \mathrm{~mm}$ de espesor. Las rodajas, sin ningún tratamiento previo, fueron analizadas con rayos $X$. Finalmente las fibras fueron calcadas a mano sobre la imagen.

Stähli y van Mier (2007) desarrollaron un ensayo para evaluar la distribución de fibras en hormigones autocompactantes, el ensayo consiste en llenar un molde de 100 x 100 x $300 \mathrm{~mm}$ que se encuentra dividido al medio por una pared de $100 \mathrm{~mm}$ de profundidad como muestra la Fig. 2.3.2, al ensayo lo llamaron SegBox. El llenado se realiza desde un extremo y el material fluye hacia el extremo adyacente. Al cabo de 
una semana el prisma se corta en dos partes, se fotografían las mitades y se divide la sección opuesta al llenado en 2 zonas, una inferior y otra superior. Cada zona es relevada en una grilla de $10 \times 10 \mathrm{~mm}$, contando, en cada cuadrado, el número de fibras.

También se han utilizado métodos eléctricos como métodos no destructivos para evaluar la orientación de las fibras, la segregación o la formación de erizos (Woo et al, 2005, Ozyurt et al, 2007). Estos métodos sólo pueden ser utilizados cuando las fibras son conductoras, la configuración experimental variará dependiendo del tamaño y la geometría de las fibras y el elemento que se esté evaluando (Ozyurt et al, 2006).

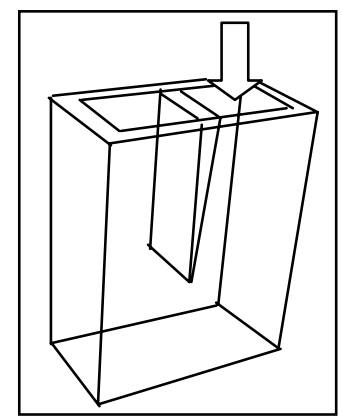

Figura 2.3.2. Ensayo SegBox (adaptado de Stähli y van Mier, 2007).

\subsubsection{Determinación analítica de la orientación de las fibras}

En diversos estudios se ha evaluado en función de las características y dosis de fibras y de la geometría del elemento estructural considerado, la orientación preferencial que adquieren las fibras y por consiguiente el número de fibras que es posible encontrar en la sección de rotura.

Stroeven (Gettu et al, 2005) propuso un modelo teórico para predecir el número de fibras por unidad de área para un elemento de hormigón de espesor t proyectado en un plano paralelo a la dirección de llenado como:

$$
\mathrm{N}_{A}^{p}=L_{v}^{*}\left(\left(t / I_{f}+0.5\right)+(2 / \pi-0.5)^{*} W\right)
$$

donde $L_{v}$ es la longitud total de fibras en un volumen unitario de hormigón, $I_{f}$ es la longitud de cada fibra y w el grado de orientación. Si w es cero significa que existe una isotropía perfecta en cambio $w=1$ muestra que las fibras están orientadas en un 
plano perpendicular a la dirección de llenado. Para un plano perpendicular a la dirección de llenado el número de fibras proyectadas será:

$$
N_{A}^{\top}=L_{v}^{*}\left(\left(t / I_{f}+0.5\right)-0.5^{*} W\right)
$$

El grado de orientación se evalúa como:

$$
W=\left(2^{*} t / I_{f}+1\right)^{*}\left(N_{A}^{p}-N_{A}^{\top}\right) /\left(N_{A}^{p}+(4 / \pi-1)^{*} N_{A}^{\top}\right)
$$

En el caso que el elemento sea de espesor nulo (por ejemplo cuando se cuentan las fibras que atraviesan un plano) las expresiones se simplifican ya que t se hace cero.

Considerando la densidad como el número de fibras por unidad de área, $\mathrm{V}_{\mathrm{f}}$ el volumen de fibras y $A_{f}$ la sección transversal de una fibra se puede definir un coeficiente de orientación de las fibras (CO) como (Dupont y Vandewalle, 2005),

$$
\text { Densidad }=\mathrm{CO} \cdot \mathrm{V}_{\mathrm{f}} / \mathrm{A}_{\mathrm{f}}
$$

Dependiendo de las condiciones de borde que se consideren dependerá la forma de calcular el coeficiente de orientación.

Soroushian y Lee (1990) desarrollaron una fórmula para calcular el coeficiente de orientación que es función de las condiciones de borde, las dimensiones de la sección con respecto a la longitud de la fibra y la relación entre las dimensiones de la sección (altura/base).

Por su parte Dupont y Vandewalle (2005) calcularon el coeficiente de orientación de las fibras que atraviesan una sección rectangular entallada como:

$\mathrm{CO}=\frac{\left[\alpha_{1} \times\left(b-l_{f}\right)\left(h-l_{f}\right)+\alpha_{2} \times\left[\left(b-l_{f}\right)^{l_{f} / 2}+\left(h-l_{f}\right) l_{f}\right]+\alpha_{3} \times l_{f}^{2} / 2+\left(l_{f} / 2-N D\right) \times\left(\alpha_{4}\left[b-l_{f}\right]+\alpha_{5} l_{f}\right)\right]}{b(h-N D)}$

En este esquema la sección transversal de una viga es dividida en 3 sectores el central donde no hay restricciones de borde, los laterales con una condición de borde y las esquinas con dos condiciones de borde, a cada uno de estos sectores les corresponde un factor de orientación $\alpha_{1}=0.5, \alpha_{2}=0.6$ y $\alpha_{3}=0.84$ respectivamente, $\alpha_{4}$ y $\alpha_{5}$ 
dependen de la relación entre la longitud de las fibras y la profundidad de la entalla (ND). Estos autores calcularon el valor de CO entre 0.54 y 0.58 para las longitudes de fibras y de probetas utilizadas por ellos.

Stähli y van Mier (2007) en el estudio sobre hormigones autocompactantes adoptaron la ecuación 4 y definieron un factor de orientación (OF) como la razón entre el número de fibras contadas en una sección transversal (No) y un número teórico $(\mathrm{N})$.

OF $=\mathrm{No} / \mathrm{N}$ siendo $\mathrm{N}=\sum \mathrm{V}(\%) / \mathrm{A}_{\text {fib }}\left(\mathrm{mm}^{2}\right) \times \mathrm{A}_{\text {trans }}\left(\mathrm{mm}^{2}\right)$

Por lo tanto si OF = 1 todas las fibras estarán dispuestas perpendicularmente a la sección transversal, cuanto menor sea este factor mayor será la inclinación promedio de las fibras respecto de la dirección perpendicular a la superficie de corte. En este caso el OF no tiene en cuenta las condiciones de borde.

\subsection{CONSIDERACIONES FINALES}

Este Capítulo trató sobre el estado del conocimiento en los temas abordados en la tesis. Como el objetivo principal es la caracterización del hormigón desde el punto de vista mesoestructural y su vinculación con el comportamiento macroscópico, en primer lugar se definieron los aspectos característicos de la estructura del hormigón a nivel mesoestructural como poros, áridos e interfaces, diferentes tipos de defectos y fibras. A su vez se resumieron las distintas formas en que puede ser estudiada la mesoestructura del hormigón, en particular las fisuras y la distribución y orientación de las fibras. También se sintetizó cómo influyen los parámetros mesoestructurales en la respuesta mecánica y las propiedades de transporte. Finalmente se trataron en forma breve los distintos casos de aplicación analizados en la tesis, hormigones dañados por altas temperaturas, por contracción por secado, por reacción álcali-sílice y hormigones especiales (autocompactante y reforzado con fibras).

A partir del análisis de la literatura se observa que:

- aunque existen varios métodos para caracterizar el cuadro de fisuración desarrollado en el material, son pocos los trabajos que además de describirlo lo cuantifican. 
- la cuantificación de las fisuras es realizada en general a una escala microscópica, analizando sólo una pequeña porción del material en estudio.

- pocos trabajos analizan la incidencia de la fisuración en las propiedades mecánicas $\mathrm{y}$, muchos menos sobre las propiedades de transporte asociadas a la durabilidad.

- en cuanto a los hormigones reforzados con fibras, a pesar que es conocida la incidencia que tiene la introducción de fibras sobre las propiedades del hormigón en estado fresco y la de la compactación por vibrado sobre la distribución del refuerzo, es necesario estudiar la influencia de las condiciones de transporte y colocación sobre la distribución y orientación de fibras en hormigón autocompactante.

- la ausencia de segregación constituye un aspecto particular a considerar en los hormigones autocompactantes, en tal sentido el estudio de la distribución de agregados permitiría evaluar la homogeneidad de estos nuevos hormigones en estado endurecido. 


\section{CAPÍTULO III}

\section{PROGRAMA EXPERIMENTAL}

\subsection{INTRODUCCIÓN}

En este Capítulo se describe en primer lugar el alcance de las diferentes etapas del programa experimental realizado y los objetivos buscados en cada caso. A continuación se detallan las técnicas experimentales utilizadas en las diversas experiencias.

Para el desarrollo del programa, considerando el significado y potencialidad del enfoque abordado para el estudio del hormigón desde el punto de vista de la aplicación en obra, se eligieron varias situaciones en las cuales la caracterización mesoestructural adquiere relevancia. Se seleccionaron dos casos de aplicación, por un lado el análisis de la mesoestructura para el estudio de hormigones sometidos a distintos procesos de daño y por otro la evaluación de la mesoestructura para la caracterización de hormigones especiales (hormigones autocompactantes y reforzados con fibras). Tal como surge del Capítulo II, las características mesoestructurales observadas difieren según el caso analizado.

En lo referente a las técnicas experimentales en primer lugar se detallan los métodos y criterios adoptados para realizar el relevamiento de fisuras y agregados, así como la forma de valoración de la distribución y densidad de fibras de acero y sintéticas tanto sobre superficies fracturadas como sobre cortes interiores. Por último se describen sintéticamente los ensayos utilizados a lo largo de las experiencias para evaluar las propiedades de transporte y mecánicas a nivel macroscópico, en su mayoría no difieren significativamente de las técnicas habitualmente empleadas para caracterizar al hormigón. 


\subsection{PLAN DE TRABAJOS EXPERIMENTALES}

\subsubsection{Estudios sobre hormigones dañados}

Se realizaron experiencias sobre hormigones con diferentes niveles de alteración, considerando como casos de aplicación, la exposición a altas temperaturas, la contracción por secado y el daño por desarrollo de la reacción álcali sílice.

La exposición a alta temperatura es una manera sencilla de provocar defectos a nivel de la pasta, de las interfaces y en algunos casos en los agregados y poder comparar su incidencia frente a diversas solicitaciones. Mediante su empleo es posible conseguir grados de alteración comparables a los generados a lo largo de la vida en servicio como por ejemplo el secado al aire. La exposición a mayores temperaturas $\left(500^{\circ} \mathrm{C}\right)$ representa un caso típico de estructuras afectadas por fuego. Los otros casos considerados representan algunas de las problemáticas de mayor interés para las estructuras de hormigón. La contracción por secado afecta a la mayoría de las construcciones. El desarrollo de la reacción álcali-sílice (RAS) constituye un tema relevante para obras de infraestructura como sistemas de contención y transporte de agua y obras viales en general; en esta tesis se estudiará en particular el desarrollo de la reacción bajo carga, sus efectos sobre la mesoestructura y su vinculación con las propiedades mecánicas y de transporte.

Se seleccionaron la longitud y apertura de fisuras y la distribución de agregados como elementos que caracterizan la mesoestructura de un hormigón. Se eligieron fisuras observables a simple vista tanto en la superficie interna como externa del elemento de hormigón estudiado. La distribución de agregados fue caracterizada a través de la densidad de agregados por unidad de área y el perímetro total de agregados, tomando a la interfaz como un factor importante a nivel mesoestructural.

Considerando que dichos parámetros serían utilizados en el análisis de la vinculación entre estructura y propiedades macroscópicas, fue necesario en primer lugar analizar la fiabilidad del método desarrollado para el estudio de las fisuras y agregados, a fin de acotar el error en las determinaciones. Para ello se calentaron a $500{ }^{\circ} \mathrm{C}$ hormigones elaborados con dos tipos de agregados (canto rodado y piedra partida) que se comportan de forma marcadamente diferente cuando son expuestos a alta temperatura. En primer lugar se relevaron las fisuras sobre la superficie perimetral 
de las probetas, que luego fueron cortadas en forma transversal en 4 o 5 rodajas. Sobre las dos caras de corte de cada rodaja se analizó la densidad de fisuras y agregados. En base a estos datos se evaluó la cantidad mínima de probetas, y dentro de cada probeta, el número de cortes a analizar para obtener datos representativos del hormigón en estudio. Finalmente se vincularon las características mesoestructurales evaluadas con los resultados de ensayos de permeabilidad del hormigón.

En segundo lugar se realizó un estudio comparativo de la relación entre la fisuración interna y las propiedades macroscópicas en hormigones afectados por alta temperatura y hormigones dañados por contracción por secado; en dicho estudio en forma paralela y a modo de referencia se incluyeron evaluaciones sobre algunas probetas que se mantuvieron en cámara húmeda. Para evaluar la mesoestructura se determinó la densidad y el ancho de las fisuras visibles a simple vista y la densidad de agregados sobre cortes transversales de probetas cilíndricas. A su vez y como complemento del análisis del daño se midieron la velocidad de pulso ultrasónico y el módulo de elasticidad dinámico. Entre las propiedades mecánicas fueron evaluadas la resistencia a compresión, el módulo estático de elasticidad, el coeficiente de Poisson y la resistencia a tracción por compresión diametral. Como propiedades de transporte se determinaron la absorción capilar y el coeficiente de permeabilidad.

En un tercer estudio se evaluó la mesoestructura y propiedades residuales en hormigones dañados por exposición a alta temperatura sometidos a cargas de larga duración. Se moldearon numerosos cilindros de un hormigón elaborado en una planta industrial, que luego de curados, fueron sometidos a diferentes estados de alteración. Un grupo fue expuesto a una temperatura igual a $150{ }^{\circ} \mathrm{C}$ y otro a $500{ }^{\circ} \mathrm{C}$, un tercer grupo fue almacenado en ambiente de laboratorio. Luego los tres grupos fueron sometidos a cargas de compresión durante 1 año, al cabo del cual se determinaron la variación de longitud, peso y velocidad de pulso ultrasónico y la resistencia y deformabilidad en compresión. Para caracterizar la mesoestructura se observaron el espesor y longitud de fisuras, y la distribución y contenido de agregados. Como propiedades de transporte se midieron la absorción, absorción capilar, penetración de agua y coeficiente de permeabilidad.

Finalmente se planteó un cuarto programa experimental a fin de evaluar la vinculación entre la mesoestructura y las propiedades macroscópicas en un hormigón con reacción álcali-sílice (RAS) sometido a cargas de larga duración. La RAS posee 
diversas manifestaciones (fisuras en la interfaz, matriz, presencia de gel) que afectan tanto la respuesta mecánica como las propiedades de transporte. En este estudio, además, el desarrollo de la fisuración es afectado por las cargas de larga duración. Se elaboró un hormigón donde la reacción se produciría en forma rápida y otro sin reacción como referencia. En ambos hormigones las probetas se separaron en varios grupos, unos fueron cargados durante 14 meses a compresión y otros mantenidos sin cargar, este proceso se realizó en una cámara a $20{ }^{\circ} \mathrm{C}$ y en otra a $38{ }^{\circ} \mathrm{C}$. Todos los grupos fueron almacenados en condiciones saturadas para fomentar el desarrollo de la reacción. Luego de un año se realizaron determinaciones similares a las de la experiencia anterior.

Los detalles de las técnicas empleadas para caracterizar a la mesoestructura y las correspondientes a las evaluaciones a nivel macroscópico de la respuesta mecánica y las propiedades de transporte se describen más adelante.

\subsubsection{Estudios sobre hormigones especiales}

Es conocido que la capacidad de las fibras de controlar la fisuración es función no sólo de la cantidad de fibras incorporadas sino también de la orientación que adquieran con respecto a las solicitaciones de tracción. El conocimiento de la orientación y distribución de fibras dentro de la masa de hormigón endurecido y su vinculación con el proceso de producción constituye una herramienta útil para el diseño de elementos estructurales y la elección del método de elaboración así como para predecir el comportamiento de estos elementos. Es por esta razón que se eligió el análisis de hormigones reforzados con fibras, tomando la distribución de fibras como elemento característico de su mesoestructura.

En el caso de los hormigones autocompactantes (HAC) se analizó la distribución de agregados gruesos dentro del hormigón endurecido; ya que este parámetro de la mesoestructura permite valorar la homogeneidad alcanzada por el material.

En primer lugar se estudiaron hormigones vibrados reforzados con distintas dosis y tipos de fibras de acero con los que se moldearon probetas de diferentes tamaños. En este caso se vinculó la densidad de fibras en la superficie de rotura con las propiedades mecánicas del material, principalmente la respuesta en flexión. 
Además se analizó la orientación de las fibras dentro de las vigas, evaluando la cantidad de fibras en tres planos perpendiculares entre sí.

En el mismo sentido fue realizado otro estudio sobre hormigones vibrados reforzados con fibras de acero y sintéticas. En este estudio se varió la dosis y tipo de fibras tanto de acero como sintéticas. Se analizó la orientación de las fibras dentro de las vigas y se comparó la orientación entre las fibras de acero y las sintéticas.

También se aplicaron los métodos de evaluación de la mesoestructura en hormigones autocompactantes con fibras para estudiar el efecto de la forma de llenado en la orientación y distribución del refuerzo y su vinculación con la respuesta mecánica. En este caso se elaboraron tres hormigones, uno con fibras de acero de $50 \mathrm{~mm}$ de longitud, otro con fibras de acero de $30 \mathrm{~mm}$ de longitud y finalmente con fibras sintéticas estructurales. Se llenaron vigas de tres formas distintas, desde el centro del molde, mediante un tubo de $5 \mathrm{~m}$ ubicado en un extremo del molde en probetas dispuestas en forma horizontal y desde un extremo del molde ubicado a modo de columna en dirección vertical. Las vigas fueron ensayadas a flexión y posteriormente se evaluó la orientación y distribución de las fibras de acero sobre cortes en tres direcciones perpendiculares entre sí.

En forma complementaria se utilizó un modelo teórico de fácil empleo para analizar la orientación de las fibras. Se compararon los resultados del modelo con los resultados experimentales obtenidos en los estudios anteriores tanto sobre hormigones convencionales vibrados como en los hormigones autocompactantes reforzados con fibras de acero (HACRF).

Otro caso estudiado fue la evaluación de la homogeneidad en columnas de $2 \mathrm{~m}$ de altura elaboradas con HAC y HACRF. El propósito del mismo estaba orientado al análisis de HAC destinados al llenado de elementos estructurales tipo tabique para la construcción de, por ejemplo, muros perimetrales de vivienda. Una vez elaboradas las columnas se realizaron cortes transversales a diferentes alturas obteniendo muestras adecuadas para estudiar la distribución de agregados a lo largo de la columna, así como la resistencia a compresión y módulo de elasticidad, el peso por unidad de volumen y la velocidad de pulso ultrasónico. 
Finalmente se evaluó la homogeneidad en HAC elaborados con tres tipos de agregado grueso de uso frecuente en la Provincia de Buenos Aires, piedra partida granítica, piedra partida cuarcítica y canto rodado. Estos agregados presentan diferencias significativas en su forma y textura, que influyen en el comportamiento del hormigón en estado fresco y, en particular, en la tendencia a la segregación. Con estos HAC se moldearon tubos en $U$ de $1.90 \mathrm{~m}$ de altura, que fueron cortados en forma transversal de manera de obtener cilindros de aproximadamente $0.40 \mathrm{~m}$ de longitud. Sobre las caras de corte de estos cilindros se evaluó la densidad de agregados.

\subsection{TÉCNICAS EXPERIMENTALES}

\subsubsection{Caracterización del cuadro de fisuración y de la distribución de agregados}

Uno de los objetivos de la tesis era encontrar un método para valorar la mesoestructura del hormigón, sencillo, de bajo costo y compatible con la variabilidad propia de este material. Se buscó una forma de relevar la longitud, número y ancho de fisuras, sin importar su origen, como así también la distribución de tamaños y longitud de interfaz de los agregados.

\subsubsection{Descripción del método}

En primer lugar se analizó el estado de la superficie identificando fisuras, oquedades, entre otros defectos. Esto se realizó en la mayoría de los casos sobre el perímetro de cilindros de 150 × $300 \mathrm{~mm}$. Luego se realizó el relevamiento de la distribución de agregados y el tamaño y tipo de fisuras sobre cortes de $50 \mathrm{~mm}$ de espesor realizados a diferentes alturas de las probetas. Se optó por este tipo de probetas porque son las habitualmente utilizadas en el ensayo de resistencia a compresión del hormigón. Además, también fueron empleados cortes de estos cilindros para evaluar el coeficiente de permeabilidad o la penetración de agua a presión.

Las fisuras y el perímetro de los agregados (en el caso de los cortes) se calcaron directamente en un papel transparente sin ninguna preparación previa de la muestra. Las fisuras fueron delimitadas mediante una lupa. El registro sobre dicho papel se escaneó para obtener la imagen en formato digital y se la analizó a través de 
un procesador de imágenes. Se utilizaron dos software de procesamiento de imágenes, mediante el primero se las acondicionó para poder ser fácilmente evaluadas con el segundo procesador.

En la Fig. 3.3.1.1 se muestra la secuencia para obtener la imagen a analizar, en primer lugar la rodaja de hormigón, a continuación la imagen escaneada y finalmente la imagen luego del acondicionamiento. Mediante el segundo software se obtuvieron fácilmente la cantidad y longitud de las fisuras y el área, perímetro y cantidad de agregados (Fig. 3.3.1.2). Asimismo a partir de estos datos se calcularon como parámetros para el análisis el área $\left(\mathrm{cm}^{2} / \mathrm{cm}^{2}\right)$ y perímetro $(\mathrm{cm})$ de agregados y la longitud de fisuras por unidad de área $\left(\mathrm{cm} / \mathrm{cm}^{2}\right)$.

Para definir los parámetros vinculados a la distribución de agregados se adoptó como tamaño mínimo las partículas que en el corte presentaban una dimensión mínima superior a $5 \mathrm{~mm}$.

Otro parámetro utilizado para caracterizar el cuadro de fisuración es el ancho máximo de fisuras. El mismo se determinó sobre cada sección en forma manual mediante una lupa que posee una precisión de $0.05 \mathrm{~mm}$. Se adoptaron como datos de referencia la fisura más ancha a nivel de interfaz y la más ancha de la matriz.
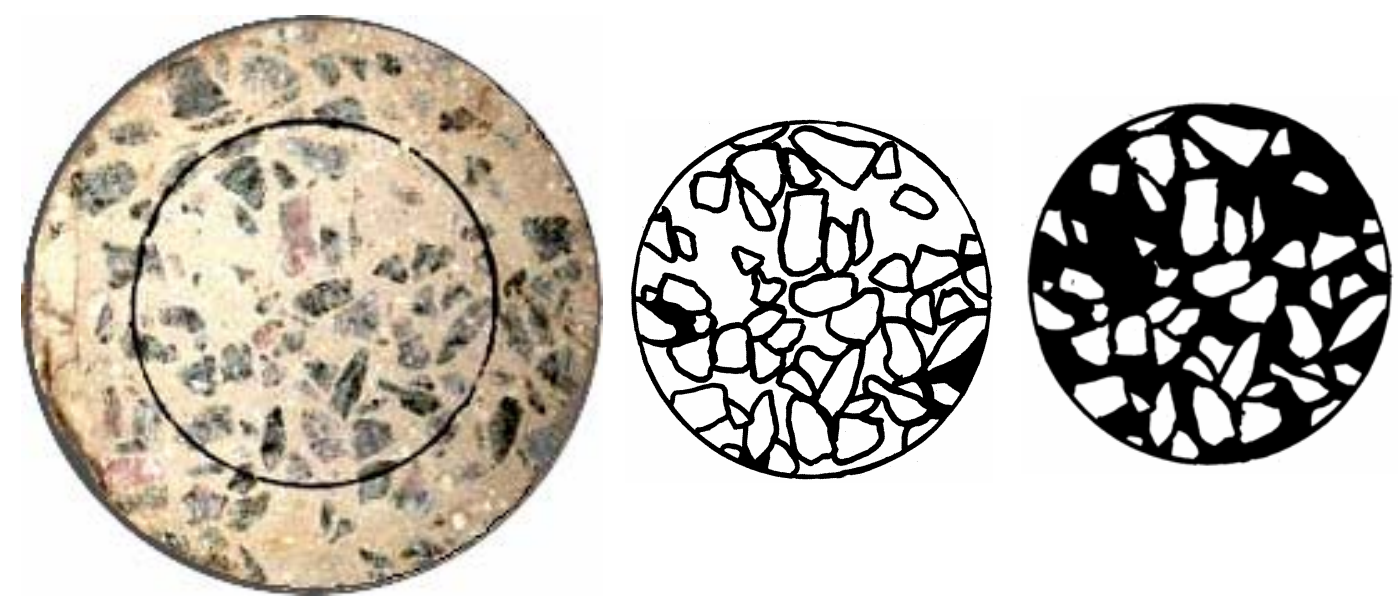

Figura 3.3.1.1. Sección de hormigón, imagen escaneada y posterior acondicionamiento. 


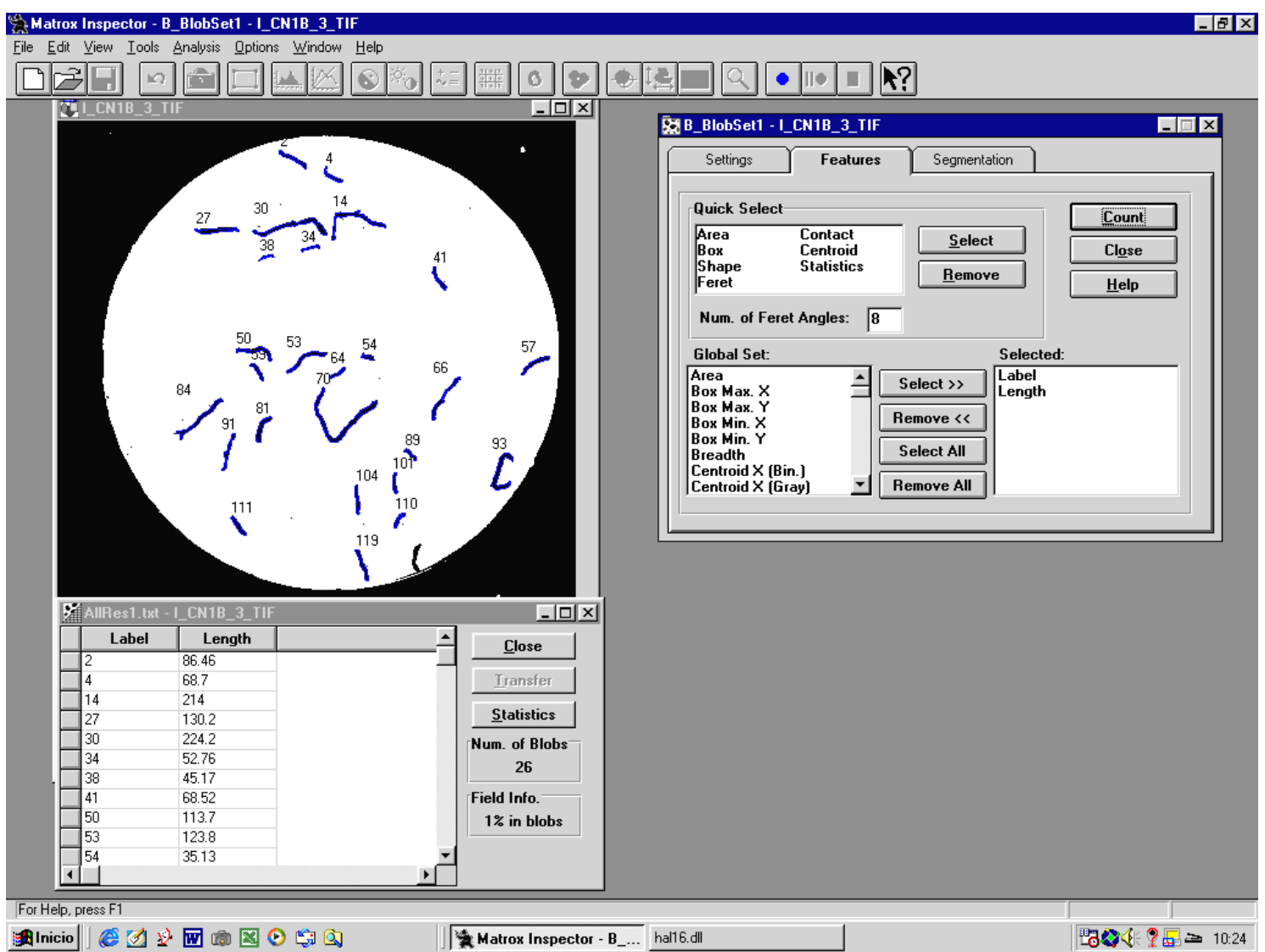

Figura 3.3.1.2. Programa utilizado en el cálculo de las características de las fisuras y agregados. Se muestra el análisis de la longitud de fisuras sobre un corte transversal.

\subsubsection{Evaluación del método}

Para evaluar la fiabilidad del relevamiento manual de fisuras y agregados se fotografiaron mediante una cámara digital (6M zoom digital) cortes de probetas dañadas por exposición a alta temperatura (ver inciso 4.2 del Capítulo IV). Se utilizaron cortes de un hormigón elaborado con canto rodado silíceo (CR) y de otro hormigón elaborado con piedra partida granítica (PP); estos dos tipos de agregados gruesos poseen marcadas diferencias en la forma y la textura superficial de las partículas. A las imágenes fotográficas visualizadas con un programa de procesamiento de imágenes se las aumentó de tamaño (hasta un límite que depende de la resolución de la imagen) de manera tal que los bordes de los agregados a relevar se distingan fácilmente (Fig. 3.3.1.3) y se marcaron los bordes dibujándolos sobre la imagen. 
En la Tabla 3.3.1.1 se muestran los resultados del relevamiento de agregados (densidad y perímetro de agregados); el mismo fue realizado calcándolos directamente sobre el corte y luego analizando la imagen escaneada (escaneada) o marcándolos directamente sobre la imagen fotográfica (foto). La nomenclatura utilizada para distinguir las rodajas en la Tabla 3.3.1.1 será explicada con detalle en el Capítulo IV, su conocimiento a los fines de este estudio no es significativo.

Tabla 3.3.1.1. Densidad y perímetro de fisuras obtenidos mediante diferentes métodos.

\begin{tabular}{ccccc}
\hline Agregados & PPd-1foto & PPd-1escaneada & CRd-4foto & CRd-4escaneada \\
\hline Densidad $\left(\mathrm{cm}^{2} / \mathrm{cm}^{2}\right)$ & 0.379 & 0.350 & 0.297 & 0.299 \\
Perímetro $(\mathrm{cm})$ & 167.6 & 165.5 & 117.4 & 116.9 \\
\hline
\end{tabular}

De la Tabla 3.3.1.1 surge que prácticamente no existen diferencias entre el relevamiento realizado observando la rodaja a simple vista y el realizado con un procesador de imágenes. Cabe comentar que tanto para la densidad como para el perímetro de los agregados la variación es menor en el hormigón CR con respecto al PP. En las fotos de la Fig. 3.3.1.3 se puede observar que las partículas de canto rodado son más redondeadas y poseen los bordes más definidos, características que facilitan el relevamiento.
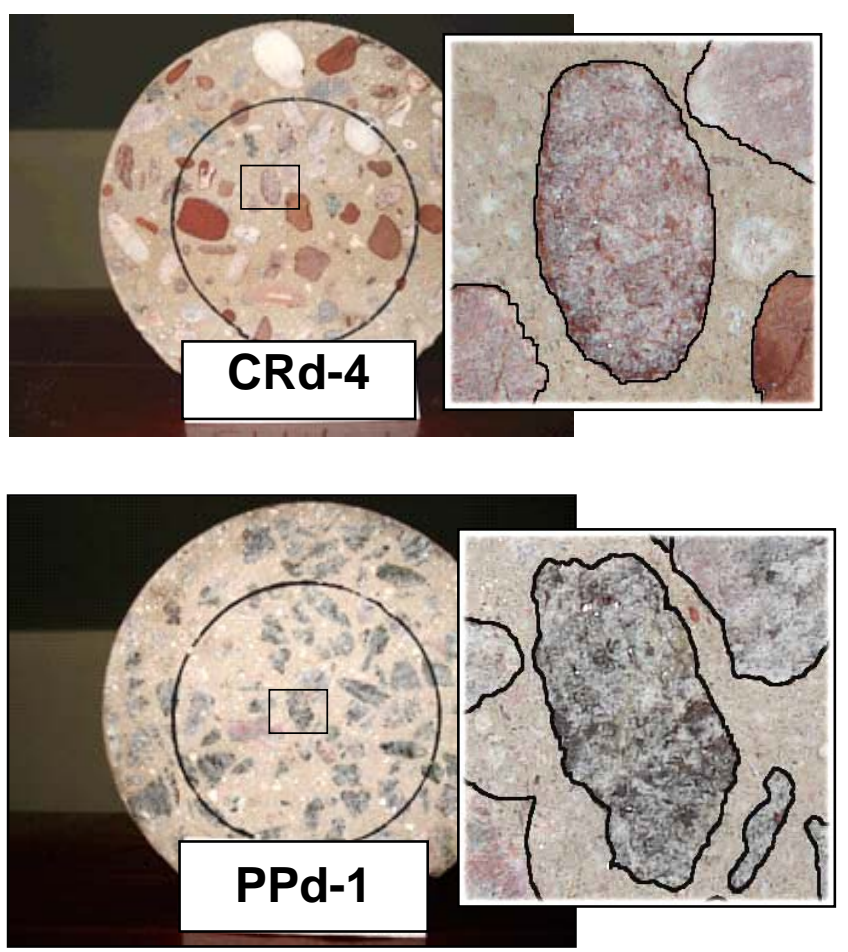

Figura 3.3.1.3. Fotografías de los cortes y zoom de los agregados relevados. 


\subsubsection{Análisis de la densidad de fibras}

Para evaluar los hormigones reforzados con fibras el relevamiento de fibras también debe ser fácil de implementar y poco costoso, por este motivo en esta tesis las fibras fueron contadas en forma manual.

El recuento de fibras de acero se puede llevar a cabo sobre la superficie fracturada de probetas sometidas al ensayo de flexión o sobre superficies cortadas (Fig. 3.3.2.1 y Fig. 3.3.2.2). En el primer caso es posible verificar las fibras que actuaron en la superficie de fractura, en algunos casos, cuando las fibras poseen extremos conformados, se puede hacer la distinción entre fibras eficaces (aquellas que toman carga durante el ensayo y por lo tanto presentan sus extremos deformados) y fibras no eficaces. Para poder conocer la orientación que adquieren las fibras dentro de las probetas se realizan cortes en distintos planos.

En lo que respecta a las fibras sintéticas el recuento sobre la superficie de fractura se realiza de igual forma que con las fibras de acero pero en el caso de la superficie de un corte resulta muy difícil distinguir las fibras cortadas. Por esta razón en estos casos las probetas fueron abiertas en las diferentes direcciones aplicando esfuerzos similares a los utilizados en un ensayo de tracción por compresión diametral para analizar la orientación. De todos modos con determinado tipo de fibras sintéticas, especialmente las de uso no estructural, el recuento es difícil de realizar porque las fibras cuando están sometidas a esfuerzos sufren un proceso de desfibrilación que no permite distinguir fácilmente la cantidad de fibras que efectivamente hay. Además muchas veces existe la incertidumbre acerca de si las fibras se rompen o son arrancadas, y de ello depende la forma de calcular su densidad, como se verá a continuación.

Para calcular la densidad de fibras se debe hacer la distinción entre el análisis de la superficie de fractura y el análisis de la cara de corte. En la superficie de fractura se deben sumar las fibras contadas en las dos mitades fracturadas, esta suma dividida por la sección de hormigón constituye la densidad de fibras en la sección fracturada. En las caras aserradas la densidad de fibras se obtiene promediando el número de fibras contado a ambos lados del corte y dividiéndolo por el área relevada. 

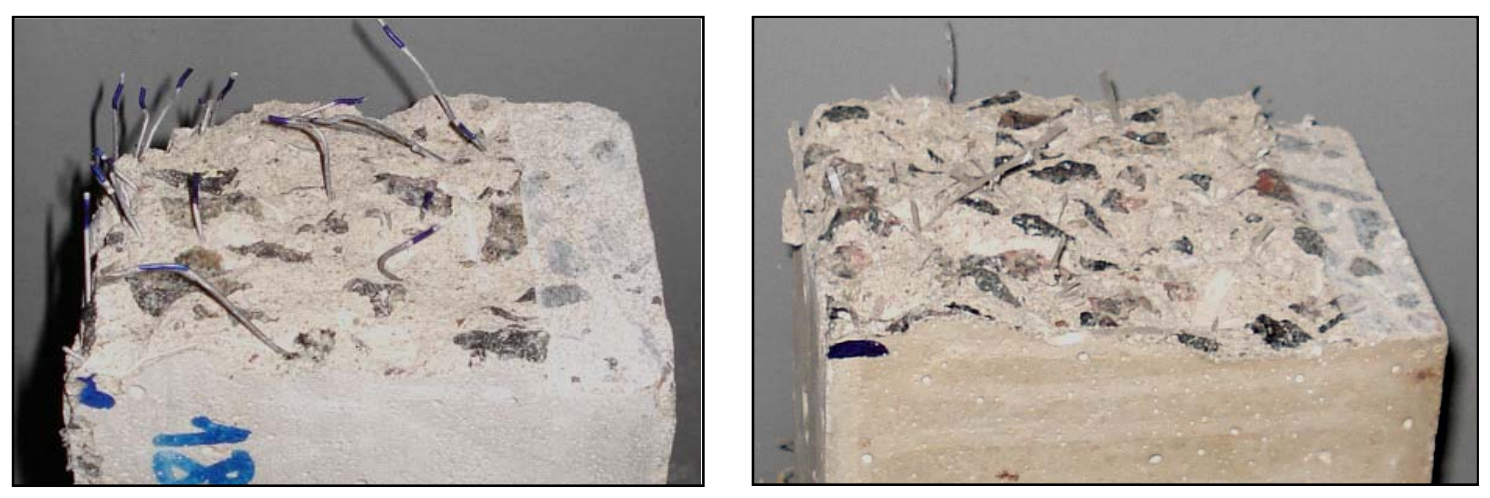

Figura 3.3.2.1. Superficies fracturadas de vigas entalladas ensayadas a flexión. Izquierda: HRFacero. Derecha: HRFsintética.

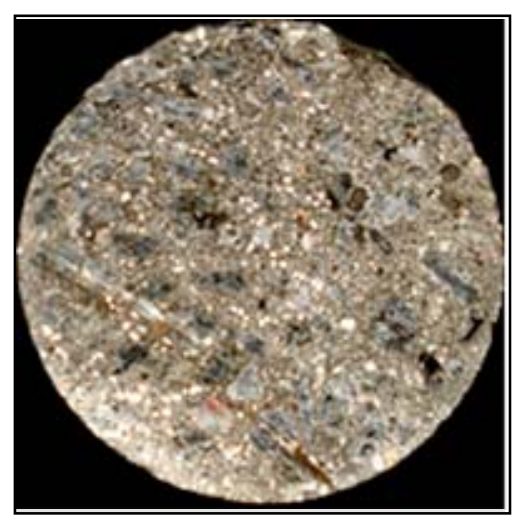

Figura 3.3.2.2. Superficie cortada de probeta de HRF con fibras de acero.

\subsubsection{Evaluación de las propiedades macroscópicas}

A continuación se describen sucintamente los métodos de ensayos utilizados para la evaluación de las propiedades físicas, mecánicas y de transporte del hormigón.

\subsubsection{Velocidad de pulso ultrasónico}

Este método es sumamente empleado para valorar la homogeneidad y el estado de estructuras de hormigón. Resulta especialmente sensible a la presencia de defectos de compactación, fisuras y/o cambios en la porosidad del hormigón. Para la determinación del tiempo de pasaje de la onda ultrasónica se utilizó un equipo ultrasónico digital portátil (Fig. 3.3.3.1) con una frecuencia de $54 \mathrm{KHz}$ y una precisión de $0.1 \mu \mathrm{s}$. La mayoría de las determinaciones se realizaron sobre probetas cilíndricas de 150 × $300 \mathrm{~mm}$, colocando uno de los palpadores, el emisor, sobre una cara de la 
probeta y el otro llamado receptor sobre la otra; el aparato registra el tiempo que tarda la onda ultrasónica en recorrer la longitud de la probeta.

La velocidad de pulso ultrasónico es igual a:

$$
\begin{aligned}
& V P U=\frac{l(\mathrm{~km})}{t(\mathrm{~s})} \\
& \begin{aligned}
\text { siendo I } & =\text { longitud de la probeta. } \\
\mathrm{t} & =\text { tiempo que tarda la onda en atravesar la probeta. }
\end{aligned}
\end{aligned}
$$

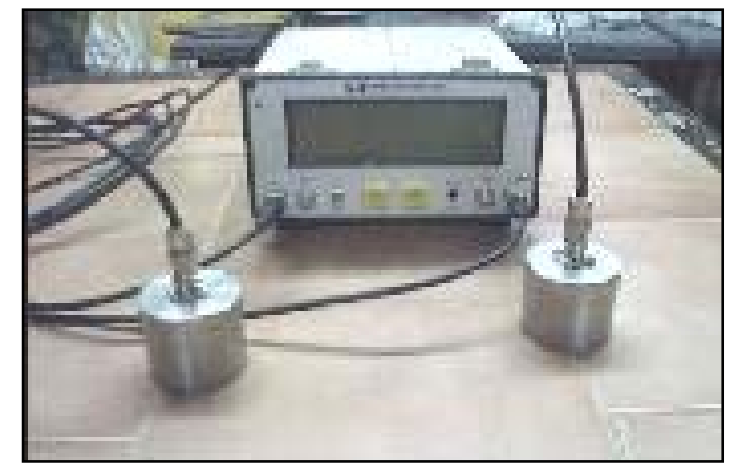

Figura 3.3.3.1. Equipo para la medición de la velocidad de pulso ultrasónico.

\subsubsection{Variación de longitud}

Este método es de interés para valorar los efectos de expansión por exposición a alta temperatura o desarrollo de reacciones deletéreas como la reacción álcali-sílice, como así también las contracciones por exposición a ambientes secos. Para la determinación de la variación de longitud se empleó un comparador de longitudes con una precisión de $0.01 \mathrm{~mm}$. Se utilizaron probetas prismáticas de 75 × 105 × $430 \mathrm{~mm}$, con pernos de acero insertos en sus extremos.

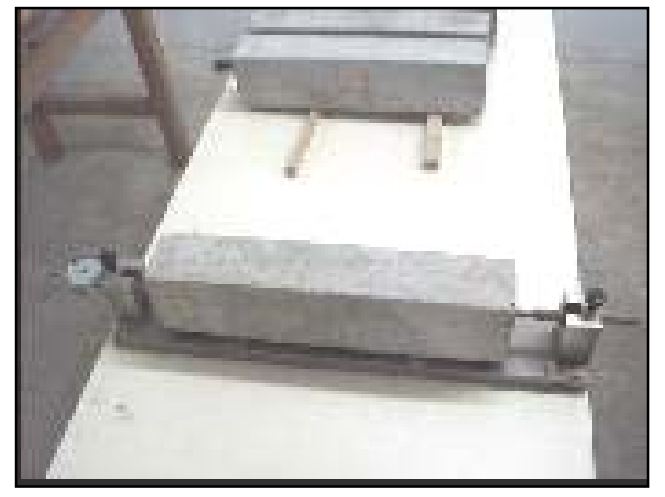

Figura 3.3.3.2. Comparador de longitudes. 


\subsubsection{Frecuencia de resonancia}

Otra forma de valorar el estado del hormigón es la determinación del módulo de elasticidad dinámico (Ed). El método es muy sensible a la presencia de defectos y se aplica por ejemplo para estudiar la degradación del hormigón frente a acciones como el congelamiento y deshielo o el ataque de sulfatos. Se utilizó un equipo sónico (Fig. 3.3.3.3) con un rango de frecuencia que oscila entre $10 \mathrm{KHz}$ y $100 \mathrm{KHz}$.

A partir de la frecuencia de resonancia medida, las dimensiones y el peso de la probeta es posible calcular el Ed como:

$$
\begin{aligned}
& E d=e \times n^{2} \times \text { peso } \\
& \text { siendo } e=\text { cte } \times \frac{\text { longitud }_{\text {diámetro }^{2}}}{}
\end{aligned}
$$

el valor de $n$ se obtiene de tablas en función del valor de la frecuencia de resonancia.

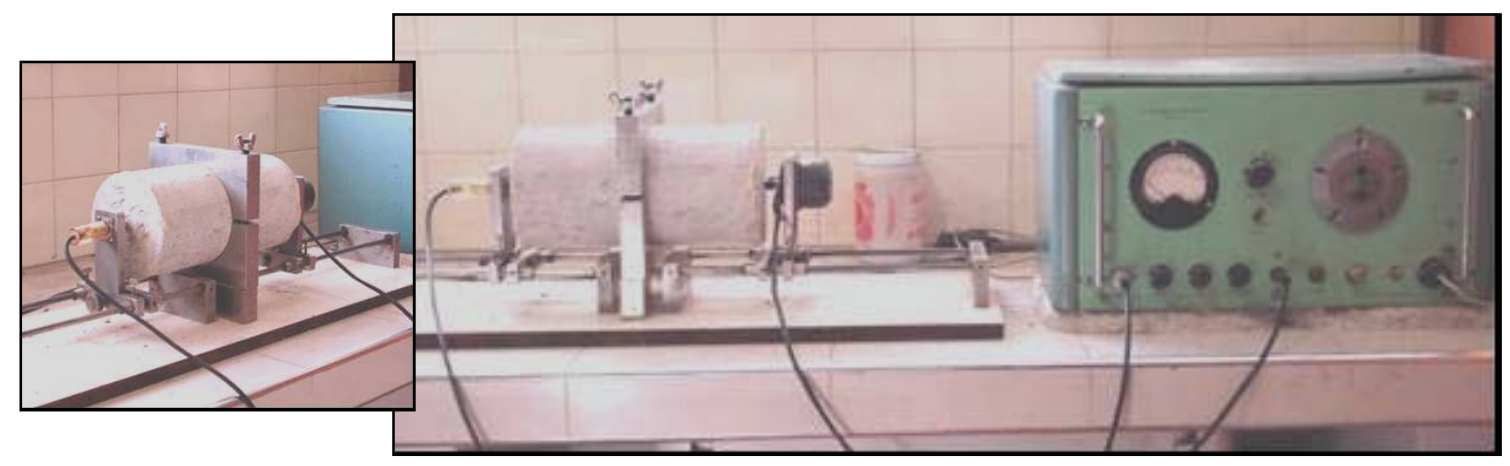

Figura 3.3.3.3. Equipo para la determinación del módulo de elasticidad dinámico.

\subsubsection{Absorción de agua 24 horas y Densidad (ASTM C 642-90)}

La absorción en agua y la densidad constituyen herramientas sencillas para caracterizar al hormigón. La primera está directamente vinculada con la porosidad del material mientras que la segunda puede evidenciar defectos de compactación o cambios en la distribución de agregados.

Para determinar la absorción de agua se utilizaron cortes de 50 × $75 \times 105$ mm, obtenidos a partir de los prismas de $75 \times 105 \times 430 \mathrm{~mm}$ utilizados para ensayos de flexión o para medir los cambios dimensionales. Los cortes fueron sumergidos en agua 
durante 24 horas, luego secados superficialmente y pesados obteniendo el peso saturado a superficie seca (Psss). Finalmente fueron secados en estufa a $105{ }^{\circ} \mathrm{C}$ hasta peso constante (Ps), se utilizó una balanza con una precisión de $0.1 \mathrm{~g}$.

$$
A b s=\frac{(P s s s-P s)}{P s} \times 100
$$

donde Psss = peso saturado a superficie seca $(\mathrm{kg})$.

$\mathrm{Ps}=$ peso seco en estufa $(\mathrm{kg})$.

Para determinar la densidad $(\delta)$ además del Psss se determinó el peso sumergido (Psum).

$$
\delta=\frac{P s s s \times \gamma_{H 2 O}}{(\text { Psum }- \text { Psss })}
$$

\subsubsection{Absorción capilar (IRAM 1871)}

Este ensayo brinda información sobre la porosidad del hormigón conectada con el exterior y se relaciona con varios procesos de degradación del material. El método consiste en registrar el incremento de masa de una probeta, en contacto con agua en una de sus bases. Para este ensayo también se utilizaron cortes de 50 × 75 × 105 mm de los prismas de $75 \times 105 \times 430 \mathrm{~mm}$. Las superficies laterales de las muestras fueron selladas con pintura impermeabilizante a fin de asegurar la direccionalidad del flujo. Luego las muestras se secaron en estufa a $50 \pm 2{ }^{\circ} \mathrm{C}$ hasta peso constante (Po). Posteriormente se colocaron en el interior de un recipiente con agua y cierre hermético dispuestas sobre apoyos puntuales, de forma de asegurar una altura de agua sobre la probeta igual a $3 \mathrm{~mm}$ (Fig. 3.3.3.4). Las probetas se pesaron diariamente hasta obtener una diferencia entre dos pesadas sucesivas menor a $0.1 \%$. Como resultados de ensayo se determinan la velocidad de ascensión capilar y la capacidad de succión.

La capacidad de succión capilar $\left(\mathrm{g} / \mathrm{m}^{2}\right)$, es el valor del incremento de masa por unidad de área de la sección transversal de la probeta, en el instante de lectura, que corresponde al tiempo en que la variación de masa es menor que $0.1 \%$ entre dos determinaciones sucesivas. La velocidad se calcula tomando la pendiente de una recta que ajuste las curvas capacidad $\left(\mathrm{g} / \mathrm{m}^{2}\right)$ - tiempo $\left(\mathrm{s}^{1 / 2}\right)$, considerando los puntos comprendidos entre 0.1 y 0.9 de la capacidad de succión. 


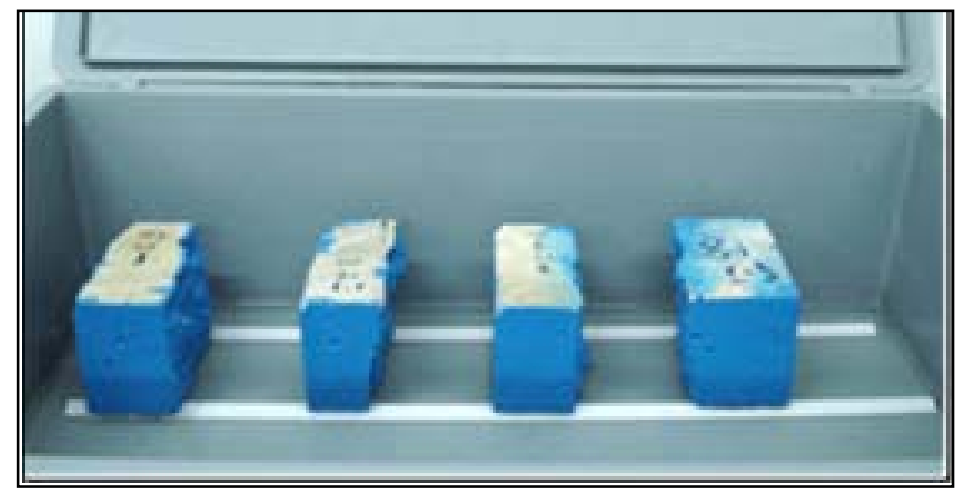

Figura 3.3.3.4. Ensayo de absorción capilar.

\subsubsection{Penetración de agua a presión (IRAM 1554) y Permeabilidad}

Otras dos determinaciones de interés para valorar la durabilidad del hormigón están representadas por los ensayos de penetración de agua a presión y la valoración del coeficiente de permeabilidad. El primero considera la profundidad que puede alcanzar el agua en contacto con el material mientras que en el segundo se establece un flujo pasante a través de una rodaja de hormigón.

En ambos casos para realizar las determinaciones se utilizó un permeámetro de carga variable. Cada escalón de carga especificado puede ser mantenido mediante un regulador de presión en el circuito. En el aparato la presión es aplicada a través de aire provisto por un motocompresor de accionamiento eléctrico; el aire transmite la presión a la superficie libre del agua contenida en un reservorio aguas arriba de la muestra. El agua a presión se aplica sobre una cara de la muestra en un círculo de diámetro igual a $100 \mathrm{~mm}$. Para asegurar el sellado de cada probeta, el equipo dispone de juntas de goma en la superficie de contacto y además se aplica un sellador tipo epoxílico para evitar filtraciones en las superficies de apoyo entre la probeta y el equipo. El equipo utilizado se muestra en la Fig. 3.3.3.5.

Los ensayos fueron realizados sobre cortes transversales de las probetas cilíndricas de 150 × 300 mm, lo que posibilitaba utilizar el mismo tipo de probetas que el empleado en los ensayos no destructivos y de resistencia mecánica. Se cortaron muestras de $150 \mathrm{~mm}$ de altura para el ensayo de penetración de agua a presión y rodajas de $50 \mathrm{~mm}$ de altura para los ensayos de permeabilidad. 
En todos los casos se aplicó sobre el perímetro de las probetas y sobre un anillo de $25 \mathrm{~mm}$ de espesor en cada cara, pintura impermeabilizante en base a caucho clorado para evitar pérdidas laterales y asegurar la condición de flujo axial.

El ensayo de penetración consiste en aplicar durante 48 horas agua a $0.1 \mathrm{MPa}$ de presión, luego subir la presión a $0.3 \mathrm{MPa}$ durante 24 horas y finalmente elevar la presión hasta 0.7 MPa manteniéndola durante 24 horas más. Una vez finalizado el ciclo se retiran las probetas del equipo y se les aplica una carga perpendicular a la superficie sobre la que se aplicó la presión de agua a fin de dividir la probeta en dos mitades para observar la penetración. Inmediatamente se resalta sobre la superficie de fractura el contorno del frente de penetración del agua. Luego se mide la distancia a partir de la cara sobre la que actúa la presión de agua hasta el frente de penetración marcado, con una precisión de $1 \mathrm{~mm}$ y a intervalos de $5 \mathrm{~mm}$. La medida de la penetración de agua está dada por el valor medio del frente de penetración, también se suele indicar el valor de la penetración máxima.

El ensayo de permeabilidad consiste en impulsar agua a presión sobre una probeta y medir el caudal de agua que fluye a través del espesor de la misma. Para conocer el caudal se fue pesando, a intervalos conocidos de tiempo, la cantidad de agua que atravesaba la rodaja. El procedimiento seguido fue ajustado en función del nivel de daño que presentaban las muestras, en todos los casos se inició el ensayo con una presión de $0.1 \mathrm{MPa}$. Luego se mantuvo la presión constante o se aumentó hasta alcanzar un flujo estable. El coeficiente de permeabilidad se obtiene de la siguiente manera:

$$
\begin{aligned}
& \mathrm{Q} / \mathrm{A}=-\mathrm{K} \Delta \mathrm{P} / \Delta \mathrm{I} \\
& \text { siendo } \mathrm{K}=\text { coeficiente de permeabilidad al agua }(\mathrm{m} / \mathrm{s}) . \\
& \Delta \mathrm{P}=\text { variación de presión. } \\
& \Delta \mathrm{I}=\text { trayectoria del flujo = espesor rodaja. } \\
& \mathrm{A}=\text { área donde se aplica el agua a presión. } \\
& \mathrm{Q}=\text { caudal de agua que pasa a través de la rodaja. }
\end{aligned}
$$




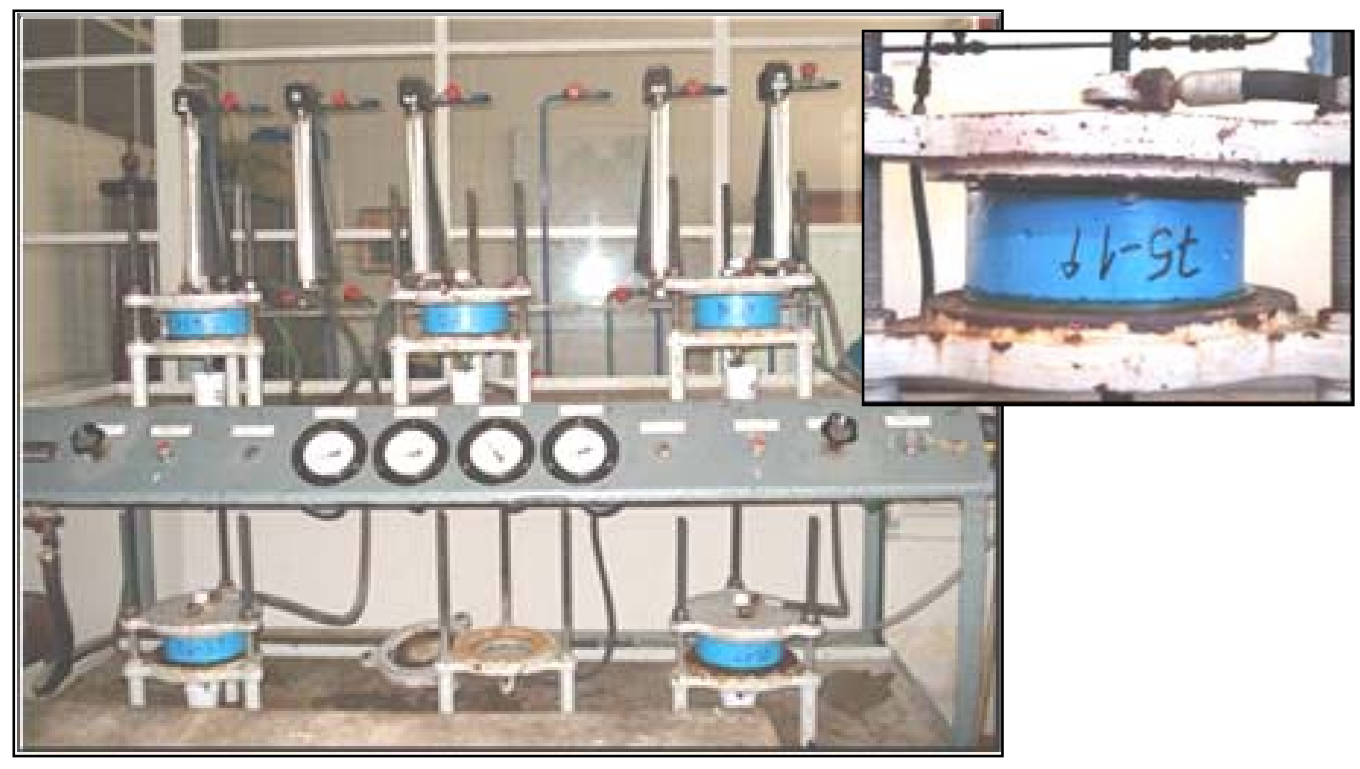

Figura 3.3.3.5. Equipo utilizado para los ensayos de permeabilidad y penetración de agua a presión. La foto corresponde al ensayo de permeabilidad.

\subsubsection{Caracterización del comportamiento mecánico en compresión uniaxial}

Para la determinación de la respuesta en compresión se ensayaron probetas cilíndricas de 150 × 300 mm utilizando un sistema Instron con control de velocidad de carga a través de la medición de las deformaciones longitudinales. La velocidad de ensayo se ajustó conforme las características de cada hormigón y el nivel de daño de forma tal de asegurar la estabilidad del ensayo.

Además de la tensión de rotura $\left(f_{c}^{\prime}\right)$ en la mayoría de los ensayos se determinaron las deformaciones transversales y longitudinales a fin de analizar la influencia del daño sobre el mecanismo de rotura. Para registrar las deformaciones transversales se utilizó un LVDT y para las longitudinales un clip o un LVDT, en la Fig. 3.3.3.6 se puede ver un detalle de los dispositivos utilizados. Para determinar el módulo de elasticidad (E) y el coeficiente de Poisson ( $\mu$ ) se aplicaron sobre las probetas 2 ciclos de carga hasta el $40 \%$ de la carga última y luego el tercer ciclo hasta la rotura. Para el cálculo del módulo de elasticidad se utilizó la cuerda entre el 5 y el $40 \%$ de la carga última, los valores del coeficiente de Poisson también fueron calculados para tensiones correspondientes al $40 \%$ de la carga última. 

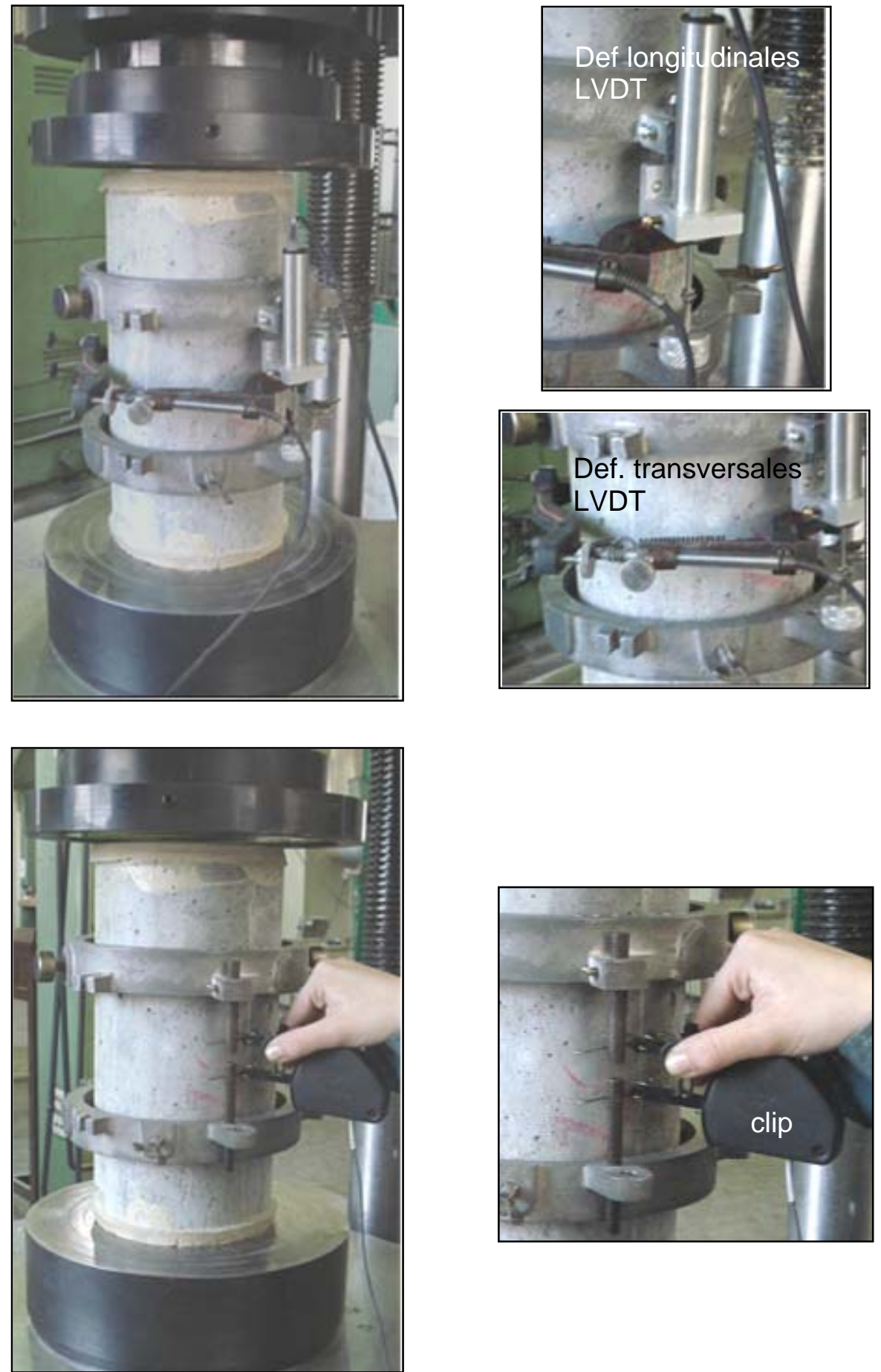

Figura 3.3.3.6. Disposición del ensayo de compresión. Arriba: dispositivos utilizados para medir las deformaciones longitudinales (LVDT) y transversales (LVDT). Abajo: dispositivo tipo clip para medir deformaciones longitudinales.

A partir de las deformaciones laterales y longitudinales se calcularon las deformaciones volumétricas y con las curvas volumétricas se definieron las tensiones 
críticas ( $\mathrm{f}_{\text {crít, }}$ tensión para la cual comienzan a crecer en mayor proporción las deformaciones transversales respecto a las axiales, por tanto la curva de deformaciones volumétricas cambia de sentido, ver Fig. 3.3.3.7).

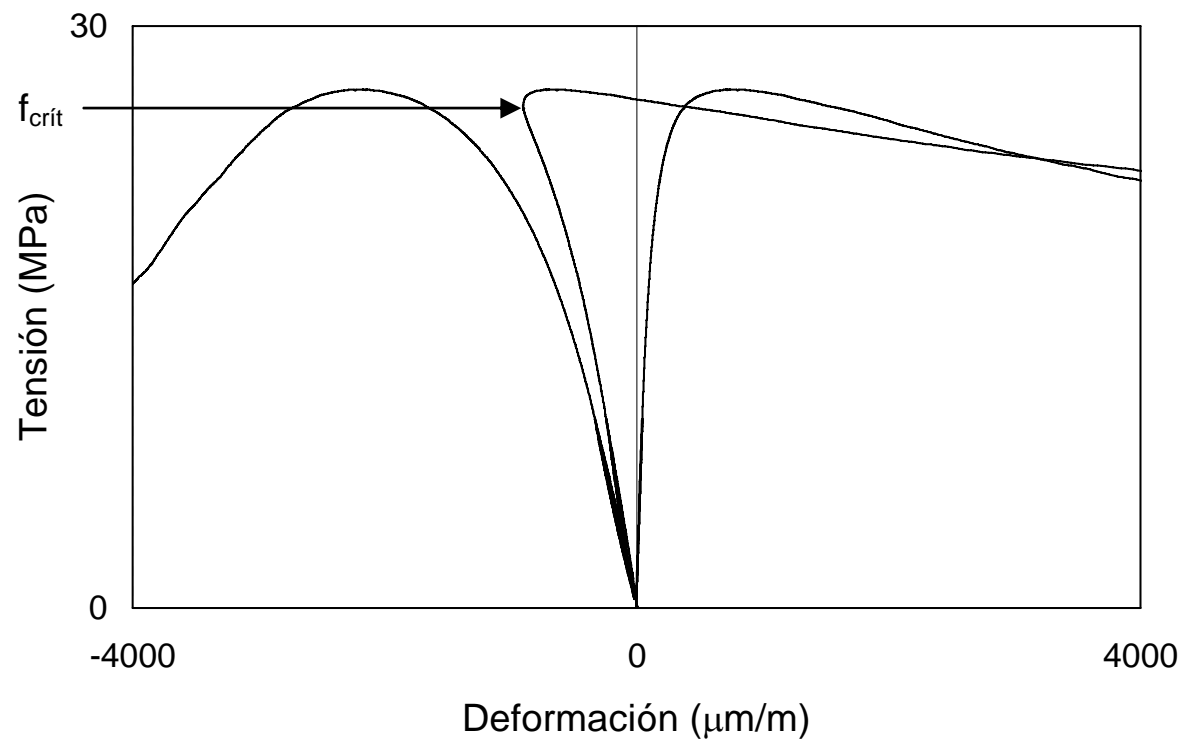

Figura 3.3.3.7. Curvas tensión-deformación longitudinal, transversal y volumétrica.

\subsubsection{Flexión sobre hormigón convencional (RILEM TC50-FMC)}

Este ensayo se realizó sobre prismas de $75 \times 105 \times 430 \mathrm{~mm}$ previamente entallados a una profundidad de $50 \mathrm{~mm}$ siguiendo los lineamientos del comité RILEM 50-FMC. Las probetas fueron colocadas sobre los apoyos girando $90^{\circ}$ con respecto a la cara de moldeo. La carga fue aplicada utilizando un sistema Instron, midiendo la apertura de fisura a través de un dispositivo tipo clip o las flechas mediante un LVDT. Se determinó la tensión neta de flexión ( $\left.f_{\text {net }}\right)$ como:

$$
\begin{aligned}
& f_{\text {net }}=6 \times(P) \times L / 4 \times b \times h^{2} \\
& \text { donde: } \mathrm{b}=\text { ancho de la viga. } \\
& \mathrm{h}=\text { altura neta. } \\
& \mathrm{L}=\text { luz entre apoyos. } \\
& \mathrm{P}=\text { carga máxima. }
\end{aligned}
$$




\subsubsection{Tracción por compresión diametral (IRAM 1658)}

Se determinó la resistencia a tracción por compresión diametral utilizando las mitades de las vigas de $75 \times 105 \times 430 \mathrm{~mm}$ resultantes del ensayo de flexión. Las cargas fueron aplicadas mediante una máquina Amsler de 30 Tn a través de una pieza cilíndrica, apoyada sobre un listón de madera de $16 \mathrm{~mm}^{2}$ de sección y longitud igual a la de la probeta. La disposición del ensayo se muestra en la Fig. 3.3.3.8. Del ensayo se registra la carga de rotura y la resistencia a tracción $\left(f_{c d}\right)$ se obtiene a partir de la fórmula:

$$
\begin{aligned}
f_{c d}=\frac{2 \times P}{b \times h \times \pi} \\
\text { donde: } \mathrm{P}=\text { carga máxima } \\
\mathrm{b}=\text { ancho de la probeta } \\
\mathrm{h}=\text { altura de la probeta }
\end{aligned}
$$

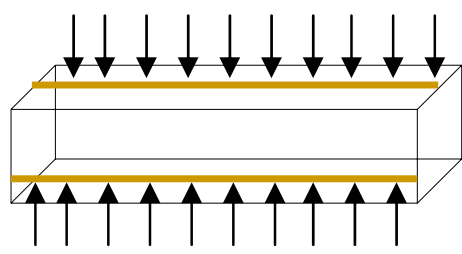

Figura 3.3.3.8. Disposición del ensayo de tracción por compresión diametral.

\subsubsection{Flexión sobre hormigones con fibras (RILEM TC162-TDF - EN 14651)}

La caracterización en flexión del HRF (inciso 5.2, Capítulo V) fue realizada en base a la recomendación del RILEM TC 162 y para el HACRF (inciso 5.4, Capítulo V) se utilizó su actualización posterior volcada en la norma EN 14651. Los principios generales para la realización del ensayo y cálculo de los parámetros de resistencia y tenacidad no difieren significativamente.

Los ensayos fueron realizados en sistemas con control por lazo cerrado midiéndose la apertura de fisura (CMOD) mediante un clip ubicado en el tramo medio del ancho de la probeta, y en los casos (inciso 5.2) donde se midieron flechas se hizo a través de un LVDT. 
En la Fig. 3.3.3.9 se muestran los dispositivos utilizados y el montaje de una probeta para ser ensayada según la norma EN 14651. Las vigas poseen una entalladura central de $25 \mathrm{~mm}$ de profundidad realizada por aserrado. El ensayo fue controlado a través de la apertura de fisura. De los ensayos se obtuvieron las tensiones de primera fisura $f_{L}$, última $f_{M}$ y las tensiones residuales para aperturas de fisura iguales a 500, 1500, 2500 y $3500 \mu \mathrm{m}\left(f_{R 1}, f_{R 2}, f_{R 3}\right.$ y $\left.f_{R 4}\right)$. Para determinar la tensión $\mathrm{f}_{\mathrm{L}}$ se traza una línea paralela al eje de cargas de la curva carga-CMOD a una distancia igual a $0.05 \mathrm{~mm}$ y se toma $\mathrm{f}_{\mathrm{L}}$ igual al valor máximo de la carga en el intervalo 0-0.05 mm (Fig. 3.3.3.10).
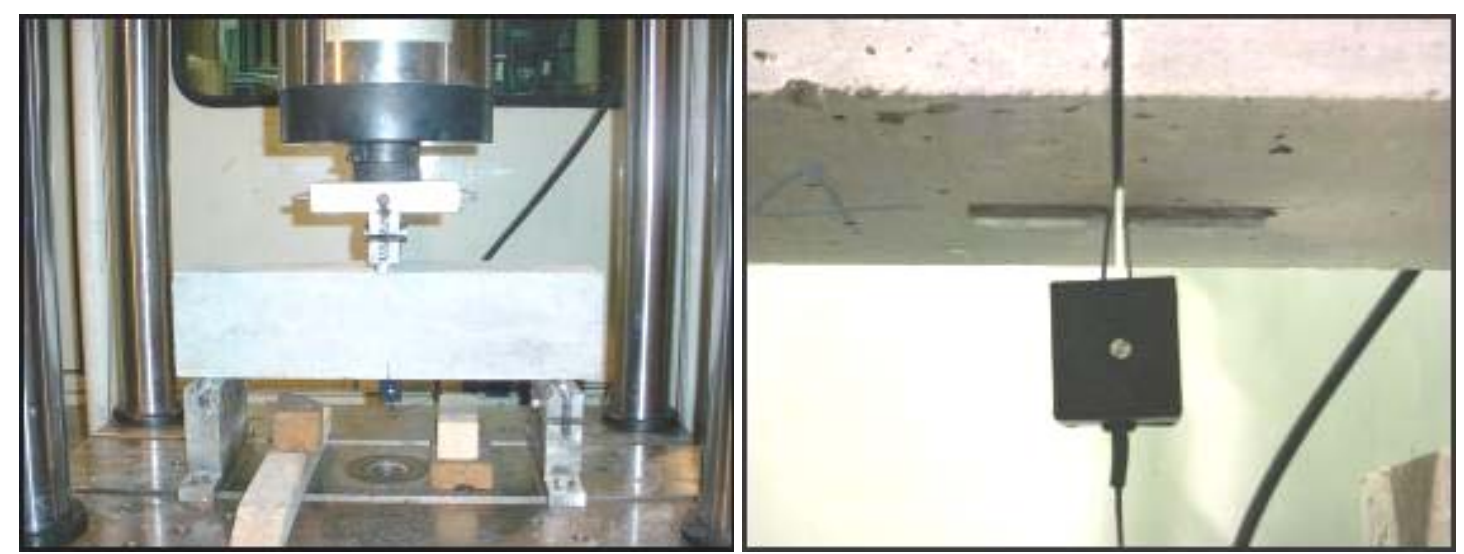

Figura 3.3.3.9. Disposición del ensayo de flexión (ensayo de las vigas del inciso 5.4) y detalle del clip utilizado para medir el CMOD.
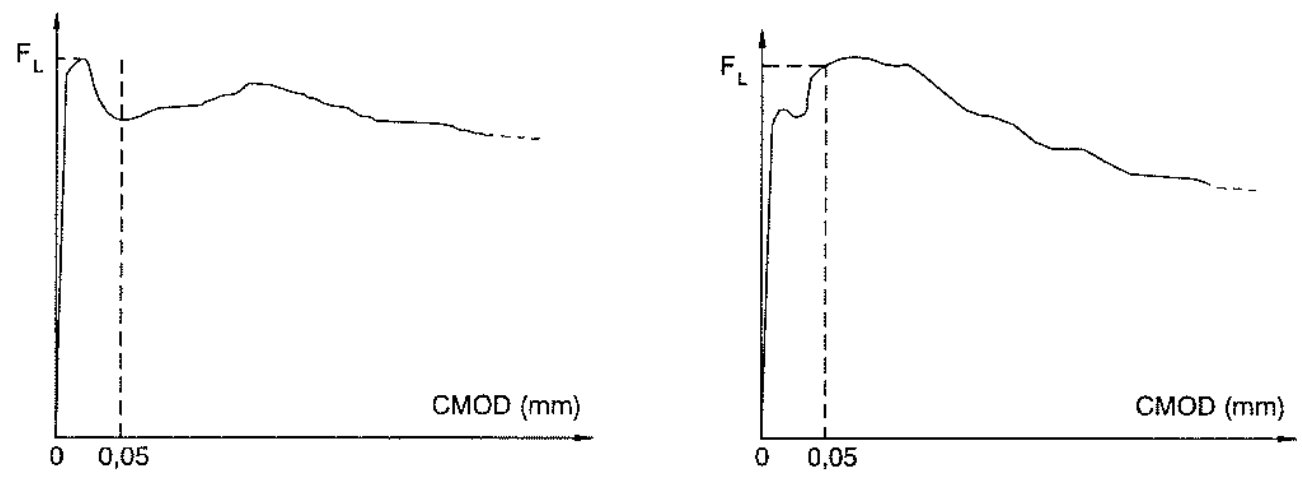

Figura 3.3.3.10. Curvas Carga-CMOD y modelo para delimitar la tensión de primera fisura $\left(f_{L}\right)$. 
En los casos donde también fueron medidas las flechas (ensayos según RILEM TC 162), el LVDT utilizado para medirlas fue montado sobre un marco rígido fijo a media altura de la probeta y en coincidencia con los apoyos, Fig. 3.3.3.11.
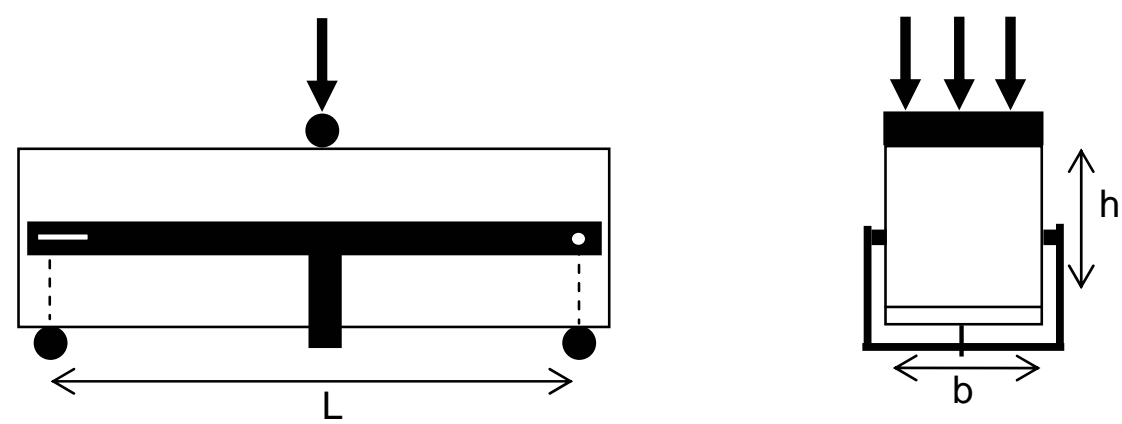

Figura 3.3.3.11. Disposición del marco para el LVDT utilizado para medir las flechas.

En la propuesta del RILEM TC 162, la tensión de primera fisura y las resistencias residuales se calculan según las indicaciones de la norma EN 14651 y además se obtienen las tensiones equivalentes $f_{\text {eq2 }}$ y $f_{\text {eq3 }}$. Para calcularlas se asume que el área bajo la curva carga-flecha consta de dos partes que responden al aporte del hormigón simple y al aporte de las fibras de acero $\left(D_{\mathrm{BZ2}, 3}^{\mathrm{f}}\right.$, ver Fig. 3.3.3.12). La línea que divide las dos partes se puede simplificar como una recta que conecta el punto de la curva correspondiente a $f_{L}$ y el punto en el eje de abscisas correspondiente a $\delta_{\mathrm{L}}+0.3 \mathrm{~mm}$ (ver Fig. 3.3.3.12). Siendo $\delta_{\mathrm{L}}$ la flecha correspondiente a la primera fisura.

Las deformaciones establecidas para $\mathrm{f}_{\mathrm{eq} 2}$ y $\mathrm{f}_{\mathrm{eq} 3}$ son:

$\delta_{2}=\delta_{\mathrm{L}}+0.65 \mathrm{~mm}$ y $\delta_{3}=\delta_{\mathrm{L}}+2.65 \mathrm{~mm}$ respectivamente.

Las tensiones equivalentes representan, entonces, las tensiones medias correspondientes a las áreas $D_{B z 2,3}^{f}$ :

$$
f_{e q 2,3}=\frac{3}{2}\left(\frac{D_{B Z 2,3}^{f}}{0.50}\right) \frac{L}{b h_{s p}^{2}}
$$



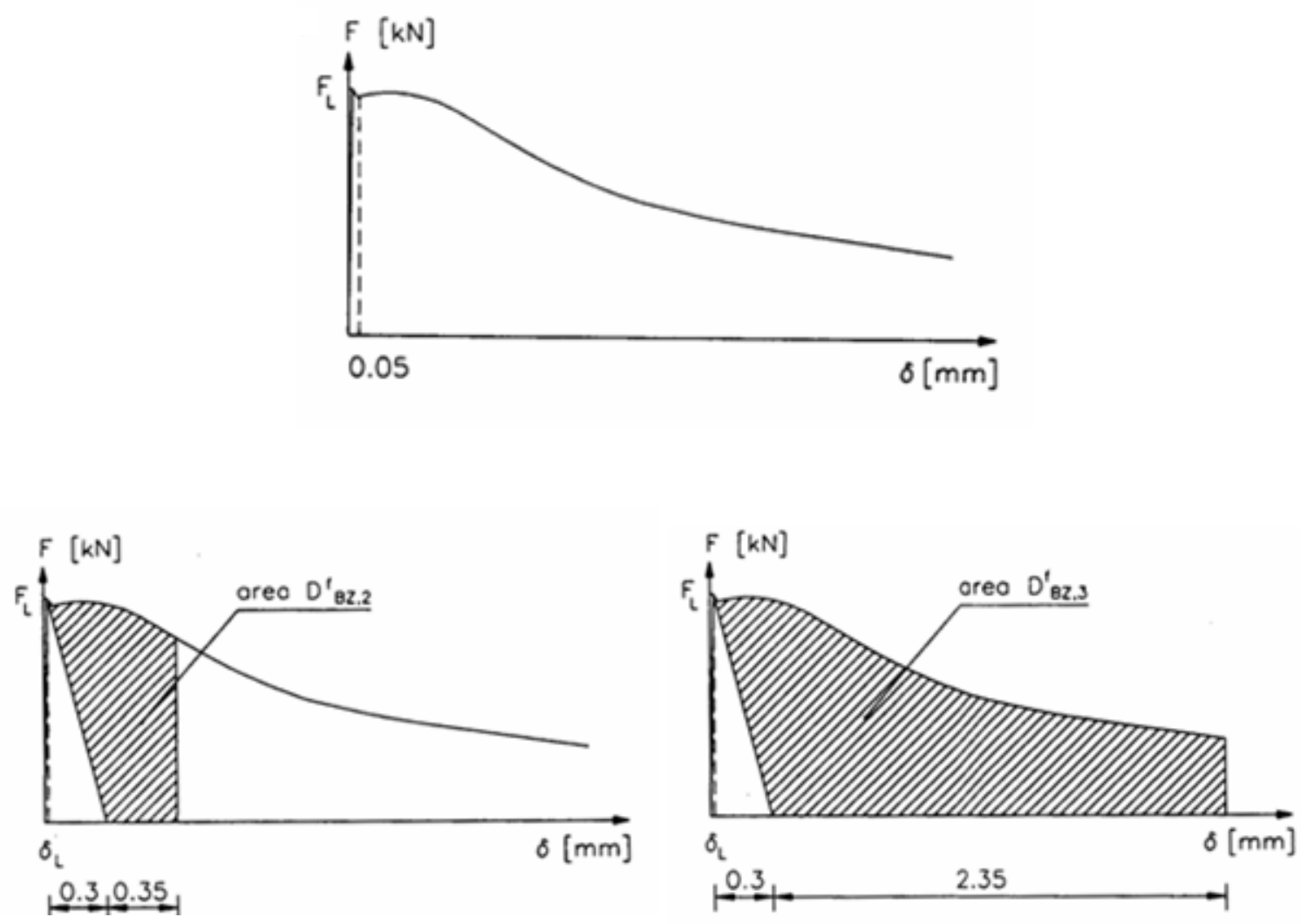

Figura 3.3.3.12. Diagramas Carga-Flecha (RILEM TC 162).

\subsubsection{Fluencia bajo cargas de compresión de larga duración}

Para la aplicación de las cargas de compresión de larga duración se utilizaron pórticos con resortes para mantener el nivel de carga (Fig. 3.3.3.13). Cada pórtico permite colocar entre 3 y 5 cilindros de 150 × 300 mm. Las caras de los cilindros fueron previamente encabezadas con mortero de cemento en el caso del estudio de reacción álcali - sílice (inciso 4.5, Capítulo IV) y con mortero de azufre en los estudios de probetas dañadas por exposición a altas temperaturas (inciso 4.4, Capítulo IV).

Para medir las deformaciones en cada cilindro se pegaron 6 pernos de acero inoxidable, sobre tres generatrices ubicadas a $120^{\circ}$ entre sí, siendo la distancia entre pernos igual a $250 \mathrm{~mm}$ (Fig. 3.3.3.13). Para la determinación de las variaciones dimensionales de los cilindros se empleó un deformómetro de láminas paralelas (Huggenberger) de 10 pulgadas de base y precisión 0.0001 pulgadas. Los valores de deformación de cada probeta corresponden al promedio de las tres determinaciones. Las lecturas se realizaron diariamente durante las primeras semanas de aplicación de 
las cargas y luego se fueron espaciando en función del crecimiento de las deformaciones.
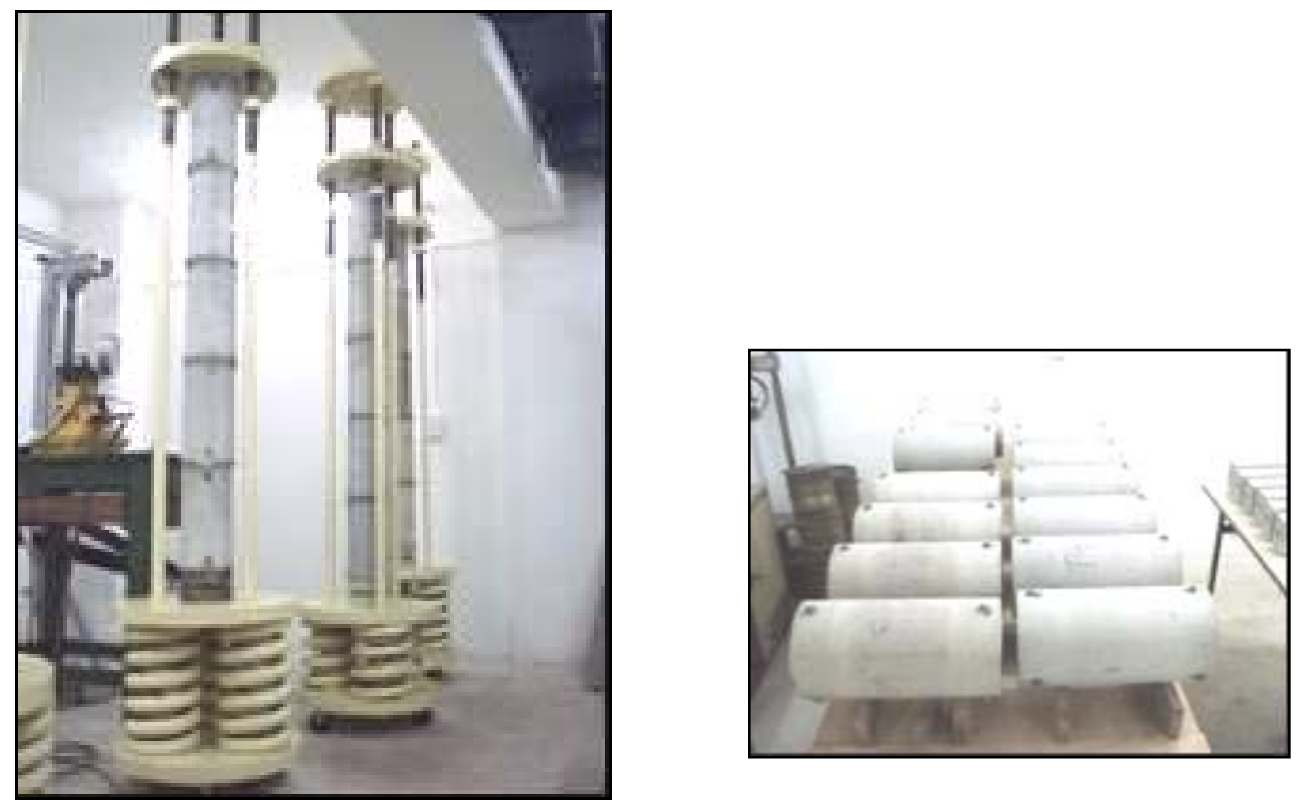

Figura 3.3.3.13. Pórticos con resortes y detalle de las probetas con los pernos de acero inoxidable, en la foto se muestran los ensayos para el estudio del inciso 4.4.

\subsubsection{Acondicionamiento para el desarrollo de los procesos de degradación}

\subsubsection{Exposición a alta temperatura}

Para provocar la degradación de las probetas por exposición a alta temperatura se emplearon a lo largo del programa experimental una estufa con circulación de aire, un horno eléctrico con control automático de temperatura y ventilación superior para permitir el escape de gases con dimensiones $0.60 \times 0.60 \times 0.70 \mathrm{~m}$ y una mufla más pequeña.

La estufa fue utilizada para calentar hasta una temperatura de $150^{\circ} \mathrm{C}$, tiene capacidad para alojar hasta cuatro cilindros de $150 \times 300 \mathrm{~mm}$. En el caso de las probetas que fueron calentadas hasta $500^{\circ} \mathrm{C}$ se utilizó el horno eléctrico con ventilación superior, el mismo permite calentar varias probetas a la vez, sin embargo para asegurar en todas ellas una exposición similar se introdujeron de a seis muestras por vez. En otras experiencias se calentaron probetas hasta $500^{\circ} \mathrm{C}$ empleando una mufla más pequeña con capacidad para 4 probetas. 
En todos los casos antes de exponer las probetas a altas temperaturas, se dejaron al aire durante un tiempo adecuado para que perdieran humedad. En todas las experiencias incluidas en la tesis, luego de la exposición a alta temperatura las probetas se dejaron enfriar dentro del horno en forma lenta.

\subsubsection{Contracción por secado}

Para favorecer la degradación de las probetas por secado las muestras fueron estacionadas en una cámara con control de temperatura $\left(22 \pm 2^{\circ} \mathrm{C}\right)$ y humedad $\left(55 \pm 5^{\circ} \mathrm{C}\right)$ durante el tiempo del estudio. La cámara es la habitualmente utilizada para estudios de fluencia y contracción de hormigones.

\subsubsection{Reacción álcali - sílice}

En las experiencias sobre reacción álcali-sílice (RAS) las probetas fueron mantenidas con humedad para asegurar el desarrollo de la reacción. Para ello fueron envueltas en una tela húmeda y colocadas en bolsas plásticas herméticamente cerradas. En el caso de las probetas sometidas a cargas de larga duración se dispuso de un tubo plástico que envolvía a todas las probetas y se cerraba en las partes superior e inferior de cada pórtico. Como para realizar las mediciones las probetas se sacaban de las bolsas o se bajaba el tubo, luego se rociaban los paños y se incorporaban $5 \mathrm{ml}$ de agua por probeta antes de volver a sellar los envoltorios.

En los estudios sobre RAS las probetas se dispusieron en dos ambientes, algunas en una cámara a $20 \pm 2{ }^{\circ} \mathrm{C}$ y otras en una cámara a $38 \pm 2{ }^{\circ} \mathrm{C}$; de este modo se logró el desarrollo de diferente cinética de reacción. 


\section{CAPÍTULO IV}

\section{ESTUDIOS SOBRE HORMIGONES DAÑADOS}

\subsection{INTRODUCCIÓN}

Las experiencias presentadas en este Capítulo fueron desarrolladas con el objetivo de evaluar la mesoestructura de hormigones con distinto nivel de daño y vincularla con la respuesta mecánica o las propiedades de transporte. La caracterización de la mesoestructura se realiza a través de la cuantificación de las fisuras visibles y el análisis de la distribución de agregados gruesos y sus interfaces. Los estudios comprenden hormigones expuestos a altas temperaturas, hormigones afectados por contracción por secado y hormigones dañados por reacción álcali-sílice.

En primer lugar se analiza la variabilidad en las valoraciones de la mesoestructura del hormigón; para ello se seleccionaron hormigones elaborados con dos tipos de agregado grueso con marcadas diferencias en la adherencia de interfaces, que fueron dañados por exposición a alta temperatura $\left(500^{\circ} \mathrm{C}\right)$. En este estudio también se analiza la vinculación entre mesoestructura y permeabilidad.

Luego se incluye un estudio realizado sobre muestras de un hormigón estructural de uso corriente que fueron expuestas a temperaturas de 150 y $500{ }^{\circ} \mathrm{C}$ y a un ambiente seco durante 2 años, al mismo tiempo como referencia un cuarto grupo de muestras fue mantenido en cámara húmeda. Se analizan las propiedades mecánicas (resistencia a compresión, módulo de elasticidad, coeficiente de Poisson, resistencia a tracción), las propiedades de transporte (permeabilidad y absorción capilar) junto con la mesoestructura observada en cada caso.

En tercer lugar se presenta un estudio sobre hormigones que luego de ser dañados por exposición a temperaturas de 150 y $500^{\circ} \mathrm{C}$, fueron sometidos a cargas 
de larga duración por el lapso de 1 año. En este caso se evaluaron el comportamiento mecánico (resistencia y deformabilidad en compresión y resistencia a tracción) y las propiedades de transporte junto con la mesoestructura, antes y después de la aplicación de las cargas.

Finalmente se presenta un estudio efectuado sobre hormigones afectados por reacción álcali-sílice. Dos hormigones, uno donde la reacción se produjo en forma muy rápida y otro de referencia, fueron sometidos a cargas de larga duración durante un año en ambientes saturados a 20 y a $38^{\circ} \mathrm{C}$. Luego de la descarga se evaluó el desarrollo de la fisuración externa y la estructura interna de las probetas, también se determinaron la resistencia a compresión, el módulo de elasticidad y el coeficiente de Poisson y se realizaron los ensayos de permeabilidad y penetración de agua a presión.

Los citados estudios permiten apreciar los efectos de las fisuras y otros tipos de alteraciones presentes en el hormigón sobre las propiedades macroscópicas y ponen en evidencia el significado del estudio sobre los aspectos mesoestructurales del material.

\subsection{VARIABILIDAD DE LA MESOESTRUCTURA EN HORMIGONES DAÑADOS POR TEMPERATURA}

El relevamiento de las fisuras y agregados, como ya fue planteado, presenta varios inconvenientes. Uno de ellos es que la naturaleza heterogénea del hormigón hace difícil definir el número y tamaño de las muestras necesarias para obtener resultados representativos. El tamaño de las muestras es función de la escala de observación, en este caso no representa un problema, ya que el objetivo de la tesis es estudiar al hormigón a nivel mesoestructural. Pero sí surge como incógnita la cantidad necesaria de muestras a relevar en este nivel de observación y definir qué características de las fisuras y agregados se evaluarán.

Es en este sentido que fue planteada la experiencia que se desarrolla a continuación, con el propósito de observar la variación de los parámetros de caracterización de la mesoestructura dentro de un mismo hormigón. Para ello se evaluaron diferentes probetas de un mismo hormigón que fueron previamente dañadas 
por exposición a una temperatura de $500{ }^{\circ} \mathrm{C}$ durante una hora. A esta temperatura se generan en el hormigón fisuras visibles a simple vista.

Para incrementar el alcance del estudio se consideraron dos hormigones elaborados con dos tipos de agregados naturales ampliamente conocidos en el mercado local y que poseen marcadas diferencias tanto en su textura superficial como en su respuesta al ser expuestos a alta temperatura: un canto rodado silíceo y una piedra partida granítica. La evaluación de la mesoestructura fue realizada analizando diferentes zonas de cada probeta.

Además de valorar la variabilidad de la mesoestructura de cada hormigón se realizaron, en forma complementaria, ensayos de permeabilidad, de forma tal de vincular los parámetros de la mesoestructura con el comportamiento del material.

\subsubsection{Materiales y mezclas}

Se prepararon dos hormigones convencionales utilizando dos tipos de agregados gruesos naturales: canto rodado silíceo (hormigón CR) procedente del río Uruguay y piedra partida granítica (hormigón PP) obtenida en la zona central de la Provincia de Buenos Aires. En la Tabla 4.2.1 se presenta la dosificación utilizada en ambos hormigones.

Tabla 4.2.1 Proporciones $\left(\mathrm{kg} / \mathrm{m}^{3}\right)$ de los hormigones.

\begin{tabular}{cll}
\hline Hormigón & CR & PP \\
\hline Agua & 182 & 191 \\
Cemento & 344 & 348 \\
Arena Oriental & 162 & 164 \\
Arena Argentina & 646 & 654 \\
Agregado Grueso & 982 & 994 \\
\hline
\end{tabular}

\subsubsection{Detalles experimentales}

Se elaboraron 4 probetas cilíndricas de 150 × $300 \mathrm{~mm}$ de cada hormigón que fueron curadas en cámara húmeda durante 28 días. Luego se mantuvieron en ambiente de laboratorio durante dos semanas para disminuir su nivel de humedad antes de la exposición a alta temperatura. 
Para generar el proceso de degradación (fisuración interna) las muestras se expusieron a una temperatura máxima de $500^{\circ} \mathrm{C}$ durante 1 hora, la velocidad de elevación de la temperatura fue igual a $100^{\circ} \mathrm{C}$ por hora. Dicho proceso se realizó para dos probetas de CR y dos de PP (identificadas como a y b) en una mufla pequeña, y se repitió para otras dos probetas de cada hormigón (llamadas c y d) utilizando para el calentamiento un horno eléctrico. El proceso de enfriamiento (donde en realidad se produce el mayor daño) fue mucho más rápido en el segundo caso.

Finalizado el proceso de daño se realizó el relevamiento de la superficie perimetral de cada probeta, registrando la extensión de las fisuras y el ancho de las mismas. Luego se realizaron 4 cortes transversales en el primer grupo (probetas a y b), mientras que en el segundo (probetas $c$ y d) sólo se hicieron 3 cortes (ver Fig 4.2.1). El relevamiento se efectuó sobre las dos caras de cada corte según lo indicado en el Capítulo III.
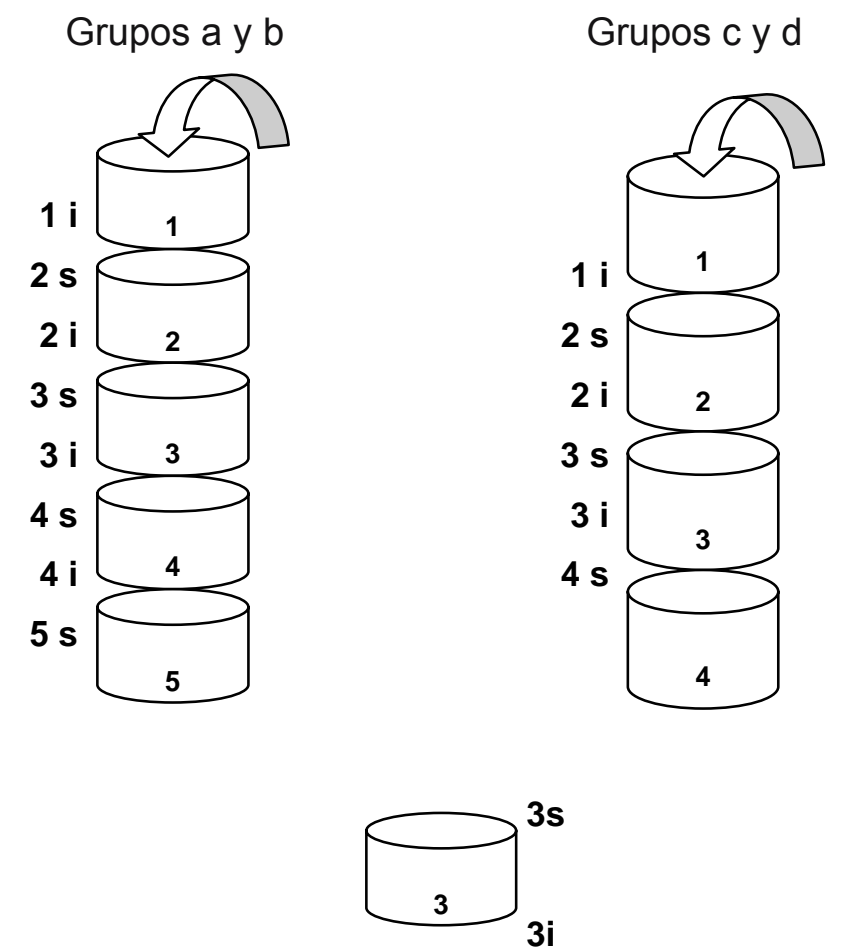

Figura 4.2.1. Cortes transversales para el análisis de la densidad de fisuras. Izquierda: cortes realizados en los grupos a y b, derecha: cortes realizados en los grupos c y d.

Las caras se identificaron como muestra la Fig. 4.2.1, las rodajas se numeraron en orden ascendente comenzando por la cara de moldeo, el subíndice "s" representa 
la cara superior (más cercana a la de moldeo) y el "i" la cara opuesta de cada una de las rodajas.

\subsubsection{Resultados y discusión}

\subsubsection{Evaluación de la mesoestructrua}

En la Tabla 4.2.2 se presentan los resultados del relevamiento de fisuras, se indican para las diferentes rodajas de cada una de las probetas la altura del corte respecto a la base de la probeta, la densidad de fisuras (longitud de fisura por unidad de área, $\mathrm{cm} / \mathrm{cm}^{2}$ ) en cada corte, el promedio de toda la probeta y los valores relativos respecto a dicho promedio. Dado que en algunos casos hay valores que se alejan marcadamente del resto, también se han incluido en la tabla los valores de la mediana; los que en la mayoría de los casos son similares al promedio. Además se incluye la densidad de fisuras sobre la superficie lateral (perímetro de toda la probeta).

También se informan en la Tabla 4.2.2 los datos que surgen del relevamiento del ancho de fisuras discriminando fisuras de interfaces y de matriz (mortero) en los cortes y las fisuras del perímetro. Cabe aclarar que en las casillas de la tabla donde dice 'sí' significa que se observó un notable deterioro de la pasta pero no fisuras. En el grupo de probetas elaboradas con piedra partida no se observa una fisura nítida como en el caso de las de canto rodado pero sí es posible observar la interfaz más deteriorada (ver Fig. 4.2.2)

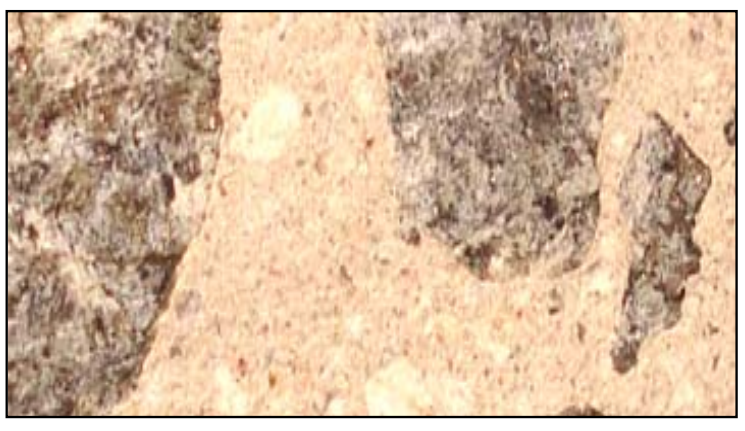

a)

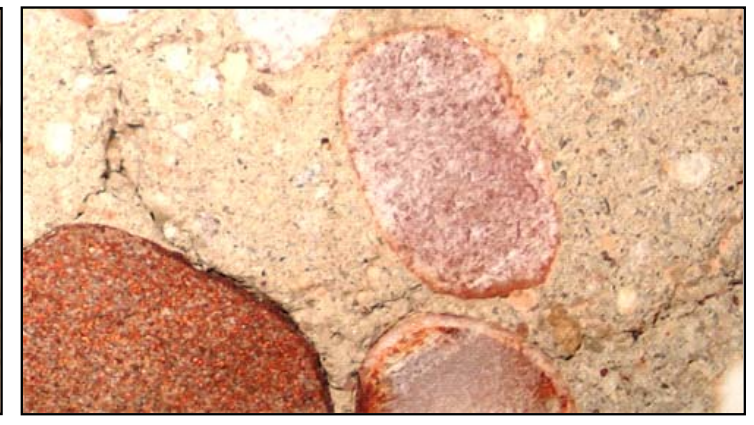

b)

Figura 4.2.2. Interfaces: a) Deterioro de la interfaz en PP, b) Fisuras en CR.

En la Tabla 4.2.3 se presentan los resultados del relevamiento de agregados en las diferentes rodajas de cada probeta, nuevamente se indica la altura del corte respecto a la base de la probeta, la densidad de agregados y la longitud de interfaces (perímetro alrededor de los agregados). 
Tabla 4.2.2. Relevamiento de fisuras, probetas de hormigón CR.

\begin{tabular}{|c|c|c|c|c|c|c|c|}
\hline \multirow[b]{2}{*}{ Probeta } & \multirow{2}{*}{$\begin{array}{l}\text { Altura } \\
(\mathrm{cm})\end{array}$} & \multicolumn{3}{|c|}{ Densidad } & \multicolumn{3}{|c|}{ Ancho } \\
\hline & & $\begin{array}{c}\text { Corte } \\
\left(\mathrm{cm} / \mathrm{cm}^{2}\right)\end{array}$ & Corte/Promedio & $\begin{array}{l}\text { Perímetro } \\
\left(\mathrm{cm} / \mathrm{cm}^{2}\right)\end{array}$ & $\begin{array}{c}\text { Interfaz } \\
(\mathrm{mm})\end{array}$ & $\begin{array}{c}\text { Matriz } \\
(\mathrm{mm})\end{array}$ & $\begin{array}{c}\text { Perímetro } \\
(\mathrm{mm})\end{array}$ \\
\hline CRa-1i & 6 & 0.78 & 1.08 & \multirow{8}{*}{0.45} & - & - & \multirow{8}{*}{$0.10-0.20$} \\
\hline CRa-2s & 6 & 0.63 & 0.86 & & 0.25 & 0.10 & \\
\hline CRa-2i & 12 & 0.84 & 1.17 & & 0.30 & 0.10 & \\
\hline CRa-3s & 12 & 0.90 & 1.24 & & 0.25 & 1.00 & \\
\hline CRa-3i & 18 & 0.89 & 1.23 & & 0.75 & 0.20 & \\
\hline CRa-4s & 18 & 0.94 & 1.30 & & 0.50 & 0.10 & \\
\hline CRa-4i & 24 & 0.35 & 0.49 & & 0.70 & 0.05 & \\
\hline CRa-5s & 24 & 0.45 & 0.63 & & 1.00 & 0.10 & \\
\hline \multirow[t]{3}{*}{$\mathrm{CRa}$} & Promedio & 0.72 & & & 0.54 & 0.24 & \\
\hline & Mediana & 0.81 & & & 0.50 & 0.10 & \\
\hline & $\sigma$ & 0.22 & & & 0.29 & 0.34 & \\
\hline CRb-1i & 6 & 0.80 & 1.31 & \multirow{8}{*}{0.39} & 0.25 & 0.10 & \multirow{8}{*}{$0.20-0.30$} \\
\hline CRb-2s & 6 & 0.41 & 0.68 & & 0.50 & 0.10 & \\
\hline CRb-2i & 12 & 0.84 & 1.39 & & 0.30 & 0.05 & \\
\hline CRb-3s & 12 & 0.71 & 1.17 & & 0.50 & 0.15 & \\
\hline CRb-3i & 18 & 0.73 & 1.20 & & 0.50 & 0.25 & \\
\hline CRb-4s & 18 & 0.52 & 0.85 & & 0.50 & 0.20 & \\
\hline CRb-4i & 24 & 0.41 & 0.67 & & 0.20 & 0.20 & \\
\hline CRb-5s & 24 & 0.44 & 0.73 & & 0.15 & 0.10 & \\
\hline \multirow[t]{3}{*}{$\mathrm{CRb}$} & Promedio & 0.61 & & & 0.36 & 0.14 & \\
\hline & Mediana & 0.62 & & & 0.40 & 0.13 & \\
\hline & $\sigma$ & 0.18 & & & 0.15 & 0.07 & \\
\hline CRc-1i & 7.5 & 0.16 & 0.63 & \multirow{6}{*}{0.43} & 0.20 & 0.05 & \multirow{6}{*}{$0.10-0.20$} \\
\hline CRc-2s & 7.5 & 0.22 & 0.88 & & 0.05 & 0.25 & \\
\hline CRc-2i & 15 & 0.28 & 1.10 & & 0.10 & 0.05 & \\
\hline CRc-3s & 15 & 0.26 & 1.02 & & 0.20 & sí & \\
\hline CRc-3i & 22.5 & 0.27 & 1.08 & & 0.05 & sí & \\
\hline CRc-4s & 22.5 & 0.33 & 1.30 & & 0.20 & sí & \\
\hline \multirow[t]{3}{*}{ CRc } & Promedio & 0.25 & & & 0.13 & 0.12 & \\
\hline & Mediana & 0.27 & & & 0.15 & 0.05 & \\
\hline & $\sigma$ & 0.06 & & & 0.07 & 0.11 & \\
\hline CRd-1i & 7.5 & 0.41 & 1.30 & \multirow{6}{*}{0.39} & 0.05 & no & \multirow{6}{*}{$0.10-0.05$} \\
\hline CRd-2s & 7.5 & 0.22 & 0.69 & & 0.10 & sí & \\
\hline CRd-2i & 15 & 0.22 & 0.69 & & 0.20 & 0.10 & \\
\hline CRd-3s & 15 & 0.21 & 0.66 & & 0.10 & 0.05 & \\
\hline CRd-3i & 22.5 & 0.37 & 1.17 & & 0.10 & 0.05 & \\
\hline CRd-4s & 22.5 & 0.48 & 1.50 & & 0.30 & 0.05 & \\
\hline \multirow[t]{3}{*}{ CRd } & Promedio & 0.32 & & & 0.14 & 0.06 & \\
\hline & Mediana & 0.30 & & & 0.10 & 0.05 & \\
\hline & $\sigma$ & 0.12 & & & 0.09 & 0.02 & \\
\hline
\end{tabular}


Tabla 4.2.2. (continuación) Relevamiento de fisuras, probetas de hormigón PP.

\begin{tabular}{|c|c|c|c|c|c|c|c|}
\hline \multirow[b]{2}{*}{ Probeta } & \multirow{2}{*}{$\begin{array}{l}\text { Altura } \\
(\mathrm{cm})\end{array}$} & \multicolumn{3}{|c|}{ Densidad } & \multicolumn{3}{|c|}{ Ancho } \\
\hline & & $\begin{array}{c}\text { Corte } \\
\left(\mathrm{cm} / \mathrm{cm}^{2}\right)\end{array}$ & Corte/Promedio & $\begin{array}{l}\text { Perímetro } \\
\left(\mathrm{cm} / \mathrm{cm}^{2}\right)\end{array}$ & $\begin{array}{c}\text { Interfaz } \\
(\mathrm{mm})\end{array}$ & $\begin{array}{l}\text { Matriz) } \\
(\mathrm{mm})\end{array}$ & $\begin{array}{c}\text { Perímetro } \\
(\mathrm{mm})\end{array}$ \\
\hline PPa-1i & 6 & 0.21 & 0.87 & & 0.05 & no & \\
\hline $\mathrm{PPa}-2 \mathrm{~s}$ & 6 & 0.17 & 0.71 & & 0.05 & sí & \\
\hline PPa-2i & 12 & 0.37 & 1.54 & & 0.05 & sí & \\
\hline PPa-3s & 12 & 0.36 & 1.50 & & 0.05 & sí & \\
\hline PPa-3i & 18 & 0.25 & 1.04 & 0.11 & 0.05 & sí & $<0.05$ \\
\hline $\mathrm{PPa}-4 \mathrm{~s}$ & 18 & 0.24 & 1.00 & & 0.20 & 0.10 & \\
\hline PPa-4i & 24 & 0.11 & 0.46 & & 0.05 & no & \\
\hline PPa-5s & 24 & 0.17 & 0.71 & & 0.05 & sí & \\
\hline \multirow[t]{3}{*}{$\mathrm{PPa}$} & Promedio & 0.24 & & & 0.07 & 0.10 & \\
\hline & Mediana & 0.23 & & & 0.05 & 0.10 & \\
\hline & $\sigma$ & 0.09 & & & 0.05 & & \\
\hline PPb-1i & 6 & 0.22 & 0.91 & & 0.05 & sí & \\
\hline PPb-2s & 6 & 0.14 & 0.58 & & 0.05 & 0.05 & \\
\hline PPb-2i & 12 & 0.32 & 1.32 & & 0.05 & 0.05 & \\
\hline $\mathrm{PPb}-3 \mathrm{~s}$ & 12 & 0.34 & 1.43 & & 0.05 & 0.05 & \\
\hline PPb-3i & 18 & 0.22 & 0.94 & 0.16 & 0.05 & no & $<0.05$ \\
\hline PPb-4s & 18 & 0.37 & 1.57 & & 0.10 & 0.05 & \\
\hline PPb-4i & 24 & 0.12 & 0.49 & & 0.10 & 0.05 & \\
\hline PPb-5s & 24 & 0.18 & 0.76 & & 0.05 & sí & \\
\hline \multirow{3}{*}{$\mathrm{PPb}$} & Promedio & 0.24 & & & 0.06 & 0.05 & \\
\hline & Mediana & 0.22 & & & 0.05 & 0.05 & \\
\hline & $\sigma$ & 0.09 & & & 0.02 & & \\
\hline PPc-1i & 7.5 & 0.14 & 0.95 & & 0.05 & no & \\
\hline PPc-2s & 7.5 & 0.12 & 0.84 & & 0.05 & no & \\
\hline PPc-2i & 15 & 0.09 & 0.59 & & 0.05 & no & \\
\hline PPc-3s & 15 & 0.17 & 1.14 & 0.31 & 0.10 & sí & $0.10-0.05$ \\
\hline PPc-3i & 22.5 & 0.16 & 1.11 & & 0,05 & sí & \\
\hline PPc-4s & 22.5 & 0.20 & 1.37 & & 0.05 & 0.05 & \\
\hline \multirow[t]{3}{*}{$\mathrm{PPc}$} & Promedio & 0.15 & & & 0.06 & 0.05 & \\
\hline & Mediana & 0.15 & & & 0.05 & 0.05 & \\
\hline & $\sigma$ & 0.04 & & & 0.02 & & \\
\hline PPd-1i & 7.5 & 0.27 & 1.52 & & 0.05 & no & \\
\hline PPd-2s & 7.5 & 0.24 & 1.31 & & 0.05 & no & \\
\hline PPd-2i & 15 & 0.18 & 1.00 & 020 & 0.05 & no & \\
\hline PPd-3s & 15 & 0.08 & 0.43 & 0.29 & 0,05 & sí & $<0.05$ \\
\hline PPd-3i & 22.5 & 0.13 & 0.74 & & 0,05 & sí & \\
\hline PPd-4s & 22.5 & 0.18 & 1.00 & & 0.05 & no & \\
\hline \multirow[t]{3}{*}{$\mathrm{PPd}$} & Promedio & 0.18 & & & 0.05 & & \\
\hline & Mediana & 0.18 & & & 0.05 & & \\
\hline & $\sigma$ & 0.07 & & & 0.00 & & \\
\hline
\end{tabular}


Tabla 4.2.3. Relevamiento de agregados, hormigón CR.

\begin{tabular}{cccc}
\hline & \multirow{2}{c}{ Altura } & \multicolumn{2}{c}{ Agregados } \\
\cline { 2 - 4 } Probeta & $(\mathrm{cm})$ & $\begin{array}{c}\text { Densidad } \\
\left(\mathrm{cm}^{2} / \mathrm{cm}^{2}\right)\end{array}$ & $\begin{array}{c}\text { Perímetro } \\
(\mathrm{cm})\end{array}$ \\
\hline CRa-1i & 6 & 0.38 & 143.9 \\
CRa-2s & 6 & 0.30 & 117.3 \\
CRa-2i & 12 & 0.32 & 119.2 \\
CRa-3s & 12 & 0.32 & 129.8 \\
CRa-3i & 18 & 0.28 & 121.3 \\
CRa-4s & 18 & 0.29 & 136.2 \\
CRa-4i & 24 & 0.25 & 122.0 \\
CRa-5s & 24 & 0.29 & 125.4 \\
\hline CRa & Promedio & 0.30 & 126.9 \\
& $\sigma$ & 0.04 & 9.2 \\
\hline CRb-1i & 6 & 0.27 & 116.8 \\
CRb-2s & 6 & 0.26 & 109.5 \\
CRb-2i & 12 & 0.31 & 126.3 \\
CRb-3s & 12 & 0.29 & 104.7 \\
CRb-3i & 18 & 0.25 & 107.2 \\
CRb-4s & 18 & 0.35 & 138.8 \\
CRb-4i & 24 & 0.30 & 117.5 \\
CRb-5s & 24 & 0.29 & 112.2 \\
\hline CRb & Promedio & 0.29 & 116.6 \\
& $\sigma$ & 0.03 & 11.3 \\
\hline CRc-1i & 7.5 & 0.36 & 122.8 \\
CRc-2s & 7.5 & 0.29 & 124.0 \\
CRc-2i & 15 & 0.34 & 116.8 \\
CRc-3s & 15 & 0.33 & 115.3 \\
CRc-3i & 22.5 & 0.28 & 114.4 \\
CRc-4s & 22.5 & 0.32 & 121.9 \\
\hline CRc & Promedio & 0.32 & 119.2 \\
& $\sigma$ & 0.03 & 4.2 \\
\hline CRd-1i & 7.5 & 0.33 & 130.8 \\
CRd-2s & 7.5 & 0.38 & 125.8 \\
CRd-2i & 15 & 0.31 & 129.1 \\
CRd-3s & 15 & 0.33 & 140.2 \\
CRd-3i & 22.5 & 0.29 & 122.7 \\
CRd-4s & 22.5 & 0.27 & 112.0 \\
\hline CRd & Promedio & 0.32 & 126.8 \\
& $\sigma$ & 0.04 & 9.4 \\
\hline & & & \\
\hline
\end{tabular}


Tabla 4.2.3. (continuación) Relevamiento de agregados, hormigón PP.

\begin{tabular}{|c|c|c|c|}
\hline \multirow[b]{2}{*}{ Probeta } & \multirow[b]{2}{*}{$\begin{array}{l}\text { Altura } \\
(\mathrm{cm})\end{array}$} & \multicolumn{2}{|c|}{ Agregados } \\
\hline & & $\begin{array}{l}\text { Densidad } \\
\left(\mathrm{cm}^{2} / \mathrm{cm}^{2}\right)\end{array}$ & $\begin{array}{l}\text { Perímetro } \\
(\mathrm{cm})\end{array}$ \\
\hline PPa-1i & 6 & 0.22 & 117.0 \\
\hline PPa-2s & 6 & 0.33 & 153.6 \\
\hline PPa-2i & 12 & 0.33 & 153.6 \\
\hline PPa-3s & 12 & 0.28 & 126.8 \\
\hline PPa-3i & 18 & 0.26 & 137.7 \\
\hline $\mathrm{PPa}-4 \mathrm{~s}$ & 18 & 0.30 & 154.1 \\
\hline $\mathrm{PPa}-4 \mathrm{i}$ & 24 & 0.28 & 134.2 \\
\hline $\mathrm{PPa}-5 \mathrm{~s}$ & 24 & 0.30 & 141.4 \\
\hline \multirow[t]{2}{*}{$\mathrm{PPa}$} & Promedio & 0.29 & 139.8 \\
\hline & $\sigma$ & 0.04 & 13.7 \\
\hline PPb-1i & 6 & 0.29 & 148.0 \\
\hline PPb-2s & 6 & 0.26 & 117.1 \\
\hline PPb-2i & 12 & 0.29 & 134.5 \\
\hline PPb-3s & 12 & 0.32 & 148.2 \\
\hline PPb-3i & 18 & 0.33 & 126.1 \\
\hline PPb-4s & 18 & 0.32 & 129.7 \\
\hline PPb-4i & 24 & 0.31 & 128.5 \\
\hline PPb-5s & 24 & 0.32 & 145.5 \\
\hline \multirow[t]{2}{*}{$\mathrm{PPb}$} & Promedio & 0.31 & 134.7 \\
\hline & $\sigma$ & 0.02 & 11.5 \\
\hline PPc-1i & 7.5 & 0.29 & 149.6 \\
\hline PPc-2s & 7.5 & 0.28 & 129.4 \\
\hline PPc-2i & 15 & 0.28 & 119.8 \\
\hline PPc-3s & 15 & 0.28 & 129.4 \\
\hline PPc-3i & 22.5 & 0.29 & 143.2 \\
\hline PPc-4s & 22.5 & 0.28 & 130.3 \\
\hline \multirow[t]{2}{*}{ PPc } & Promedio & 0.28 & 133.6 \\
\hline & $\sigma$ & 0.01 & 10.8 \\
\hline PPd-1i & 7.5 & 0.31 & 147.4 \\
\hline PPd-2s & 7.5 & 0.33 & 141.3 \\
\hline PPd-2i & 15 & 0.30 & 123.1 \\
\hline PPd-3s & 15 & 0.29 & 127.6 \\
\hline PPd-3i & 22.5 & 0.29 & 134.8 \\
\hline $\mathrm{PPd}-4 \mathrm{~s}$ & 22.5 & 0.23 & 120.4 \\
\hline \multirow[t]{2}{*}{ PPd } & Promedio & 0.29 & 132.4 \\
\hline & $\sigma$ & 0.03 & 10.6 \\
\hline
\end{tabular}


En la Fig. 4.2.3 se muestra la distribución de la densidad de fisuras a lo largo de cada probeta, representando la densidad calculada para cada corte. Es posible observar que aunque las probetas de CR y PP presentan distinto cuadro de fisuración, en ambos casos las probetas a y b son las más afectadas. En cuanto a la variación de la fisuración dentro de las muestras se puede apreciar que la zona central de las probetas presenta en general un cuadro de fisuración más homogéneo, y que en las probetas a y b es, además, la zona más fisurada.

En la Tabla 4.2.4 se resumen los promedios de la densidad y número específico de fisuras (por unidad de área) y sus respectivos desvíos estándar y COV, como así también la densidad de fisuras relevada sobre toda la superficie perimetral de las probetas. Al comparar longitud (densidad) y número de fisuras por unidad de área entre las probetas $C R$ y $P P$ se observa que todas tienen similar número de fisuras; sin embargo las CR presentan una mayor densidad, ya que poseen fisuras más largas que bordean los agregados y atraviesan la matriz. Consecuentemente el análisis de la densidad de fisuras es más efectivo para determinar el grado de deterioro del material en comparación con el análisis del número de fisuras. Con respecto a la variabilidad entre cortes, Ios COV indican que es bastante elevada, con valores del orden del 30 al $40 \%$, tanto si se considera la densidad como el número de fisuras.

Del relevamiento del perímetro de los cilindros surge que las probetas $C R$ poseen mayor densidad de fisuras, lo que es concordante con las medidas sobre los cortes transversales. Otro aspecto evidente son las diferencias entre los pares de probetas a-b y c-d que fueron calentadas con distintos equipos y enfriadas a distintas velocidades; las probetas a-b tanto las de CR como las de PP mostraron mayor densidad de fisuras en los cortes que en el perímetro mientras que sucede lo contrario con los pares c-d; que fueron enfriados más bruscamente. Además se puede observar que los pares de probetas de un mismo hormigón, sometidas a las mismas condiciones de calentamiento y enfriamiento, poseen en el perímetro una densidad de fisuras similar, pudiendo ser también éste un parámetro para caracterizar al material. 


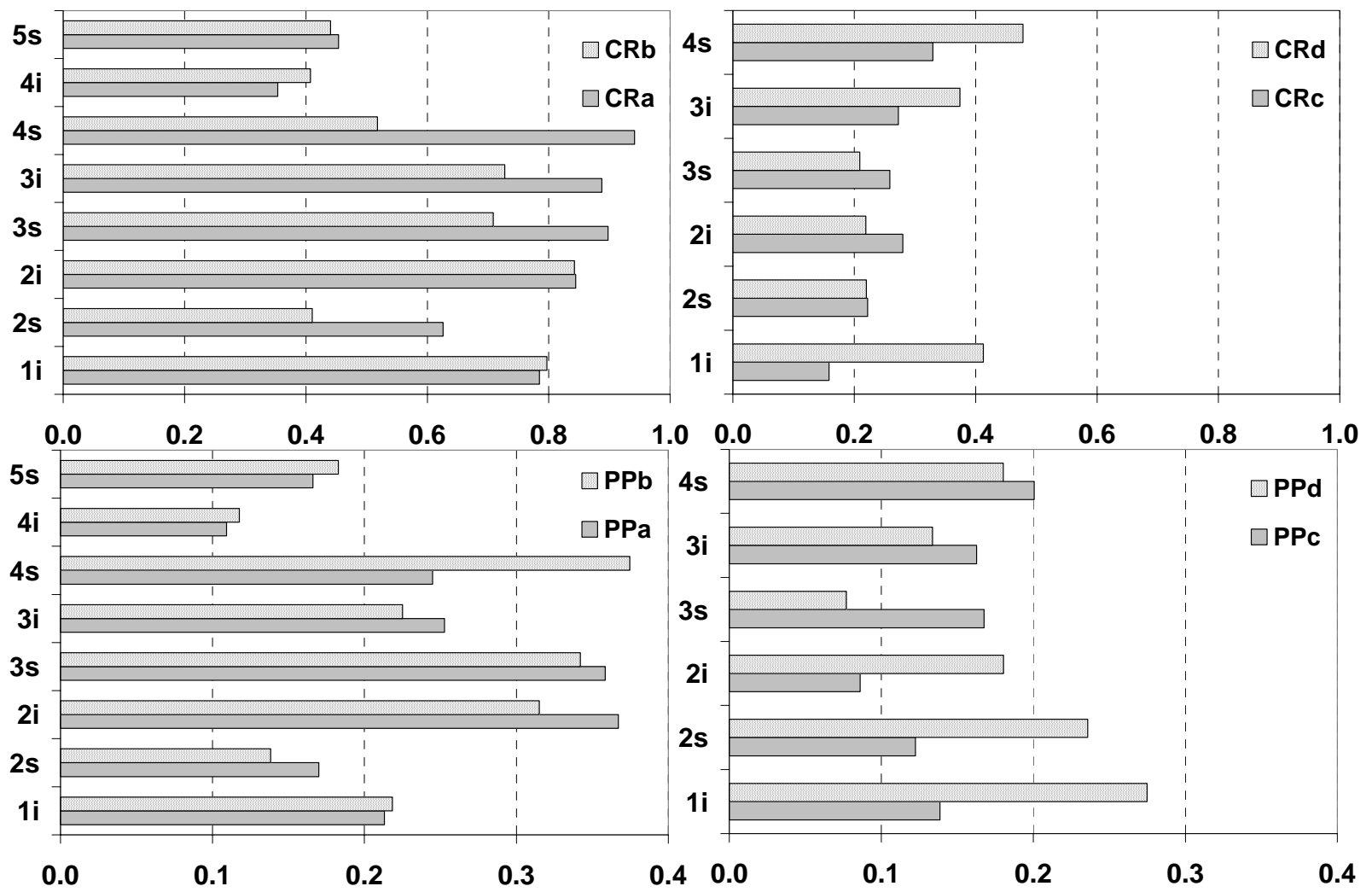

Figura 4.2.3. Densidad de fisuras en cada corte $\left(\mathrm{cm} / \mathrm{cm}^{2}\right)$

Tabla 4.2.4. Densidad y número de fisuras. Valores promedios.

\begin{tabular}{ccccccccc}
\hline & CRa & CRb & CRc & CRd & PPa & PPb & PPc & PPd \\
\hline Densidad de fisuras $\left(\mathrm{cm} / \mathrm{cm}^{2}\right)$ & 0.72 & 0.61 & 0.29 & 0.31 & 0.24 & 0.24 & 0.15 & 0.18 \\
Desviación Estándar $\left(\mathrm{cm} / \mathrm{cm}^{2}\right)$ & 0.22 & 0.18 & 0.11 & 0.12 & 0.09 & 0.10 & 0.04 & 0.06 \\
COV $(\%)$ & 30 & 30 & 37 & 37 & 39 & 40 & 27 & 31 \\
\hline $\mathrm{N}^{\circ}$ de fisuras $\left(\mathrm{N} / \mathrm{cm}^{2}\right)$ & 0.29 & 0.27 & 0.25 & 0.26 & 0.23 & 0.25 & 0.18 & 0.21 \\
Desviación Estándar $\left(\mathrm{N} / \mathrm{cm}^{2}\right)$ & 0.09 & 0.10 & 0.07 & 0.11 & 0.09 & 0.12 & 0.06 & 0.06 \\
COV $(\%)$ & 33 & 37 & 29 & 42 & 38 & 47 & 34 & 29 \\
\hline $\begin{array}{c}\text { Densidad en el perímetro } \\
\left(\mathrm{cm} / \mathrm{cm}^{2}\right)\end{array}$ & 0.45 & 0.39 & 0.43 & 0.39 & 0.11 & 0.16 & 0.31 & 0.29 \\
\hline
\end{tabular}

Uno de los interrogantes planteados dentro de este estudio fue la definición de la cantidad de cortes requerida para lograr un relevamiento representativo de toda la probeta. Para analizar este aspecto se realizaron promedios de los resultados con distintas combinaciones de las secciones analizadas, a saber: 
Criterio A: promedio de todos los cortes.

Criterio B: promedio cortes mitad superior de la probeta (caras $1 \mathrm{i}, 2 \mathrm{~s}, 2 \mathrm{i}$ y $3 \mathrm{~s}$ ).

Criterio C: promedio cortes zona central (probetas a-b promedio de las caras $2 \mathrm{i}$, $3 s, 3 i$ y 4 s y probetas $c-d$ promedio de las caras $2 i$ y $3 s)$.

Criterio D: un sólo corte en la mitad de la probeta (probetas a-b promedio de las caras $2 \mathrm{i}$ y $3 \mathrm{~s}$ y probetas $\mathrm{c}-\mathrm{d}$ promedio de las caras $2 \mathrm{~s}$ y $2 \mathrm{i}$ ).

Criterio E: promedio cortes mitad inferior de la probeta (probetas a-b promedio de las caras $3 \mathrm{i}, 4 \mathrm{~s}, 4 \mathrm{i}$ y $5 \mathrm{~s}$ y probetas $\mathrm{c}-\mathrm{d}$ promedio de las caras $2 \mathrm{i}, 3 \mathrm{~s}$, $3 \mathrm{i}$ y $4 \mathrm{~s}$ ).

Los valores obtenidos se resumen en la Tabla 4.2.5 junto con la desviación estándar y el COV. Es posible observar que las menores variaciones se producen cuando se aplica el criterio $\mathrm{C}$, donde se toman en cuenta los valores obtenidos sobre los cortes centrales.

Otro aspecto importante vinculado con la cantidad de caras a analizar, fue analizar si es necesario relevar las dos caras de un mismo corte o basta con evaluar una sola. En la Tabla 4.2.6 se presentan los mismos promedios de la Tabla 4.2.5 pero tomando por separado las caras de abajo y de arriba de cada rodaja. Cabe aclarar que el criterio $D$ fue excluido de este análisis debido a que este promedio en el caso de las probetas $a-b$ corresponde a dos caras de un mismo corte y en las probetas $c-d$ corresponde a las dos caras de la misma rodaja. Como era previsible en la mayoría de los casos los resultados son concordantes, por lo tanto se concluye que es suficiente relevar sólo una cara de cada corte.

Finalmente en lo que respecta a la densidad de fisuras, se analizó la variabilidad entre probetas de un mismo grupo; en la Tabla 4.2.7 se pueden observar los distintos promedios de cada grupo y sus respectivos valores de COV y desviación estándar. En general el COV entre dos probetas no es muy grande (menor al 30\%), en comparación con lo que surge de analizar cortes de una misma probeta, por lo que se estima que con relevar dos probetas se obtendrá un valor suficientemente representativo. Se aprecia mayor variabilidad en el hormigón CR que en PP lo que puede atribuirse a la mayor alterabilidad de los rodados silíceos al ser expuestos a temperaturas de $500^{\circ} \mathrm{C}$. 
Tabla 4.2.5. Promedios de densidad de fisuras $\left(\mathrm{cm} / \mathrm{cm}^{2}\right)$ a partir de combinación de diversos cortes.

\begin{tabular}{cccccccccc}
\hline & Criterio & CRa & CRb & CRc & CRd & PPa & PPb & PPc & PPd \\
\hline \multirow{4}{*}{ A } & Promedio & 0.72 & 0.61 & 0.25 & 0.32 & 0.24 & 0.24 & 0.15 & 0.18 \\
& $\sigma$ & 0.22 & 0.18 & 0.06 & 0.12 & 0.09 & 0.10 & 0.04 & 0.07 \\
& COV (\%) & 31 & 30 & 23 & 37 & 39 & 40 & 27 & 39 \\
\hline \multirow{3}{*}{ B } & Promedio & 0.79 & 0.69 & 0.23 & 0.27 & 0.27 & 0.25 & 0.13 & 0.19 \\
& $\sigma$ & 0.12 & 0.19 & 0.06 & 0.11 & 0.10 & 0.09 & 0.03 & 0.05 \\
& CoV (\%) & 15 & 28 & 26 & 42 & 37 & 37 & 21 & 25 \\
\hline \multirow{3}{*}{ C } & Promedio & 0.89 & 0.70 & 0.27 & 0.21 & 0.31 & 0.31 & 0.13 & 0.13 \\
& $\sigma$ & 0.04 & 0.13 & 0.02 & 0.01 & 0.07 & 0.06 & 0.06 & 0.07 \\
& CoV (\%) & 5 & 19 & 6 & 3 & 22 & 20 & 45 & 57 \\
\hline \multirow{4}{*}{$\mathrm{D}$} & Promedio & 0.87 & 0.78 & 0.25 & 0.22 & 0.36 & 0.33 & 0.10 & 0.21 \\
& $\sigma$ & 0.04 & 0.09 & 0.04 & 0.00 & 0.01 & 0.02 & 0.03 & 0.04 \\
& CoV (\%) & 4 & 12 & 16 & 0.2 & 2 & 6 & 25 & 19 \\
\hline \multirow{2}{*}{ E } & Promedio & 0.66 & 0.52 & 0.29 & 0.32 & 0.19 & 0.23 & 0.15 & 0.14 \\
& $\sigma$ & 0.30 & 0.14 & 0.04 & 0.14 & 0.07 & 0.11 & 0.02 & 0.05 \\
& CoV (\%) & 45 & 28 & 13 & 42 & 35 & 48 & 13 & 36 \\
\hline
\end{tabular}

Ver Fig. 4.2.1.

Criterio A: promedio de todos los cortes.

Criterio B: promedio de las caras $1 \mathrm{i}, 2 \mathrm{~s}, 2 \mathrm{i}$ y $3 \mathrm{~s}$.

Criterio C: para las probetas a-b promedio de las caras $2 \mathrm{i}, 3 \mathrm{~s}, 3 \mathrm{i}$ y $4 \mathrm{~s}$ y para las $\mathrm{c}-\mathrm{d}$ promedio de las caras $2 \mathrm{i}$ y $3 \mathrm{~s}$.

Criterio D: para las probetas a-b promedio de las caras $2 i$ y $3 s$ y para las $c-d$ promedio de las caras $2 \mathrm{~s}$ y $2 \mathrm{i}$.

Criterio E: para las probetas a-b promedio de las caras $3 \mathrm{i}, 4 \mathrm{~s}, 4 \mathrm{i}$ y $5 \mathrm{~s}$ y para las c-d promedio de las caras $2 \mathrm{i}, 3 \mathrm{~s}, 3 \mathrm{i}$ y $4 \mathrm{~s}$.

Tabla 4.2.6. Promedios de la densidad de fisuras $\left(\mathrm{cm} / \mathrm{cm}^{2}\right)$ en relevamientos de caras opuestas del mismo corte.

\begin{tabular}{cccccccccc}
\hline Criterio & caras & CRa & CRb & CRc & CRd & PPa & PPb & PPc & PPd \\
\hline \multirow{2}{*}{ A } & i & 0.72 & 0.69 & 0.24 & 0.34 & 0.24 & 0.22 & 0.13 & 0.20 \\
& s & 0.73 & 0.52 & 0.27 & 0.30 & 0.23 & 0.26 & 0.16 & 0.16 \\
\hline \multirow{2}{*}{ B } & i & 0.84 & 0.79 & 0.22 & 0.32 & 0.28 & 0.25 & 0.11 & 0.23 \\
& s & 0.82 & 0.55 & 0.24 & 0.21 & 0.26 & 0.29 & 0.15 & 0.16 \\
\hline \multirow{2}{*}{ C } & i & 0.87 & 0.78 & - & - & 0.31 & 0.27 & - & - \\
& s & 0.92 & 0.61 & - & - & 0.30 & 0.36 & - & - \\
\hline \multirow{2}{*}{ E } & i & 0.76 & 0.56 & 0.29 & 0.34 & 0.26 & 0.30 & 0.18 & 0.13 \\
& s & 0.70 & 0.66 & 0.28 & 0.30 & 0.24 & 0.22 & 0.12 & 0.16 \\
\hline
\end{tabular}


Tabla 4.2.7. Variabilidad en la densidad de fisuras entre probetas de un mismo grupo.

\begin{tabular}{|c|c|c|c|c|c|}
\hline Criterio & Densidad & CR a y b & CR c y d & $P P a y b$ & PP c y d \\
\hline \multirow{3}{*}{$A$} & Promedio $\left(\mathrm{cm} / \mathrm{cm}^{2}\right)$ & 0.67 & 0.29 & 0.24 & 0.16 \\
\hline & $\sigma\left(\mathrm{cm} / \mathrm{cm}^{2}\right)$ & 0.08 & 0.05 & 0.00 & 0.02 \\
\hline & COV (\%) & 12 & 16 & 1 & 15 \\
\hline \multirow{3}{*}{$\mathrm{B}$} & Promedio $\left(\mathrm{cm} / \mathrm{cm}^{2}\right)$ & 0.74 & 0.25 & 0.26 & 0.16 \\
\hline & $\sigma\left(\mathrm{cm} / \mathrm{cm}^{2}\right)$ & 0.07 & 0.03 & 0.01 & 0.04 \\
\hline & $\operatorname{cov}(\%)$ & 10 & 10 & 5 & 28 \\
\hline \multirow{3}{*}{$\mathrm{C}$} & Promedio $\left(\mathrm{cm} / \mathrm{cm}^{2}\right)$ & 0.80 & 0.24 & 0.31 & 0.13 \\
\hline & $\sigma\left(\mathrm{cm} / \mathrm{cm}^{2}\right)$ & 0.14 & 0.04 & 0.01 & 0.01 \\
\hline & COV (\%) & 17 & 16 & 2 & 1 \\
\hline \multirow{3}{*}{$\mathrm{D}$} & Promedio $\left(\mathrm{cm} / \mathrm{cm}^{2}\right)$ & 0.82 & 0.24 & 0.35 & 0.16 \\
\hline & $\sigma\left(\mathrm{cm} / \mathrm{cm}^{2}\right)$ & 0.07 & 0.02 & 0.02 & 0.07 \\
\hline & $\operatorname{COV}(\%)$ & 8 & 10 & 7 & 47 \\
\hline \multirow{3}{*}{$E$} & Promedio $\left(\mathrm{cm} / \mathrm{cm}^{2}\right)$ & 0.59 & 0.30 & 0.21 & 0.15 \\
\hline & $\sigma\left(\mathrm{cm} / \mathrm{cm}^{2}\right)$ & 0.10 & 0.02 & 0.02 & 0.01 \\
\hline & COV (\%) & 16 & 8 & 11 & 6 \\
\hline
\end{tabular}

Otro parámetro importante al momento de caracterizar las fisuras es su ancho, que puede adquirir una influencia determinante sobre las propiedades mecánicas y de transporte. En este caso se midió la fisura más ancha en cada cara distinguiéndose entre las fisuras producidas en las interfaces, en la matriz y también las fisuras desarrolladas en el perímetro de las probetas como se muestra en la Tabla 4.2.2. Al analizar los valores obtenidos surge claramente el mayor deterioro de las probetas de canto rodado, ya que las interfaces son más débiles, y aparecen fisuras más anchas tanto en las interfaces como en la matriz. En el caso del hormigón con piedra partida se observaron muy pocas fisuras de matriz. En todos los cortes las fisuras de interfaz poseen mayor ancho que las fisuras de matriz. También se observó que las fisuras en la superficie de las probetas eran menos anchas que las de los cortes. Se asume que la mayor parte de las fisuras es producto de las diferencias entre los coeficientes de expansión de térmica de los agregados y la pasta de cemento. En este sentido cabe observar que el coeficiente de expansión térmica del rodado silíceo es del orden de 13 micrones/metro. ${ }^{\circ} \mathrm{C}$, esto es substancialmente mayor al de la piedra partida granítica (del orden de 9 micrones/metro. ${ }^{\circ} \mathrm{C}$ ). 
Estos resultados muestran que a través de parámetros de la mesoestructura como la densidad de fisuras, es posible cuantificar el nivel de daño y diferenciar probetas de un mismo hormigón expuestas a diferente velocidad de enfriamiento como así también detectar las diferencias entre probetas de hormigones preparados con distintos tipos de agregado expuestas a un mismo ciclo de deterioro.

\subsubsection{Mesoestructura y propiedades del hormigón}

Como fuera expuesto el eje motivador de esta tesis es el conocimiento de la estrecha relación existente entre la mesoestructura y las propiedades del hormigón. Entre estas últimas se consideran no sólo las propiedades mecánicas sino también las propiedades de transporte, ya que estas últimas están asociadas con la vida en servicio de las estructuras de hormigón.

Como se consigna en la Tabla 4.2.8, se realizaron ensayos de permeabilidad al agua sobre algunas de las rodajas de los hormigones CR y PP. Conforme el grado de fisuración era posible esperar fuertes alteraciones en esta propiedad. En este caso la duración de los ensayos varió entre 1 y 4 días debido al alto grado de deterioro del material y se utilizó una presión de agua igual a $0.1 \mathrm{MPa}$. Una rápida mirada indica que la permeabilidad creció significativamente en el hormigón CR y que los mayores valores se corresponden con las mayores densidades de fisuras.

La Fig. 4.2.4 representa la relación entre los anchos máximos de fisuras y el coeficiente de permeabilidad determinados sobre varias secciones de hormigón. Por su parte en la Fig. 4.2.5 se muestra la vinculación entre la densidad de fisuras y la permeabilidad evaluadas sobre cada sección. Si bien la cantidad de determinaciones es pequeña, sólo se pretende dar a este punto el carácter de ejemplo, es posible inferir que la permeabilidad aumenta en forma considerable para anchos de fisuras mayores a $0.2 \mathrm{~mm}$, para anchos de fisuras menores el aumento de la permeabilidad se corresponde con el aumento en la densidad de fisuras. Conforme se ha indicado en el Capítulo II la existencia de valores umbrales para la permeabilidad ha sido planteada por otros autores (Wang et al, 1997, Aldea et al, 1999a y b). 
Tabla 4.2.8. Parámetros de caracterización de la mesoestructura y coeficientes de permeabilidad.

\begin{tabular}{lcccccc}
\hline \multirow{2}{*}{ Probeta } & Altura & \multicolumn{2}{c}{ Fisuras } & \multicolumn{2}{c}{ Agregados } & Coeficiente de \\
& $(\mathrm{cm})$ & $\begin{array}{c}\text { Densidad } \\
\left(\mathrm{cm} / \mathrm{cm}^{2}\right)\end{array}$ & $\begin{array}{c}\text { Ancho } \\
(\mathrm{mm})\end{array}$ & $\begin{array}{c}\text { Densidad } \\
\left(\mathrm{cm}^{2} / \mathrm{cm}^{2}\right)\end{array}$ & $\begin{array}{c}\text { Perímetro } \\
(\mathrm{cm})\end{array}$ & $\begin{array}{c}\text { permeabilidad } \\
\left(10^{-11} \mathrm{~m} / \mathrm{s}\right)\end{array}$ \\
\hline CRa-4s & 18 & 0.94 & 0.50 & 0.29 & 136 & 4000 \\
CRa-5s & 24 & 0.45 & 1.00 & 0.29 & 125 & 2000 \\
CRb-1i & 6 & 0.80 & 0.25 & 0.27 & 117 & 3800 \\
CRb-4s & 18 & 0.52 & 0.50 & 0.35 & 139 & 3700 \\
CRc-4s & 22.5 & 0.33 & 0.20 & 0.32 & 122 & 800 \\
CRd-1i & 7.5 & 0.41 & 0.05 & 0.33 & 131 & 250 \\
\hline PPa-1i & 6 & 0.21 & 0.05 & 0.22 & 117 & 180 \\
PPa-4s & 18 & 0.25 & 0.20 & 0.30 & 154 & 250 \\
PPa-5s & 24 & 0.17 & 0.05 & 0.30 & 141 & 70 \\
PPb-2s & 6 & 0.14 & 0.05 & 0.26 & 117 & 330 \\
PPb-3s & 12 & 0.34 & 0.05 & 0.32 & 148 & 600 \\
PPb-4s & 18 & 0.37 & 0.10 & 0.32 & 130 & 230 \\
PPb-5s & 24 & 0.18 & 0.05 & 0.32 & 146 & 90 \\
PPc-1i & 7.5 & 0.14 & 0.05 & 0.29 & 150 & 60 \\
PPd-4s & 22.5 & 0.18 & 0.05 & 0.23 & 120 & 200 \\
\hline
\end{tabular}

Los hormigones estudiados presentan diferencias significativas en las interfaces que inciden en el proceso de fisuración y como consecuencia en las propiedades del hormigón luego de su exposición a altas temperaturas. Por tanto también se analizó la relación entre la densidad y el perímetro de agregados con el coeficiente de permeabilidad, tal como se muestra en las Fig. 4.2.6 y 4.2.7.

En estos casos si bien no se observa una relación entre la cantidad de agregados o interfaces y la permeabilidad, es evidente que el grupo CR presenta una mayor permeabilidad que el grupo PP, lo que evidencia una mayor degradación. 


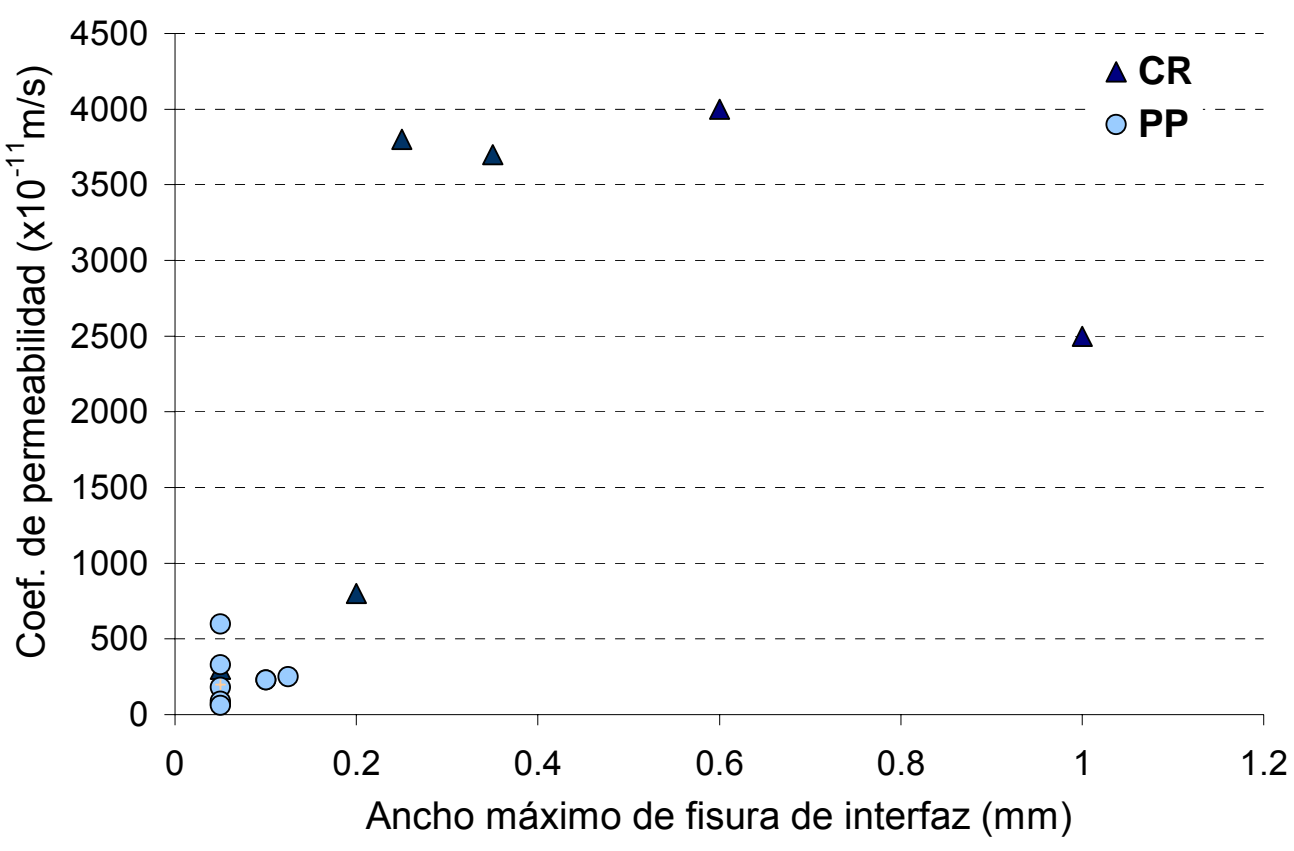

Figura 4.2.4 Relación entre ancho de fisuras y coeficiente de permeabilidad.

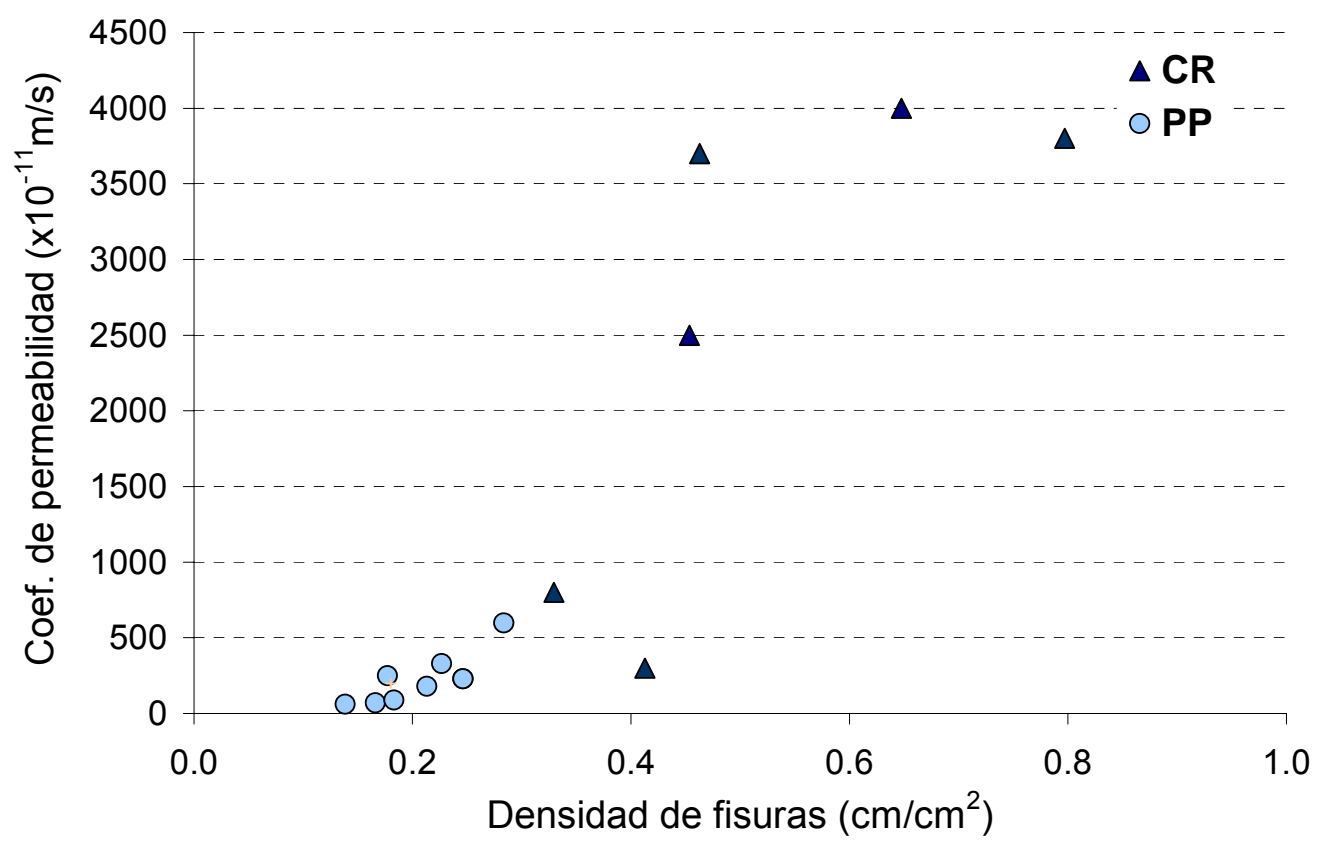

Figura 4.2.5 Relación entre densidad de fisuras y coeficiente de permeabilidad. 


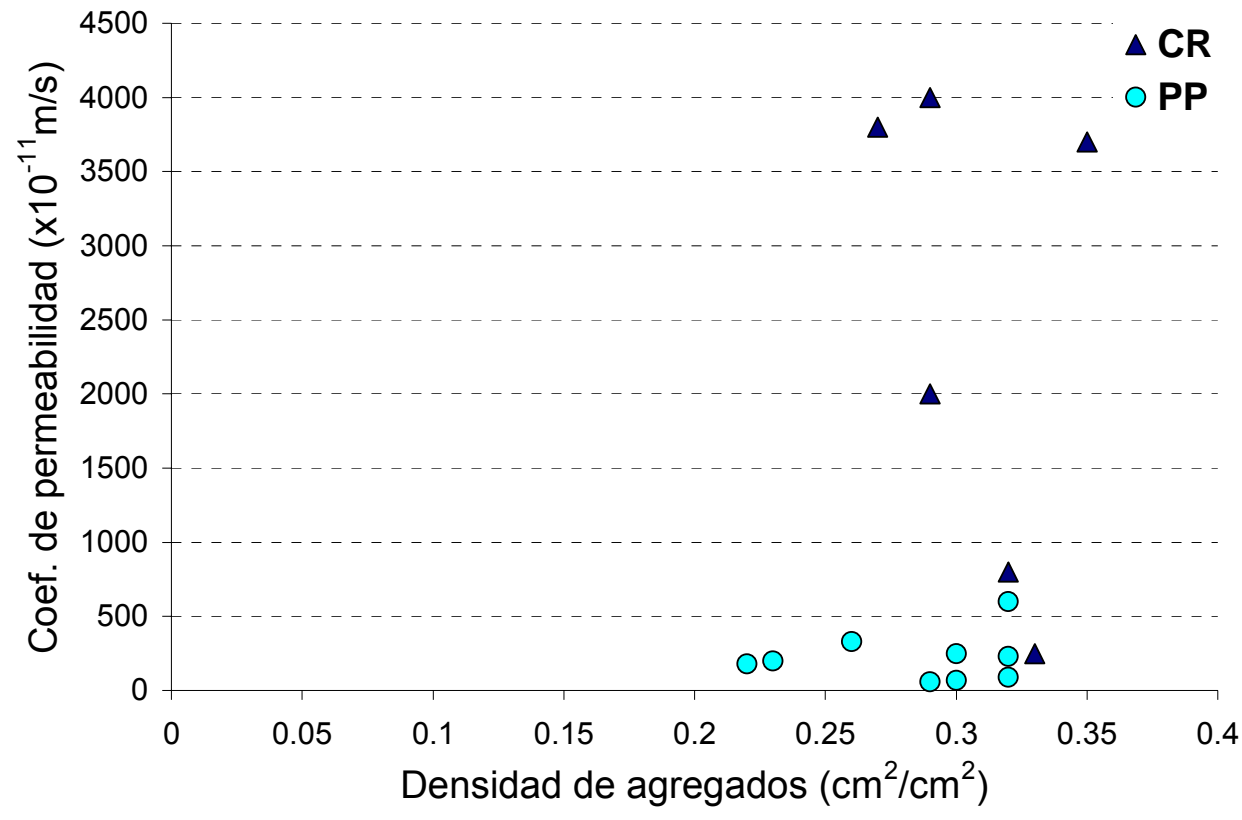

Figura 4.2.6 Relación entre densidad de agregados y coeficiente de permeabilidad.

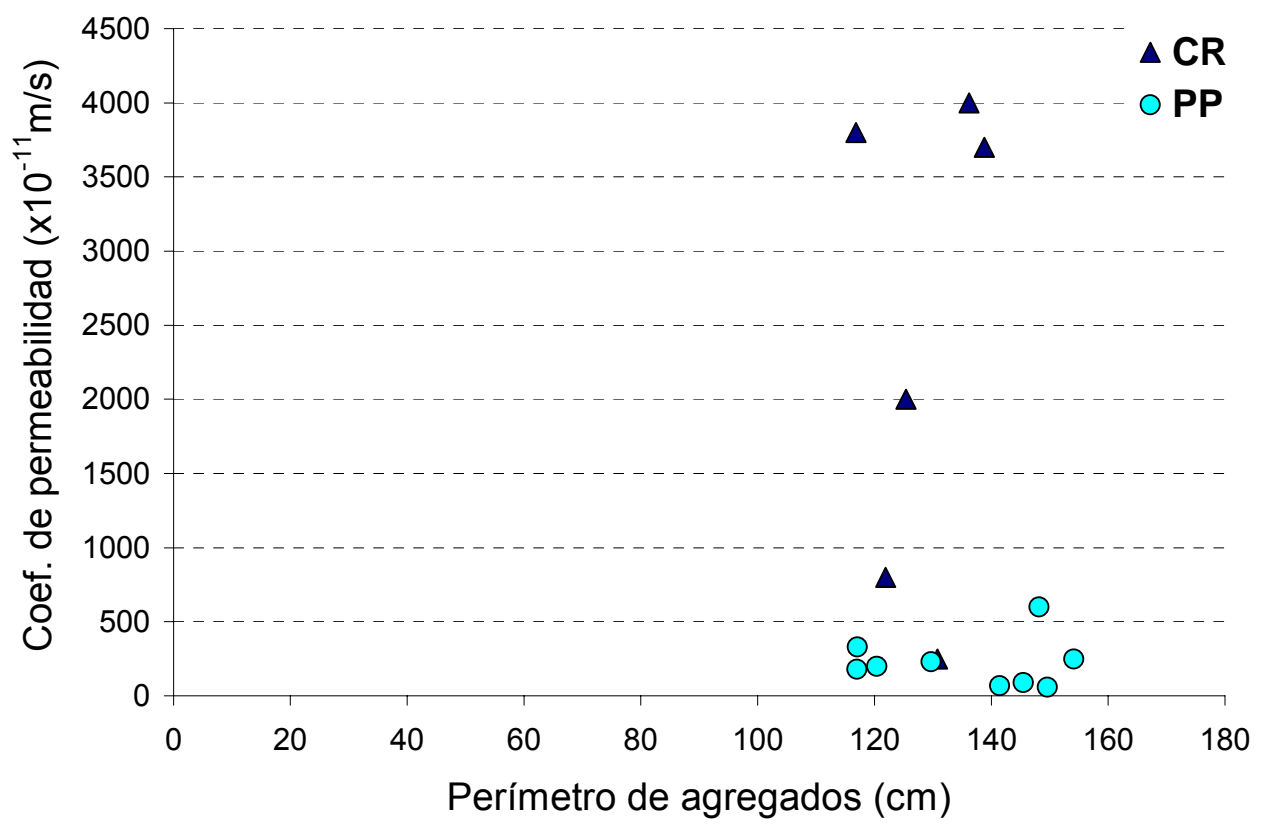

Figura 4.2.7. Relación entre perímetro de agregados y coeficiente de permeabilidad. 


\subsubsection{Conclusiones}

En este apartado se analizó la variabilidad en las determinaciones de parámetros característicos de la mesoestructura del hormigón como la distribución de agregados y la distribución y características (principalmente el ancho) de las fisuras.

En base a los datos obtenidos con el método de observación empleado se encontró que, teniendo en cuenta la variabilidad propia del material, es suficiente relevar dos cortes por probeta para obtener resultados representativos y, además, basta con relevar sólo una cara en cada uno de los cortes.

En cuanto a los parámetros a analizar se observó que es más significativo el estudio de la densidad de fisuras que el número de las mismas. En el caso de los agregados se analizó tanto la densidad de agregados de mayor tamaño como su perímetro, ya que la interfaz agregado-matriz es una zona de mayor porosidad que resulta determinante al momento de evaluar la durabilidad del hormigón.

A pesar de que la variabilidad es alta en las medidas de los parámetros de mesoestructura como la densidad de fisuras, fue posible cuantificar el nivel de daño diferenciando entre probetas de un mismo hormigón expuestas a diferente velocidad de enfriamiento o probetas de hormigones preparados con distintos tipos de agregado expuestas a un mismo ciclo de deterioro.

Finalmente se encontró que el ancho máximo de fisura constituye uno de los parámetros mesoestructurales más vinculado a las variaciones en el transporte de fluidos dentro del hormigón. Este parámetro mesoestructural podría ser aplicado para la definición de la vida útil de las estructuras. 


\subsection{MESOESTRUCTURA Y PROPIEDADES MACROSCÒPICAS EN HORMIGONES DAÑADOS POR ALTA TEMPERATURA Y POR CONTRACCIÓN POR SECADO}

En este apartado se presentan experiencias desarrolladas a fin de estudiar en hormigones sometidos a distintos procesos de daño, la influencia de la mesoestructura en la respuesta mecánica y las propiedades relacionadas con la durabilidad. Para producir distintos grados de alteración muestras de un mismo hormigón fueron expuestas a condiciones de baja humedad (secado al aire) y a temperaturas de 150 y $500^{\circ} \mathrm{C}$. En un ambiente con baja humedad se generan fisuras de pequeñas dimensiones debido a la contracción por secado. Un hormigón expuesto a una temperatura de $150^{\circ} \mathrm{C}$ se fisura debido a la pérdida del agua de los poros capilares y del gel y a diferencias en los coeficientes de expansión térmica de los agregados y la pasta, estas fisuras se generan principalmente en las interfaces. Al elevar la temperatura a $500{ }^{\circ} \mathrm{C}$ se generan fisuras más grandes que se ubican no sólo en las interfaces sino que también se extienden a través de la matriz.

\subsubsection{Materiales y mezclas}

Se seleccionó un hormigón de uso corriente en estructuras de hormigón. El mismo se elaboró en una planta hormigonera utilizando $280 \mathrm{~kg} / \mathrm{m}^{3}$ de cemento portland normal (IRAM 50000), piedra partida granítica en la fracción 6-20 mm y arena silícea de río. Con dicho hormigón se moldearon 32 cilindros de 150 × 300 mm y 9 prismas de $75 \times 105 \times 430 \mathrm{~mm}$.

\subsubsection{Detalles experimentales}

Las probetas fueron curadas en cámara húmeda durante 28 días. Luego se separaron en cinco grupos incluyendo prismas y cilindros. El primer grupo (A) fue expuesto al aire en ambiente de laboratorio $\left(22 \pm 5^{\circ} \mathrm{C}\right.$ y humedad relativa $70 \pm 20 \%$ ) durante los 3 meses siguientes de elaborado el hormigón. El segundo grupo, identificado como $\mathrm{CH}$, fue mantenido en cámara húmeda $\left(20 \pm 2^{\circ} \mathrm{C}\right.$ y humedad relativa mayor a $95 \%$ ) durante 2 años. El tercer grupo CS fue ubicado en cámara seca (20 $\pm 2{ }^{\circ} \mathrm{C}$ y $55 \pm 5 \%$ humedad relativa) también durante 2 años. El cuarto grupo (150) fue expuesto a una temperatura de $150^{\circ} \mathrm{C}$ durante 24 horas, mientras que el quinto (500) fue calentado en un horno eléctrico con control automático de temperatura y ventilación superior para el escape de gases, a razón de $100{ }^{\circ} \mathrm{C} /$ hora hasta alcanzar 
$500^{\circ} \mathrm{C}$, dicha temperatura fue mantenida durante 1 hora y luego las probetas se enfriaron lentamente dentro del horno. De ese modo se provocaron diferentes tipos de daño en los grupos CS, 150 y 500. Los grupos $\mathrm{A}$ y $\mathrm{CH}$ aparecen como referencia de hormigones sin mayores fisuras $u$ otros tipos de alteraciones.

Para evaluar los distintos niveles de degradación del material se midieron el peso y, como ensayos no destructivos, la velocidad de pulso ultrasónico y el módulo de elasticidad dinámico. Las determinaciones fueron efectuadas sobre todas las probetas al cabo de 28 días, al cabo de 3 meses de elaborado el hormigón (grupo A), también se repitieron antes y después de realizar la exposición a alta temperatura en el caso de los grupos 150 y 500 y luego de los dos años de permanencia en las cámaras húmeda y seca en los grupos $\mathrm{CH}$ y CS.

Para caracterizar la mesoestructura se realizaron observaciones sobre cortes transversales de algunos cilindros, contabilizando el ancho y longitud de fisuras y tamaño y área de agregados gruesos mayores a $5 \mathrm{~mm}$.

En forma paralela se realizó el estudio de las propiedades mecánicas de los hormigones incluyendo evaluaciones de resistencia y deformabilidad en compresión sobre otros cilindros y de la resistencia a tracción (ensayo de tracción por compresión diametral) sobre trozos de prismas.

Como propiedades de transporte se determinaron la absorción en agua durante 24 horas empleando cortes de prismas de $50 \times 75 \times 105 \mathrm{~mm}$, la absorción capilar sobre cortes similares utilizando como cara expuesta la cara de moldeo de cada prisma. También se realizaron ensayos de permeabilidad al agua utilizando los mismos cortes de cilindros de $50 \mathrm{~mm}$ de espesor previamente empleados para valorar la mesoestructura, exponiendo una superficie de $100 \mathrm{~mm}$ de diámetro de la cara de moldeo.

\subsubsection{Resultados y discusión}

En la Tabla 4.3.1 se presentan los resultados de los ensayos no destructivos realizados sobre los cilindros, a partir de los mismos se pueden inferir los diferentes niveles de alteración de las muestras. Tanto la velocidad de pulso ultrasónico (VPU) como el módulo dinámico $(E d)$ sufrieron reducciones con el aumento del daño en el 
hormigón. Se observa que las variaciones en el módulo de elasticidad dinámico, entre los hormigones afectados y el grupo A, son el doble en todos los casos que las de la velocidad de pulso ultrasónico, evidenciando la mayor sensibilidad del primer método (Di Maio et al, 2002). Las probetas que permanecieron 2 años en cámara húmeda sólo experimentaron pequeños aumentos en el peso, velocidad de pulso y módulo dinámico, del 1,5 y $14 \%$ respectivamente, los mismos se deben relacionar con la evolución de resistencia (disminución de porosidad) producto del proceso de curado.

Tabla 4.3.1. Ensayos no destructivos sobre cilindros.

\begin{tabular}{cccccc}
\hline Grupo & $\begin{array}{c}\text { Pérdida de } \\
\text { peso (\%) }\end{array}$ & $\begin{array}{c}\text { VPU } \\
(\mathbf{k m} / \mathbf{s})\end{array}$ & $\begin{array}{c}\text { Variación de la } \\
\text { VPU (\%) }\end{array}$ & $\begin{array}{c}\text { Ed } \\
(\mathbf{G P a})\end{array}$ & $\begin{array}{c}\text { Variación del Ed } \\
\mathbf{( \% )}\end{array}$ \\
\hline $28 \mathrm{~d}$ & - & 4.32 & - & 33.2 & - \\
$\mathrm{A}$ & -3 & 4.30 & 0 & 33.4 & 1 \\
$\mathrm{CH}$ & 1 & 4.55 & 5 & 37.8 & 14 \\
$\mathrm{CS}$ & -4 & 4.09 & -5 & 28.4 & -14 \\
150 & -5 & 3.69 & -15 & 23.5 & -29 \\
500 & -6 & 3.00 & -31 & 12.7 & -62 \\
\hline
\end{tabular}

En la Tabla 4.3.2 se muestra, para cada grupo, un ejemplo del cuadro de fisuración relevado sobre los cortes transversales de las probetas preparadas para el ensayo de permeabilidad, junto con una fotografía donde es posible apreciar el nivel de deterioro de la matriz y la interfaz. En las fotografías se pueden observar las diferencias que presentan los cinco grupos principalmente en las interfaces matrizagregado, se ve que los grupos 150 y 500 poseen fisuras bien definidas en la interfaz, además en el grupo 500 la matriz se encuentra deteriorada. Es muy interesante destacar que el grupo CS, aunque no fue sometido a altas temperaturas, posee las interfaces degradadas pero no se observan fisuras claramente definidas. El grupo CS representa una condición típica de hormigones sometidos a ambientes secos, sin que esto implique condiciones extremas (contracción por secado). Finalmente cabe notar que se aprecian algunas fisuras de menor tamaño en el grupo A y algunas interfaces discontinuas en el caso del $\mathrm{CH}$, estos defectos pueden haberse originado durante el proceso de aserrado de los cilindros. 
Tabla 4.3.2. Detalle de fotografías de los cortes analizados y cuadro de fisuración.

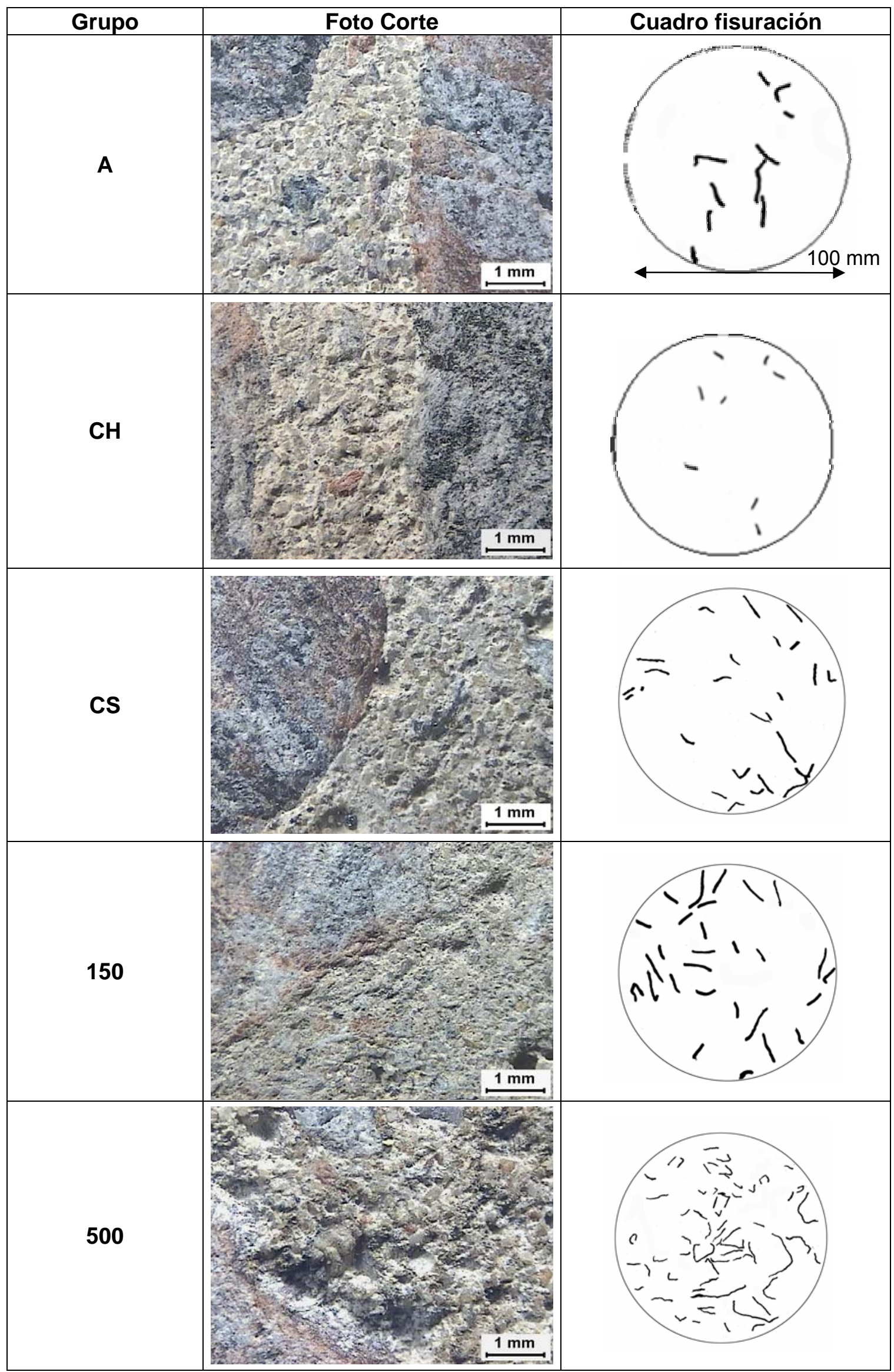


En la Tabla 4.3.3 se presentan los resultados que surgen del análisis realizado sobre los cortes: se incluyen el promedio de la densidad de fisuras ( $\mathrm{cm}$ de fisura por unidad de área observada) en función de la longitud de fisura y ancho máximo de fisura. Se observa que el ancho de fisura aumenta considerablemente en el grupo 500 junto con la densidad de fisuras mayores a $10 \mathrm{~mm}$ de longitud. El grupo A y el grupo CS presentan un esquema de fisuración similar. Cabe aclarar que se informan en los grupos $A$, CS y 150 un ancho máximo de fisuras menor a $0.05 \mathrm{~mm}$ porque es el menor ancho que puede ser apreciado con la lupa utilizada, en consecuencia no significa que los tres grupos posean anchos de fisura similares.

Tabla 4.3.3. Cuadro de fisuración.

\begin{tabular}{cccccc}
\hline Grupo & \multicolumn{3}{c}{ Densidad de fisuras $\left(\mathbf{c m} / \mathbf{c m}^{2}\right)$} & & $\begin{array}{c}\text { Ancho de } \\
\text { fisuras }(\mathbf{m m})\end{array}$ \\
\hline $\mathrm{A}$ & 0.06 & 0.11 & 0.04 & 0.21 & $<0.05$ \\
$\mathrm{CH}$ & 0.03 & 0.09 & 0.03 & 0.15 & $\begin{array}{c}\text { Interfaces } \\
\text { discontinuas }\end{array}$ \\
$\mathrm{CS}$ & 0.08 & 0.11 & 0.04 & 0.23 & $<0.05$ \\
150 & 0.11 & 0.18 & 0.04 & 0.33 & $<0.05$ \\
500 & 0.22 & 0.04 & 0.17 & 0.43 & 0.14 \\
\hline
\end{tabular}

En la Tabla 4.3.4 se resumen los resultados de los ensayos realizados para evaluar las propiedades de transporte. Las medidas de absorción en agua durante 24 horas no revelan diferencias apreciables entre los hormigones, de acuerdo con De Schutter y Audenaert (2004) el ensayo de absorción no brinda un parámetro fiable para la estimación de la durabilidad del hormigón ya que sólo da una idea del volumen de poros permeables en contacto con el exterior, y es poco representativo de la permeabilidad.

En cuanto a la absorción capilar los resultados indican que el ensayo no es efectivo para evaluar un hormigón que posee defectos de gran tamaño como los provocados por la exposición a la temperatura de $500{ }^{\circ} \mathrm{C}$. Cabe recordar que la absorción de agua por capilaridad es inversamente proporcional al radio de poros, cuanto menor es el radio mayores son las fuerzas ejercidas sobre el agua (Assié et al, 2007). Obsérvese que en el caso del grupo 500, a pesar de haberse verificado un grado de fisuración importante, el valor de la velocidad de absorción capilar es del 
mismo orden que la del grupo A $\left(9 \mathrm{~g} / \mathrm{m}^{2} / \mathrm{s}^{1 / 2}\right)$ y la capacidad de absorción capilar es aún menor.

En cambio los resultados del ensayo de permeabilidad muestran claramente la influencia del nivel de deterioro. El grupo más dañado (500) posee el coeficiente de permeabilidad más alto con un valor igual a $120 \times 10^{-11} \mathrm{~m} / \mathrm{s}$.

Al comparar los diversos ensayos que valoran propiedades de transporte entre los grupos CS y 150, se observa que aunque presentan velocidades y capacidades de absorción capilar similares, 19.1 y $17.9 \mathrm{~g} / \mathrm{m}^{2} / \mathrm{s}^{1 / 2}$ y 7990 y $8610 \mathrm{~g} / \mathrm{m}^{2}$ respectivamente, el coeficiente de permeabilidad del grupo 150 es más del doble que el correspondiente al grupo CS. Esto se puede relacionar con una mayor densidad de fisuras en el grupo afectado por temperatura. A la vez es probable que la absorción capilar esté más relacionada con el ancho de fisuras que es similar entre los grupos CS y 150.

Tabla 4.3.4. Densidad y propiedades de transporte.

\begin{tabular}{|c|c|c|c|c|c|}
\hline \multirow{2}{*}{ Grupo } & \multirow{2}{*}{ Densidad } & \multirow{2}{*}{$\begin{array}{c}\text { Absorción } \\
(\%)\end{array}$} & \multicolumn{2}{|c|}{ Absorción Capilar } & \multirow{2}{*}{$\begin{array}{c}\text { Coeficiente } \\
\text { permeabilidad } \\
\left(10^{-11} \mathrm{~m} / \mathrm{s}\right)\end{array}$} \\
\hline & & & $\begin{array}{l}\text { Velocidad } \\
\left(\mathrm{g} / \mathrm{m}^{2} / \mathrm{s}^{1 / 2}\right)\end{array}$ & $\begin{array}{c}\text { Capacidad } \\
\left(\mathrm{g} / \mathrm{m}^{2}\right)\end{array}$ & \\
\hline$A$ & 2.36 & 5.5 & 8.8 & 6020 & 2.2 \\
\hline $\mathrm{CH}$ & 2.36 & 5.4 & 4.4 & 2640 & Nota \\
\hline CS & 2.36 & 5.4 & 19.1 & 7990 & 15 \\
\hline 150 & 2.36 & 5.5 & 17.9 & 8610 & 35 \\
\hline 500 & 2.37 & 5.2 & 9.0 & 5120 & 120 \\
\hline
\end{tabular}

Nota: durante 6 días este grupo fue sometido a presión de agua (hasta $0.3 \mathrm{MPa}$ ) $\sin$ que se registrara pasaje de agua.

En la Fig. 4.3.1 se representa la variación del coeficiente de permeabilidad a lo largo del tiempo, se observa que en los hormigones deteriorados existe un alto coeficiente al inicio del ensayo y luego el flujo de agua va disminuyendo en forma gradual. Las mediciones sobre el grupo de probetas más dañadas (500) fueron realizadas durante un intervalo de tiempo relativamente breve (50 horas); debido al alto coeficiente de permeabilidad que presentaban estas probetas el ensayo debía ser detenido constantemente para recargar el equipo con agua. 

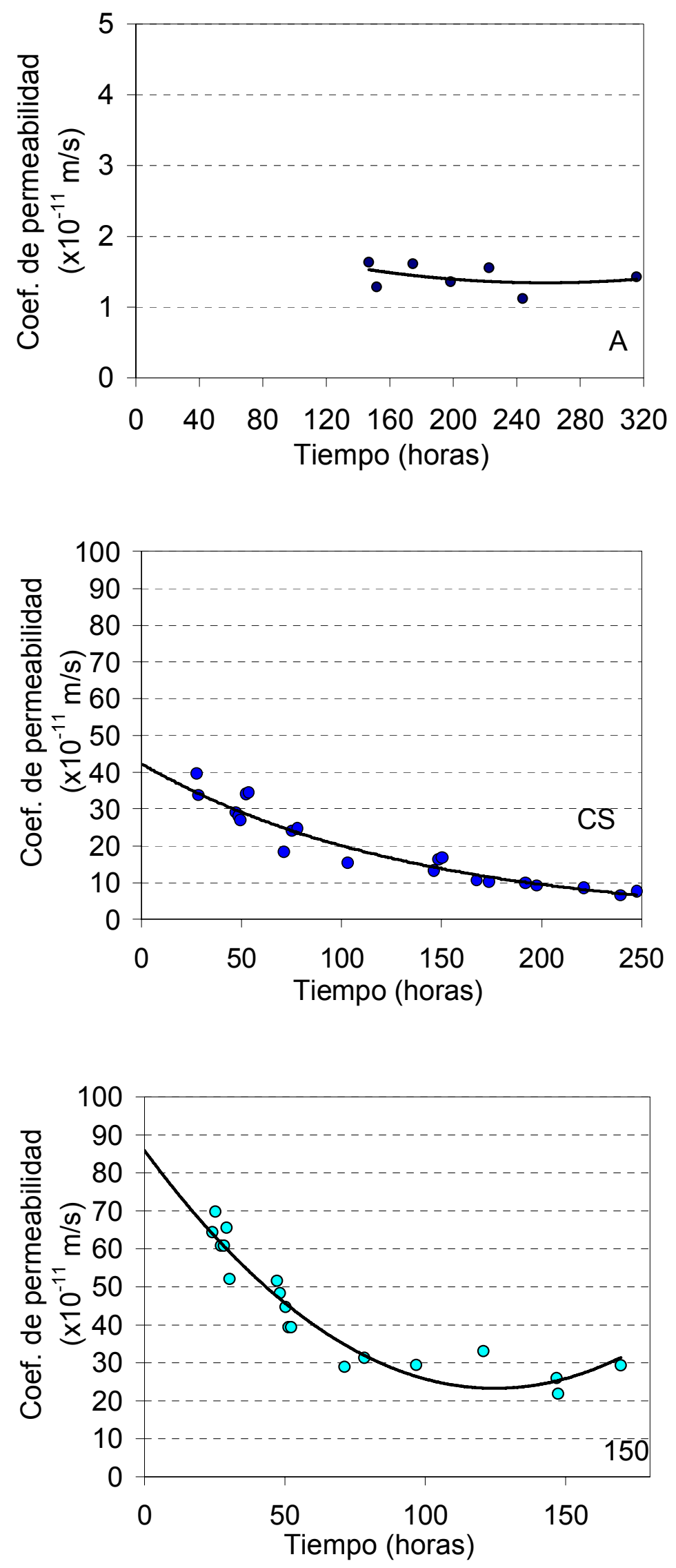


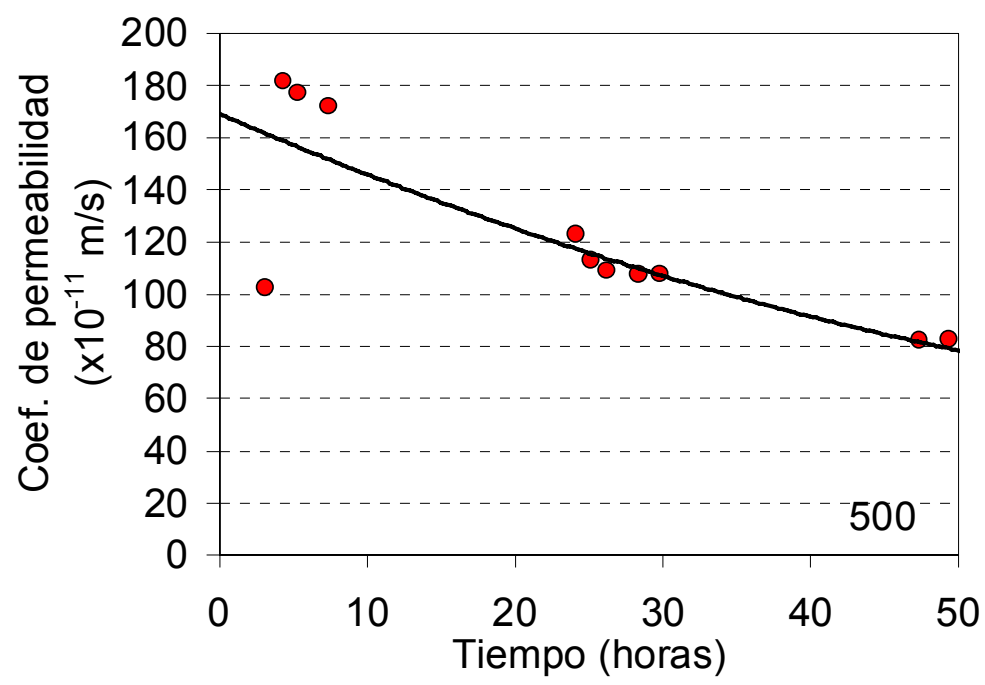

Figura 4.3.1. Variación de la permeabilidad en el tiempo.

En la Fig. 4.3.2 se puede apreciar la influencia de la densidad de fisuras en el coeficiente de permeabilidad, cada valor corresponde a los promedios obtenidos en cada grupo. Se realizó la distinción entre el total de fisuras y las fisuras mayores a $10 \mathrm{~mm}$ de longitud, ya que la permeabilidad aumenta cuanto más interconectados se encuentran los defectos. En ambos casos existe una buena correlación. El valor más alto del coeficiente se corresponde con el grupo 500.

En la Fig. 4.3.3 se muestra la variación de la absorción capilar con la densidad de fisuras. Se observa que la absorción capilar crece con la densidad de fisuras hasta llegar a un máximo para densidades de fisura entre 0.23 y $0.33 \mathrm{~cm} / \mathrm{cm}^{2}$ que se corresponden con anchos de fisura menores a $0.05 \mathrm{~mm}$ (Tabla 4.3 .3 grupos CS y 150), luego la velocidad y la capacidad de absorción capilar decrecen, a pesar que la densidad es mayor (igual a $0.43 \mathrm{~cm} / \mathrm{cm}^{2}$ ), este punto corresponde al grupo 500 cuyo ancho máximo de fisura es igual a $0.14 \mathrm{~mm}$. 


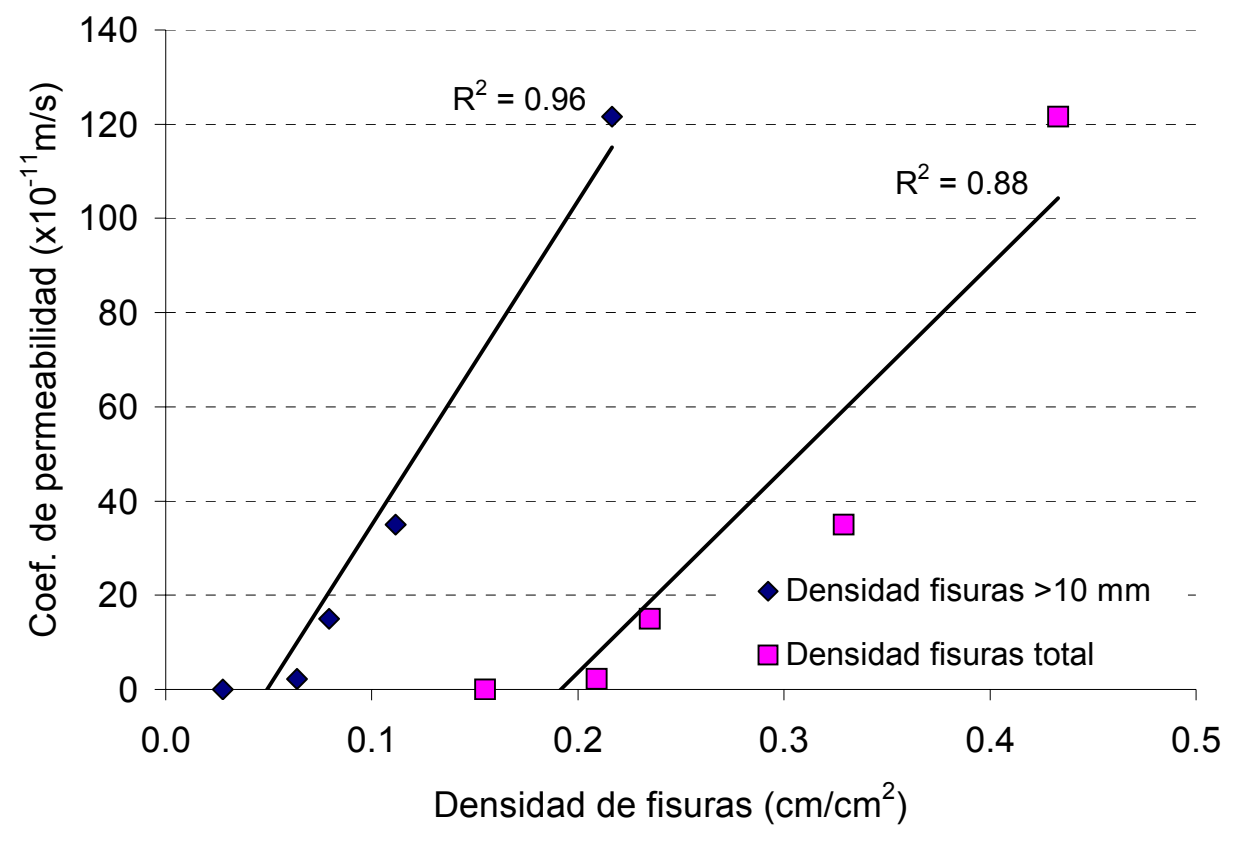

Figura 4.3.2. Variación del coeficiente de permeabilidad con la densidad de fisuras mayores a $10 \mathrm{~mm}$ y la densidad total de fisuras.

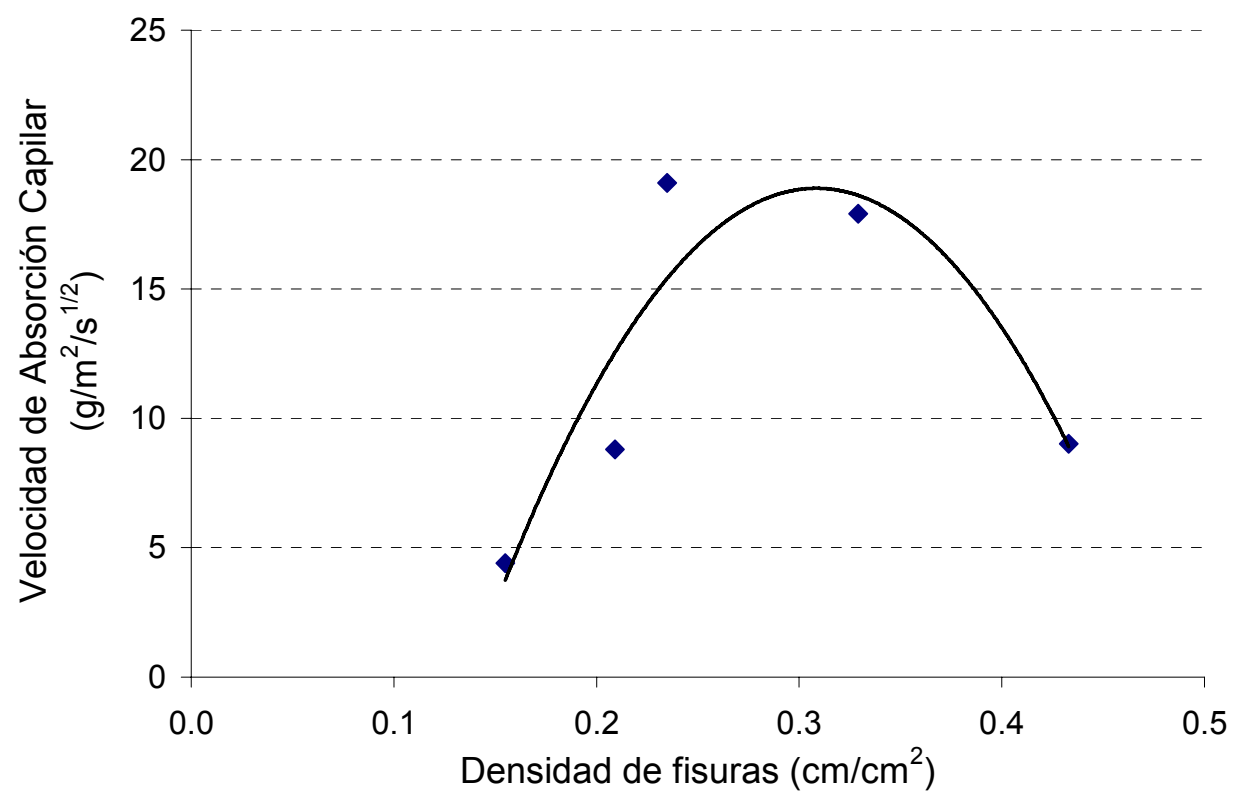

Figura 4.3.3. Variación de la velocidad de absorción capilar con la densidad de fisuras. 


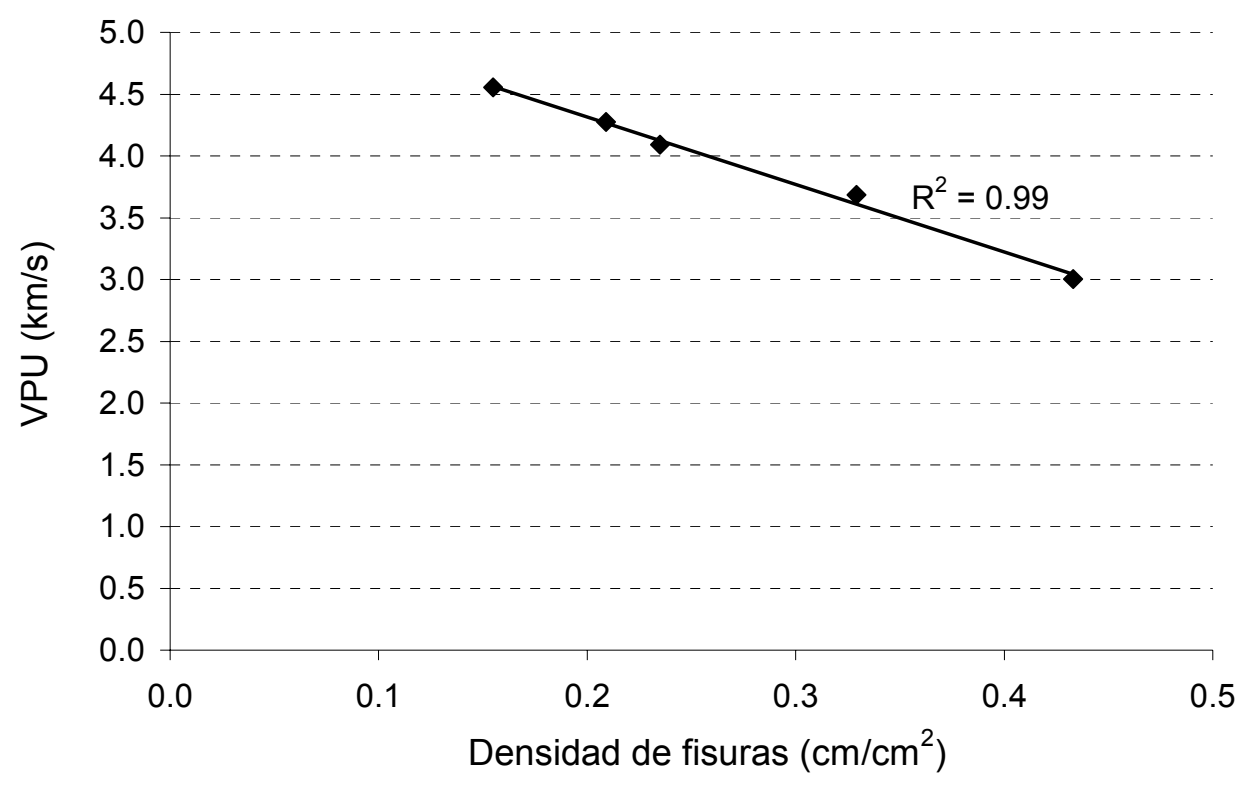

Figura 4.3.4. Variación de la velocidad de pulso ultrasónico con la densidad total de fisuras.

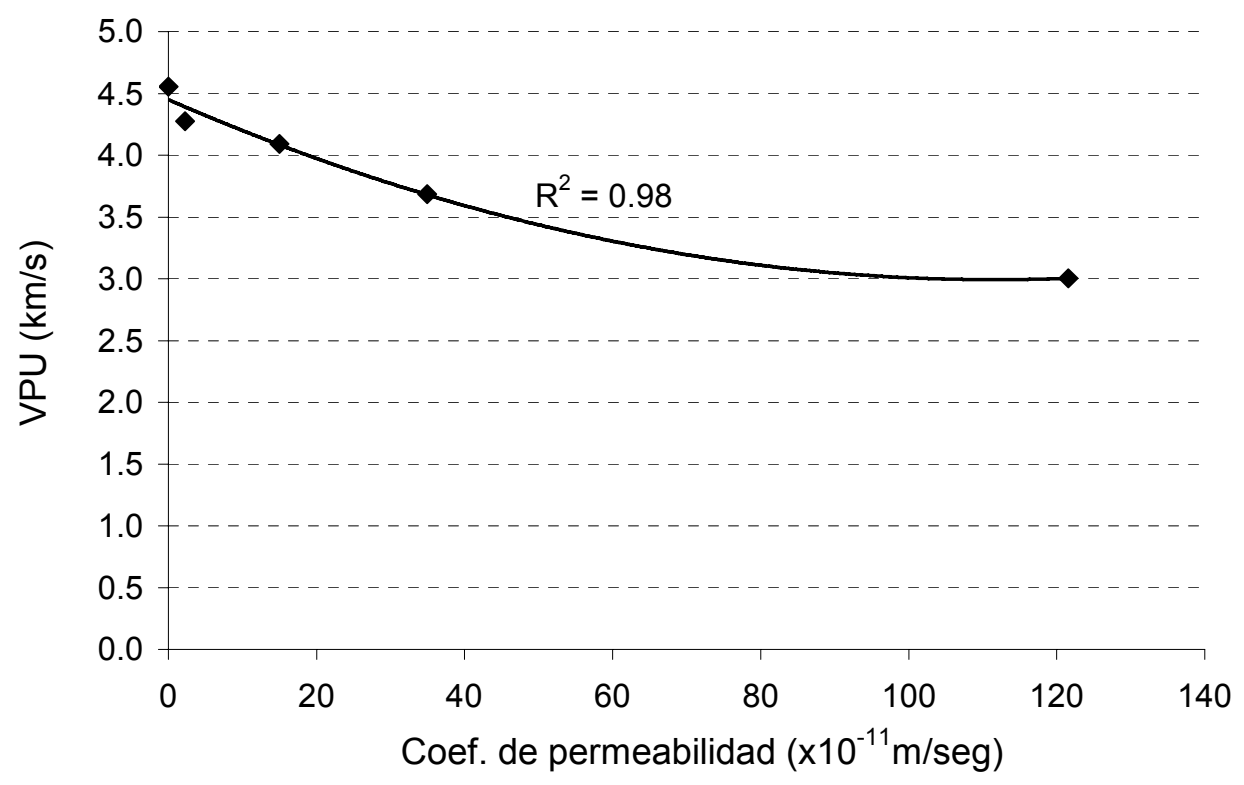

Figura 4.3.5. Variación de la velocidad de pulso ultrasónico con el coeficiente permeabilidad.

En lo referente a los propiedades físicas y mecánicas en las Fig. 4.3.4 y 4.3.5 se representan respectivamente la variación de la velocidad de pulso ultrasónico (VPU) y la densidad de fisuras y la VPU con la permeabilidad. Los valores experimentales muestran una buena correlación entre las determinaciones, con un 
decrecimiento de la VPU que se puede asociar a la magnitud de los defectos en la estructura del hormigón. En trabajos anteriores se ha demostrado cómo este método no destructivo constituye una herramienta de interés para diferenciar zonas alteradas en general y en particular en aquellas dañadas por exposición a altas temperaturas (Di Maio et al, 1999, Di Maio et al, 2002). Las variaciones en la VPU entre los grupos CS y 150 y entre los grupos 150 y 500 fueron iguales a un 10 y un $20 \%$ respectivamente, la densidad por su parte, varió un 40 y un $30 \%$ entre grupos y la permeabilidad un 133 y un $240 \%$. A pesar que tanto la VPU como la permeabilidad variaron en mayor proporción entre los grupos 150 y 500 que entre los grupos CS y 150 sucedió lo contrario con la densidad de fisuras, en este caso lo que aumentó en mayor proporción y afectó en forma significativa las propiedades de transporte fue el ancho máximo de fisuras.

En la Tabla 4.3.5 se presentan los resultados de los ensayos de compresión y tracción por compresión diametral. A partir de las medidas de deformaciones durante el ensayo de compresión se obtuvieron la resistencia a compresión, el módulo de elasticidad y el coeficiente de Poisson y la tensión crítica, que corresponde al inicio de la fisuración inestable a lo largo de la matriz. El ensayo de tracción indirecta se realizó sobre prismas y se obtuvo como resultado la resistencia a tracción (fcd).

Tabla 4.3.5. Respuesta mecánica.

\begin{tabular}{ccccccc}
\hline Grupo & f'c (MPa) $^{\prime}$ & fcrít (MPa) & fcrít (\%f'c) & E (GPa) & $\mu$ & fcd (MPa) \\
\hline A & 21.8 & 20.7 & 94.9 & 25.2 & 0.17 & 2.7 \\
CH & 22.6 & 21.9 & 96.9 & 28.0 & 0.16 & 3.4 \\
CS & 21.2 & 20.1 & 94.8 & 25.2 & 0.13 & 2.8 \\
150 & 19.5 & 18.3 & 93.8 & 23.1 & 0.16 & 3.0 \\
500 & 18 & 16 & 88.8 & 13.9 & 0.11 & 2.1 \\
\hline
\end{tabular}

De los ensayos mecánicos surge un mayor aumento de la deformabilidad del material con respecto a la resistencia a compresión en el grupo 500 , producto del importante cuadro de fisuración que se desarrolló principalmente en las interfaces. En este grupo la resistencia a compresión sólo disminuye un $17 \%$ con respecto al control mientras que el módulo de elasticidad experimenta una pérdida de casi un $45 \%$. En el grupo 150 la resistencia a compresión disminuyó un 10 y el módulo de elasticidad sólo un $8 \%$. El grupo CS se comporta en forma similar al grupo A, con una pequeña disminución en la resistencia presentando valores levemente menores en comparación con el grupo que permaneció dos años en cámara húmeda, lo que se atribuye a la 
degradación de las interfaces. Los ensayos mecánicos también verifican que la fisuración interna afecta con mayor intensidad el comportamiento en tracción que en compresión (Barragán et al, 2001), esto surge con claridad si se consideran los valores relativos al grupo $\mathrm{CH}$, en especial en el grupo más dañado.

En la Fig. 4.3.6-a se representan para cada grupo curvas típicas tensióndeformación obtenidas en ensayos de compresión. Las curvas manifiestan aspectos del mecanismo de falla relacionados con la presencia de fisuras y otros tipos de alteraciones en la estructura del material. En el grupo más dañado (500) se observa no sólo una disminución en la resistencia sino también una mayor deformabilidad y una disminución de la tensión crítica (mínimo de deformaciones en la curva volumétrica, ver Tabla 4.3.5), debido a la fisuración producida durante el calentamiento y el enfriamiento. Por el contrario el grupo 150 se comporta en forma similar a los restantes grupos. En la Fig. 4.3.6-b se muestran para cada grupo, ampliando la escala en el eje de abscisas, una curva tensión-deformación longitudinal incluyendo los ciclos de carga y descarga. Se observa que el hormigón más dañado presenta un comportamiento no lineal y existe una deformación residual del orden de $300 \mu \mathrm{m} / \mathrm{m}$ luego del primer ciclo, lo que evidencia el grado de fisuración previo que posee el hormigón. El grupo 150 también presenta deformaciones residuales luego del primer ciclo pero de menor magnitud. Los grupos $\mathrm{CH}$ y $\mathrm{CS}$ muestran un comportamiento similar, el daño producido por la contracción por secado fue poco significativo en relación con los parámetros resistentes y en la escala utilizada tampoco se observan diferencias entre el primer ciclo de cargas y los subsiguientes.

Cabe notar que otras propiedades como la absorción capilar o la permeabilidad experimentaron fuertes modificaciones en el grupo 150 respecto a los hormigones menos dañados. Como ya fuera desarrollado en el Capítulo II varios ejemplos indican que existen procesos de microfisuración que no afectan la resistencia pero resultan definitorios al momento de ponderar la durabilidad del hormigón (Barragán et al, 2000), tal es el caso de las propiedades de transporte. 

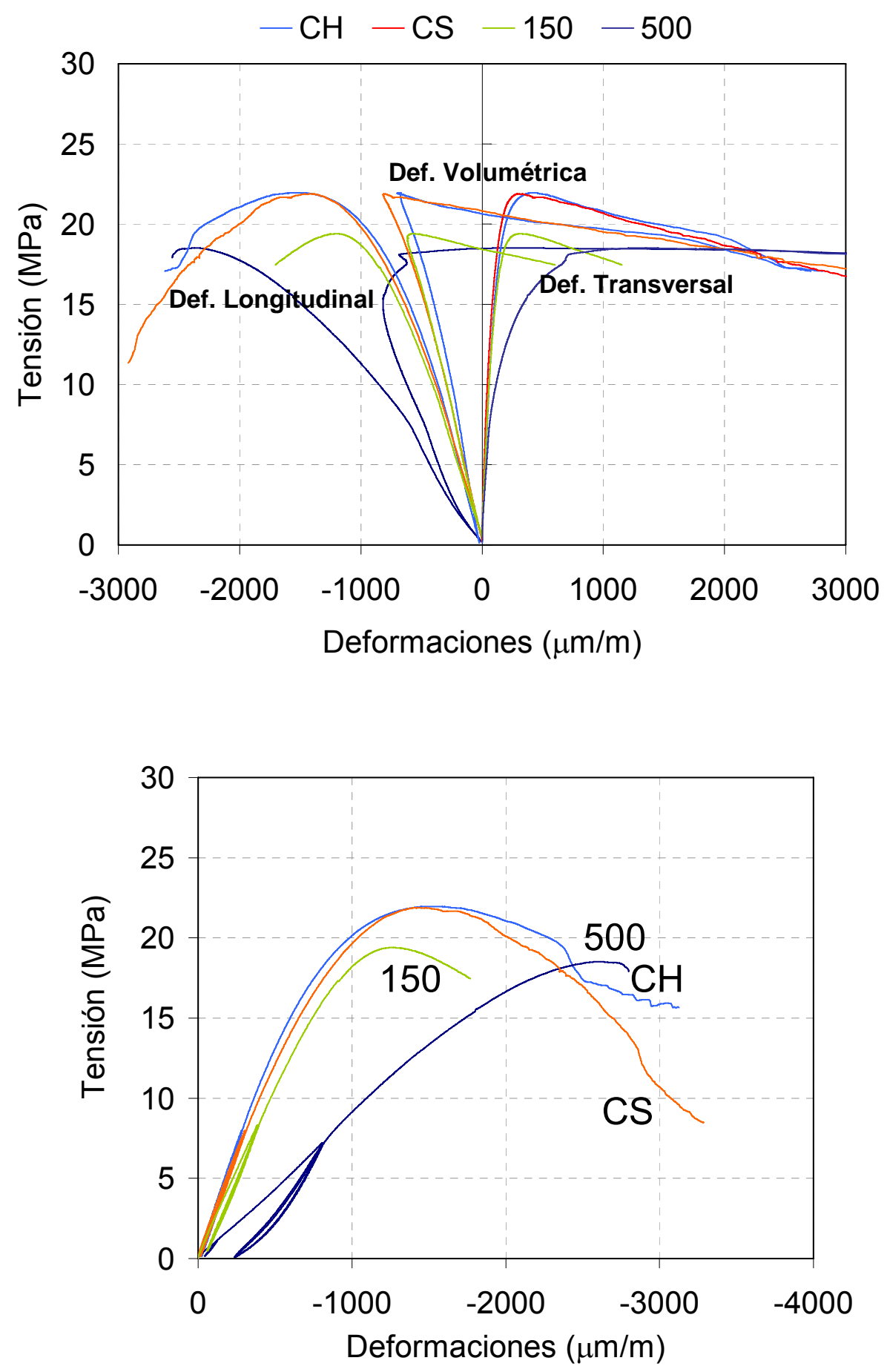

Figura 4.3.6. a- Curvas Tensión-Deformación específica longitudinal, transversal y volumétrica para cada grupo.

b- Curvas Tensión-Deformación específica longitudinal. 


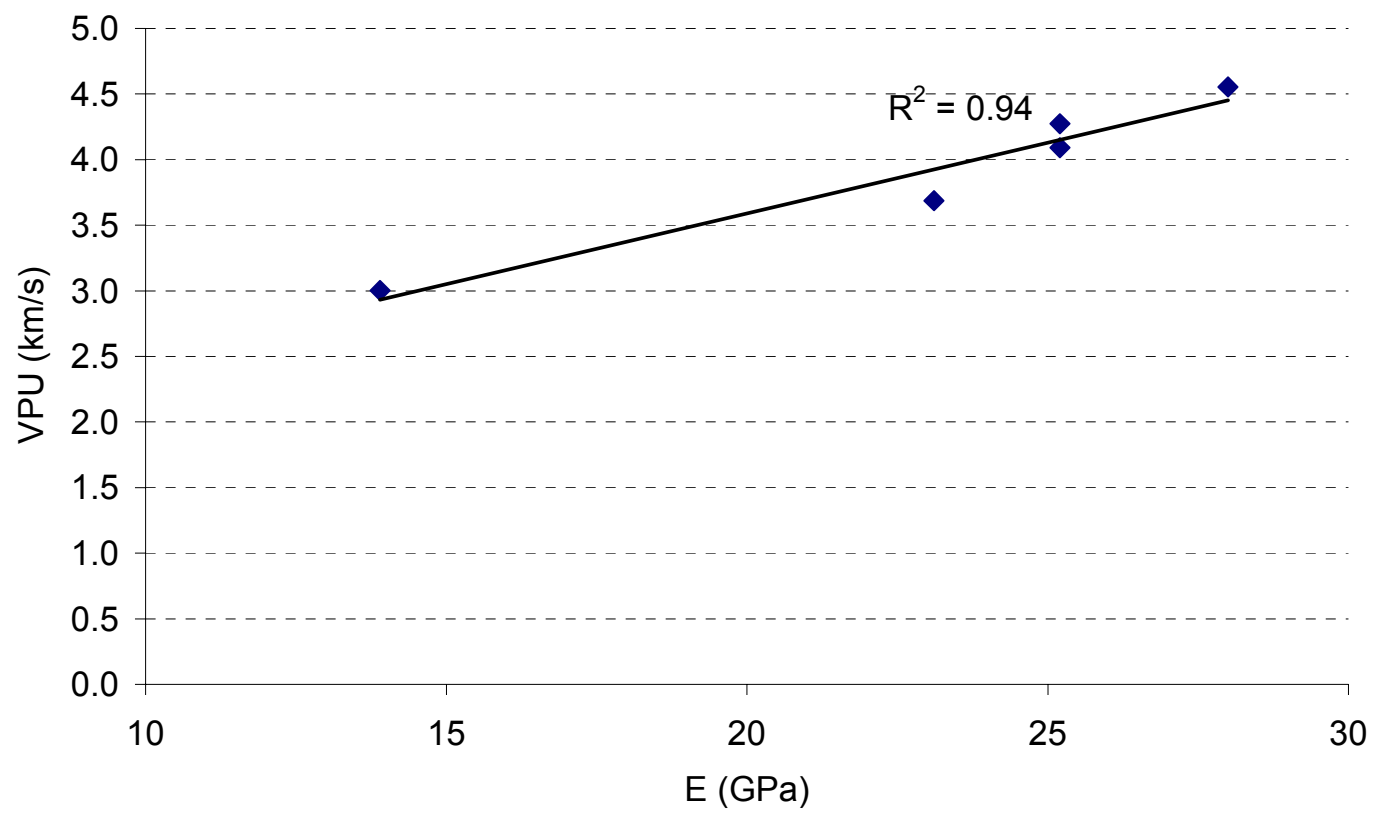

Figura 4.3.7. Variación de la VPU con el módulo de elasticidad.

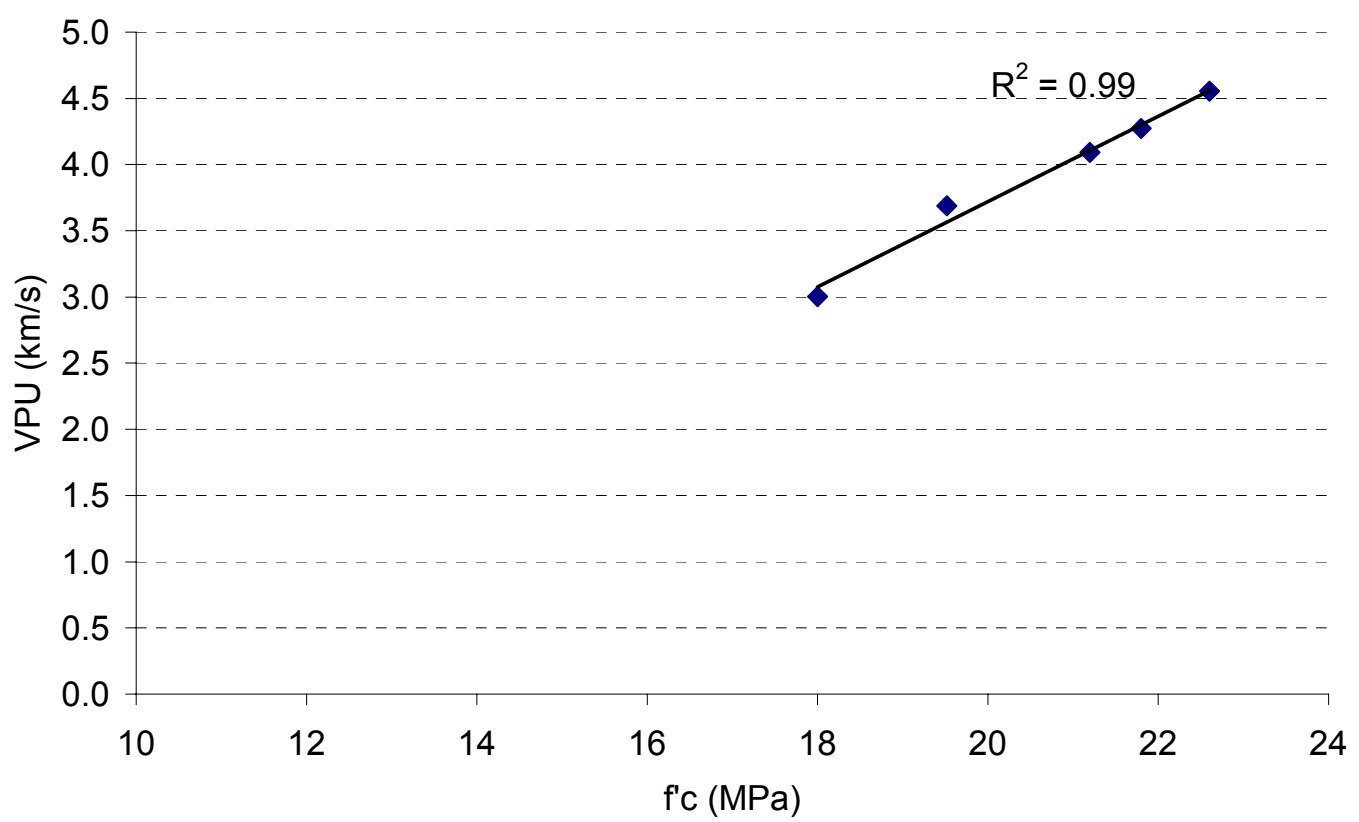

Figura 4.3.8. Variación de la VPU con la resistencia a compresión.

En la Fig. 4.3.7 se observa la relación entre la velocidad de pulso ultrasónico y el módulo de elasticidad. Esto es consistente con lo expresado en párrafos anteriores respecto a que este método no destructivo es un buen indicador del grado de deterioro del material. Por su parte en la Fig. 4.3.8 se representan los valores de VPU con respecto a la resistencia a compresión. Si bien los cinco puntos parecen seguir una 
misma tendencia, ésta se aparta de las curvas de variación velocidad-resistencia correspondientes a hormigones sin afectar preparados con los mismos materiales, estas curvas poseen mayores pendientes, es decir las variaciones en la resistencia son significativamente menores que en la VPU. Las diferencias se deben a la suma de los cambios de humedad y fundamentalmente a los grandes defectos, en especial en el grupo 500. Como ya fue comentado las variaciones de la VPU entre los grupos CS y 150 y 150 y 500 fueron iguales al 10 y $20 \%$, el módulo de elasticidad varió el 10 y $40 \%$ respectivamente, en cambio la resistencia a compresión varió sólo el $10 \%$ en ambos casos. Se observa que tanto el módulo de elasticidad como la VPU son más sensibles al deterioro sufrido por el hormigón que la resistencia a compresión.

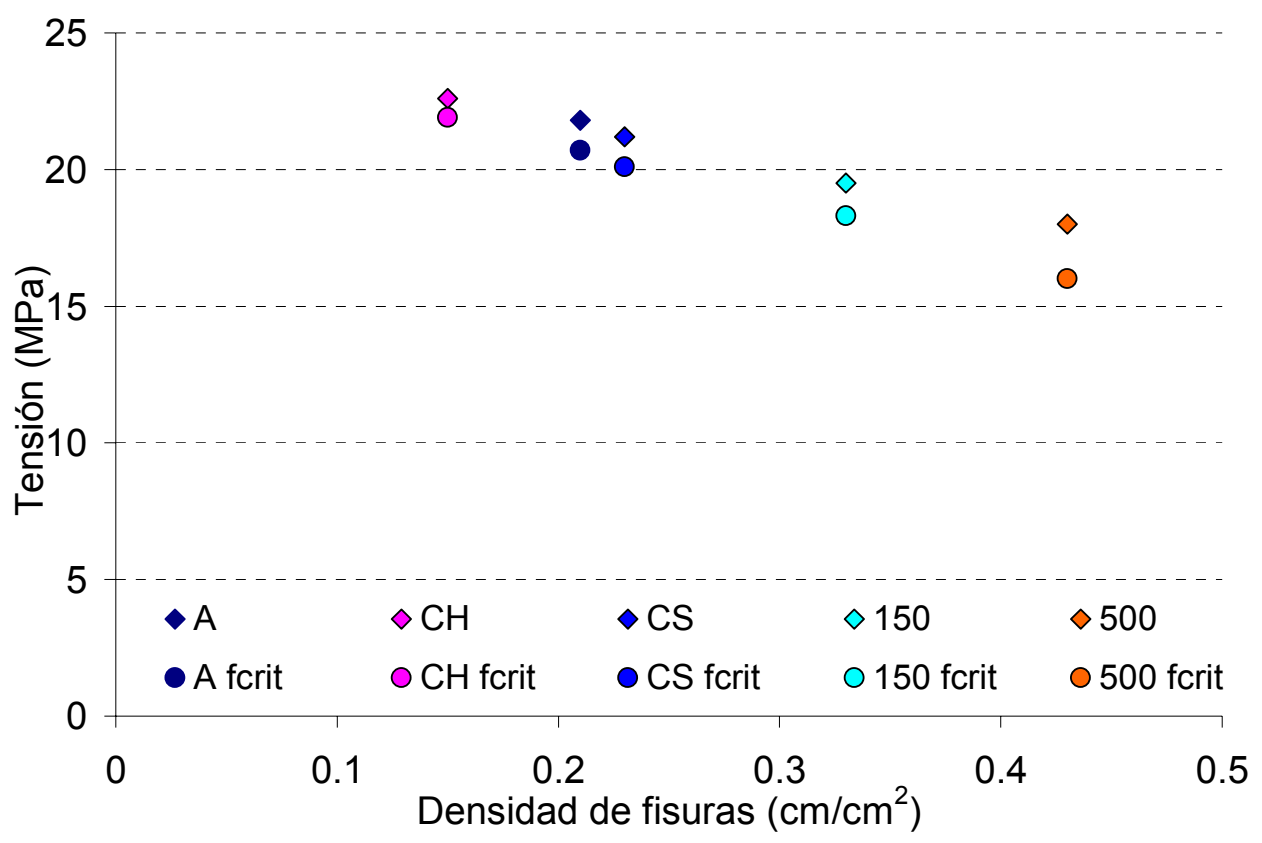

Figura 4.3.9. Tensiones Máxima y Crítica en función de la densidad de fisuras.

En la Fig. 4.3.9 se muestra la variación de la resistencia y de la tensión crítica en función de la densidad de fisuras determinada sobre cada grupo. Se verifica que a medida que aumenta el daño aumenta la diferencia entre tensión crítica y tensión máxima en valor absoluto. Si se toman en términos relativos las diferencias son aún mayores. La tensión crítica está asociada con el inicio de la propagación inestable de fisuras. En el grupo 500, la relación entre tensión crítica y resistencia es igual a 1.13. Se observa que a pesar que el grupo CS y el A se comportan en forma similar al $\mathrm{CH}$ el crecimiento inestable de fisuras comienza antes. Los grupos A y CS presentan una relación entre tensión crítica y resistencia igual a 1.05 mientras que en el $\mathrm{CH}$ es igual a 1.03. 


\subsubsection{Conclusiones}

En este apartado se analizó un hormigón estructural de uso corriente sobre el que se generaron diferentes niveles de deterioro mediante la exposición a altas temperaturas $\left(150\right.$ y $\left.500^{\circ} \mathrm{C}\right)$ y bajas condiciones de humedad $(55 \pm 5 \%$ de HR).

Se encontraron diferentes tamaños y densidades de fisuras conforme el tipo de exposición. La mayor densidad de fisuras se encontró en el grupo expuesto a $500{ }^{\circ} \mathrm{C}$, con fisuras principalmente en la interfaz y en menor medida en la matriz. El grupo expuesto a $150{ }^{\circ} \mathrm{C}$ también presentó fisuras en la interfaz aunque de menor tamaño. En el grupo CS donde las probetas fueron mantenidas dos años en cámara seca, se encontraron pequeñas fisuras en las interfaces. También se observaron en menor medida las interfaces degradadas en el grupo A ensayado luego de 3 meses en ambiente de laboratorio y en el $\mathrm{CH}$ conformado por muestras mantenidas dos años en cámara húmeda.

Se verificó que la pérdida de calidad del material es función del grado de daño existente. El desarrollo del daño interno quedó evidenciado a través de los resultados de ensayos no destructivos como la velocidad de pulso ultrasónico y la frecuencia de resonancia. Los ensayos mecánicos confirmaron que la fisuración interna puede provocar efectos diferenciales entre la deformabilidad y los parámetros resistentes.

Se observó que cuando el hormigón se encuentra deteriorado crece en gran medida la variabilidad de los resultados de los ensayos que valoran las propiedades de transporte. En el ensayo de absorción capilar la velocidad y capacidad de succión capilar fueron máximas para densidades de fisuras entre 0.23 y $0.33 \mathrm{~cm} / \mathrm{cm}^{2}$ y anchos menores a $0.05 \mathrm{~mm}$, en cambio resultaron menores para una densidad de fisuras de $0.43 \mathrm{~cm} / \mathrm{cm}^{2}$ y $0.14 \mathrm{~mm}$ de ancho. Por el contrario el ensayo de permeabilidad mostró una relación directa con el nivel de daño, el coeficiente de permeabilidad creció significativamente a medida que se incrementó la densidad y ancho de fisuras.

Una de las conclusiones salientes de este apartado es que se han encontrado marcadas diferencias entre propiedades mecánicas y de transporte. Existen procesos de fisuración que tienen poca incidencia sobre la resistencia pero sí son importantes al momento de ponderar la durabilidad del hormigón, como por ejemplo el desarrollado por la contracción por secado. 


\subsection{MESOESTRUCTURA $Y$ PROPIEDADES RESIDUALES EN HORMIGONES DAÑADOS POR EXPOSICIÓN A ALTA TEMPERATURA $Y$ SOMETIDOS A CARGAS DE LARGA DURACIÓN}

En esta experiencia se estudia la vinculación entre mesoestructura y propiedades residuales de hormigones dañados por exposición a alta temperatura (siguiendo procedimientos similares a los utilizados anteriormente, 24 horas a $150{ }^{\circ} \mathrm{C} \mathrm{y}$ 1 hora a $500{ }^{\circ} \mathrm{C}$ ) que fueron posteriormente sometidos durante 1 año a cargas de compresión del orden del $30 \%$ de la resistencia. Como se observó en los apartados anteriores estas temperaturas generan defectos de diferente tipo y magnitud por lo que podrían afectar en forma diversa el desarrollo de las deformaciones diferidas durante la aplicación de las cargas.

\subsubsection{Materiales y mezclas}

Para la realización de estas experiencias se obtuvieron muestras de un hormigón H21 elaborado en una planta hormigonera; la mezcla es similar a la del estudio anterior y representa a uno de los tipos de hormigón de mayor uso en la región. Se utilizaron como materiales cemento portland normal $\left(280 \mathrm{~kg} / \mathrm{m}^{3}\right)$, piedra partida granítica en la fracción $6-20 \mathrm{~mm}$ y arena silícea de río. Se moldearon 40 cilindros de $150 \times 300 \mathrm{~mm}$ y 10 prismas de $75 \times 105 \times 430 \mathrm{~mm}$ con pernos de acero inoxidable insertos en sus extremidades, con el fin de estudiar la variación dimensional. El hormigón se mezcló en un mixer y las probetas fueron compactadas mediante varilleo. A las 24 horas fueron desmoldadas y trasladadas a cámara húmeda.

\subsubsection{Detalles experimentales}

Las probetas, se dividieron en tres grupos, el primero (14 probetas cilíndricas y 4 prismas) fue mantenido en ambiente de laboratorio a $20^{\circ} \mathrm{C}$, el segundo ( 13 cilindros y 3 prismas) fue sometido a una temperatura de $150^{\circ} \mathrm{C}$, mientras que el tercer grupo (13 cilindros y 3 prismas) fue sometido a $500^{\circ} \mathrm{C}$. Los grupos se identifican de acuerdo a la temperatura de exposición, 20 (grupo de referencia o control), 150 o 500.

Para la exposición a $150^{\circ} \mathrm{C}$ y $500^{\circ} \mathrm{C}$ se utilizaron hornos eléctricos, en el primer caso se mantuvieron las probetas 24 horas a $150^{\circ} \mathrm{C}$ y en el segundo se empleó 
una velocidad de calentamiento de $100^{\circ} \mathrm{C} /$ hora hasta alcanzar la temperatura máxima que fue mantenida durante 1 hora. Las probetas se dejaron enfriar en forma lenta dentro del horno. Tanto en el caso del grupo 150 como en el de 500, luego de la exposición las probetas se dejaron en ambiente de laboratorio durante 48 horas antes de proceder a las evaluaciones.

Una vez definidos los tres grupos con diferentes niveles de daño se realizaron ensayos de compresión simple sobre 4 cilindros para definir el nivel de resistencia de cada uno de ellos. Luego cinco cilindros de cada grupo fueron sometidos a cargas de larga duración iguales al $30 \%$ de la carga de rotura. Las probetas permanecieron cargadas durante 1 año en una cámara seca (temperatura $20 \pm 2{ }^{\circ} \mathrm{C}$ y $55 \pm 5 \%$ de humedad relativa).

En forma paralela un tercer juego de al menos cuatro cilindros fue mantenido sin cargar junto con las probetas cargadas, con el propósito de acotar los cambios en las dimensiones producto de eventuales variaciones de humedad y temperatura en la cámara seca. Luego de un año las probetas fueron descargadas, midiéndose durante 1 mes la recuperación.

Sobre los prismas se determinaron el peso y la longitud, antes y después de la exposición a alta temperatura. En el caso de los cilindros fueron medidas la velocidad de pulso ultrasónico y la variación de peso de cada una de las probetas antes y después de la exposición a alta temperatura para comparar el nivel de daño con el de los prismas, las mismas determinaciones se repitieron una vez finalizado el estudio de fluencia tanto sobre las probetas que habían sido cargadas en los pórticos como sobre aquellas que permanecieron sin cargar. En el grupo de referencia (20) también se repitieron las medidas de peso, ultrasonido y variaciones de la longitud, como forma de control.

Finalizado el estudio de fluencia, tres cilindros de cada grupo sometido a cargas de larga duración y otros tres cilindros que habían permanecido sin cargar se ensayaron a compresión simple, midiendo en forma simultánea a las cargas las deformaciones laterales y longitudinales. 
Los cilindros restantes se utilizaron para valorar la mesoestructura y las propiedades de transporte. Se realizaron cortes de $50 \mathrm{~mm}$ de espesor para ensayos de permeabilidad y de $100 \mathrm{~mm}$ para el estudio de la penetración de agua a presión.

La mesoestructura fue caracterizada en base al relevamiento de la longitud y ancho de fisuras y de la superficie de agregados, el estudio fue realizado sobre los cortes que luego serían usados para el ensayo de permeabilidad. También se observó el estado de las interfaces sobre cortes delgados.

En los ensayos de permeabilidad los cortes de $50 \mathrm{~mm}$ de espesor fueron sometidos a $0.1 \mathrm{MPa}$ durante aproximadamente 30 horas, exponiendo una superficie de $100 \mathrm{~mm}$ de diámetro de la cara de moldeo.

La penetración de agua a presión sobre los cortes de $100 \mathrm{~mm}$ de altura, también con una superficie de exposición de $100 \mathrm{~mm}$ de diámetro, se realizó inicialmente utilizando el ciclo establecido en la norma IRAM 1554. Luego se repitió el ensayo empleando un ciclo menos exigente de 48 horas a $0.1 \mathrm{MPa}$ ya que al estar el material tan deteriorado al finalizar el ensayo según norma se encontró que el agua había penetrado la totalidad del corte.

Las probetas prismáticas utilizadas para evaluar las variaciones de peso y los cambios dimensionales durante la exposición a alta temperatura fueron entalladas y ensayadas a flexión con carga centrada. De cada viga las mitades resultantes del ensayo de flexión fueron utilizadas para realizar ensayos de tracción por compresión diametral y se obtuvieron cortes de $50 \times 75 \times 105 \mathrm{~mm}$ para determinar como propiedades de transporte: la absorción en agua 24 horas y la absorción capilar, en este último caso se empleó como cara expuesta la superficie de moldeo de la probeta.

\subsubsection{Resultados y discusión}

Los resultados de pérdida de peso y variación de longitud medidos sobre prismas, desde el momento en que las probetas se pusieron al aire en laboratorio hasta que finalizó la exposición a alta temperatura se indican en la Tabla 4.4.1. Es posible observar una disminución del peso del $3.6 \%$ en el grupo 150 y de un $4.2 \%$ en las expuestas a $500^{\circ} \mathrm{C}$. En lo que se refiere a las variaciones de longitud las probetas mantenidas en ambiente de laboratorio experimentaron una ligera contracción, en el 
grupo 150 la contracción fue de 175 micrones por metro, por el contrario, las probetas del grupo 500 sufrieron una expansión de 295 micrones por metro, evidenciando un significativo cuadro de fisuración.

Tabla 4.4.1. Pérdida de peso y variación de longitud medida sobre prismas.

\begin{tabular}{ccc}
\hline Grupo & Pérdida de peso (\%) & Variación de longitud (micrones por metro) \\
\hline 20 & 0.13 & -40 \\
150 & 3.62 & -175 \\
500 & 4.22 & 295 \\
\hline
\end{tabular}

Cabe destacar que cuando las probetas se ubicaron en cámara seca ya habían experimentado un proceso de secado en ambiente de laboratorio durante 4 meses (las condiciones típicas de laboratorio son temperaturas de $20 \pm 4{ }^{\circ} \mathrm{C}$ y humedad relativa de $70 \pm 10 \%$ ). Durante los meses que permanecieron en cámara seca se midieron las variaciones dimensionales sobre las probetas cilíndricas. Los grupos 150 y 500 no experimentaron contracciones mientras que en el grupo 20 se midió una contracción adicional de 58 micrones por metro.

Tabla 4.4.2. Propiedades físicas y mecánicas determinadas sobre cilindros luego de la exposición a altas temperaturas.

\begin{tabular}{|c|c|c|c|c|c|c|c|c|c|}
\hline \multirow{2}{*}{ 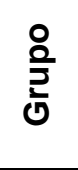 } & \multicolumn{2}{|c|}{ VPU (km/s) } & \multirow{2}{*}{$\begin{array}{c}\text { Variación } \\
\text { VPU (\%) }\end{array}$} & \multirow{2}{*}{$\begin{array}{c}\text { Pérdida de } \\
\text { peso (\%) }\end{array}$} & \multirow{2}{*}{$\begin{array}{c}\mathbf{f}_{c}^{\prime} \\
(\mathrm{MPa})\end{array}$} & \multirow{2}{*}{$\begin{array}{c}\mathbf{f}_{\text {crit }} \\
(\mathrm{MPa})\end{array}$} & \multirow{2}{*}{$\begin{array}{c}f_{c r i ́ t} \\
\left(\% f_{c}^{\prime}\right)\end{array}$} & \multirow{2}{*}{$\begin{array}{c}E \\
(\mathrm{GPa})\end{array}$} & \multirow{2}{*}{$\mu$} \\
\hline & Original & $\begin{array}{l}\text { Luego de la } \\
\text { exposición }\end{array}$ & & & & & & & \\
\hline 20 & 4.54 & 4.48 & -1 & 0.14 & 25.3 & $>24.5$ & $>98$ & 34.5 & 0.19 \\
\hline 150 & 4.53 & 3.77 & -17 & 4.48 & 24.1 & 22 & 92 & 24 & 0.13 \\
\hline 500 & 4.55 & 2.31 & -49 & 5.13 & 16.9 & 12 & 71 & 12.0 & 0.11 \\
\hline
\end{tabular}

En la Tabla 4.4.2 se muestran los resultados de velocidad de pulso ultrasónico (VPU), el valor original y el medido luego de la exposición a alta temperatura, así como la pérdida de peso sufrida durante el ciclo de calentamiento de las probetas cilíndricas. A su vez se informan los valores de resistencia a compresión $\left(f^{\prime}{ }_{c}\right)$, tensión crítica $\left(f_{\text {crit }}\right)$, módulo de elasticidad (E) y coeficiente de Poisson $(\mu)$ medidos en el ensayo de compresión de corta duración realizado antes de iniciar los estudios de fluencia. Es posible observar que las pérdidas de peso fueron de un orden similar a las medidas sobre los prismas. La VPU disminuyó $17 \%$ en el grupo 150 y $49 \%$ en el 500, lo que sugiere la presencia de fisuras. En el grupo 20, como era de esperar, no se produjeron mayores cambios en la VPU ni variaciones de peso. 
En cuanto a la respuesta mecánica los resultados muestran que la resistencia a compresión disminuye por efecto de la exposición a alta temperatura. En el grupo 500 se observa una disminución del $33 \%$ con respecto a las probetas mantenidas en ambiente de laboratorio, pero la reducción de resistencia fue menor al $5 \%$ en el grupo 150. Como fue observado en el inciso 4.3 y por otros autores (Phan y Carino, 2000, Khoury, 2000, Bazant y Kaplan, 1996) las temperaturas inferiores a $200^{\circ} \mathrm{C}$ tienen poca incidencia en la resistencia a compresión. Aunque se pueden producir microfisuras por secado, también puede favorecerse la resistencia por consolidación de los productos de hidratación y la eliminación de parte del agua entre capas y de los poros capilares (Bazant y Kaplan, 1996). Al analizar los valores de la tensión crítica, la mayor disminución se produce en el grupo 500 con niveles de tensión crítica del orden del $70 \%$ de la resistencia a compresión; por su parte en el grupo 150 la variación es

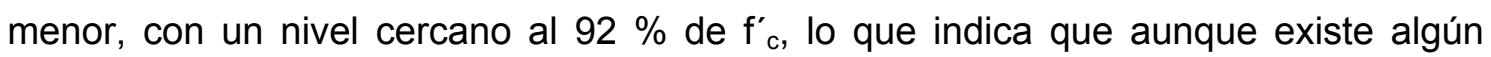
grado de microfisuración, éste no afecta en forma substancial la propagación de las fisuras y el proceso de fractura en general. La deformabilidad del hormigón degradado por exposición a alta temperatura muestra cambios más importantes. Las medidas del módulo de elasticidad indican una disminución de la rigidez del orden del $30 \%$ en las probetas sometidas a $150^{\circ} \mathrm{C}$ (a pesar de no presentar cambios en la resistencia) y de aproximadamente $60 \%$ en las expuestas a $500{ }^{\circ} \mathrm{C}$. Como fuera desarrollado en el Capítulo II, diversos estudios coinciden en que el módulo de elasticidad resulta más afectado que la resistencia por acción de las altas temperaturas. La degradación de la estructura del hormigón también se refleja en las reducciones en el módulo de Poisson.

Es interesante notar que la alteración en el módulo de elasticidad es coherente con los cambios en la velocidad de pulso ultrasónico como ya fue observado en el apartado 4.3. No sucede lo mismo con la resistencia a compresión, mientras en el grupo 150 la resistencia a compresión no pone de manifiesto el proceso de degradación, la velocidad de pulso ultrasónico cambia substancialmente.

Para valorar el comportamiento y efecto de la aplicación de cargas de larga duración probetas de los tres grupos $(20,150$ y 500) fueron sometidas durante un año a cargas iguales al $30 \%$ de la resistencia a compresión. En la Tabla 4.4 .3 se informan los resultados de estos ensayos. En la Fig. 4.4.1 se muestra para cada grupo el desarrollo de las deformaciones bajo carga, calculadas como la diferencia entre las deformaciones de las probetas cargadas y las que en paralelo registraban las probetas 
sin cargar. Cabe mencionar que, a diferencia de los estudios típicos de fluencia en los que la contracción libre afecta a las probetas sin cargar, en este caso estas últimas prácticamente no registraron cambios debido al proceso de secado previo.

Tabla 4.4.3. Resultados ensayos de larga duración.

\begin{tabular}{cccccc}
\hline \multirow{2}{*}{ Grupo } & \multicolumn{2}{c}{ Deformaciones $\left(\mathbf{1 0}^{-6}\right)$} & \multicolumn{2}{c}{ Recuperaciones $\left(\mathbf{1 0}^{-6}\right)$} \\
& elásticas instantáneas & totales & diferidas & elásticas instantáneas & totales \\
\hline 20 & 230 & 1110 & 880 & 280 & 360 \\
150 & 255 & 1015 & 760 & 325 & 460 \\
500 & 500 & 1320 & 820 & 535 & 690 \\
\hline
\end{tabular}

Las deformaciones elásticas instantáneas medidas inmediatamente luego de la aplicación de las cargas fueron 230, 255 y 500 micrones por metro para los grupos 20, 150 y 500 . El grupo expuesto a $500{ }^{\circ} \mathrm{C}$ a pesar de estar sometido a cargas menores, muestra un incremento en la deformación, lo que refleja la estructura alterada del hormigón. Considerando el efecto de las cargas sostenidas, en la Fig. 4.4.1 se observa una respuesta similar en los grupos 20 y 150, y deformaciones mayores en el grupo 500. Cabe notar que las deformaciones diferidas (deformaciones totales - elástica inicial) fueron menores en los hormigones afectados por temperatura, siendo iguales a 880,760 y 820 micrones por metro para los grupos 20,150 y 500 .

Durante la descarga se midieron recuperaciones elásticas inmediatas iguales a 280,325 y 535 micrones por metro, y recuperaciones totales iguales a 360, 460 y 690 micrones por metro, para los grupos 20, 150 y 500 respectivamente.

Luego de descargar los cilindros se eligieron algunos para evaluar la mesoestructura. En la Fig. 4.4.2 se muestra el cuadro de fisuración relevado sobre cortes transversales de cilindros de $150 \times 300 \mathrm{~mm}$ que luego serían destinados a los estudios de permeabilidad. De la misma surge que la longitud de fisuras crece, como era dado esperar, para los estados más dañados, pero se destaca que también existen algunas fisuras en el grupo 20. Esto es, en un hormigón de resistencia convencional que estuvo en ambiente de laboratorio durante varios meses y luego un año en cámara seca existen fisuras de un tamaño detectable a simple vista. 


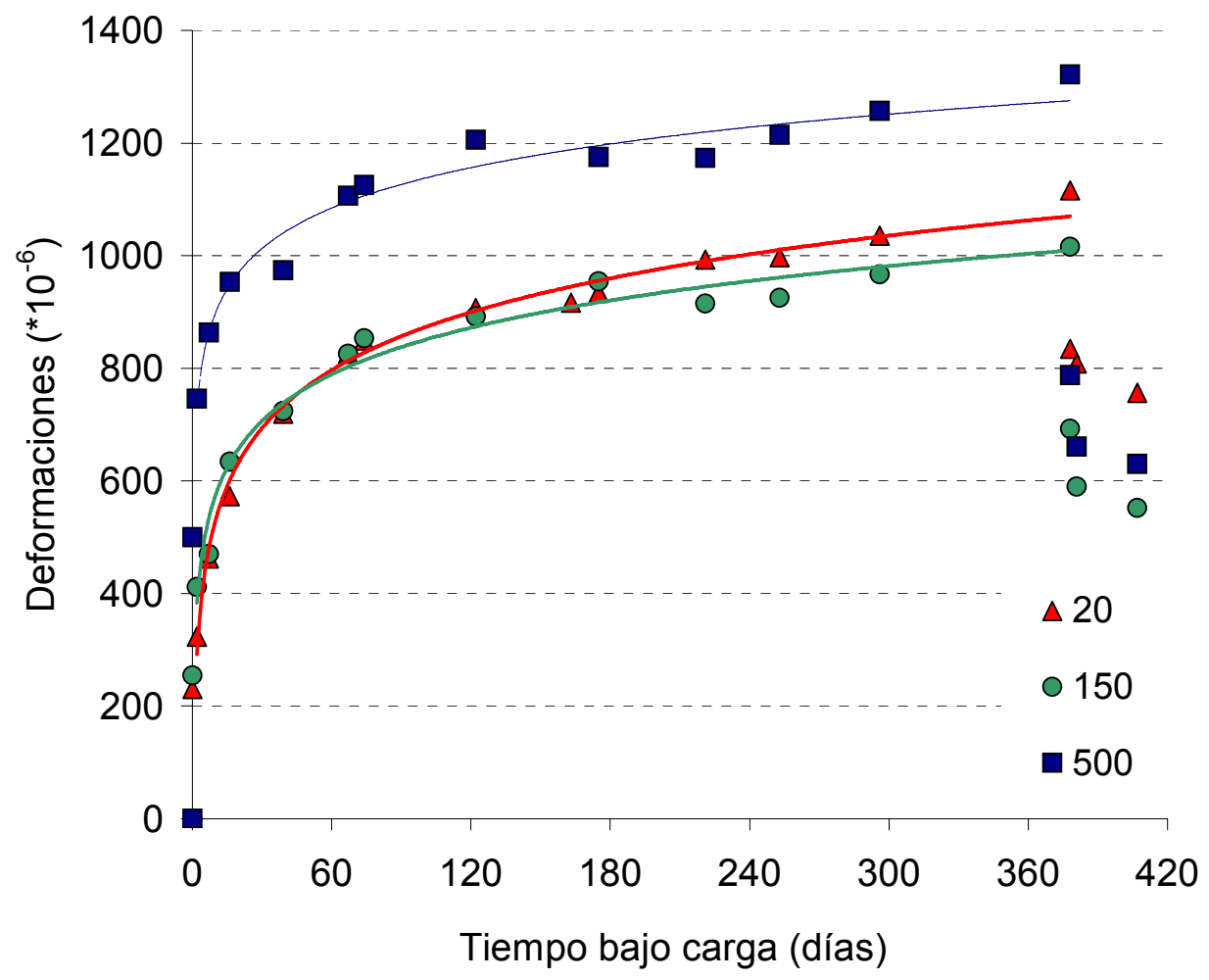

Figura 4.4.1. Deformaciones totales bajo carga sostenida.

20

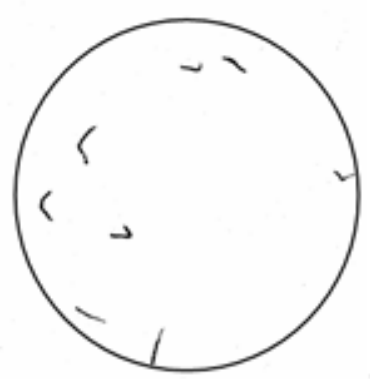

150

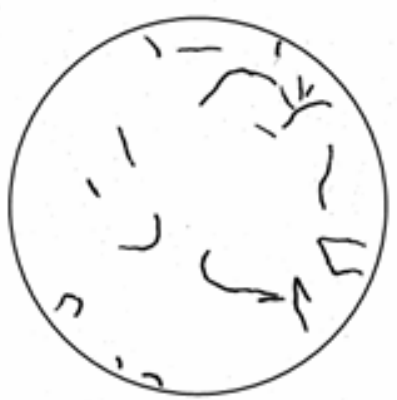

500

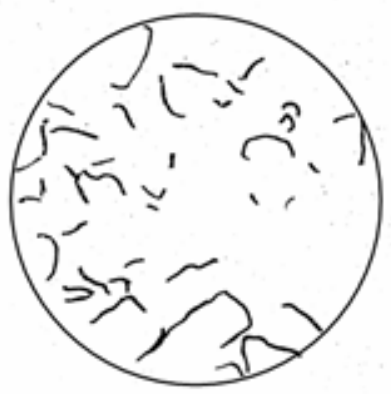

Figura 4.4.2. Cuadro de fisuración relevado sobre cortes de probetas cilíndricas preparados para ensayos de permeabilidad.

En la Tabla 4.4 .4 se presenta el relevamiento de agregados y fisuras informándose superficie de agregados por unidad de área en función de la longitud máxima, longitud de fisuras por unidad de área y ancho máximo de fisura. Es posible observar que en los grupos sometidos a temperatura es mayor tanto la cantidad de fisuras como la proporción de fisuras de mayor longitud. En cuanto al ancho máximo las probetas pertenecientes a los grupos 20 y 150 poseen fisuras en general menores 
a $0.1 \mathrm{~mm}$ de ancho mientras que en el grupo 500 se midieron fisuras del orden de $0.3 \mathrm{~mm}$.

En la Tabla 4.4.5 se agrupan la cantidad de fisuras según su longitud y se distingue entre probetas cargadas y sin cargar. De su observación surge que existe un leve incremento en la densidad de fisuras (en este caso $\mathrm{N}^{\circ}$ de fisuras por $\mathrm{cm}^{2}$ ) en las probetas que permanecieron sin cargar.

Finalmente en la Fig. 4.4.3 se muestran cortes delgados obtenidos a partir de las probetas prismáticas de cada grupo. Se puede apreciar el estado de las interfaces matriz agregado. Se destaca que en el grupo 500 se observan zonas con falta de pasta por la alteración de los productos de hidratación. Las diferencias en este nivel de observación entre los grupos 20 y 150 no son tan notorias.

Tabla 4.4.4. Relevamiento de fisuras y agregados sobre cilindros.

\begin{tabular}{|c|c|c|c|c|c|c|}
\hline \multirow{2}{*}{$\frac{\circ}{\frac{0}{2}}$} & \multicolumn{2}{|c|}{$\begin{array}{l}\text { Superficie de } \\
\text { agregados }\left(\mathrm{cm}^{2} / \mathrm{cm}^{2}\right)\end{array}$} & \multicolumn{3}{|c|}{ Densidad de fisuras $\left(\mathrm{cm} / \mathrm{cm}^{2}\right)$} & \multirow{2}{*}{$\begin{array}{l}\text { Ancho } \\
\text { máximo de } \\
\text { fisura } \\
(\mathrm{mm})\end{array}$} \\
\hline & $>15 \mathrm{~mm}$ & de 15 a $5 \mathrm{~mm}$ & $>10 \mathrm{~mm}$ & $\begin{array}{c}\text { de } 10 \text { a } 5 \\
\mathrm{~mm}\end{array}$ & de 5 a $1 \mathrm{~mm}$ & \\
\hline 20 & 0.08 & 0.11 & 0.06 & 0.04 & 0.005 & $\leq 0.1$ \\
\hline 150 & 0.14 & 0.09 & 0.25 & 0.05 & 0.01 & $\leq 0.1$ \\
\hline 500 & 0.15 & 0.08 & 0.35 & 0.10 & 0.01 & 0.3 \\
\hline
\end{tabular}

Tabla 4.4.5. Relevamiento de fisuras sobre cilindros.

\begin{tabular}{|c|c|c|c|c|c|c|c|c|}
\hline \multirow{3}{*}{$\frac{8}{\frac{2}{2}}$} & \multicolumn{8}{|c|}{ Densidad de fisuras $\left(\mathrm{N} / \mathrm{cm}^{2}\right)$} \\
\hline & \multicolumn{2}{|c|}{ total } & \multicolumn{2}{|c|}{$>10 \mathrm{~mm}$} & \multicolumn{2}{|c|}{ de 10 a $5 \mathrm{~mm}$} & \multicolumn{2}{|c|}{ de 5 a $1 \mathrm{~mm}$} \\
\hline & 1 & 2 & 1 & 2 & 1 & 2 & 1 & 2 \\
\hline 20 & 0.11 & 0.18 & 0.04 & 0.08 & 0.04 & 0.07 & 0.01 & 0.02 \\
\hline 150 & 0.21 & 0.22 & 0.10 & 0.17 & 0.07 & 0.05 & 0.03 & 0.000 \\
\hline 500 & 0.32 & 0.38 & 0.17 & 0.17 & 0.13 & 0.13 & 0.02 & 0.06 \\
\hline 1 & \multicolumn{8}{|c|}{ luego de un año en cámara seca, probetas cargadas } \\
\hline 2 & \multicolumn{8}{|c|}{ luego de un año en cámara seca, probetas sin cargar } \\
\hline
\end{tabular}



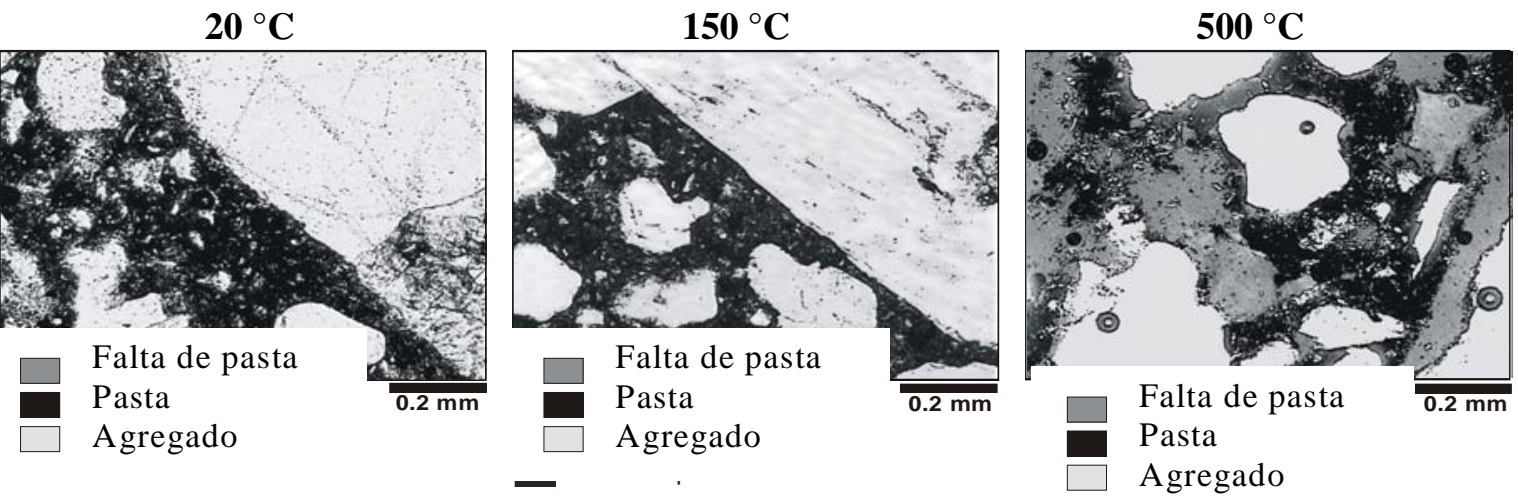

Figura 4.4.3. Cortes delgados de los hormigones luego de ser sometidos al proceso de degradación.

La Tabla 4.4.6 muestra los resultados de velocidad de pulso ultrasónico considerando para cada grupo las mediciones luego de un año de permanencia en cámara seca tanto de los cilindros sometidos a carga como de los que permanecieron sin cargar. Se aprecia que existe un ligero incremento en la VPU en las probetas cargadas y un ligero decrecimiento en las que permanecieron descargadas lo que puede asociarse a algunos procesos de consolidación y aumento de la fisuración por secado respectivamente. Comparando la velocidad entre las probetas cargadas y sin cargar, el incremento en las probetas cargadas es mayor en los hormigones más dañados, lo que se puede relacionar con un proceso de cierre de fisuras por efecto de las cargas.

En la Tabla 4.4.7 se informan los valores de la resistencia a compresión (f'c), el módulo de elasticidad $(E)$ y el coeficiente de Poisson $(\mu)$ medidos al cabo de un año de permanencia en cámara seca tanto sobre las probetas que fueron cargadas como sobre aquellas que no fueron sometidas a cargas de larga duración.

Tabla 4.4.6. Ensayos no destructivos sobre cilindros al cabo de un año en cámara seca.

\begin{tabular}{ccccc}
\hline \multirow{2}{*}{$\frac{2}{2}$} & \multicolumn{2}{c}{ VPU (km/s) } & \multicolumn{2}{c}{$\begin{array}{c}\text { Relación entre la VPU luego de la } \\
\text { exposición y al cabo de 1 año }\end{array}$} \\
\cline { 2 - 5 } & Probetas·cargadas & $\begin{array}{c}\text { Probetas sin } \\
\text { cargar }\end{array}$ & Probetas·cargadas & $\begin{array}{c}\text { Probetas sin } \\
\text { cargar }\end{array}$ \\
\hline 20 & 4.46 & 4.44 & 1.00 & 0.99 \\
150 & 3.80 & 3.68 & 1.01 & 0.98 \\
500 & 2.44 & 2.26 & 1.06 & 0.98 \\
\hline
\end{tabular}


Tabla 4.4.7. Propiedades mecánicas medidas sobre cilindros y prismas al cabo de un año en cámara seca.

\begin{tabular}{|c|c|c|c|c|c|c|c|c|}
\hline \multirow{3}{*}{$\frac{8}{\frac{0}{2}}$} & \multirow{2}{*}{\multicolumn{3}{|c|}{ Probetas cargadas }} & \multicolumn{5}{|c|}{ Probetas sin cargar } \\
\hline & & & & \multicolumn{3}{|c|}{ cilindros } & \multicolumn{2}{|c|}{ prismas } \\
\hline & $\begin{array}{c}f^{\prime} \mathrm{c} \\
(\mathrm{MPa})\end{array}$ & $\begin{array}{c}\mathrm{E} \\
(\mathrm{GPa})\end{array}$ & $\mu$ & $\begin{array}{c}f^{\prime} \mathrm{c} \\
(\mathrm{MPa})\end{array}$ & $\begin{array}{c}\mathrm{E} \\
(\mathrm{GPa})\end{array}$ & $\mu$ & $\begin{array}{c}f_{\text {net }} \\
(\mathrm{MPa})\end{array}$ & $\begin{array}{c}\mathrm{f}_{\mathrm{cd}} \\
(\mathrm{MPa})\end{array}$ \\
\hline 20 & 29.8 & 31.7 & 0.16 & 24.8 & 30.5 & 0.16 & 7.0 & 3.2 \\
\hline 150 & 22.2 & 21.7 & 0.12 & 22.7 & 23.6 & 0.14 & 5.0 & 2.6 \\
\hline 500 & 18.5 & 12.8 & 0.11 & 19.8 & 12.2 & 0.10 & 3.9 & 2.5 \\
\hline
\end{tabular}

En la Fig. 4.4.4 se representan los valores relativos de resistencia a compresión, módulo de elasticidad y coeficiente de Poisson de cada grupo tomando como referencia las probetas del grupo 20 que permanecieron en cámara seca 1 año sin carga. Al comparar entre probetas cargadas y sin cargar, en el hormigón sin dañar se verifica un proceso de consolidación que incrementa la resistencia un $20 \%$. Esto no ocurre en los grupos 150 y 500, lo que implica que el fenómeno no se produce o la influencia de las fisuras y su propagación es un factor de mayor peso. Las diferencias en el módulo de elasticidad o en la relación de Poisson entre probetas cargadas y sin cargar son poco significativas.

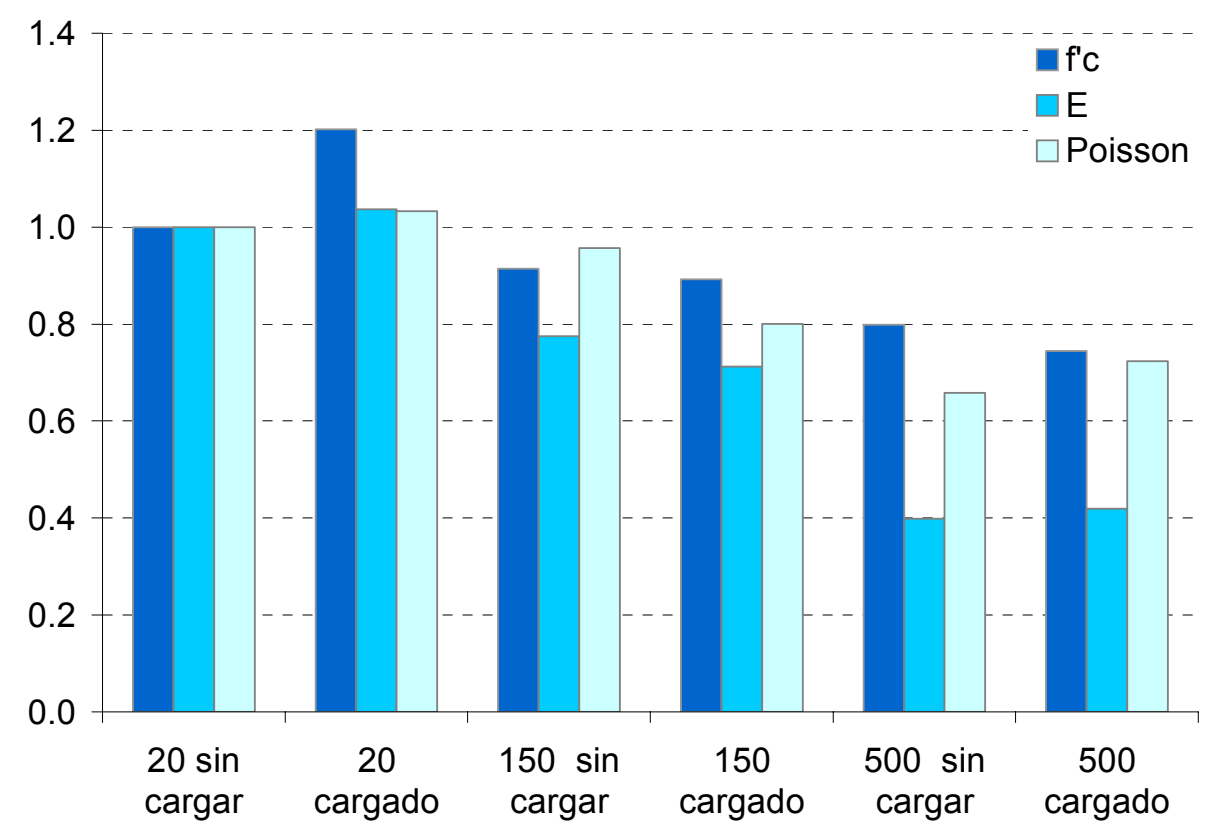

Figura 4.4.4. Variación de la resistencia a compresión, módulo de elasticidad y coeficiente de Poisson en función de los diferentes tipos de exposición. Los valores están referenciados al grupo 20 sin cargar. 
En la Tabla 4.4.7 también se informan los valores residuales de resistencia a tracción sobre vigas entalladas $\left(\mathrm{f}_{\text {net }}\right)$ y resistencia a tracción por compresión diametral $\left(\mathrm{f}_{\mathrm{cd}}\right)$ medidas sobre las mitades restantes del ensayo de flexión. Los valores son consistentes con lo observado sobre la resistencia a compresión. Las mayores reducciones se presentan en $f_{\text {net }}$ seguido por $f_{c}$ y por último $f_{c d}$.

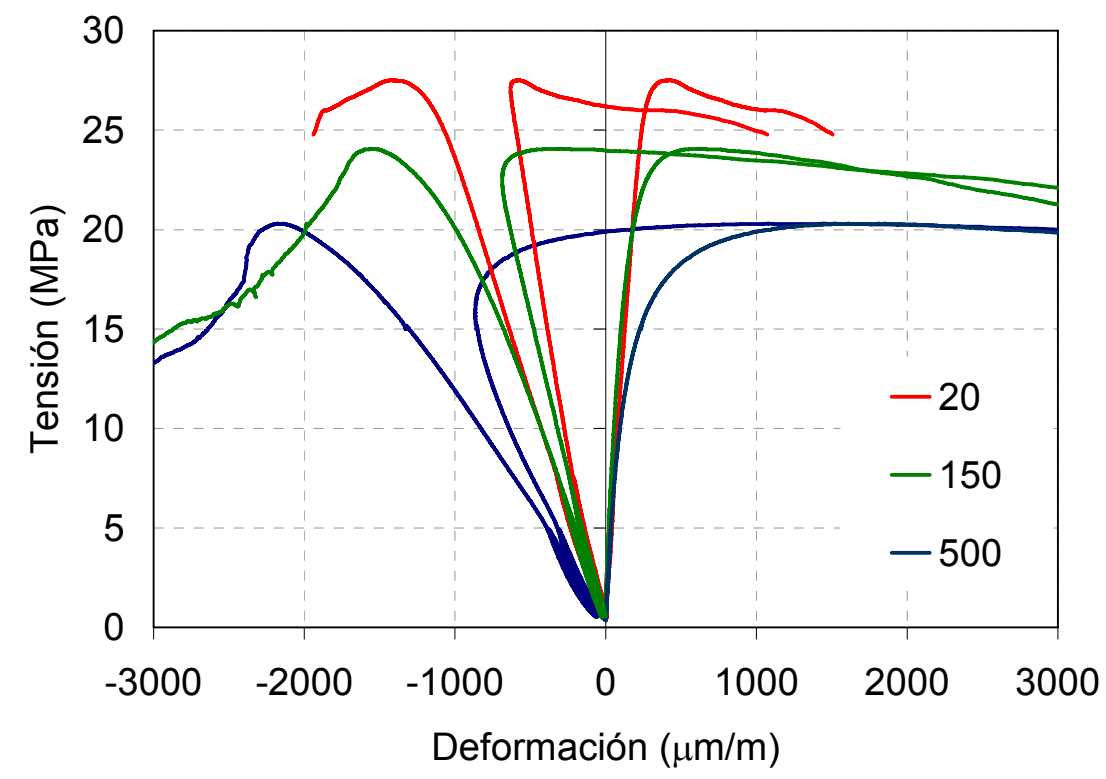

Figura 4.4.5. Curvas tensión-deformación (longitudinal, transversal y volumétrica) obtenidas sobre las probetas que permanecieron 1 año en cámara seca sin cargar.

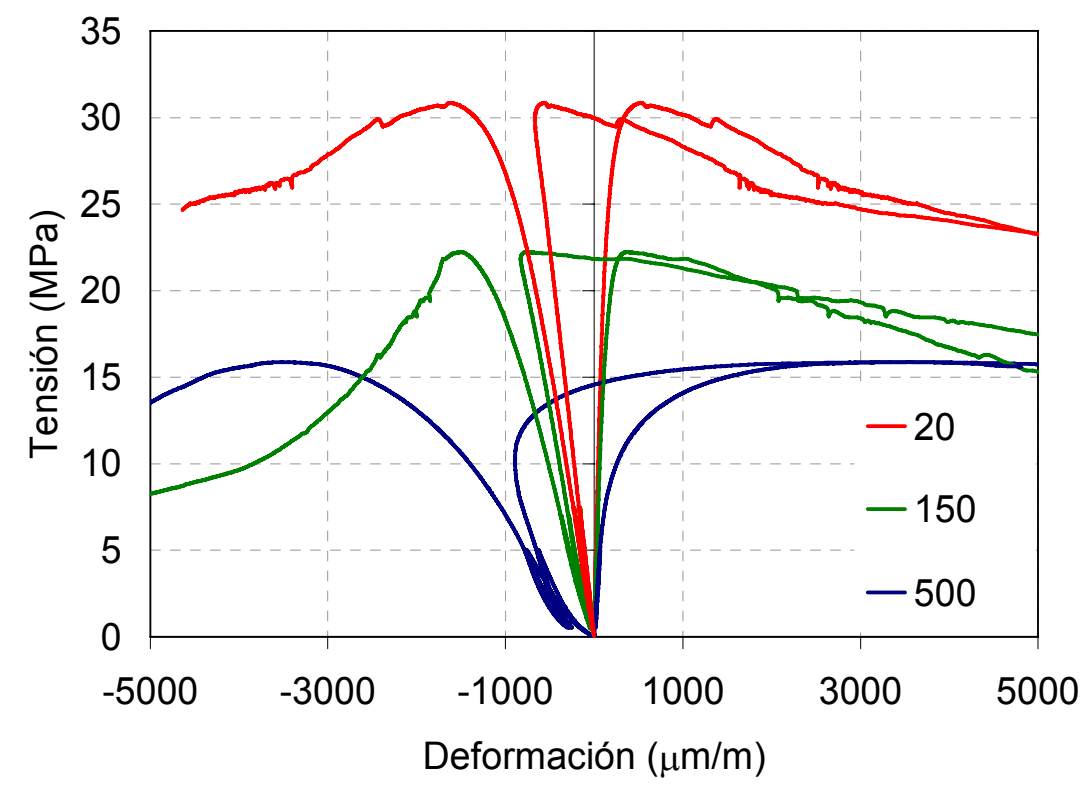

Figura 4.4.6. Curvas tensión-deformación (longitudinal, transversal y volumétrica) obtenidas sobre las probetas que permanecieron 1 año cargadas. 
En las Fig. 4.4 .5 y 4.4 .6 se presentan algunas curvas tensión-deformación transversal, longitudinal y volumétrica tanto de los grupos que permanecieron sin cargar como los que estuvieron bajo carga. Se puede apreciar un comportamiento pre y post pico muy diferente entre los tres grupos tanto para las probetas cargadas como las que permanecieron sin cargar. En la Fig. 4.4.5 donde están graficadas las curvas de las probetas que no fueron sometidas a cargas de larga duración, la variación más notable se produce en el grupo 500 donde existe una pronunciada no linealidad entre esfuerzos y deformaciones, estas diferencias son propias de las fisuras causadas por la exposición a alta temperatura. Se observa una mayor linealidad en el inicio de las curvas y menores diferencias en los ciclos de carga y descarga en el caso de las probetas que permanecieron sin cargar. En ambas curvas también es posible observar la mayor disminución de la tensión crítica en el grupo más dañado, producto del estado de fisuración previo.

En la Tabla 4.4.8 se informan los resultados de densidad, absorción de agua durante 24 horas, absorción capilar y coeficiente de permeabilidad. Los ensayos de densidad y absorción realizados sobre prismas no arrojaron diferencias entre los tres grupos. En cambio en el ensayo de absorción capilar se pudo ver un incremento de la velocidad de absorción en los grupos más afectados con respecto al grupo 20. La mayor velocidad se observó en las probetas sometidas a $150{ }^{\circ} \mathrm{C}$, ya que estas probetas poseen defectos de menor tamaño que las del grupo 500.

En la Fig. 4.4.7 se representan curvas promedio de absorción capilar correspondientes a los tres grupos, de la misma surge que en las primeras horas el grupo 500 presentó una mayor velocidad de absorción seguido por el 150, siendo el grupo 20 el que presentó la menor velocidad. Además la mayor capacidad de absorción capilar se observó en el grupo 150 siendo la del grupo 500 ligeramente menor. Esto es coherente con lo observado en el estudio anterior.

Con respecto al coeficiente de permeabilidad, en la Tabla 4.4 .8 al comparar las probetas sometidas a 150 y $500^{\circ} \mathrm{C}$, se observa que en el segundo caso el coeficiente es significativamente mayor, lo cual se corresponde con el mayor tamaño y densidad de fisuras de este último grupo. Asimismo es de destacar que en todos los casos los coeficientes resultaron muy altos, en especial en el grupo 500. En este caso el ensayo duró sólo un día porque se debía parar constantemente para recargar el equipo con 
agua, por lo tanto las mediciones tomadas no corresponden con un flujo estable de agua y se presentan sólo a nivel comparativo.

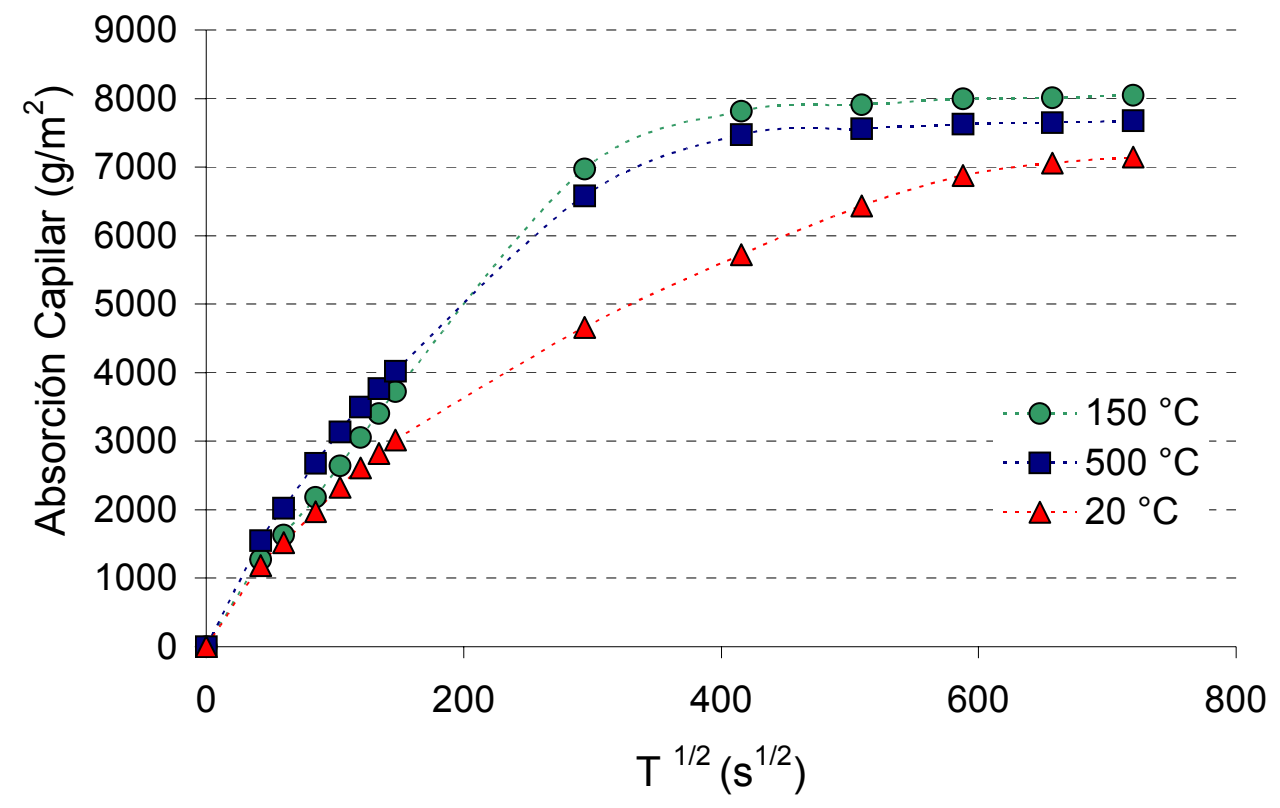

Figura 4.4.7. Curvas promedio obtenidas a partir del ensayo de absorción capilar.

Como ya fue comentado se observó que los anchos máximos de fisuras medidos en las probetas pertenecientes a los grupos 20 y 150 fueron, en general, menores a $0.1 \mathrm{~mm}$, mientras que en el grupo 500 el ancho máximo de fisura fue del orden de $0.3 \mathrm{~mm}$, esto se correlaciona con los valores de permeabilidad medidos dado que en otros trabajos también se ha observado que al aumentar la fisuración de $50 \mu \mathrm{m}$ a $200 \mu \mathrm{m}$ aproximadamente la permeabilidad se incrementa sustancialmente (Wang et al, 1997).

En los ensayos de penetración de agua a presión, realizados sobre probetas de $100 \mathrm{~mm}$ de altura, fue posible observar que en todos los grupos las probetas se saturaron completamente. Esto pone de manifiesto que el grupo 20 también presenta cierto grado de alteración que se atribuye a la contracción por secado. 
Tabla 4.4.8. Propiedades físicas y de transporte.

\begin{tabular}{cccccc}
\hline Grupo & Densidad & $\begin{array}{c}\text { Absorción } \\
\mathbf{( \% )}\end{array}$ & $\begin{array}{c}\text { Capacidad de } \\
\text { absorción } \\
\text { capilar }\left(\mathbf{g} / \mathbf{m}^{2}\right)\end{array}$ & $\begin{array}{c}\text { Velocidad de } \\
\text { absorción } \\
\text { capilar } \\
\left(\mathbf{g} / \mathbf{m}^{2} / \mathbf{s}^{\mathbf{1 / 2}}\right)\end{array}$ & $\begin{array}{c}\text { Coeficiente } \\
\text { permeabilidad } \\
\left(\mathbf{1 0}^{-11} \mathbf{m} / \mathbf{s}\right)\end{array}$ \\
\hline 20 & 2.45 & 4.4 & 7220 & 9.5 & - \\
150 & 2.44 & 4.9 & 8020 & 15.3 & 30 \\
500 & 2.46 & 4.6 & 7660 & 13.4 & 1250 \\
\hline
\end{tabular}

\subsubsection{Conclusiones}

En esta experiencia se confirma el aumento de daño en el hormigón producto de la exposición a alta temperatura. Al analizar la fisuración como elemento mesoestructural se observó una mayor densidad de fisuras en las probetas sometidas a temperaturas de $500^{\circ} \mathrm{C}$ con respecto a las sometidas a $150^{\circ} \mathrm{C}$, a su vez se verificó un aumento significativo en el ancho máximo de fisura. También se encontraron pequeñas fisuras en el grupo que no fue afectado por temperatura luego de permanecer un año en cámara seca. La velocidad de pulso ultrasónico confirmó el daño en los hormigones sometidos a temperatura.

Este estudio confirma que el daño causado por la exposición a alta temperatura afecta en mayor medida la deformabilidad que la resistencia. El grado de fisuración también influye considerablemente en el mecanismo de rotura.

Con respecto a la influencia de las cargas de larga duración sobre el proceso de deterioro, se encontraron diferencias en el comportamiento entre los hormigones sanos y dañados sometidos a cargas de larga duración, y dentro del grupo de los hormigones dañados entre las probetas cargadas y las que no fueron cargadas. En los hormigones dañados se midieron mayores deformaciones elásticas y menores deformaciones diferidas durante la aplicación de las cargas sostenidas. Comparando la respuesta mecánica de las probetas sometidas a cargas de larga duración con las que permanecieron sin cargar se observó un incremento de resistencia por consolidación en el hormigón sin dañar, lo que no sucedió en los hormigones afectados por temperatura.

A su vez se encontraron diferencias en la respuesta mecánica de los hormigones (resistencia y deformabilidad) con respecto a las propiedades de transporte. Asimismo los diferentes ensayos que evalúan las propiedades de transporte también presentaron 
resultados dispares en función del grado de deterioro del hormigón. El ensayo de permeabilidad mostró un aumento importante del coeficiente de permeabilidad con el daño, cuantificado a través del ancho máximo y la densidad de fisuras. Mientras que las probetas dañadas por temperatura y sometidas al ensayo de absorción capilar se comportaron de forma opuesta, la velocidad y capacidad de absorción fue mayor en el grupo 150 con respecto al 500 debido al menor tamaño de los defectos. 


\subsection{MESOESTRUCTURA Y PROPIEDADES RESIDUALES EN HORMIGONES DAÑADOS POR REACCIÓN ÁLCALI-SÍLICE SOMETIDOS A CARGAS DE LARGA DURACIÓN}

Como consecuencia del desarrollo de la reacción álcali sílice aparecen en el hormigón diversos tipos de manifestaciones como por ejemplo fisuras en la interfaz y en la matriz, productos de reacción llenando fisuras, poros o alrededor de los agregados reactivos. Estas alteraciones afectan en distinto grado las propiedades del hormigón.

En esta experiencia se analizó la vinculación entre los defectos a nivel mesoestructural y el comportamiento macroscópico del hormigón para el caso de hormigones dañados por reacción álcali-sílice (RAS). Una singularidad de la aplicación abordada es que se analizaron hormigones donde la reacción se desarrolló mientras eran expuestos a cargas de compresión de larga duración; otras muestras se mantuvieron sin cargar por lo que se produjeron cuadros de fisuración diferentes en uno y otro caso. Además las muestras fueron expuestas a diferentes temperaturas (20 y $38^{\circ} \mathrm{C}$ ) lo que dio lugar a diferentes velocidades de reacción. Como referencia también se estudió un hormigón sin reacción. Sumados a la distribución de agregados y sus interfaces, se distinguieron como elementos característicos de la estructura interna la presencia de fisuras y poros, identificando los casos en que se encontraban llenos con el gel de reacción. Como propiedades macroscópicas se analizaron la respuesta a compresión, midiendo no sólo la carga de rotura sino también las deformaciones axiales y transversales y como propiedades de transporte se realizaron ensayos de permeabilidad y penetración de agua a presión.

\subsubsection{Materiales y mezclas}

Se elaboraron dos hormigones de razón a/c 0.44 empleando dos tipos de agregados gruesos con una distribución granulométrica similar (5-19 mm) uno de reacción rápida compuesto por $10 \%$ de ortocuarcita silícea muy reactiva y $90 \%$ de piedra partida granítica no reactiva y el otro compuesto en su totalidad por piedra partida granítica que da lugar a una velocidad de reacción tan lenta que se comporta como un agregado no reactivo en el período estudiado. Además se emplearon como materiales un cemento portland normal y arena silícea natural de río no reactiva. En ambos hormigones se adicionó $\mathrm{NaOH}$ (en forma granular) en el agua de mezclado 
hasta alcanzar una cantidad total de álcalis en el hormigón igual a $5.25 \mathrm{~kg} / \mathrm{m}^{3}$. En la Tabla 4.5.1 se muestran las proporciones de los hormigones.

En el primer hormigón, identificado como C, era previsible que se produjeran expansiones significativas desde las primeras semanas, mientras que en el segundo identificado como $\mathrm{T}$, los antecedentes garantizaban que no se iban a producir expansiones importantes durante el período del estudio, por lo que se estableció como hormigón de referencia (sin reacción).

Tabla 4.5.1. Proporciones de los hormigones.

\begin{tabular}{cccc}
\hline Hormigón & & T & C \\
\hline Cemento & $\left(\mathrm{kg} / \mathrm{m}^{3}\right)$ & 420 & 420 \\
Agua & $\left(\mathrm{kg} / \mathrm{m}^{3}\right)$ & 185 & 185 \\
Arena & $\left(\mathrm{kg} / \mathrm{m}^{3}\right)$ & 700 & 700 \\
Piedra & $\left(\mathrm{kg} / \mathrm{m}^{3}\right)$ & 1102 & 1080 \\
Aire & $(\%)$ & 1.5 & 1.2 \\
\hline
\end{tabular}

\subsubsection{Detalles experimentales}

Con cada hormigón se moldearon 20 cilindros de 150 × $300 \mathrm{~mm}$. A las 48 horas fueron desmoldados y se les realizó un encabezado con mortero. Los cilindros se dividieron en tres grupos, el primero (4 cilindros) fue ensayado a compresión a la edad de 7 días, el segundo fue mantenido en una cámara a una temperatura de $20 \pm 2{ }^{\circ} \mathrm{C}$ y el tercero en otra cámara a $38 \pm 2^{\circ} \mathrm{C}$. Para mantener la humedad y asegurar el desarrollo de la reacción, las probetas fueron envueltas con una tela humedecida y colocadas en bolsas plásticas individuales herméticamente cerradas. Después de cada medición la tela era rehumedecida.

Cinco cilindros del hormigón $\mathrm{C}$ y otros cinco del T fueron sometidos a cargas de larga duración, equivalentes al $40 \%$ de la resistencia a compresión, en una cámara a $20{ }^{\circ} \mathrm{C}$, estas probetas fueron identificadas como 20c. Lo mismo se realizó sobre 3 cilindros de cada hormigón en la cámara a $38^{\circ} \mathrm{C}$, llamando a este grupo 38c. Las probetas cargadas también fueron envueltas con una tela húmeda y selladas mediante un tubo plástico cerrado en los extremos en los pórticos de carga. Paralelamente se mantuvieron 3 probetas de cada grupo sin cargar, estos grupos fueron denominados 
$20 d$ y $38 d$ según la temperatura a la que estuvieron almacenadas. Periódicamente se realizaban mediciones de las deformaciones en todas las probetas. Luego de un año se descargaron los bastidores y se midieron las recuperaciones durante dos meses.

Para evaluar la evolución del daño, se midieron el peso por unidad de volumen (PUV) y la velocidad de pulso ultrasónico (VPU) antes de aplicar las cargas de larga duración (7 días) y al finalizar el programa (14 meses).

Se realizaron ensayos de compresión con medición de deformaciones transversales y longitudinales sobre algunas probetas de cada grupo que estuvieron cargadas y sobre otras que estuvieron descargadas.

También se seleccionaron 2 cilindros de cada grupo para ensayos de penetración de agua a presión y para determinar el coeficiente de permeabilidad. Con cada grupo se realizaron tres ensayos de permeabilidad y uno de penetración de agua. Para ello los cilindros se cortaron en cuatro sectores, 3 rodajas de $50 \mathrm{~mm}$ de alto para el ensayo de permeabilidad y la mitad restante de $150 \mathrm{~mm}$ para el ensayo de penetración de agua a presión.

Finalmente en las probetas dañadas por RAS (hormigón C) se analizó el cuadro de fisuración. Sobre la superficie perimetral de los cilindros se evaluó la densidad, el ancho y la orientación de fisuras. Sobre los cortes transversales de las rodajas preparadas para los ensayos de permeabilidad y penetración de agua, se determinaron la densidad y el ancho de fisuras de matriz e interfaces y la presencia de gel en poros y fisuras. En los cortes transversales también se midieron la densidad y el perímetro total de agregados. Cabe recordar que las probetas del hormigón $T$ no presentaban signos de reacción.

\subsubsection{Resultados y discusión}

En la Tabla 4.5.2 se presentan los valores de peso por unidad de volumen (PUV) y velocidad de pulso ultrasónico (VPU) y de resistencia a compresión y módulo de elasticidad de los hormigones $\mathrm{C}$ y $\mathrm{T}$ a la edad de 7 días. En base a ellos se determinaron las cargas a aplicar equivalentes al $40 \%$ de la resistencia a compresión. En ambos hormigones la resistencia a compresión fue similar, del orden de $25 \mathrm{MPa}$, existieron pequeñas diferencias en el módulo de elasticidad y el coeficiente de Poisson 
debidas al cambio en el tipo de agregado grueso. En la Fig. 4.5.1 están graficadas las curvas tensión - deformación longitudinal, transversal y volumétrica de los hormigones C y T, se observa que los dos hormigones se comportan en forma similar.

Tabla 4.5.2. Propiedades mecánicas medidas a los 7 días en los hormigones C y T.

\begin{tabular}{ccc}
\hline Grupo & C 7d & T 7d \\
\hline PUV $\left(\mathrm{kg} / \mathrm{m}^{3}\right)$ & 2390 & 2380 \\
Velocidad Pulso Ultrasónico $(\mathrm{km} / \mathrm{s})$ & 4.42 & 4.42 \\
$\mathrm{f}^{\prime}{ }_{\mathrm{c}}(\mathrm{MPa})$ & 26.3 & 25.4 \\
$\mathrm{f}_{\text {crit }}\left(\% \mathrm{f}^{\prime}{ }_{\mathrm{c}}\right)$ & 96 & 97 \\
$\mathrm{E}(\mathrm{GPa})$ & 31.4 & 29.8 \\
Coeficiente de Poisson & 0.17 & 0.16 \\
\hline
\end{tabular}

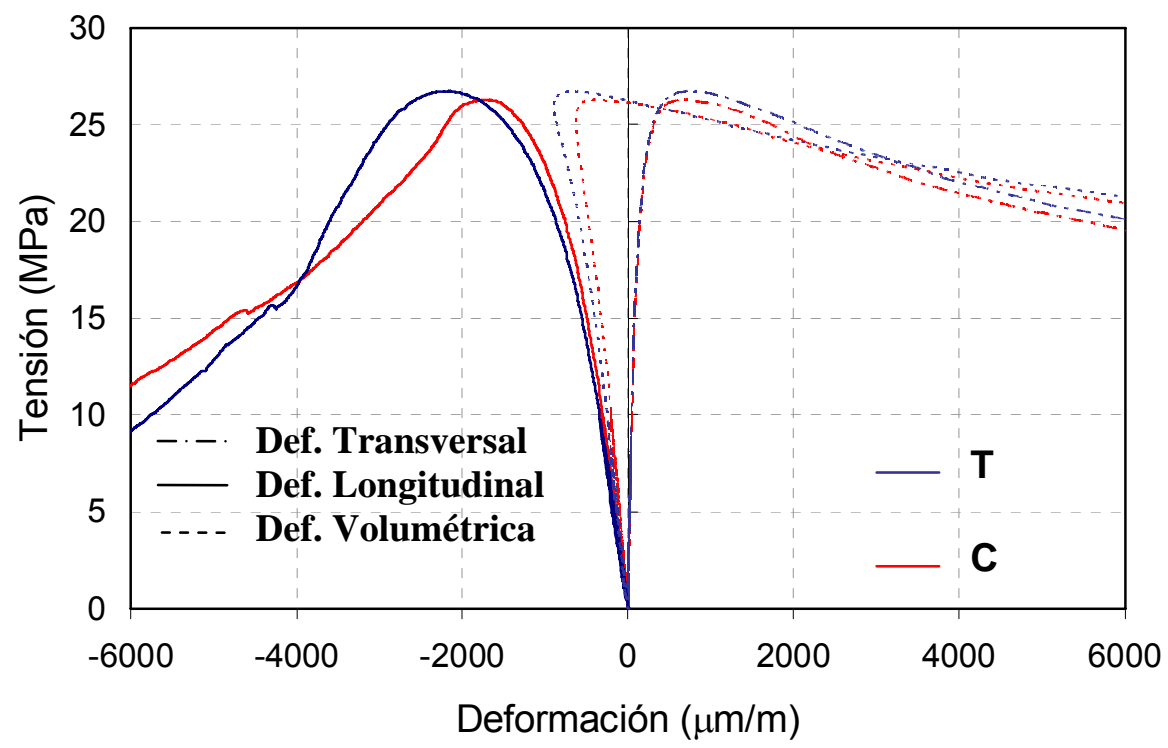

Figura 4.5.1. Curvas tensión-deformación (longitudinal, axial y volumétrica) medidas a la edad de 7 días.

En la Fig. 4.5.2 se muestra la evolución de las deformaciones totales bajo carga y la contracción libre de los hormigones. En el hormigón $T$ las deformaciones fueron ligeramente mayores en el grupo $38 \mathrm{c}$ que en el grupo $20 \mathrm{c}$. Cabe mencionar que aunque las probetas estuvieron cubiertas por bolsas plásticas y se les incorporó agua periódicamente (al momento de abrir las bolsas para realizar las mediciones), la evolución de las deformaciones de contracción libre indica que el agua incorporada no fue suficiente para evitar la contracción de la pasta. Las deformaciones bajo carga en 
el hormigón $C$ fueron similares a las medidas en el hormigón $T$, pero se observaron diferencias significativas en las probetas descargadas. Mientras en el hormigón T se midieron contracciones, en el hormigón $\mathrm{C}$ se produjeron expansiones muy importantes debido a la reacción, como era previsible el desarrollo de la reacción fue inicialmente mayor en el grupo $38 \mathrm{~d}\left(\mathrm{a} 38^{\circ} \mathrm{C}\right)$ que en el $20 \mathrm{~d}$.

Comparando ambos hormigones después de 1 año de exposición, no se observan grandes diferencias en las deformaciones totales bajo carga, que fueron del orden de 2000 y $1500 \mu \mathrm{m} / \mathrm{m}$ según hubieran permanecido a 20 o a $38{ }^{\circ} \mathrm{C}$ respectivamente. Por el contrario mientras en el hormigón $\mathrm{C}$ las probetas que permanecieron descargadas experimentaron expansiones cercanas a $4000 \mu \mathrm{m} / \mathrm{m}$ en el hormigón T se midieron contracciones próximas a $500 \mu \mathrm{m} / \mathrm{m}$.

El desarrollo de la RAS no sólo provocó cambios en las deformaciones de las probetas sino que se evidenció a partir de la aparición de geles, manchas y fundamentalmente fisuras. Por lo tanto una vez finalizados los ensayos de larga duración y descargadas las probetas, se realizó en primer lugar un análisis del cuadro de fisuras sobre las superficies de las probetas, tanto de las que estuvieron cargadas como las que permanecieron sin cargar.

Al cabo de 14 meses las probetas del grupo $\mathrm{T}$, no presentaron fisuras, mientras que las del grupo $\mathrm{C}$ se encontraban visiblemente deterioradas. En este último grupo se observó un cuadro de fisuración diferente según las probetas hubieran estado sometidas o no a cargas de larga duración.

En la Fig. 4.5.3 se puede observar el aspecto del cuadro de fisuración desarrollado en cada grupo del hormigón C. En las probetas cargadas las fisuras se desarrollaron preferencialmente en la dirección del eje de los cilindros, es decir paralelas a las cargas. Por el contrario las probetas descargadas presentaban fisuras en todas las direcciones, con la propagación característica en ángulos a $120^{\circ}$. 

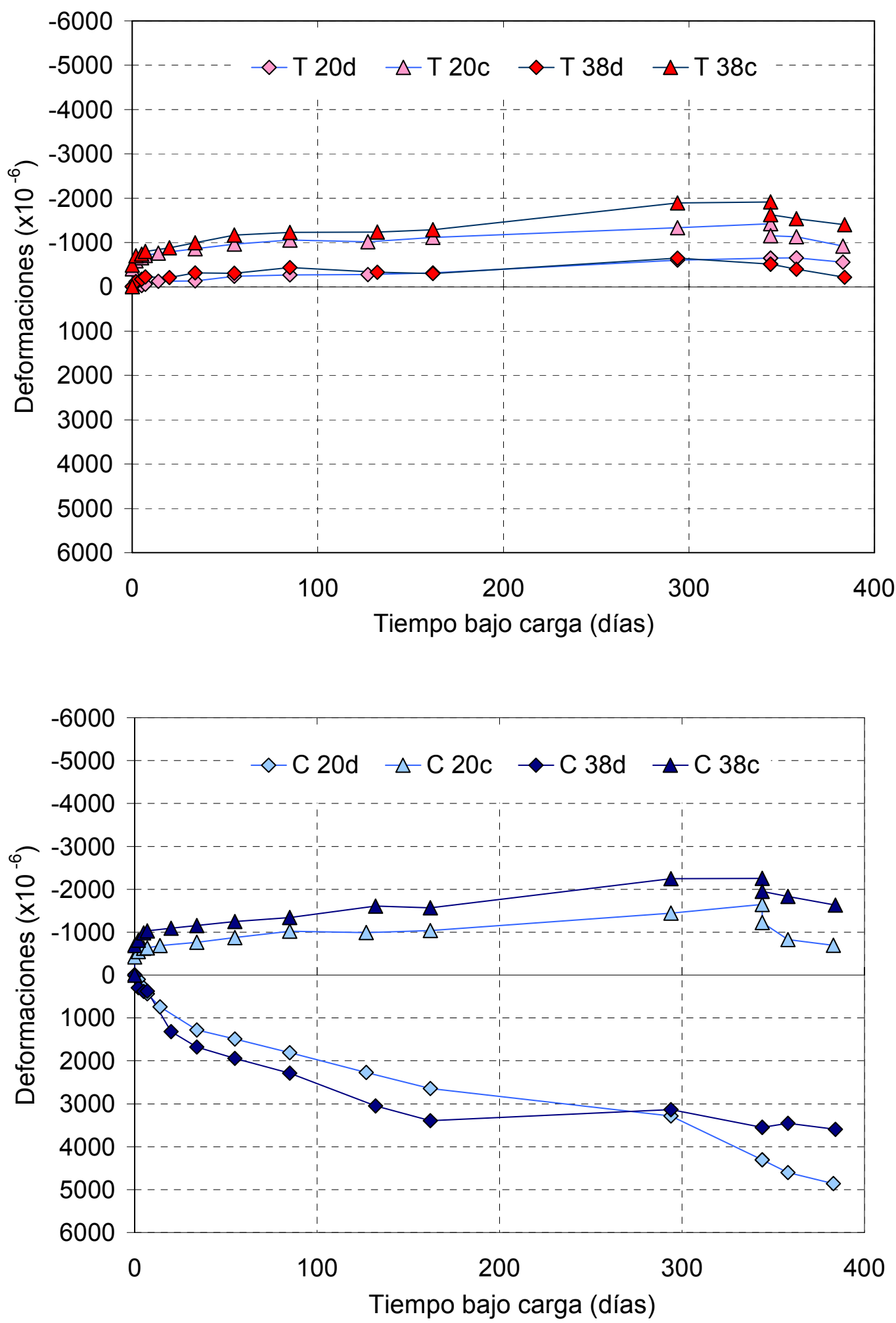

Figura 4.5.2. Deformaciones totales bajo carga y deformaciones libres (sin cargar) medidas durante 14 meses. Arriba: Hormigón T. Abajo: Hormigón C. 


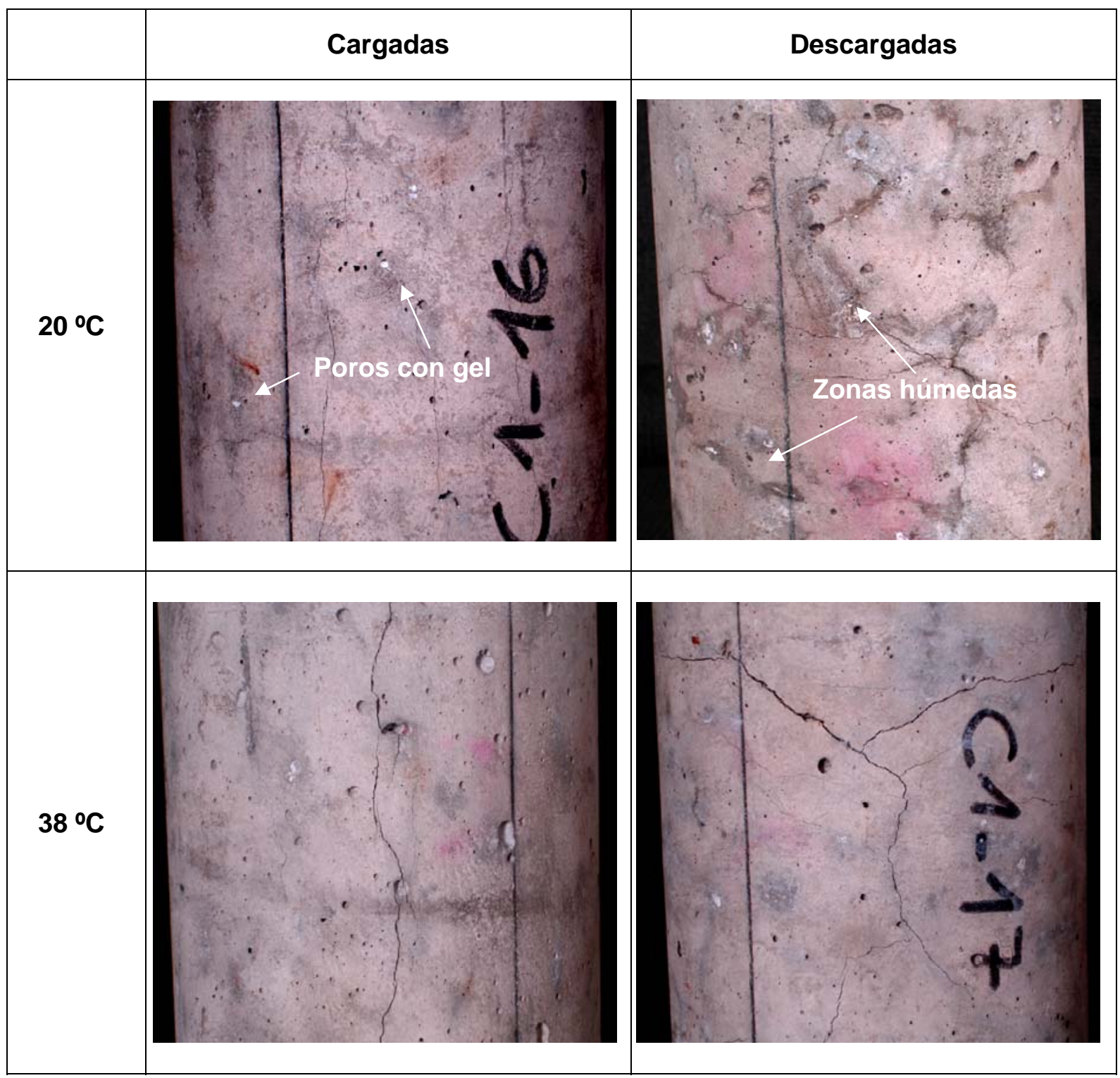

Figura 4.5.3. Cuadro de fisuración en la superficie de los cilindros del hormigón $C$ Arriba: C20c y C20d. Abajo: C38c y C38d.

En la Tabla 4.5.3 se muestran los resultados del relevamiento del perímetro de los cilindros de los diferentes grupos del hormigón $\mathrm{C}$, incluye el ancho máximo, la densidad y la orientación de las fisuras.

Para definir la orientación de las fisuras se adoptaron ángulos de $0^{\circ}, 22.5^{\circ}, 45^{\circ}$, $67.5^{\circ}$ y $90^{\circ}$, correspondiendo el ángulo igual a $90^{\circ}$ a la dirección paralela al eje longitudinal de los cilindros. En la Fig. 4.5 .4 se presenta el criterio adoptado. 


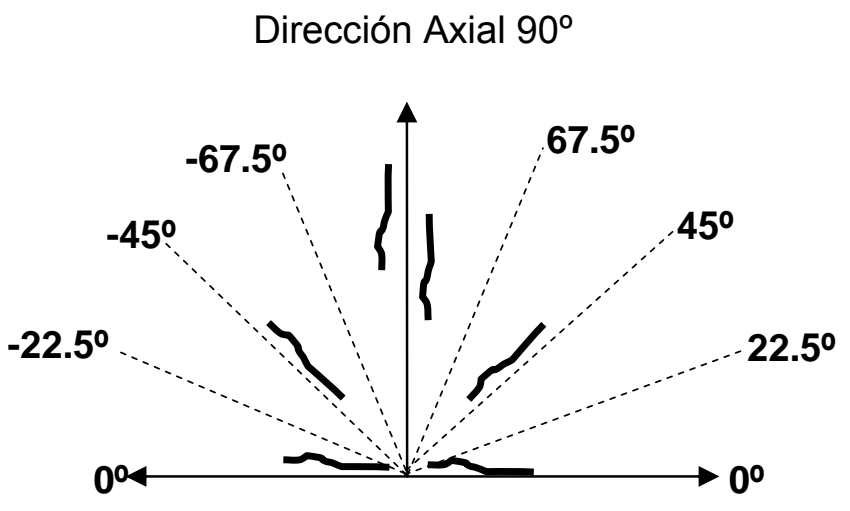

Figura 4.5.4. Esquema del criterio adoptado para evaluar la orientación de las fisuras.

Todas las probetas presentaron fisuras bien definidas con anchos máximos de aproximadamente $0.3 \mathrm{~mm}$, sin embargo las probetas descargadas (grupos 20d y $38 \mathrm{~d}$ ) mostraron una densidad de fisuras $40 \%$ mayor que las sometidas a cargas de larga duración (20c y 38c respectivamente). En la Tabla 4.5 .3 se observa que más del $67 \%$ de las fisuras en los grupos que permanecieron bajo carga se desarrollaron en la dirección axial, un $23 \%$ formando un ángulo de aproximadamente $67.5^{\circ}$ y menos del $4 \%$ de las fisuras se orientaron de manera perpendicular a las cargas. Por el contrario en los grupos $20 \mathrm{~d}$ y $38 \mathrm{~d}$ la mayoría de las fisuras se orientaron con ángulos entre 22.5 y $45^{\circ}$ y sólo un $7 \%$ en la dirección del eje de los cilindros.

Tabla 4.5.3. Caracterización del cuadro de fisuración del perímetro de los cilindros.

\begin{tabular}{cccccccc}
\hline Grupo & $\begin{array}{c}\text { Densidad de } \\
\text { fisuras } \\
\mathrm{cm} / \mathrm{cm}^{2}\end{array}$ & Ancho Máximo & \multicolumn{5}{c}{ Ángulos de orientación } \\
& 0.26 & $\mathrm{~mm}$ & $0^{\circ}$ & $\pm 22.5^{\circ}$ & $\pm 45^{\circ}$ & $\pm 67.5^{\circ}$ & $90^{\circ}$ \\
\hline $\mathrm{C} 38 \mathrm{c}$ & 0.42 & 0.4 & $18 \%$ & $36 \%$ & $21 \%$ & $18 \%$ & $7 \%$ \\
$\mathrm{C} 38 \mathrm{~d}$ & 0.24 & 0.3 & $4 \%$ & $4 \%$ & $3 \%$ & $22 \%$ & $67 \%$ \\
$\mathrm{C} 20 \mathrm{c}$ & 0.40 & 0.3 & $17 \%$ & $34 \%$ & $24 \%$ & $18 \%$ & $7 \%$ \\
$\mathrm{C} 20 \mathrm{~d}$ & & & & & & & \\
\hline
\end{tabular}

Luego todos los cilindros fueron evaluados mediante ensayos no destructivos y fueron seleccionadas probetas de cada grupo para realizar los ensayos de compresión, permeabilidad y penetración de agua a presión.

Sobre los cortes transversales de las rodajas destinadas a los ensayos de permeabilidad y penetración de agua a presión del hormigón $\mathrm{C}$, se realizó previamente una evaluación de la mesoestructura. Se analizaron la densidad y el ancho máximo de 
las fisuras, diferenciando las fisuras de interfaces de las de matriz, y el número de poros y fisuras rellenos con gel, los resultados se informan en la Tabla 4.5.4. Respecto a la densidad de fisuras se evaluó el número de fisuras por unidad de área distinguiendo entre fisuras con longitudes entre 5 y $10 \mathrm{~mm}$, entre 10 y $20 \mathrm{~mm}$ y mayores a $20 \mathrm{~mm}$, también se calculó la densidad total de fisuras expresada en $\mathrm{cm}$ por unidad de área.

En la Tabla 4.5 .5 se resumen los resultados del relevamiento de agregados, se analizó la densidad, perímetro total o longitud de interfaz y número de agregados reactivos.

Tabla 4.5.4. Relevamiento de fisuras y poros con gel en cortes del hormigón C.

\begin{tabular}{|c|c|c|c|c|c|c|c|c|c|}
\hline \multirow{4}{*}{ 足 } & \multicolumn{8}{|c|}{ Fisuras } & \multirow{4}{*}{$\begin{array}{c}\text { Poros } \\
\text { con } \\
\text { gel } \\
\left(N^{\circ}\right)\end{array}$} \\
\hline & \multicolumn{4}{|c|}{ Densidad } & \multirow{2}{*}{\multicolumn{2}{|c|}{$\begin{array}{l}\text { Ancho máximo } \\
(\mathrm{mm})\end{array}$}} & \multirow{2}{*}{\multicolumn{2}{|c|}{ Fisuras con gel $\left(\mathrm{N}^{\circ}\right)$}} & \\
\hline & \multicolumn{3}{|c|}{$\mathrm{N}^{\circ} / \mathrm{cm}^{2}$} & \multirow{2}{*}{$\begin{array}{c}\mathrm{cm} / \mathrm{cm}^{2} \\
\text { Total }\end{array}$} & & & & & \\
\hline & $>20 \mathrm{~mm}$ & $10-20 \mathrm{~mm}$ & $5-10 \mathrm{~mm}$ & & Matriz & Interfaz & Matriz & Interfaz & \\
\hline \multirow{4}{*}{$20 d$} & 0.03 & 0.09 & 0.10 & 0.33 & 0.05 & 0.30 & 1 & 5 & 3 \\
\hline & 0.01 & 0.09 & 0.11 & 0.27 & 0.50 & 0.50 & - & 1 & 1 \\
\hline & 0.05 & 0.10 & 0.19 & 0.43 & - & 0.25 & - & 12 & 4 \\
\hline & 0.01 & 0.23 & 0.14 & 0.50 & 0.15 & 0.70 & 1 & 10 & 1 \\
\hline Promedio & 0.03 & 0.13 & 0.14 & 0.38 & 0.23 & 0.40 & 1 & 7 & 2.3 \\
\hline \multirow{4}{*}{$20 c$} & 0.05 & 0.05 & 0.18 & 0.47 & $0.15^{\star}$ & 0.45 & 2 & 5 & 2 \\
\hline & 0.13 & 0.06 & 0.13 & 0.55 & 0.05 & 0.70 & - & 3 & 1 \\
\hline & 0.06 & 0.09 & 0.25 & 0.54 & 0.20 & 1.00 & 1 & 16 & 7 \\
\hline & 0.04 & 0.09 & 0.22 & 0.48 & 0.35 & 0.40 & 2 & 16 & 2 \\
\hline Promedio & 0.07 & 0.07 & 0.20 & 0.51 & 0.26 & 0.60 & 1.7 & 10 & 3 \\
\hline \multirow{4}{*}{$38 d$} & 0.04 & 0.18 & 0.19 & 0.51 & 0.10 & 0.50 & 1 & 6 & 6 \\
\hline & 0.04 & 0.13 & 0.13 & 0.44 & 0.10 & 0.70 & 1 & 5 & 3 \\
\hline & 0.11 & 0.15 & 0.15 & 0.71 & 0.10 & 0.40 & 1 & 10 & 1 \\
\hline & 0.10 & 0.11 & 0.23 & 0.67 & 0.20 & 1.00 & 2 & 7 & 1 \\
\hline Promedio & 0.07 & 0.14 & 0.18 & 0.58 & 0.13 & 0.70 & 1.3 & 7 & 2.8 \\
\hline \multirow{2}{*}{$38 c$} & 0.06 & 0.09 & 0.11 & 0.40 & 0.10 & 0.10 & 1 & 10 & 3 \\
\hline & 0.03 & 0.05 & 0.11 & 0.22 & 0.05 & 0.10 & - & 2 & 1 \\
\hline Promedio & 0.05 & 0.07 & 0.11 & 0.31 & 0.08 & 0.10 & 1 & 6 & 2 \\
\hline
\end{tabular}

*Nota: una única fisura presentó en un sector un ancho máximo igual a $0.8 \mathrm{~mm}$. 
Tabla 4.5.5. Relevamiento de agregados.

\begin{tabular}{|c|c|c|c|}
\hline \multirow[b]{2}{*}{ Grupo } & \multicolumn{3}{|c|}{ Agregados } \\
\hline & $\begin{array}{l}\text { Reactivos } \\
\left(\mathrm{N}^{\circ}\right)\end{array}$ & $\begin{array}{l}\text { Densidad } \\
\left(\mathrm{cm}^{2} / \mathrm{cm}^{2}\right)\end{array}$ & $\begin{array}{l}\text { Perímetro } \\
\text { (cm) }\end{array}$ \\
\hline \multirow{4}{*}{$20 d$} & 8 & 0.23 & 121.2 \\
\hline & 6 & 0.28 & 135.6 \\
\hline & 12 & 0.41 & 202.0 \\
\hline & 10 & 0.37 & 158.1 \\
\hline \multirow{4}{*}{$20 c$} & 4 & 0.33 & 159.1 \\
\hline & 5 & 0.35 & 167.6 \\
\hline & 16 & 0.37 & 177.0 \\
\hline & 16 & 0.31 & 146.7 \\
\hline \multirow{4}{*}{$38 d$} & 6 & 0.34 & 171.8 \\
\hline & 2 & 0.34 & 156.1 \\
\hline & 7 & 0.43 & 151.0 \\
\hline & 7 & 0.31 & 128.8 \\
\hline \multirow{2}{*}{$38 c$} & 4 & 0.36 & 176.7 \\
\hline & 2 & 0.39 & 198.5 \\
\hline
\end{tabular}

En la Fig. 4.5.5 se observa que existe cierta relación entre la cantidad de agregados con desarrollo de reacción y la densidad de fisuras, esta vinculación parece variar según el tipo de exposición. Las probetas de los grupos 38 presentaron una mayor densidad de fisuras para igual cantidad de agregados reactivos que las de los grupos 20 , en el primer caso se habrían formado mayor cantidad de productos de reacción.

En la Fig. 4.5.6 se muestran cortes obtenidos en experiencias previas que permiten apreciar la microestructura del hormigón $C$ una vez desarrollada la reacción (Giaccio et al, 2008). En el corte pulido (obtenido a una edad de 30 días) se puede ver un agregado reactivo $(\mathrm{RA})$ rodeado por un anillo de reacción $(\mathrm{Rr})$, producto de la disolución del silicio de la ortocuarcita, también se observa un poro $(\mathrm{Po})$ relleno con gel (G) y una microfisura (Mc) atravesando el agregado. En el corte delgado (4 meses de edad) se observan microfisuras en la matriz, producto de la expansión del gel en las interfaces. 


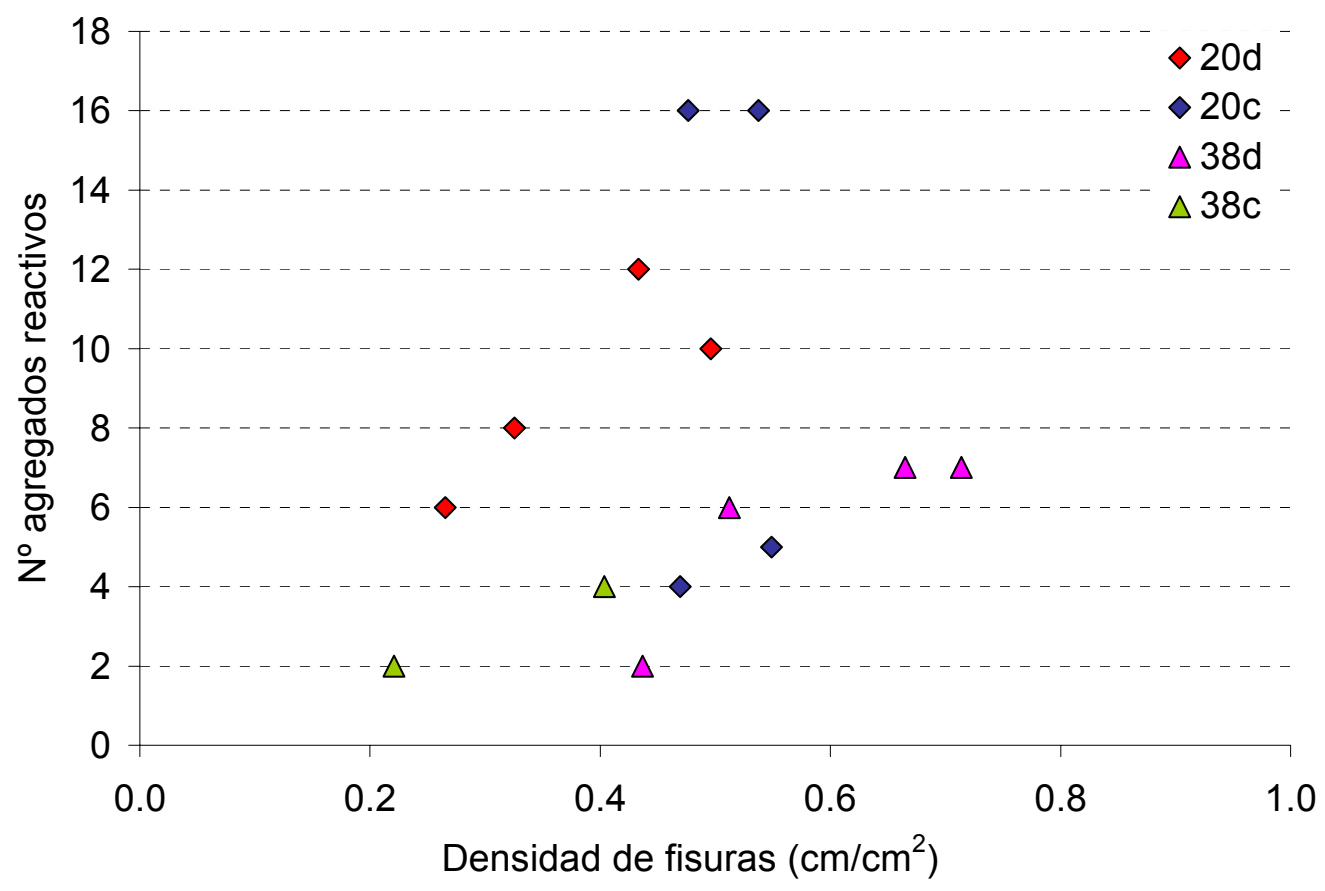

Figura 4.5.5. Variación de la densidad de fisuras con el número de agregados reactivos evaluados sobre las rodajas utilizadas en el ensayo de permeabilidad.
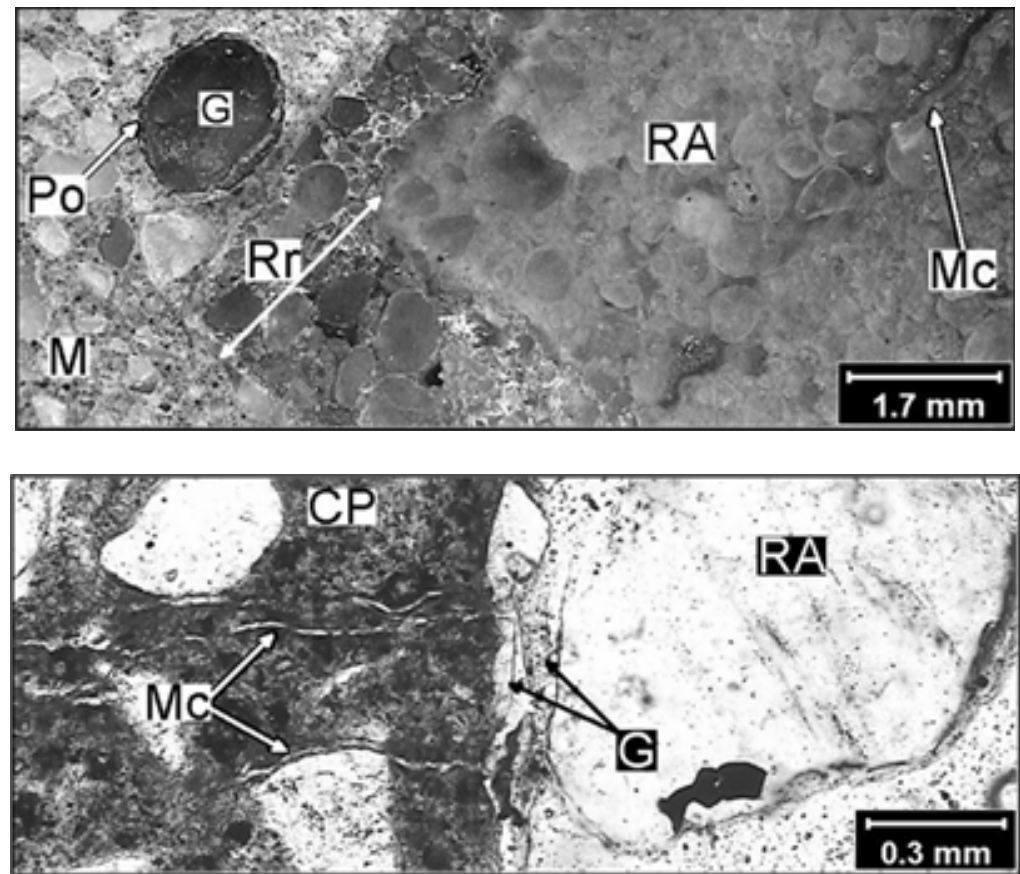

Figura 4.5.6. Efectos de la reacción álcali sílice sobre la estructura del hormigón C. Imagen superior: corte pulido. Imagen inferior: corte delgado. (Giaccio et al, 2008) 
En la Tabla 4.5.6 se muestran los valores de peso por unidad de volumen (PUV) y velocidad de pulso ultrasónico (VPU) junto con las propiedades mecánicas medidas al cabo de 14 meses. Se puede observar en el hormigón $C$ que tanto el PUV como la VPU del grupo 38 fueron menores que en el grupo 20. En el hormigón T no se encontraron diferencias significativas en la VPU entre las probetas cargadas y descargadas, mientras que en el hormigón $C$ se registraron reducciones entre un 10 y un $20 \%$ en la VPU. La velocidad se vio más afectada por la presencia de fisuras que por el proceso de consolidación debido a las cargas de larga duración.

En la Fig. 4.5.7 se representa la variación de la VPU con la densidad de fisuras medidas en la superficie perimetral de las probetas de los hormigones $\mathrm{C}$, como ya fue comentado en los estudios anteriores la VPU es un buen indicador del estado del hormigón. En este caso también se verifica que a medida que aumenta el deterioro del hormigón disminuye la VPU.

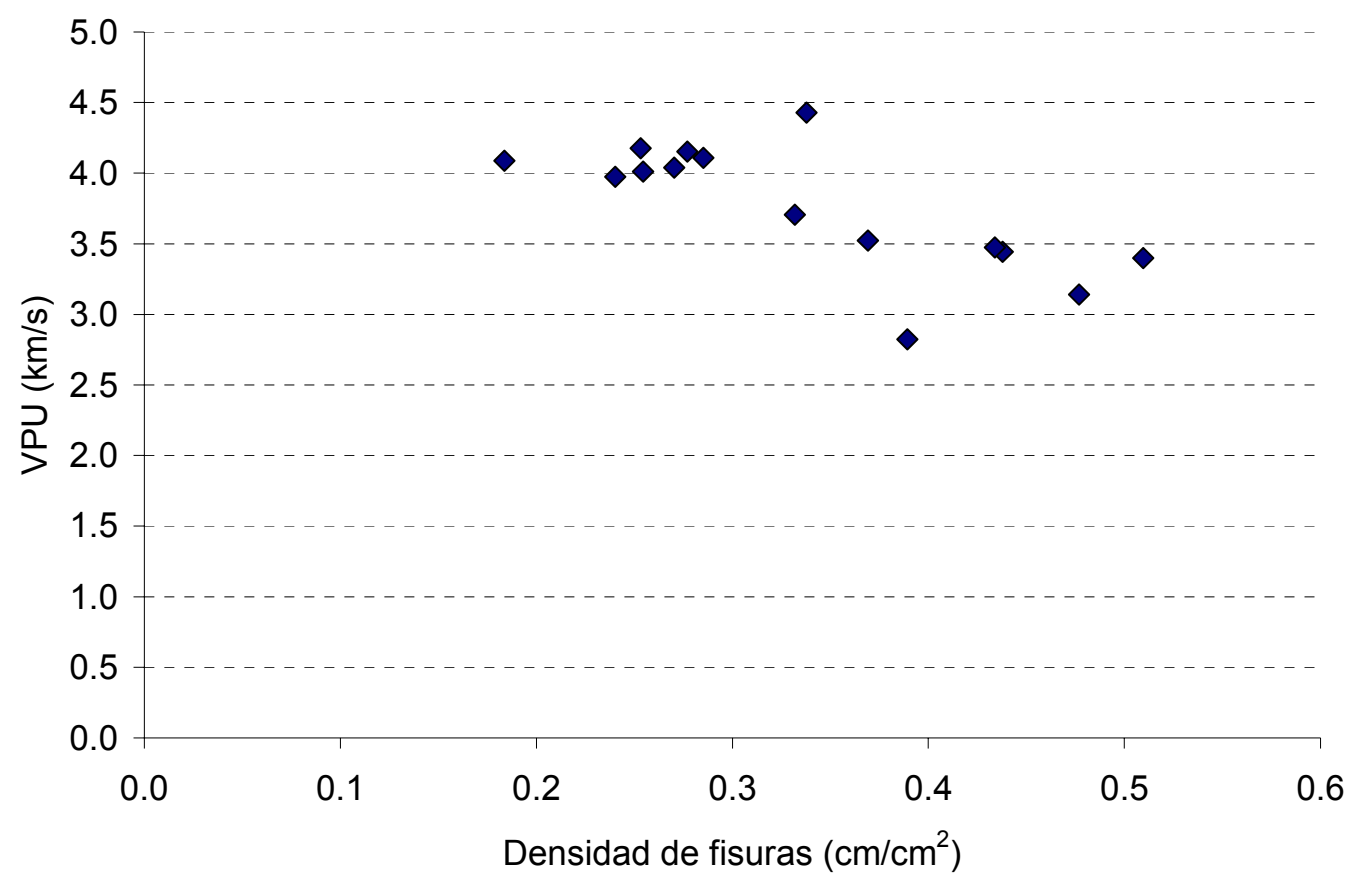

Figura 4.5.7. Relación entre la velocidad de pulso ultrasónico y la densidad de fisuras en el perímetro.

En cuanto a las propiedades mecánicas en la Tabla 4.5.6 al comparar los grupos cargados y descargados tanto para las probetas que permanecieron a $38^{\circ} \mathrm{C}$ como las que estuvieron a $20^{\circ} \mathrm{C}$, se aprecian diferencias en la resistencia y la deformabilidad, que pueden ser atribuidas al proceso de consolidación bajo cargas 
sostenidas. Estas diferencias fueron más significativas en el hormigón $C$ donde se superponen el proceso de consolidación y el desarrollo de fisuras por RAS orientadas conforme los esfuerzos aplicados.

Las probetas que estuvieron bajo cargas sostenidas presentaron mayor resistencia a compresión que las mantenidas sin cargar. En el hormigón $T$ la resistencia a compresión se incrementó cerca del $10 \%$. En el hormigón C el incremento fue de un $40 \%$ aproximadamente en comparación con los grupos sin cargar. Como era esperable, la tensión crítica (tensión que corresponde al comienzo de la propagación inestable de fisuras) también resultó afectada por el desarrollo de la fisuración interna, en el hormigón $\mathrm{C}$ la $\mathrm{f}_{\text {crit }}$ disminuyó más del $20 \%$ en los grupos descargados con respecto a los que estuvieron cargados, mientras que en el hormigón T la tensión crítica presentó un valor cercano a la tensión de rotura para todos los grupos, siendo ligeramente menor para las probetas sometidas a cargas sostenidas.

El módulo de elasticidad también se incrementó en las probetas cargadas del hormigón $\mathrm{T}$ aunque en menor proporción que en el hormigón $\mathrm{C}$. Los valores medidos en las probetas descargadas del hormigón C fueron un $50 \%$ menores que los obtenidos en los grupos 20c y 38c; a la vez son menores inclusive a los valores medidos a los 7 días, poniendo de manifiesto el proceso de degradación sufrido por el hormigón. El coeficiente de Poisson no experimentó grandes variaciones, pero en los dos hormigones el coeficiente fue mayor en las probetas que permanecieron bajo cargas de larga duración.

Tabla 4.5.6. Ensayos no destructivos y propiedades mecánicas medidas sobre los hormigones $\mathrm{C}$ y $\mathrm{T}$ una vez finalizados los ensayos de fluencia.

\begin{tabular}{ccccccccc}
\hline Grupo & C38c & C38d & C20c & C20d & T38c & T38d & T20c & T20d \\
\hline PUV $\left(\mathrm{kg} / \mathrm{m}^{3}\right)$ & 2310 & 2330 & 2370 & 2370 & 2320 & 2360 & 2410 & 2390 \\
$\operatorname{VPU}(\mathrm{km} / \mathrm{s})$ & 4.01 & 3.16 & 4.12 & 3.66 & 4.46 & 4.56 & 4.52 & 4.45 \\
$\mathrm{f}^{\prime}(\mathrm{MPa})$ & 42.1 & 26.2 & 41.5 & 25.6 & 53.4 & 49.7 & 58.1 & 54.0 \\
$\mathrm{f}_{\text {crit }}\left(\%^{\prime} \mathrm{f}_{\mathrm{c}}\right)$ & 79 & 60 & 62 & $48^{*}$ & $94^{*}$ & 96 & 93 & $100^{*}$ \\
$\mathrm{E}(\mathrm{GPa})$ & 29.3 & 8.9 & 22.7 & 12.1 & 34.3 & 30.5 & 36.7 & 35.6 \\
$\mu$ & 0.17 & 0.14 & 0.17 & 0.12 & 0.18 & 0.16 & 0.19 & 0.17 \\
\hline
\end{tabular}

*Nota: estos valores corresponden a un solo ensayo. 
En las Fig. 4.5.8a y b se muestran curvas típicas tensión-deformación transversal, longitudinal y volumétrica representativas de cada grupo, obtenidas una vez finalizado el ensayo de fluencia. Dado que el hormigón T no presentaba signos de reacción y los parámetros medidos en las probetas expuestas a $20^{\circ} \mathrm{C}$ y a $38^{\circ} \mathrm{C}$ fueron similares, sólo se hizo la distinción entre los grupos cargados y descargados. Finalmente para el hormigón $\mathrm{C}$ se muestran curvas representativas de cada uno de los grupos (20c, 20d, 38c y $38 d)$.

Las curvas muestran que la presencia y orientación de fisuras producidas por RAS y el efecto de la consolidación bajo cargas modifican el mecanismo de rotura en compresión. La existencia de un importante cuadro de fisuración también se manifestó en el comportamiento de los hormigones $\mathrm{C}$ durante los ciclos de carga y descarga iniciales. En las Fig. 4.5.8-b se observa que quedan, fundamentalmente en los grupos $20 \mathrm{~d}$ y $38 \mathrm{~d}$, deformaciones remanentes al cabo de cada ciclo. En estos grupos las probetas se encontraban fisuradas en todas las direcciones, inicialmente las fisuras orientadas en la dirección normal a la carga se fueron cerrando. Asimismo las deformaciones para la carga pico fueron significativamente mayores en los grupos $20 \mathrm{~d}$ y 38d del hormigón $\mathrm{C}$, en estos grupos las deformaciones para la carga pico fueron mayores a $3000 \mu \mathrm{m} / \mathrm{m}$ mientras que para los grupos que estuvieron cargados fueron del orden de $2000 \mu \mathrm{m} / \mathrm{m}$. El hormigón T que no se encontraba prefisurado no presentó deformaciones remanentes para los ciclos de carga y descarga (Fig. 4.5.8-a).

a- Hormigón T

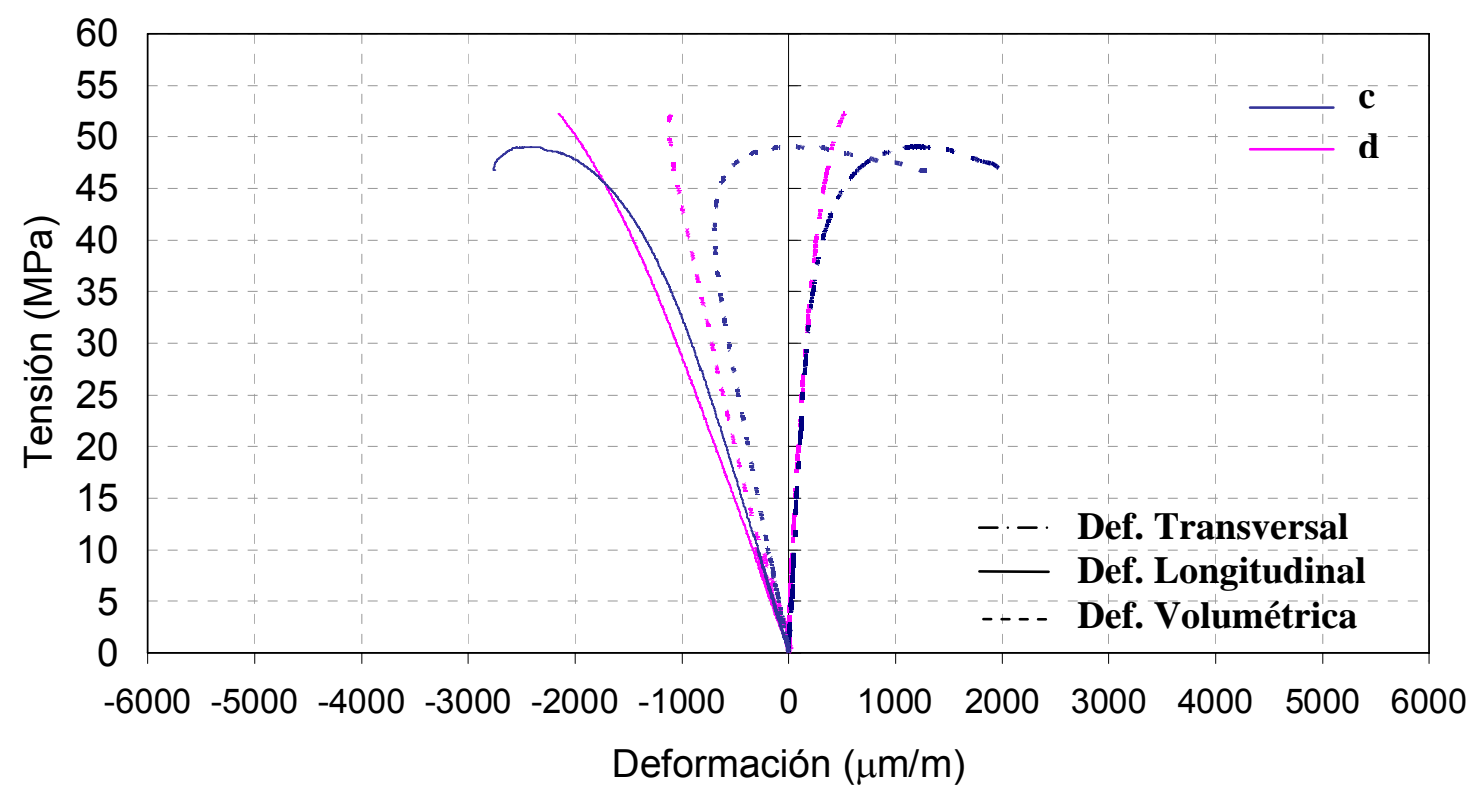


b- Hormigón C
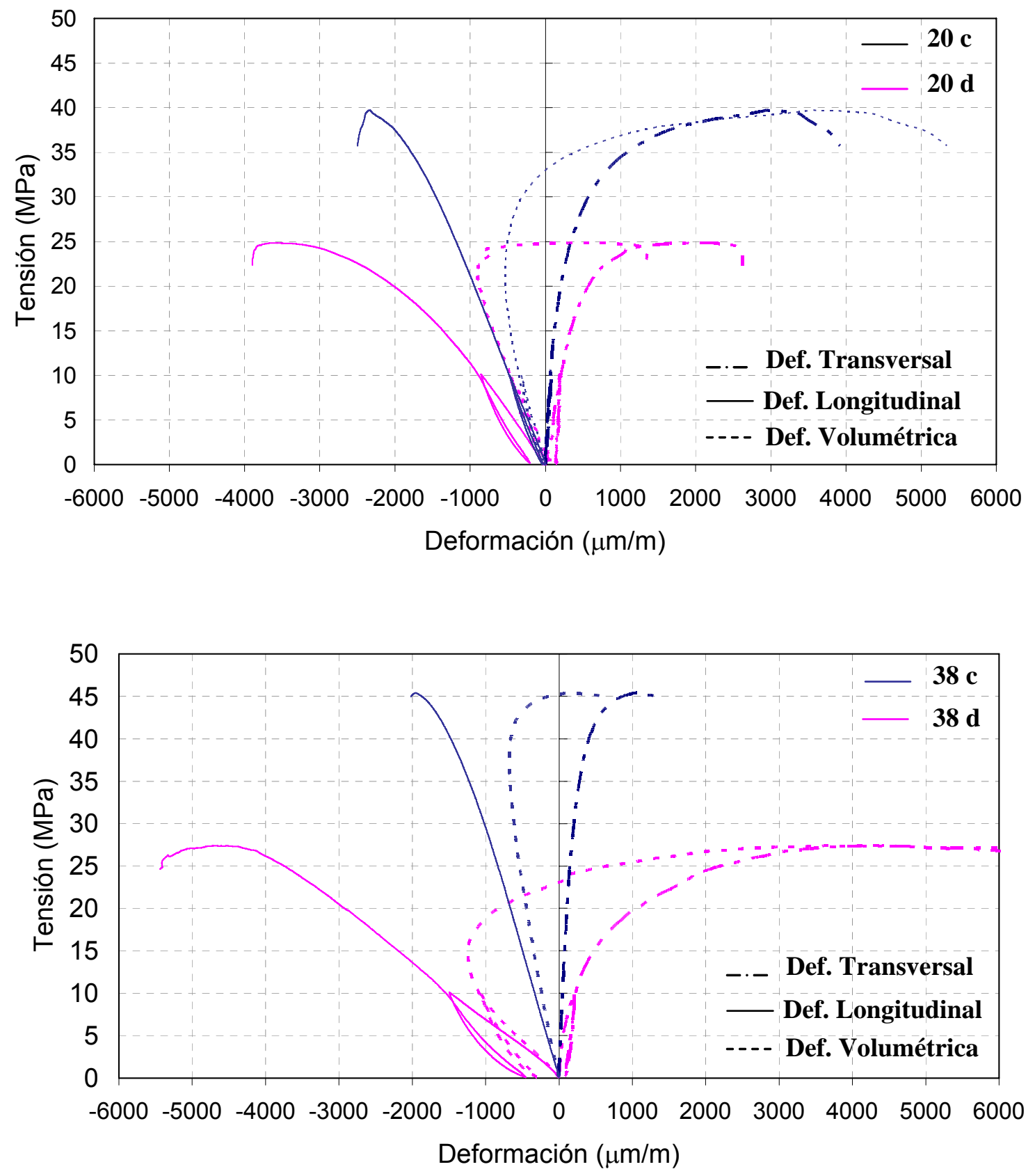

Figura 4.5.8. a- Curvas tensión-deformación para los hormigones T.

b- Curvas tensión-deformación para los hormigones C.

Arriba: Grupos 20c y 20d. Abajo: Grupos 38c y d. 
Respecto a las propiedades de transporte los hormigones C y $\mathrm{T}$ fueron ensayados a permeabilidad. El hormigón T fue ensayado durante 15 días al cabo de los cuales no se registró pasaje de agua, al descargar el equipo la cara de la rodaja opuesta a la superficie de penetración del agua se encontraba seca. Por el contrario el pasaje de agua fue importante en el hormigón dañado. En la Fig. 4.5.9 se muestran algunas curvas obtenidas a partir de ensayos de permeabilidad sobre el hormigón C.

Dichas curvas han sido seleccionadas como representativas de los diferentes comportamientos observados en los sucesivos ensayos. Se destaca que no se encontró en las curvas de cada uno de los grupos (20c, 20d, 38c, 38d) un comportamiento característico que las diferencie conceptualmente del resto. En este sentido es posible concluir que el estado de fisuración es tal que el ensayo de permeabilidad no es sensible a las variaciones que pueden existir entre los grupos. En general las curvas registraron un máximo en el coeficiente de permeabilidad al inicio del ensayo; algo similar a lo observado en las probetas sometidas a $500{ }^{\circ} \mathrm{C}$ (incisos 4.2 y 4.3). Si bien esto es concordante con el importante cuadro de fisuración observado, en este caso la posterior reducción del flujo de agua se produjo en una forma mucho más rápida.

En la Fig. 4.5.9-a es posible observar que el coeficiente de permeabilidad inicial fue del orden de $5 \times 10^{-11} \mathrm{~m} / \mathrm{s}$, presentando un máximo al cabo de 30 horas, luego la permeabilidad fue disminuyendo en forma gradual. En la Fig. 4.5.9-c se observa un máximo del coeficiente al inicio del ensayo, a partir del cual disminuyó abruptamente en las primeras 15 horas, en las 15 horas siguientes el coeficiente de permeabilidad se incrementó hasta aproximadamente $30 \times 10^{-11} \mathrm{~m} / \mathrm{s}$ y finalmente se estabilizó en un valor cercano a $20 \times 10^{-11} \mathrm{~m} / \mathrm{s}$. Según se observa en las Fig. 4.5.9-b y d las curvas presentaron un coeficiente inicial muy grande (superior a $100 \times 10^{-11} \mathrm{~m} / \mathrm{s}$ ) el cual al cabo de las primeras 15 horas aproximadamente disminuyó en forma pronunciada. Esta rápida disminución en el coeficiente de permeabilidad encontrado en todos los casos puede ser atribuido a la rehidratación del gel. 
a

$20 c$

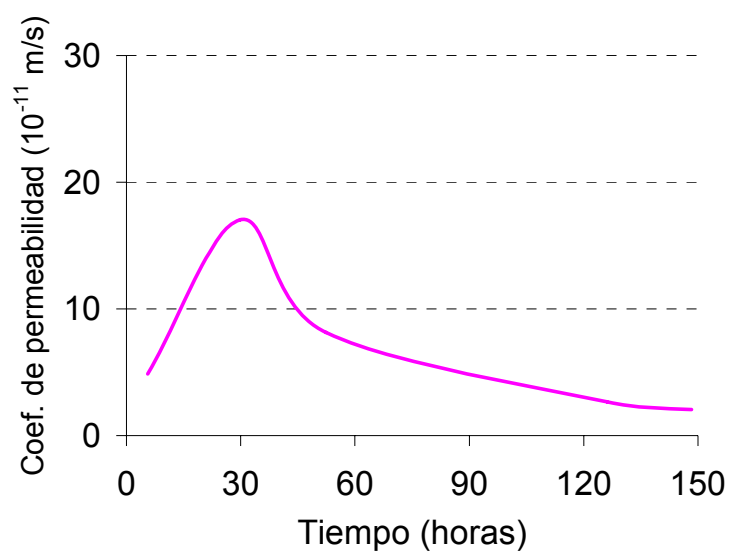

C

$38 \mathrm{c}$

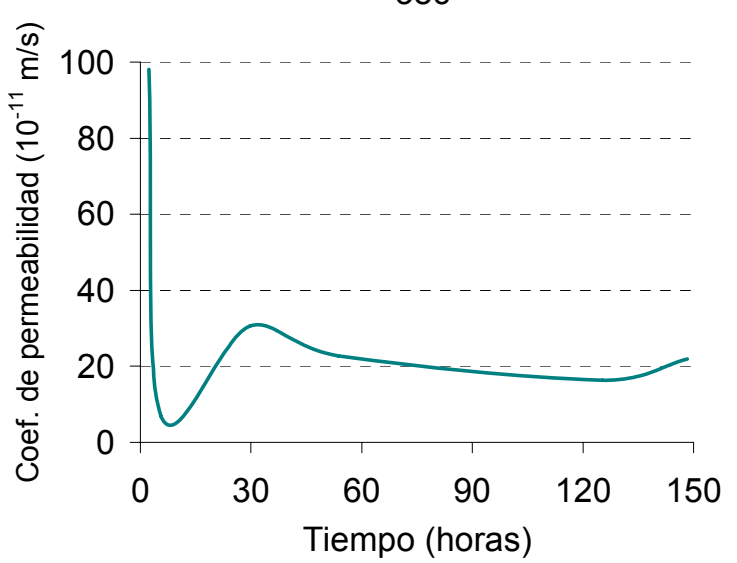

b

$20 c$

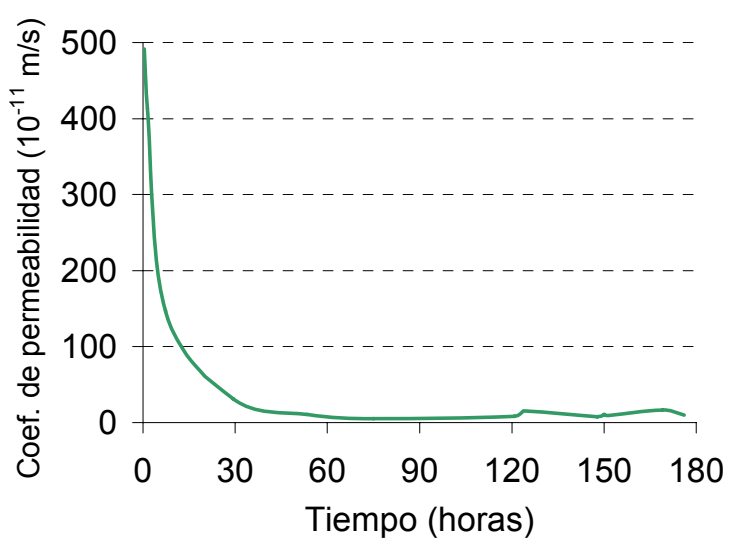

d

$38 d$

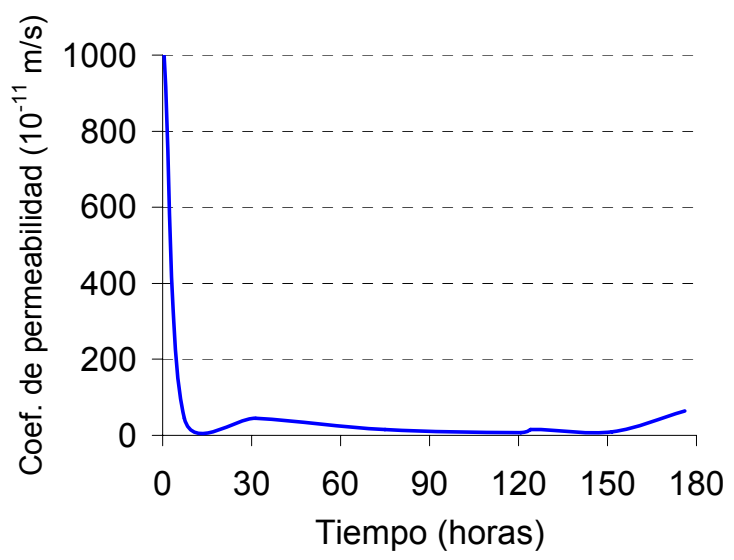

Figura 4.5.9. Curvas típicas del ensayo de permeabilidad.

En la Fig. 4.5.10 se muestran fotografías correspondientes a rodajas de los grupos 38c, 38d, 20c y 20d luego de ser sometidas al ensayo de permeabilidad. En todos los casos se observa la presencia de gel rodeando agregados o llenando poros y fisuras en mayor o menor cantidad junto con agregados reactivos muy deteriorados. En la primera fotografía se puede ver la presencia de gel con humedad en los alrededores del agregado reactivo. La segunda fotografía corresponde a una rodaja del grupo 38d, en el detalle se observa el deterioro sufrido por los agregados reactivos, que en algunos casos se encuentran totalmente desintegrados. En la tercera fotografía (grupo 20d) se aprecia la existencia de gel rodeando agregados y llenando fisuras. En la última foto, se observa gel exudado de los poros.

Debido a la dificultad de obtener un régimen de flujo estable fueron considerados distintos coeficientes de permeabilidad a fin de caracterizar al material. 
En la Tabla 4.5.7 se presentan los coeficientes calculados para cada uno de los tres ensayos de permeabilidad realizados sobre estos hormigones. El primer ensayo (1) tuvo una duración de 7 días, el segundo (2) se realizó en 2 días y finalmente el tercer ensayo (3) duró 6 días. El coeficiente $\mathrm{K}$ máximo representa el mayor valor del coeficiente de permeabilidad registrado, el $\mathrm{K}_{24}$ corresponde al valor del coeficiente medido a las 24 horas de iniciado el ensayo y finalmente el $\mathrm{K}$ final es el valor del coeficiente calculado cuando se estabilizó en buena medida el pasaje de agua.
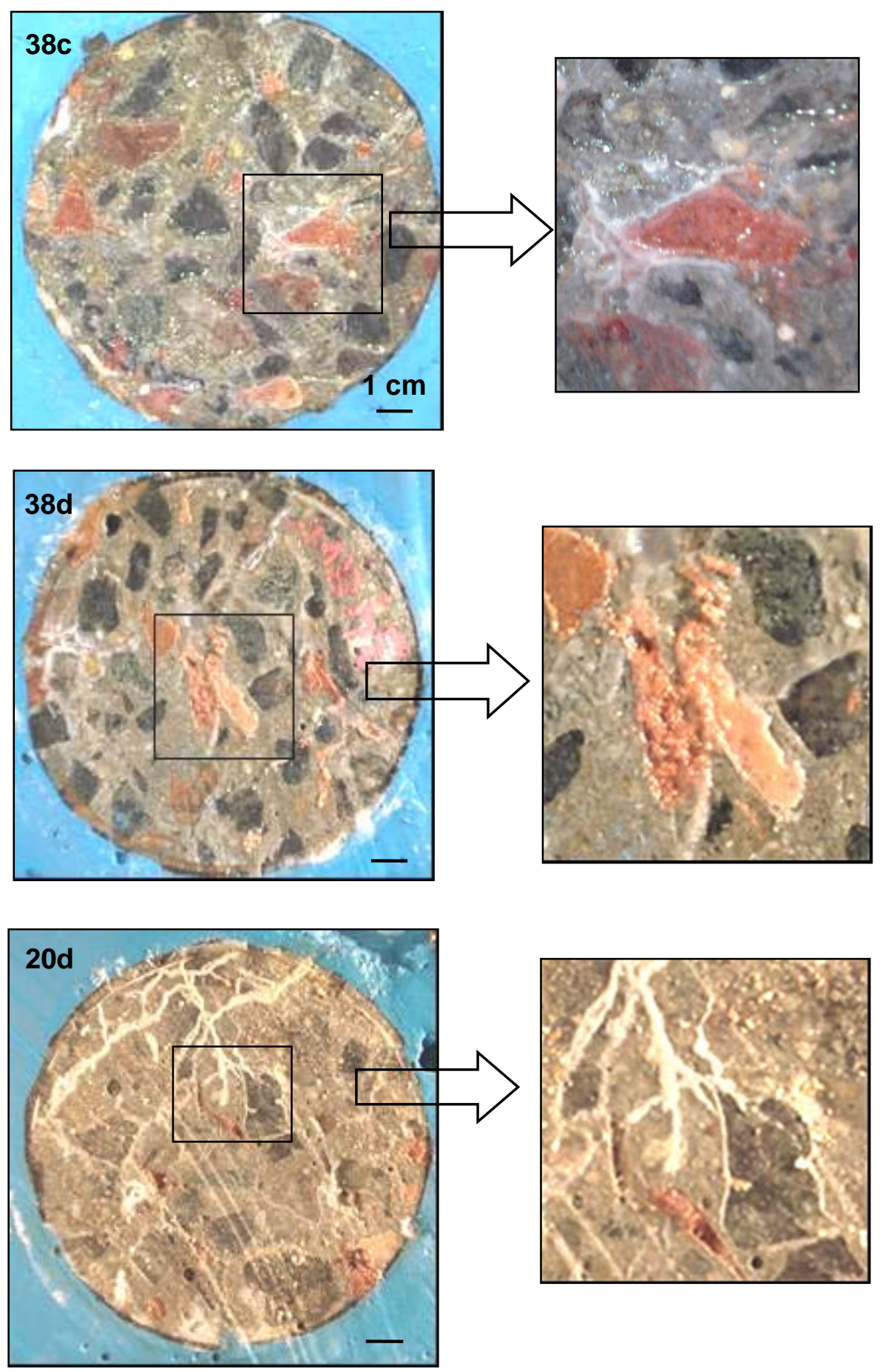


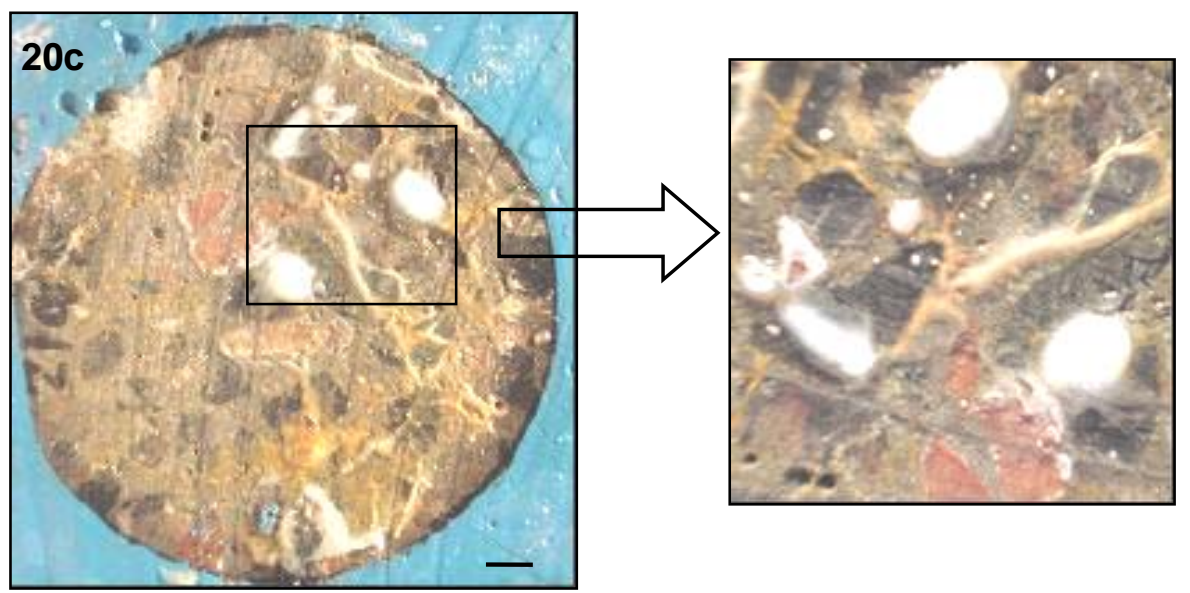

Figura 4.5.10. Fotografías de cortes transversales luego de ser sometidos al ensayo de permeabilidad (Hormigón C).

Tabla 4.5.7. Coeficientes de permeabilidad obtenidos sobre muestras del hormigón C.

\begin{tabular}{ccccccccccccc}
\hline Ensayo & \multicolumn{4}{c}{$\mathbf{1}$ (duración 7 días) } & \multicolumn{3}{c}{ 2 (duración 2 días) } & \multicolumn{3}{c}{ 3 (duración 6 días) } \\
Grupo & 20d & 20c & 38d & 38c & 20d & 20c & 38d & 38c & 20d & 20c & 38d & 38c \\
\hline $\mathbf{K}_{\text {máx }}$ & 338 & 24 & 240 & 98 & 136 & 376 & 7 & 880 & 364 & 491 & 1070 & - \\
$\mathbf{K}_{24}$ & 21 & 24 & 33 & 42 & 69 & 26 & 3.4 & - & 132 & 112 & 25 & - \\
$\mathbf{K}_{\text {final }}$ & 6 & 2 & 1.5 & 20 & 100 & 90 & 3 & 123 & 79 & 9.5 & 3 & - \\
\hline
\end{tabular}

En la Fig. 4.5.11 se muestra la variación del coeficiente de permeabilidad máximo con la densidad de fisuras sobre la cara de la rodaja ensayada y en la Fig. 4.5.12 la misma relación pero considerando el coeficiente de permeabilidad determinado a las 24 horas. En la primera figura existe una relación entre la permeabilidad máxima y la densidad de fisuras pero cuando se toman los valores de permeabilidad a las 24 horas ambos parámetros parecen independientes entre sí. El coeficiente de permeabilidad máximo en casi todos los casos se produjo durante las primeras horas del ensayo y, como era de esperar la mayor permeabilidad se corresponde con las rodajas más fisuradas. Luego de las primeras horas de ensayo la permeabilidad disminuyó en forma acentuada, en especial en el grupo 38; esta disminución se atribuye a una rehidratación del gel que rellenó las fisuras.

El ensayo de penetración de agua a presión fue realizado con variantes respecto a la norma porque algunas probetas se encontraban muy deterioradas para soportar el ciclo original. El ciclo tuvo una duración de 4 días, los 3 primeros se aplicó 
una presión igual a $0.1 \mathrm{MPa}$ y el último día se subió la presión a $0.7 \mathrm{MPa}$. Se ensayaron cuatro probetas, una por cada grupo. En las probetas de los grupos 38c y $38 \mathrm{~d}$ el ensayo tuvo que ser interrumpido por pérdidas de agua por fisuras en el perímetro de las probetas.

En la Fig. 4.5.13 se muestran los perfiles de penetración de las probetas correspondientes a los grupos 20c y $20 \mathrm{~d}$. Se puede observar que en el primero el agua penetró toda la longitud $(150 \mathrm{~mm})$ de la probeta mientras que en el $20 \mathrm{~d}$ sólo alcanzó a la mitad $(75 \mathrm{~mm})$.

Si se comparan los ensayos de permeabilidad y penetración de agua a presión, ambos relacionados con la resistencia que opone el hormigón a ser penetrado por un líquido, se observa un comportamiento diferente. Mientras en los ensayos de permeabilidad las probetas de cada uno de los grupos no mostraron grandes variaciones entre sí, en el ensayo de penetración los grupos a 20 y $38^{\circ} \mathrm{C}$ se comportaron en forma diferente y, más aún, se observaron diferencias entre la probeta 20 c y la $20 d$.

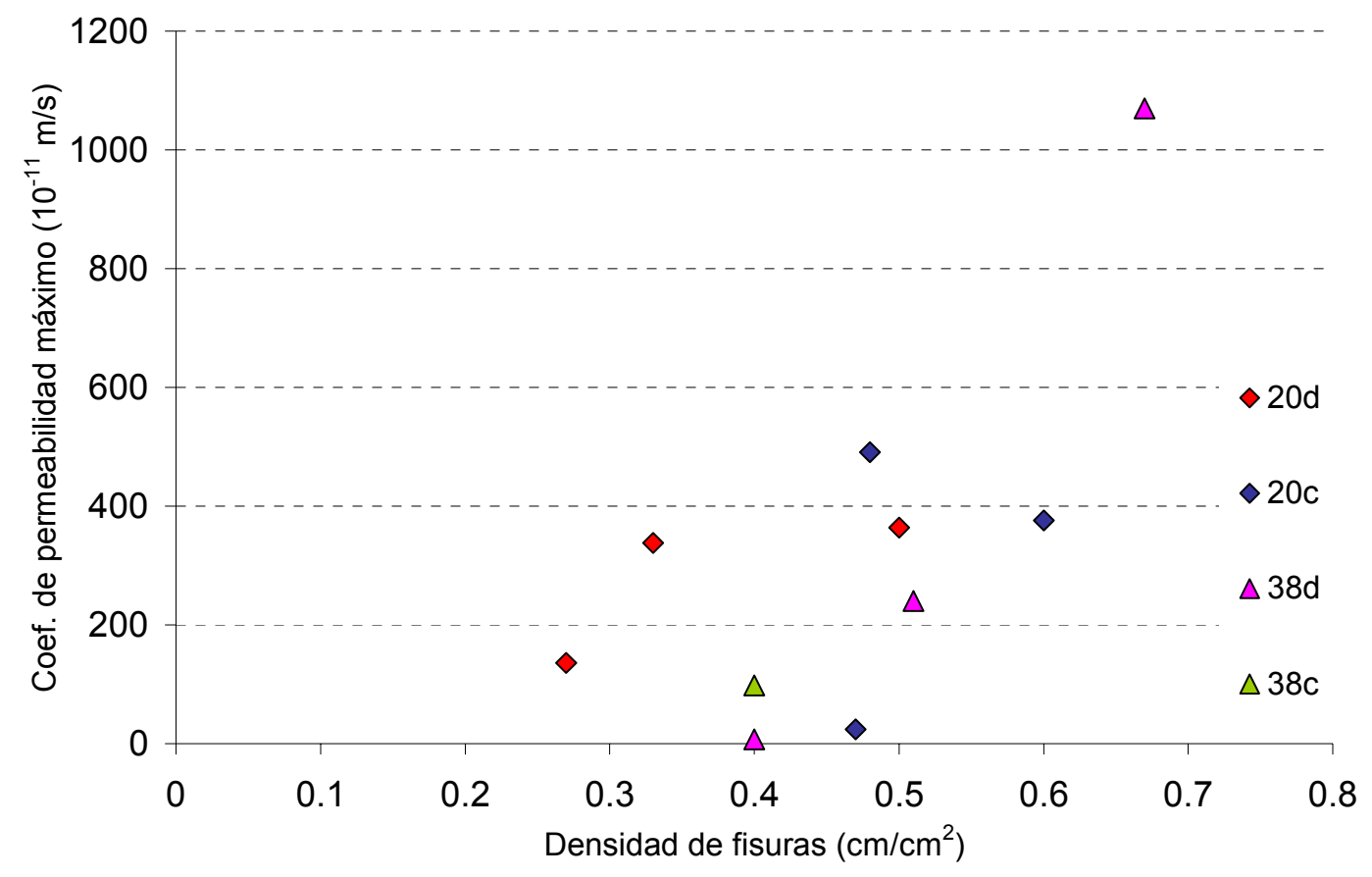

Figura 4.5.11. Relación entre el coeficiente de permeabilidad máximo y la densidad de fisuras. 


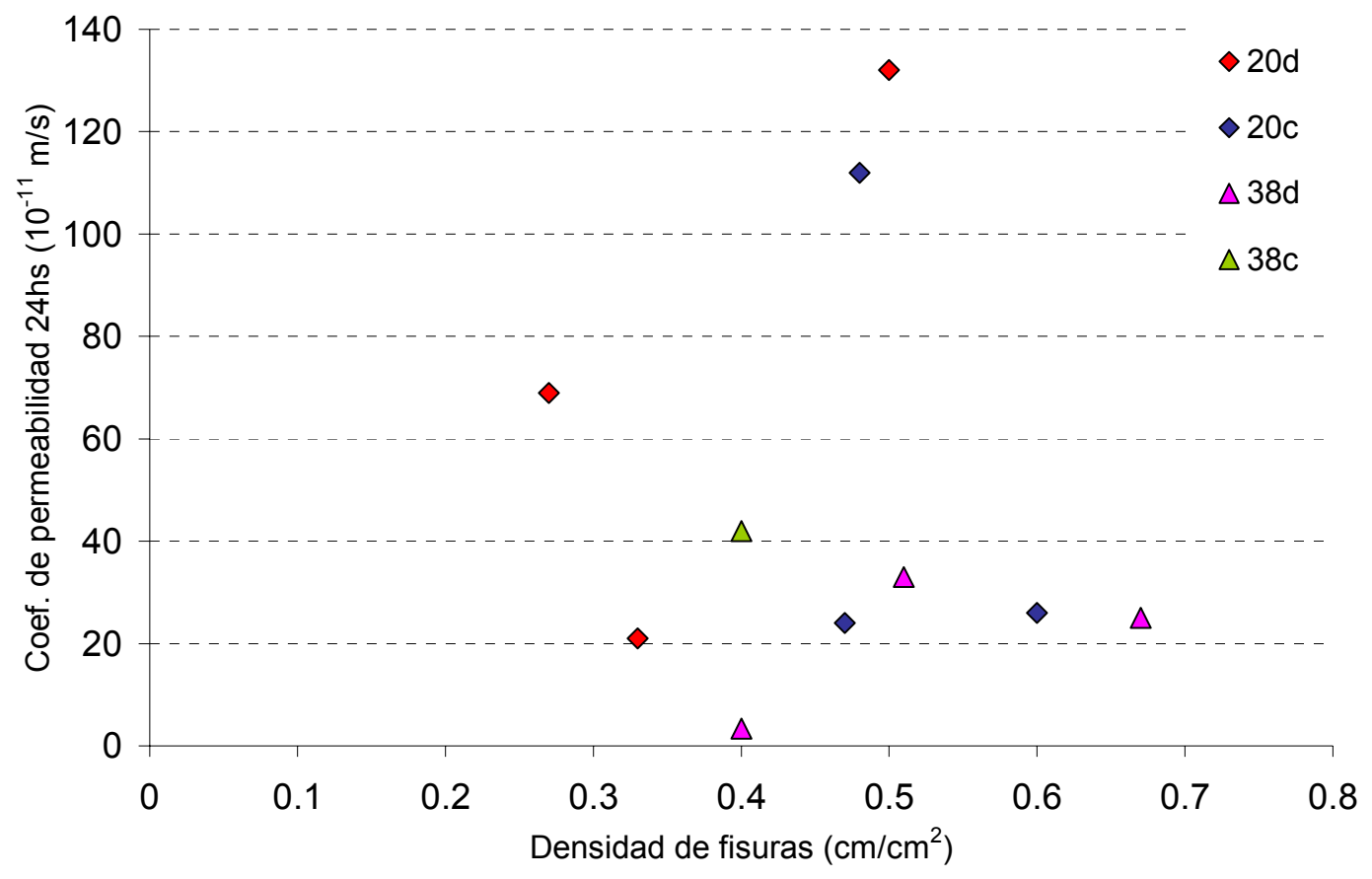

Figura 4.5.12. Relación entre el coeficiente de permeabilidad a las 24 horas y la densidad de fisuras.
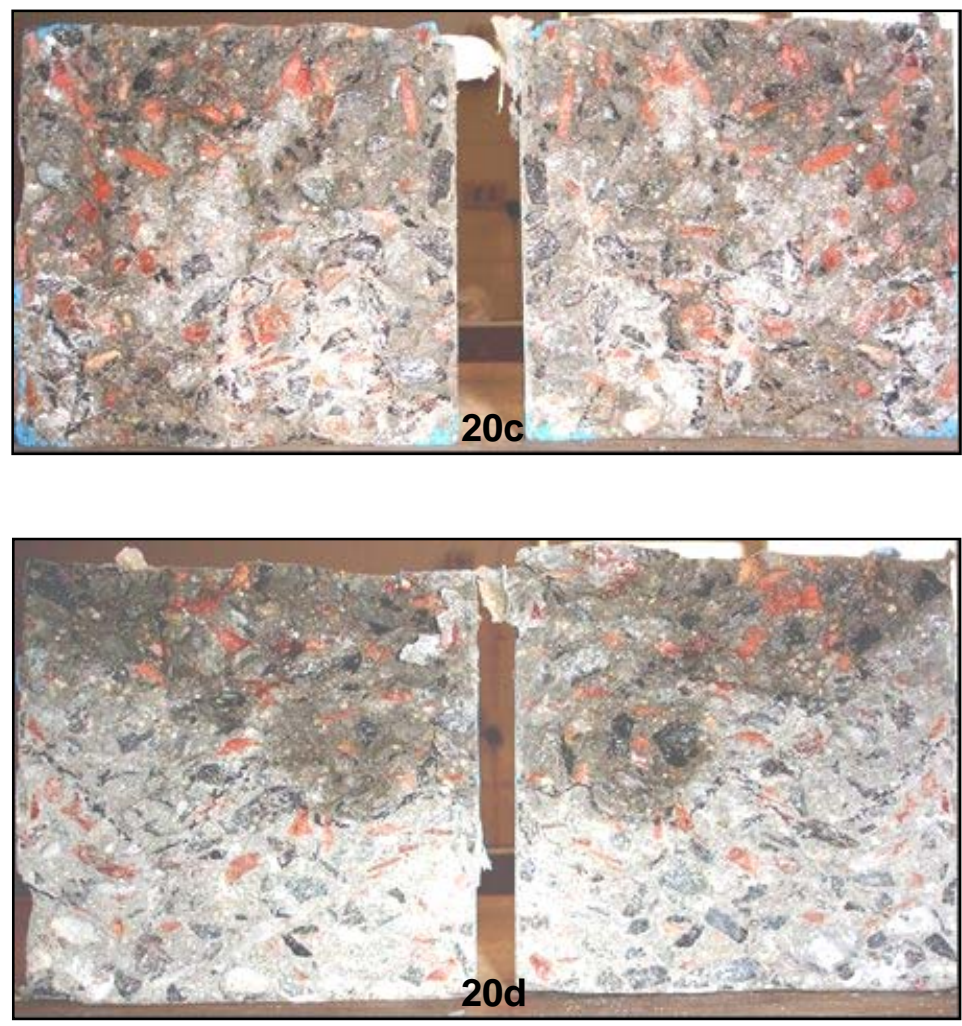

Figura 4.5.13. Perfiles de penetración. Arriba: probeta 20c, abajo: probeta 20d. 


\subsubsection{Conclusiones}

En este apartado se analizó la vinculación entre los defectos a nivel mesoestructural y el comportamiento macroscópico de un hormigón afectado por la reacción álcali-sílice $(C)$; los resultados se comparan con los de un hormigón de referencia $(T)$ que no presentó signos de reacción. A continuación se destacan las principales observaciones y conclusiones.

En las probetas sin cargar del hormigón $C$ se midieron expansiones significativas por el desarrollo de la reacción álcali-sílice, la velocidad de reacción fue mayor a $38^{\circ} \mathrm{C}$ que a $20^{\circ} \mathrm{C}$. Durante el mismo período se registraron contracciones en las probetas sin cargar del hormigón T. No hubo diferencias en la evolución de las deformaciones bajo carga entre los hormigones con presencia de reacción (C) y los que no presentaron signos de reacción al cabo de 14 meses $(T)$.

En el hormigón $\mathrm{C}$ se produjo un importante cuadro de fisuración por el desarrollo de la reacción, y se observó una fuerte influencia de las cargas aplicadas sobre la formación y propagación de las fisuras. Las probetas que estuvieron cargadas presentaron fisuras orientadas en la dirección de las cargas mientras que las que permanecieron sin cargar mostraron fisuras orientadas en todas direcciones.

En cuanto a las propiedades macroscópicas el ensayo de velocidad de pulso ultrasónico verificó el deterioro del hormigón C. En ambos hormigones se encontró un aumento de las propiedades mecánicas en las probetas sometidas a cargas de larga duración por efecto de la consolidación; sin embargo en el hormigón $\mathrm{C}$ las diferencias entre probetas cargadas y sin cargar fueron mucho más notorias debido a la orientación de las fisuras. También se encontraron diferencias en las curvas tensión deformación, cuando el hormigón permaneció sin cargar ( $20 \mathrm{~d}$ y $38 \mathrm{~d}$ ) se produjeron mayores deformaciones.

En lo que respecta a las propiedades de transporte se observó la influencia del desarrollo de la reacción sobre la permeabilidad. El hormigón C presentó una elevada permeabilidad al inicio de los ensayos y luego una disminución abrupta al cabo de las primeras horas, probablemente debido a la rehidratación del gel y llenado de las fisuras. 


\subsection{ANÁlisis COMPARATIVO DE LA INFLUENCIA DEL CUADRO DE FISURACIÓN SOBRE LAS PROPIEDADES DE HORMIGONES DAÑADOS}

En este apartado, a modo de síntesis, se comparan los resultados de las experiencias desarrolladas en este Capítulo para evaluar la influencia de las fisuras sobre la respuesta del hormigón. Se presentan en primera instancia las experiencias en hormigones expuestos a altas temperaturas y distintas condiciones de secado, y más adelante se resumen los resultados del hormigón dañado por reacción álcalisílice.

En la Tabla 4.6.1 se realiza un análisis cualitativo de la influencia de las fisuras (la densidad y el ancho de fisuras) sobre las propiedades mecánicas (resistencia a compresión y módulo de elasticidad) y de transporte (permeabilidad y absorción capilar) evaluadas en los hormigones sometidos a altas temperaturas y bajas condiciones de humedad (incisos 4.3 y 4.4). Para ello se tomó como referencia a los hormigones que no fueron expuestos a condiciones especiales y por lo tanto no presentaban mayor deterioro (grupo $\mathrm{CH}$ en el caso de los hormigones del inciso 4.3 y grupo 20 para el inciso 4.4) y se analizaron los valores relativos de cada una de las citadas propiedades mecánicas y de transporte. En función de ello se estableció una escala de referencia que permite ponderar el grado de influencia del daño sobre cada propiedad (muy bajo, bajo, medio, alto, muy alto). Es evidente que esta definición cualitativa del grado de afectación depende de cada propiedad, a modo de ejemplo se estimó un nivel "alto" de influencia para la resistencia a compresión o el módulo de elasticidad cuando se producía una caída entre el 20 y $50 \%$ de la propiedad, mientras en el caso de la permeabilidad se consideró "alto" cuando el incremento del coeficiente superaba el $100 \%$. A pesar de ser una valoración cualitativa permite verificar el modo en que las diversas características del cuadro de fisuración modifican cada propiedad. 
Tabla 4.6.1. Influencia del tamaño de las fisuras (densidad y ancho) sobre la resistencia y rigidez en compresión, el coeficiente de permeabilidad y la absorción capilar.

\begin{tabular}{ccccccc}
\hline $\begin{array}{c}\text { Densidad } \\
\left(\mathbf{c m} / \mathbf{c m}^{2}\right)\end{array}$ & $\begin{array}{c}\text { Ancho } \\
\text { máximo } \\
(\mathbf{m m})\end{array}$ & fc & E & K & \multicolumn{2}{c}{ Absorción Capilar } \\
\hline $0.1-0.2$ & $<<0.05$ & 0 & 0 & 0 & 0 & 0 \\
$0.2-0.3$ & $<<0.05$ & $\bullet$ & $\bullet$ & $\bullet$ & $\bullet$ & $\bullet$ \\
$0.2-0.3$ & $<0.05$ & $\bullet$ & $\bullet \bullet$ & $\bullet \bullet$ & $\bullet \bullet$ & $\bullet$ \\
$0.3-0.4$ & $<0.05$ & $\bullet$ & $\bullet \bullet$ & $\bullet \bullet$ & $\bullet \bullet$ & $\bullet \bullet$ \\
$0.3-0.4$ & $0.05-0.1$ & $\bullet$ & $\bullet \bullet$ & $\bullet$ & $\bullet$ & $\bullet$ \\
$0.4-0.5$ & $0.1-0.2$ & $\bullet$ & $\bullet \bullet \bullet$ & $\bullet \bullet \bullet$ & $\bullet$ & $\bullet$ \\
$0.4-0.5$ & $>0.2$ & $\bullet$ & $\bullet \bullet \bullet$ & $\bullet \bullet \bullet$ & $\bullet$ & $\bullet$ \\
\hline
\end{tabular}

Grado de influencia o muy bajo

- bajo

$\bullet \quad$ medio

$\bullet \bullet \bullet \quad$ alto

$\bullet \bullet \bullet$ muy alto

La primera fila de la Tabla 4.6.1 corresponde a las fisuras medidas en los hormigones de referencia con una densidad entre $0.1-0.2 \mathrm{~cm} / \mathrm{cm}^{2}$ y ancho mucho menor a $0.05 \mathrm{~mm}$. Las fisuras muy delgadas con una densidad entre $0.2-0.3 \mathrm{~cm} / \mathrm{cm}^{2}$, tuvieron poca influencia sobre la resistencia, la rigidez y la permeabilidad sin embargo afectaron en mayor medida los parámetros que evalúan la absorción capilar. La misma densidad de fisuras pero de ancho mayor no tuvo incidencia sobre la resistencia pero presentó una fuerte influencia sobre la rigidez, la permeabilidad y la velocidad de absorción capilar, sin embargo la capacidad de absorción capilar resultó menos afectada. Los hormigones con una densidad de fisuras entre $0.3-0.4 \mathrm{~cm} / \mathrm{cm}^{2}$ y anchos menores a $0.05 \mathrm{~mm}$ se comportaron en forma similar pero en este caso la mayor densidad de fisuras afectó en mayor medida a la resistencia y a la capacidad de absorción capilar. Por el contrario se observó que la misma densidad de fisuras pero de mayor ancho (entre $0.05-0.1 \mathrm{~mm}$ ) prácticamente no afectó la absorción capilar, la resistencia y el coeficiente de permeabilidad resultaron menos afectado que para la misma densidad de fisuras más pequeñas. Por último, para densidades y anchos de 
fisuras mayores (densidades superiores a $0.4 \mathrm{~cm} / \mathrm{cm}^{2}$ y anchos mayores a $0.1 \mathrm{~mm}$ ) resultaron muy perturbadas la rigidez y la permeabilidad, también se observó una pérdida de resistencia pero de menor magnitud, en cambio los parámetros que caracterizan la absorción capilar prácticamente no se modificaron con respecto a los hormigones de referencia.

En la Tabla 4.6.2 se presenta la influencia no sólo del tamaño de las fisuras sino también de su orientación considerando las experiencias del inciso 4.5. Se observó que las fisuras causadas por la reacción álcali-sílice bajo cargas de larga duración se propagaron en la dirección de aplicación de las cargas, en coincidencia con el eje de las probetas (1D), mientras que las probetas que estuvieron descargadas se fisuraron en todas las direcciones, orientación 3D. Para valorar la incidencia de las fisuras sobre los distintos parámetros se tomaron como referencia los hormigones que no presentaron signos de reacción (hormigón T).

Tabla 4.6.2. Influencia del tamaño (densidad y ancho) y orientación de las fisuras sobre la resistencia y rigidez en compresión, el coeficiente de permeabilidad y la penetración de agua a presión.

\begin{tabular}{ccccccc}
\hline $\begin{array}{c}\text { Densidad } \\
\left(\mathrm{cm} / \mathrm{cm}^{2}\right)\end{array}$ & $\begin{array}{c}\text { Ancho } \\
\text { máximo } \\
(\mathrm{mm})\end{array}$ & Orientación & fcc & E & K & Penetración \\
\hline $0.2-0.3$ & 0.2 & 1D & $\bullet$ & $\bullet$ & $\bullet \bullet \bullet$ & $\bullet \bullet \bullet \bullet$ \\
$0.2-0.3$ & 0.3 & 1D & $\bullet$ & $\bullet \bullet$ & $\bullet \bullet \bullet$ & $\bullet \bullet \bullet$ \\
$0.4-0.5$ & 0.3 & 3D & $\bullet \bullet$ & $\bullet \bullet \bullet$ & $\bullet \bullet \bullet$ & $\bullet \bullet \bullet \bullet$ \\
$0.4-0.5$ & 0.4 & 3D & $\bullet \bullet$ & $\bullet \bullet \bullet$ & $\bullet \bullet \bullet$ & $\bullet \bullet \bullet \bullet$ \\
\hline
\end{tabular}

$\begin{array}{rll}\text { Grado de influencia } & \text { o } & \text { muy bajo } \\ & \bullet & \text { bajo } \\ & \bullet & \text { medio } \\ \bullet \bullet \bullet & \text { alto } \\ & \bullet \bullet \bullet & \text { muy alto }\end{array}$

Una densidad de fisuras entre $0.2-0.3 \mathrm{~cm} / \mathrm{cm}^{2}$ con una orientación en la dirección del eje de las probetas tuvo una influencia "media" sobre las propiedades mecánicas, mientras que cuando la densidad de fisuras varió entre $0.4-0.5 \mathrm{~cm} / \mathrm{cm}^{2}$ con una orientación 3D se produjo una influencia "alta" sobre dichas propiedades. Por 
el contrario las propiedades de transporte se vieron altamente afectadas en todos los casos. Cabe mencionar que, en comparación con los hormigones dañados por temperatura, en este caso las fisuras generadas por la reacción relevadas en el perímetro de las probetas alcanzaron anchos importantes, mayores a $0.2 \mathrm{~mm}$ y la densidad de fisuras varió entre 0.2 y $0.5 \mathrm{~cm} / \mathrm{cm}^{2}$. 


\section{CAPÍTULO V}

\section{ESTUDIOS SOBRE \\ HORMIGONES REFORZADOS CON FIBRAS Y \\ HORMIGONES AUTOCOMPACTANTES}

\subsection{INTRODUCCIÓN}

El conocimiento de la orientación y distribución de fibras forma parte del control de calidad de los hormigones reforzados con fibras (HRF) (Brite-Euram BRPR-CT980813, 2002). En función del material con que estén elaboradas las fibras, y de sus dimensiones y geometría variarán sus efectos dentro del hormigón tanto en estado fresco (distribución y orientación) como en estado endurecido. La orientación y distribución de fibras se relaciona con el proceso de producción y afecta la respuesta mecánica del material por lo que constituye una herramienta útil para la caracterización de los HRF, para el diseño y predicción de la respuesta de los elementos estructurales, así como para la elección del método de elaboración en una determinada aplicación.

En este capítulo se presentan cinco desarrollos experimentales realizados en hormigón convencional y en hormigón autocompactante con y sin refuerzo de fibras. En primer lugar se incluye un estudio sobre hormigón vibrado con dos tipos de fibras de acero que permite apreciar la vinculación entre la respuesta mecánica y la mesoestructura en la superficie de fractura, así como la orientación del refuerzo. Con objetivos similares se presentan en segundo lugar otras experiencias que extienden el estudio al caso de fibras sintéticas. Luego se incluyen tres estudios sobre hormigones autocompactantes; en el primero de ellos se muestra la influencia de la forma de llenado de moldes prismáticos sobre la orientación de las fibras y sus efectos sobre la respuesta mecánica del hormigón, incluyendo dos tipos de fibras de acero y una fibra 
sintética. En el cuarto trabajo se estudia la distribución de las fibras y agregados y la variación de las propiedades a largo de tubos de 2 metros de altura llenos con diferentes contenidos de fibras; finalmente en el último trabajo se evalúa la influencia del tipo de agregado sobre la homogeneidad del hormigón autocompactante.

\subsection{ESTUDIO DE LA ORIENTACIÓN DEL REFUERZO Y SUS EFECTOS SOBRE LAS PROPIEDADES MECÁNICAS EN HORMIGÓN CONVENCIONAL VIBRADO REFORZADO CON FIBRAS DE ACERO}

Este estudio fue realizado con el propósito de analizar el efecto de la dosis y esbeltez de las fibras y el de las dimensiones del molde en la orientación del refuerzo y de establecer la relación entre las características mesoestructurales en la superficie de fractura y las propiedades mecánicas del hormigón.

Se realizaron series de ensayos empleando fibras de acero de 30 y $60 \mathrm{~mm}$ de longitud, variando sus dosis entre 40 y $80 \mathrm{~kg} / \mathrm{m}^{3}$ de hormigón. Se llenaron vigas de diferentes alturas que fueron ensayadas tanto en la dirección paralela al llenado como luego de ser giradas $90^{\circ}$. Una vez realizados los ensayos de flexión se evaluó la orientación de las fibras analizando la densidad del refuerzo en las 3 direcciones.

\subsubsection{Materiales y mezclas}

Se elaboraron tres HRF que se diferencian en el contenido y tipo de fibras incorporadas a un mismo hormigón de base. En todos los casos se utilizaron fibras de acero conformadas en sus extremos (tipo hooked-end, Fig. 5.2.1), las características de las mismas se presentan en la Tabla 5.2.1. Los hormigones identificados como HRF1 y HRF2 fueron realizados con un mismo tipo de fibra (F1) utilizando dosis de 40 y $80 \mathrm{~kg} / \mathrm{m}^{3}$ respectivamente. El tercer hormigón (HRF3) fue elaborado incorporando $40 \mathrm{~kg} / \mathrm{m}^{3}$ de una fibra más larga (F2).

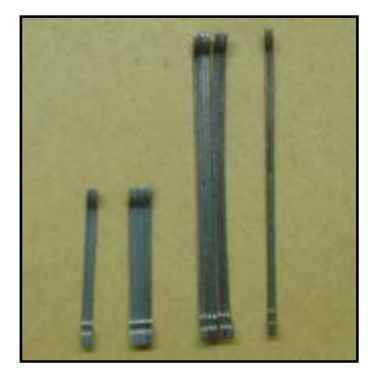

Figura 5.2.1. Fibras de acero tipo hooked-end (30 y $60 \mathrm{~mm})$. 
Tabla 5.2.1. Características de las fibras utilizadas.

\begin{tabular}{cccc}
\hline Hormigón & HRF1 & HRF2 & HRF3 \\
\hline Fibra & F1 & F1 & F2 \\
\hline Dosis de fibra $\left(\mathrm{kg} / \mathrm{m}^{3}\right)$ & 40 & 80 & 40 \\
Longitud de la fibra $(\mathrm{mm})$ & 30 & 30 & 60 \\
longitud/diámetro de la fibra & 60 & 60 & 80 \\
\hline
\end{tabular}

\subsubsection{Detalles experimentales}

Con cada hormigón se moldearon seis grupos de vigas (A a $F$ ) de 4 dimensiones diferentes. En cada grupo se analizaron como mínimo cinco vigas. Como fuera indicado se realizaron ensayos de flexión en dos direcciones: aplicando la carga en la dirección de moldeo y a $90^{\circ}$ de la cara de llenado. Los ensayos se realizaron siguiendo los lineamientos generales de la recomendación del comité RILEM-TC162. Se midieron la tensión máxima $\left(f_{M}\right)$, de primer pico $\left(f_{L}\right)$, resistencias equivalentes $\left(f_{\text {eq2 }} y\right.$ $\left.f_{\text {eq3 }}\right)$ y resistencias residuales $\left(f_{R 1-\delta}, f_{R 2-\delta}, f_{R 3-\delta}\right.$ y $\left.f_{R 4-\delta}\right)$.

Los estudios permitieron verificar que es posible utilizar el ensayo de vigas entalladas de menor altura para obtener parámetros de resistencia y tenacidad similares a los que se miden en las vigas de $150 \mathrm{~mm}$ de altura indicadas en la recomendación. En la Tabla 5.2.2 se muestran las dimensiones de las probetas estudiadas y la orientación adoptada de ensayo.

Tabla 5.2.2. Dimensiones de las probetas estudiadas.

\begin{tabular}{cccccccccc}
\hline Grupo & $\begin{array}{c}\text { Largo } \\
(\mathbf{m m})\end{array}$ & $\begin{array}{c}\text { Altura } \\
\mathbf{h}(\mathbf{m m})\end{array}$ & $\begin{array}{c}\text { Entalla } \\
\mathbf{a}(\mathbf{m m})\end{array}$ & $\begin{array}{c}\text { Base } \\
\mathbf{b}(\mathbf{m m})\end{array}$ & $\begin{array}{c}\text { Luz } \\
\mathbf{L}(\mathbf{m m})\end{array}$ & $\mathbf{a} / \mathbf{h}$ & $(\mathrm{h}-\mathbf{a}) / \mathbf{L}$ & Giro & Hormigón \\
\hline A & 550 & 153 & 26 & 152 & 500 & 0.17 & 0.25 & $90^{\circ}$ & HRF1,2,3 \\
B & 450 & 103 & 17.5 & 103 & 350 & 0.17 & 0.25 & $90^{\circ}$ & HRF1,2,3 \\
C & 450 & 103 & 17.5 & 103 & 350 & 0.17 & 0.25 & $0^{\circ}$ & HRF1,2 \\
D & 430 & 103 & 17.5 & 75 & 350 & 0.17 & 0.25 & $90^{\circ}$ & HRF1,2 \\
E & 430 & 75 & 13 & 103 & 350 & 0.17 & 0.18 & $0^{\circ}$ & HRF1,2,3 \\
F & 550 & 152 & 26 & 75 & 500 & 0.17 & 0.25 & $0^{\circ}$ & HRF1,2 \\
\hline
\end{tabular}

Luego de ensayar las vigas a flexión se realizó una evaluación de las características mesoestructurales en las superficies de fractura y más tarde se estudió la orientación sobre cortes en diferentes direcciones. 
Se seleccionaron probetas representativas de cada grupo y se contó el número de fibras en cada cara de fractura. Como las fibras en su mayoría fallan por adherencia, la densidad de fibras se calcula como la suma de las fibras de ambas mitades dividida por la sección de hormigón. Estas fibras poseen sus extremos conformados entonces fue posible hacer la distinción entre fibras eficaces (aquellas que tomaron carga y por lo tanto presentan sus ganchos deformados) y no eficaces (Barragán et al, 2003). Cabe notar que el concepto de fibra eficaz es aplicable solo a algunos tipos de fibras.

Luego cada mitad fracturada fue aserrada en tres direcciones: una transversal, otra longitudinal paralela a la dirección de moldeo y otra longitudinal perpendicular a la dirección de moldeo. Como las fibras son cortadas por la sierra, en este caso para calcular la densidad de fibras en cada sección se hace el promedio del número de fibras contadas en cada cara.

La Fig. 5.2.2 muestra un esquema de los cortes realizados en las vigas, las direcciones estudiadas incluyen el plano transversal ( $T$, paralelo a la superficie de fractura de las vigas), el plano longitudinal ( $L$, siguiendo el eje de la viga paralelo al llenado) y el plano normal a la dirección de llenado $(\mathrm{N})$.

a-

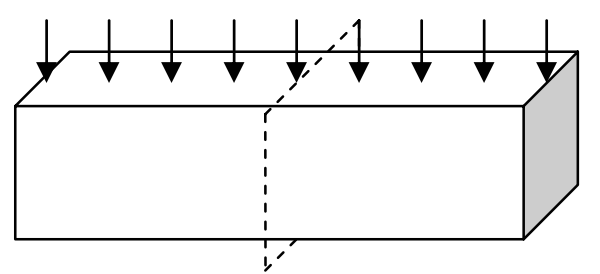

b-

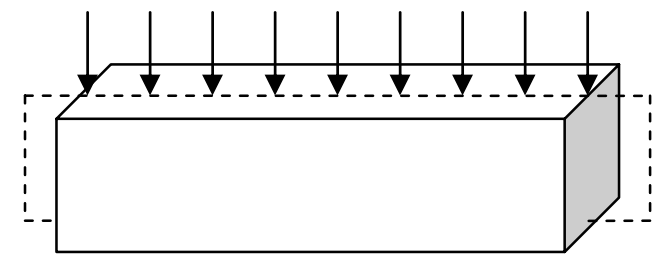

C-

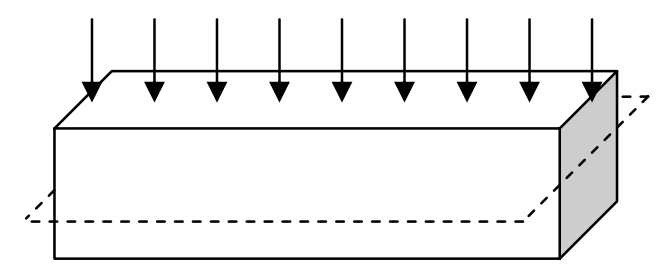

Figura 5.2.2. Planos de corte: $\mathrm{a}-$ plano $\mathrm{T}=$ transversal.

b- plano $\mathrm{L}=$ paralelo al plano de moldeo.

c- plano $\mathrm{N}=$ normal al plano de moldeo. 


\subsubsection{Resultados y discusión}

En este apartado se analizan los resultados obtenidos, en primer lugar se analiza la orientación de las fibras dentro de las probetas, considerando el efecto de la dosis utilizada, el tipo de fibra y las dimensiones del molde. Luego se discute la vinculación entre la densidad de fibras en la superficie de fractura y la respuesta mecánica del HRF.

Tabla 5.2.3. Densidad de fibras en $\mathrm{N} \% \mathrm{~cm}^{2}$.

\begin{tabular}{|c|c|c|c|c|c|}
\hline \multirow{2}{*}{ Plano } & Longitudinal & Transversal & Normal al moldeo & $N / L$ & $\mathbf{N} / \mathbf{T}$ \\
\hline & $\mathbf{L}$ & $\mathbf{T}$ & $\mathbf{N}$ & $1 \mathrm{~N} / \mathrm{L}$ & IN \\
\hline HRF1A & 1.55 & 1.75 & 0.85 & 0.55 & 0.49 \\
\hline \multirow{2}{*}{ HRF1-B } & 1.50 & 1.32 & 0.64 & 0.43 & 0.48 \\
\hline & 1.11 & 1.37 & 0.91 & 0.82 & 0.66 \\
\hline HRF1-C & 2.40 & 1.58 & 0.71 & 0.30 & 0.45 \\
\hline \multirow{2}{*}{ HRF1-D } & 1.56 & 1.30 & NM & NM & NM \\
\hline & 1.07 & 1.26 & 0.73 & 0.68 & 0.58 \\
\hline HRF1-E & 1.51 & 1.52 & 0.72 & 0.48 & 0.47 \\
\hline \multirow{2}{*}{ HRF1-F } & 1.48 & 1.45 & 0.89 & 0.60 & 0.61 \\
\hline & 1.42 & 1.90 & 1.14 & 0.80 & 0.60 \\
\hline Promedio HRF1 & 1.51 & 1.49 & 0.82 & 0.54 & 0.55 \\
\hline$\sigma$ & 0.38 & 0.22 & 0.16 & 0.18 & 0.08 \\
\hline HRF2-A & 2.11 & 2.84 & 1.22 & 0.58 & 0.43 \\
\hline \multirow{2}{*}{ HRF2-B } & 1.85 & 2.85 & 1.09 & 0.59 & 0.38 \\
\hline & NM & 2.58 & 1.30 & NM & 0.50 \\
\hline \multirow{2}{*}{ HRF2-C } & 2.58 & 2.92 & 1.45 & 0.56 & 0.50 \\
\hline & 2.13 & 2.03 & NM & NM & NM \\
\hline \multirow{2}{*}{ HRF2-D } & 2.27 & 2.20 & 1.41 & 0.62 & 0.64 \\
\hline & 2.52 & 2.31 & NM & NM & NM \\
\hline \multirow{2}{*}{ HRF2-E } & 3.24 & 2.23 & 0.85 & 0.26 & 0.38 \\
\hline & 2.56 & 2.49 & 1.32 & 0.52 & 0.53 \\
\hline \multirow{2}{*}{ HRF2-F } & 2.34 & 2.68 & 1.25 & 0.53 & 0.47 \\
\hline & NM & 3.12 & 1.20 & NM & 0.38 \\
\hline Promedio HRF2 & 2.40 & 2.57 & 1.23 & 0.51 & 0.48 \\
\hline$\sigma$ & 0.40 & 0.35 & 0.18 & 0.12 & 0.09 \\
\hline HRF3-A & 0.73 & 0.62 & 0.27 & 0.37 & 0.44 \\
\hline HRF3-B & 0.89 & 1.01 & 0.27 & 0.30 & 0.27 \\
\hline HRF3-C & 0.71 & 0.71 & 0.46 & 0.65 & 0.65 \\
\hline \multirow{2}{*}{ HRF3-D } & 0.88 & 0.66 & 0.33 & 0.38 & 0.50 \\
\hline & 0.77 & 0.77 & 0.20 & 0.26 & 0.26 \\
\hline HRF3-E & 0.66 & 0.96 & 0.26 & 0.39 & 0.27 \\
\hline Promedio HRF3 & 0.77 & 0.79 & 0.30 & 0.39 & 0.38 \\
\hline$\sigma$ & 0.09 & 0.16 & 0.09 & 0.14 & 0.16 \\
\hline
\end{tabular}

$\mathrm{NM}=$ no medida. 
En la tabla 5.2.3 se presentan los resultados de Densidad de fibras en $\mathrm{N} / \mathrm{cm} 2$ en cada una de las direcciones (Longitudinal, Transversal y Normal al moldeo) así como las relaciones entre dichos valores (Normal / Longitudinal, Normal / Transversal). Es posible observar que para todas las geometrías estudiadas se verifica la orientación preferencial en planos normales a la dirección de moldeo. Resultan del mismo orden las densidades de fibras en los planos longitudinal y transversal mientras que la densidad de fibras que atraviesan el plano normal al llenado es del orden del 54, 50 y $38 \%$ respectivamente para los hormigones HRF1, HRF2 y HRF3 de la medida en los otros dos planos. Las fibras más largas son las que más sufren el efecto pared y por lo tanto se orientan sobre el plano horizontal longitudinal.

\subsubsection{Influencia de la dosis y tipo de fibras y de las dimensiones del molde sobre la orientación del refuerzo}

Efecto de la dosis de fibras: al comparar las relaciones entre las densidades de fibras relevadas en los planos normal al llenado y longitudinal en los hormigones HRF1 y HRF2 (0.54 y 0.51 respectivamente) y normal al llenado y transversal ( 0.55 y 0.48 ), es posible inferir que en el hormigón con mayor dosis de fibras se produce una orientación más acentuada. En el HRF2 $\left(80 \mathrm{~kg} / \mathrm{m}^{3}\right)$ se aprecia que las fibras se encuentran más alineadas sobre el borde longitudinal en el plano horizontal (la densidad en el plano transversal es igual a 2.57 y en el plano longitudinal es igual a 2.40).

Efecto del tamaño de las fibras: la influencia del tamaño de las fibras sobre la orientación es más notable que el efecto de la dosis utilizada. En el caso de HRF3 las relaciones de densidad Normal / Longitudinal y Normal / Transversal son en promedio iguales a 0.39 y 0.38 , es decir que en el plano horizontal hay por lo menos un $60 \%$ más de fibras que en el plano vertical. Para igual contenido de fibras $\left(40 \mathrm{~kg} / \mathrm{m}^{3}\right)$ en el caso de las fibras más cortas (HRF1) se encontró una orientación ligeramente mayor en el plano horizontal en la dirección longitudinal, es decir es mayor la influencia del borde más corto del molde, mientras que en las fibras más largas (HRF3) sucede lo contrario.

Efecto de las dimensiones del molde: las densidades promedio de todos los tamaños de probetas resultan semejantes a las medidas en las probetas de $150 \mathrm{~mm}$ de altura que propone la norma para el ensayo de flexión. Desde este punto de vista también se 
confirma la posibilidad de emplear probetas más pequeñas cuando el tipo de aplicación y el tamaño de las fibras lo permitan.

\subsubsection{Vinculación entre mesoestructura y comportamiento mecánico en flexión}

En la Tabla 5.2.4 se presentan los resultados promedio del recuento de fibras totales y fibras eficaces sobre las superficies de fractura de vigas entalladas ensayadas a flexión. Al mismo tiempo se indican los promedios de los parámetros de resistencia y tenacidad medidos en cada grupo a partir de la respuesta carga - flecha.

Tabla 5.2.4. Densidad de fibras eficaces (Fe) y fibras totales $(\mathrm{Ft})$ en el plano de fractura y resultados del ensayo de flexión.

\begin{tabular}{ccccccccccccc}
\hline & \multicolumn{1}{c}{ Fibras } & \multicolumn{4}{c}{ Resultados del ensayo de flexión en vigas entalladas } \\
Grupo & número & $\mathbf{f i b r a s} / \mathbf{c m}^{2}$ & \multicolumn{1}{c}{$\mathbf{f}_{\mathbf{M}}$} & $\mathbf{f}_{\mathbf{L}}$ & $\mathbf{f}_{\text {eq2 }}$ & $\mathbf{f}_{\text {eq3 }}$ & $\mathbf{f}_{\mathbf{R} 1-\delta}$ & $\mathbf{f}_{\mathbf{R 2}-\delta}$ & $\mathbf{f}_{\mathbf{R 3}-\delta}$ & $\mathbf{f}_{\mathrm{R} 4-\delta}$ \\
& $\mathbf{F e}$ & $\mathbf{F t}$ & $\mathbf{F e}$ & $\mathbf{F t}$ & $\mathbf{M P a}$ & $\mathbf{M P a}$ & $\mathbf{M P a}$ & $\mathbf{M P a}$ & $\mathbf{M P a}$ & $\mathbf{M P a}$ & $\mathbf{M P a}$ & $\mathbf{M P a}$ \\
\hline 1-A & 123 & 215 & 0.6 & 1.12 & 5.5 & 5.3 & 5.7 & 5.0 & 5.2 & 5.4 & 4.9 & 4.3 \\
1-B & 46 & 81 & 0.6 & 0.96 & 6.0 & 6.0 & 5.2 & 4.8 & 4.9 & 5.1 & 4.4 & 4.4 \\
1-C & 49 & 85 & 0.6 & 1.02 & 5.7 & 5.7 & 5.1 & 4.6 & 4.6 & 4.8 & 4.4 & 4.2 \\
1-D & 33 & 77 & 0.5 & 1.16 & 6.0 & 6.0 & 4.8 & 4.8 & 5.0 & 5.0 & 4.9 & 4.3 \\
1-E & 21 & 60 & 0.3 & 0.94 & 6.1 & 6.1 & 6.4 & 5.5 & 5.1 & 5.2 & 5.5 & 4.8 \\
1-F & 63 & 122 & 0.7 & 1.31 & 6.0 & 5.7 & 5.8 & 5.2 & 5.3 & 5.5 & 5.2 & 4.6 \\
2-A & 197 & 407 & 1.0 & 2.08 & 8.4 & 6.4 & 8.8 & 8.0 & 7.8 & 8.3 & 7.4 & 7.4 \\
2-B & 100 & 220 & 1.1 & 2.6 & 8.9 & 7.0 & 9.3 & 8.5 & 8.1 & 8.8 & 8.4 & 7.0 \\
2-C & 80 & 210 & 0.9 & 2.45 & 8.4 & 6.6 & 8.8 & 8.1 & 7.8 & 8.2 & 7.6 & 7.6 \\
2-D & 64 & 171 & 1.0 & 2.59 & 8.8 & 7.4 & 9.6 & 8.0 & 8.2 & 8.4 & 7.1 & 6.2 \\
2-E & 50 & 137 & 0.8 & 2.17 & 8.1 & 6.5 & 8.1 & 7.8 & 6.8 & 7.8 & 7.7 & 7.1 \\
2-F & 98 & 229 & 1.0 & 2.29 & 8.1 & 6.1 & 8.7 & 7.5 & 7.6 & 7.7 & 6.1 & - \\
3-A & 100 & 134 & 0.5 & 0.7 & 7.2 & 4.8 & 4.2 & 6.1 & 3.7 & 5.5 & 7.0 & 7.1 \\
3-B & 36 & 51 & 0.4 & 0.58 & 5.7 & 4.9 & 4.1 & 4.6 & 3.6 & 4.6 & 5.0 & 5.0 \\
3-D & 37 & 54 & 0.6 & 0.81 & 7.2 & 5.2 & 4.8 & 6.0 & 4.2 & 6.1 & 6.7 & 6.9 \\
3-E & 44 & 57 & 0.7 & 0.87 & 8.3 & 5.1 & 5.8 & 6.2 & 4.7 & 5.7 & 6.7 & 7.8 \\
\hline
\end{tabular}

En la Fig. 5.2.3 se muestra para cada hormigón la relación entre la densidad de fibras totales y la densidad de fibras eficaces, incluyendo los dos tipos de fibras utilizadas (F1 y F2). Se diferencian los datos obtenidos sobre las vigas de $150 \mathrm{~mm}$ (grupos A y F) y $75 \mathrm{~mm}$ (grupo E) de altura, y los puntos sin recuadrar corresponden a las vigas de $100 \mathrm{~mm}$ de altura (grupos B, C y D). Es posible observar que la proporción de fibras eficaces aumenta ligeramente con las fibras más largas (F2), poniendo de manifiesto la mayor orientación del refuerzo ya considerada anteriormente. Las fibras más largas se disponen en la dirección del esfuerzo de 
tracción oponiéndose, por lo tanto, al arrancamiento. No se aprecia un efecto importante de la altura de las vigas, aunque parece existir una ligera tendencia a aumentar el número de fibras eficaces en las probetas de mayor altura para los mayores contenidos de la fibra F1. Como resultado general surge que, para estas experiencias, la relación entre fibras eficaces y fibras totales es bastante dispersa. Comparando entre los tres hormigones la misma es del orden de $0.50,0.44$ y 0.72 para HRF1, HRF2 y HRF3 respectivamente.

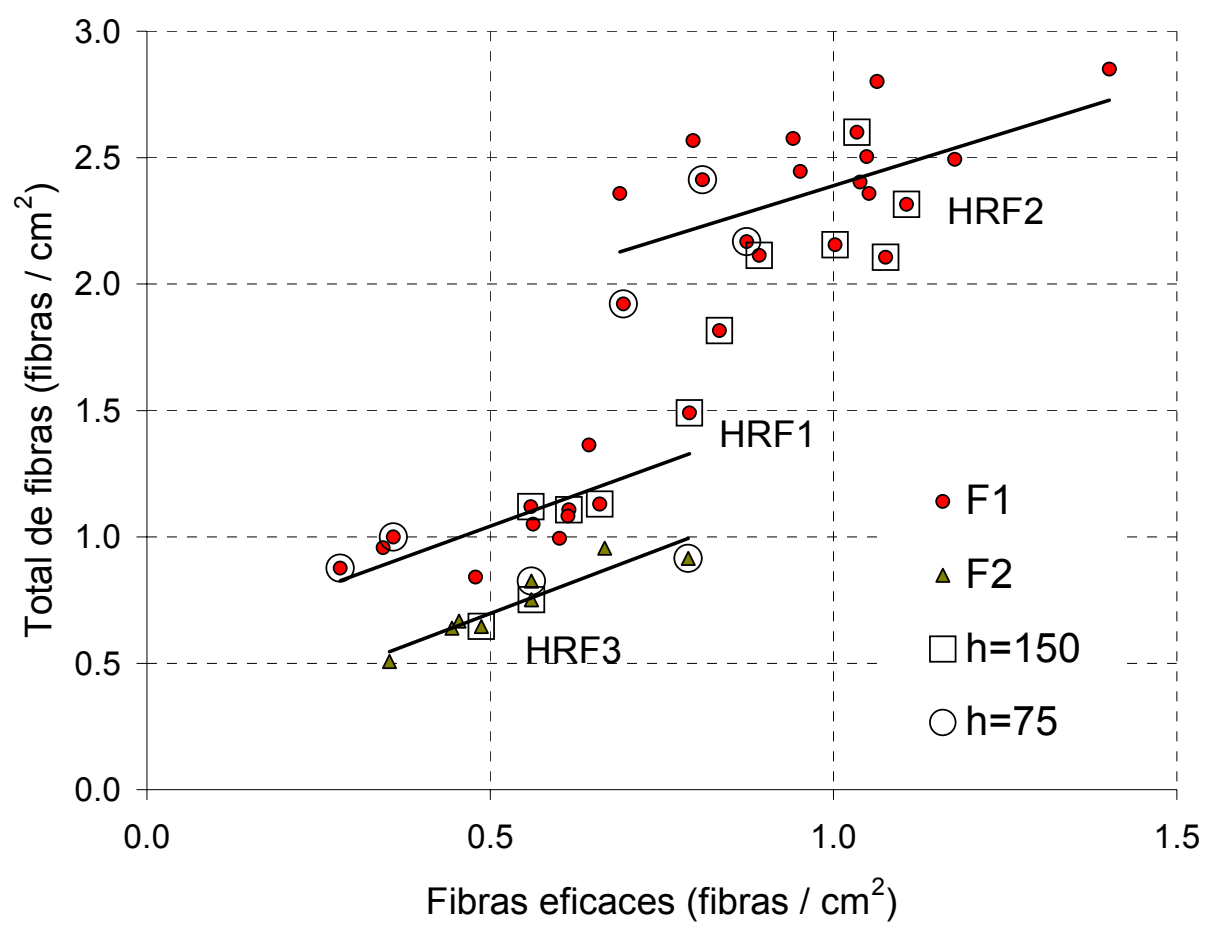

Figura 5.2.3. Relación entre fibras eficaces y fibras totales.

En la Fig. 5.2.4 se presenta la variación de las propiedades mecánicas medidas en flexión con respecto al contenido de fibras totales de cada una de las probetas seleccionadas de los hormigones HRF1 y 2.

La Fig. 5.2.4-a muestra la variación de la tensión máxima $\left(f_{M}\right)$, la resistencia a primera fisura $\left(f_{L}\right)$, y las resistencias equivalentes $f_{\text {eq2 }}, f_{\text {eq3 }}$ con la densidad de fibras para las vigas de $150 \mathrm{~mm}$ de altura elaboradas con la fibra $\mathrm{F} 1$, incluyendo los hormigones con 40 y con $80 \mathrm{~kg} / \mathrm{m}^{3}$ de refuerzo. Se observa una relación directa entre el contenido de fibras y la tensión máxima o las tensiones equivalentes representativas del comportamiento postpico. Por el contrario la tensión de primera fisura prácticamente no se modifica para diferentes contenidos de fibras. Esto es lógico ya 
que la resistencia a primera fisura se encuentra gobernada principalmente por la resistencia de la matriz (hormigón de base) mientras que la respuesta postpico depende directamente del tipo y contenido de refuerzo.

En la Fig. 5.2.4-b se presenta la misma relación incluyendo todos los tamaños de vigas. Es posible observar que el comportamiento es similar para los otros tamaños de probetas ensayados.

Por su parte la Fig. 5.2.4-c representa para todas las probetas elaboradas con la fibra F1 el efecto de la densidad de fibras totales sobre las tensiones residuales. Es evidente que la densidad de fibras posee un efecto directo sobre la tenacidad y el comportamiento postpico, que es el aspecto de mayor interés en HRF.

Para profundizar el análisis en la Fig. 5.2.5-a se ha representado la variación de la tensión residual $f_{R 3}$. Se puede apreciar que las fibras más largas (F2 en HRF3) presentan una mayor variación con la densidad que las más cortas (F1 en HRF1 y 2), el comportamiento post pico (en este caso evaluado a través de la resistencia residual para una apertura de fisura de $2.5 \mathrm{~mm}$ ) mejora en mayor proporción para menores incrementos en la densidad de fibras, lo que puede asociarse a una mayor resistencia al arrancamiento de las fibras más largas.

En la Fig. 5.2.5-b donde se vincula la densidad de fibras eficaces con la tensión $f_{R 3}$ también se observa el mejor comportamiento de las fibras largas. Para un mismo contenido de fibras (HRF1 vs HRF3) las propiedades residuales del hormigón elaborado con fibras más largas son superiores. A la vez se aprecia que, el hormigón elaborado con $40 \mathrm{~kg} / \mathrm{m}^{3}$ de fibras largas (HRF3) se comporta en forma similar al hormigón elaborado con el doble de fibras cortas (HRF2), corroborando la mayor eficacia de las fibras. 

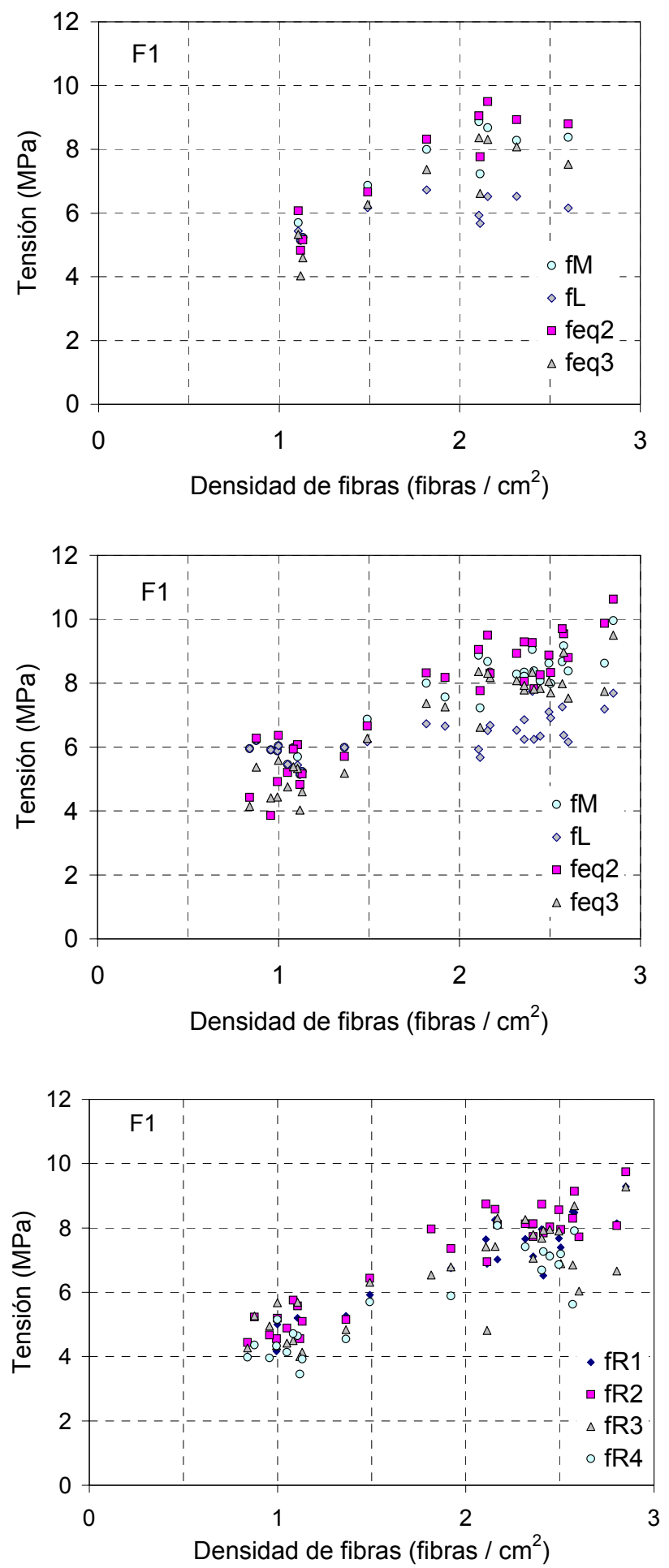

Figura 5.2.4. Efecto de la densidad de fibras totales sobre las propiedades mecánicas. a- Tensión máxima $\left(f_{M}\right)$, resistencia a primera fisura $\left(f_{L}\right)$ y resistencias equivalentes $\left(f_{\text {eq2 }}, f_{\text {eq3 }}\right.$ ) en vigas de $150 \mathrm{~mm}$ de altura elaboradas con los hormigones HRF1 y 2. b- Tensión máxima $\left(f_{M}\right)$, resistencia a primera fisura $\left(f_{L}\right)$ y resistencias equivalentes $\left(f_{\text {eq2}}, f_{\text {eq3 }}\right)$ en vigas elaboradas con los hormigones HRF1 y 2.

c- Efecto sobre las resistencias residuales. 

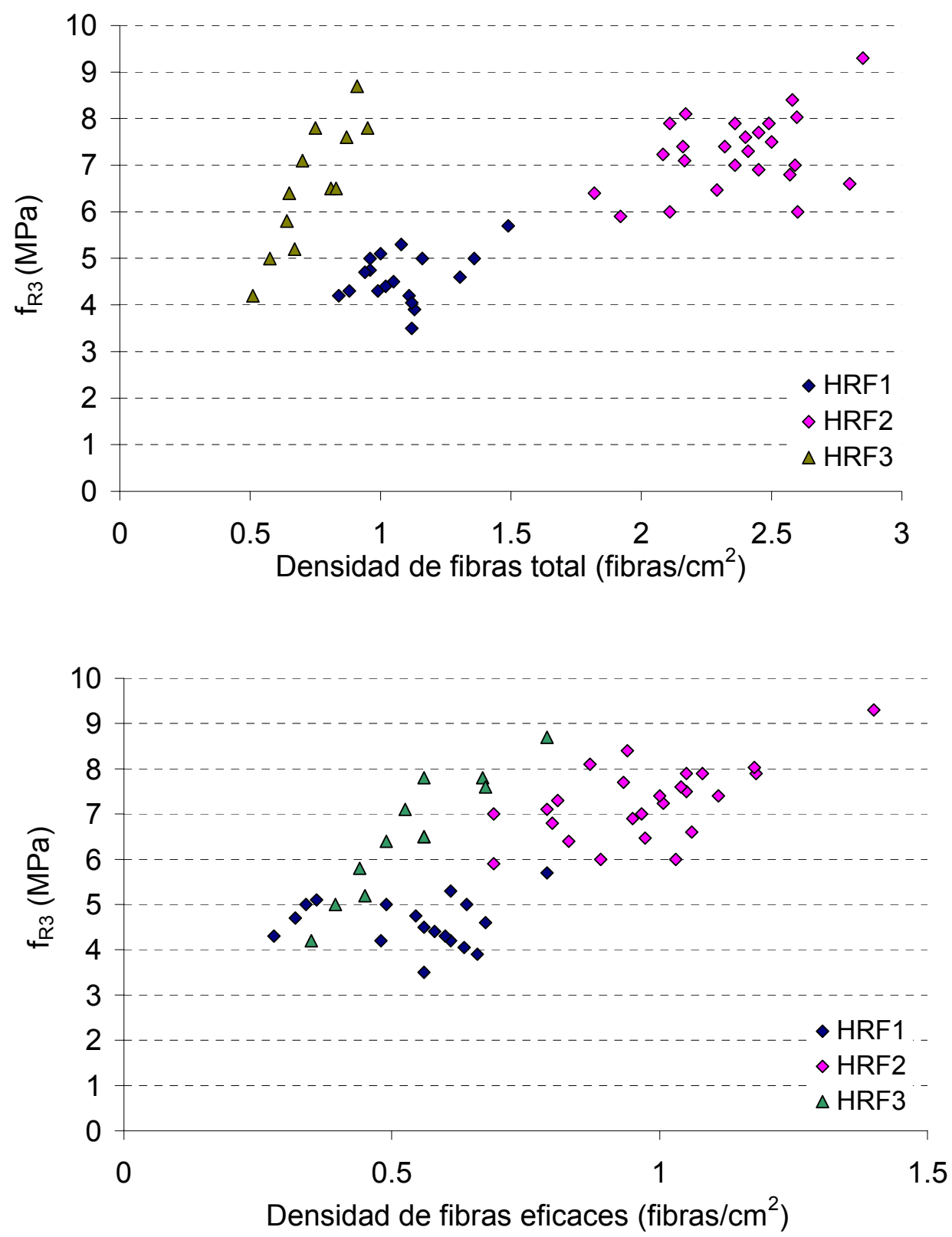

Figura 5.2.5.a- Efecto de la densidad de fibras totales sobre la resistencia $f_{R 3}$. b- Efecto de la densidad de fibras eficaces sobre la resistencia $f_{R 3}$.

\subsubsection{Conclusiones}

En este apartado se analizó la orientación del refuerzo en probetas de diferente geometría correspondientes a hormigones elaborados con diferentes tipos y contenidos de fibras de acero. A la vez se estudió la vinculación entre la distribución de las fibras y las propiedades post pico del HRF. 
Entre las principales conclusiones se destacan:

- Para todos los tamaños de probetas utilizados se verifica una relación directa entre el contenido de fibras y la tensión máxima o los parámetros representativos del comportamiento post pico del hormigón.

- Es notable la influencia del efecto pared, las fibras más largas se orientan en mayor proporción en el plano horizontal.

- Para igual dosis de refuerzo, las fibras más largas presentan un mejor comportamiento post fisuración, lo que puede justificarse en base a la observación anterior.

- La relación entre las densidades de fibras eficaces y fibras totales fue bastante dispersa.

Considerando que el comportamiento postpico es fundamental al momento de valorar la aptitud de un HRF para cualquier tipo de aplicación, la verificación de la distribución y contenido de refuerzo aparece como una herramienta de interés en el control de calidad de HRF. 


\subsection{ESTUDIO COMPARATIVO DE LA ORIENTACIÓN DE FIBRAS EN HORMIGÓN CONVENCIONAL REFORZADO CON FIBRAS SINTÉTICAS Y DE ACERO, DE USO CORRIENTE EN EL MERCADO LOCAL}

El objetivo de este estudio es comparar la orientación de fibras sintéticas estructurales y no estructurales y de fibras de acero en el hormigón. A su vez se evalúa la influencia del tipo de compactación.

Se estudiaron hormigones elaborados con dos tipos de fibras de acero y cinco tipos de fibras sintéticas. Algunos hormigones con fibras sintéticas fueron compactados manualmente (varilleo) mientras que otros fueron compactados mediante vibrado externo.

\subsubsection{Materiales y mezclas}

Se elaboraron hormigones con tres fibras sintéticas estructurales (SEa, SEb, $\mathrm{SEc}$ ), una fibra sintética no estructural (S) y dos fibras de acero (Aa: plana ondulada y Ab: twincone). En la Tabla 5.3.1 se incluyen las propiedades de las fibras y la dosis y modo de compactación de cada HRF. En la Fig. 5.3.1 se muestran las fibras utilizadas. Algunos hormigones fueron compactados mediante vibrado externo (VE) mientras que otros fueron compactados en forma manual (M) mediante varilleo, estas últimas fueron probetas de control correspondientes al hormigón de un tablero de puente.

Tabla 5.3.1. Características de las fibras y HRF elaborados.

\begin{tabular}{cccccccc}
\hline Tipo de Fibra & S & SEa & SEb & SEb & SEc & Aa & Ab \\
\hline Densidad & 0.91 & 0.91 & 0.92 & 0.92 & 0.92 & 7.8 & 7.8 \\
Largo $(\mathrm{mm})$ & 20 & 54 & 40 & 40 & 50 & 25 & 54 \\
Esbeltez $(\mathrm{l} / \mathrm{d})$ & - & - & - & - & - & 25 & 54 \\
\hline HRF & S & SEa & SEb1 & SEb2 & SEc & Aa & Ab \\
\hline Dosis de fibras $\left(\mathrm{kg} / \mathrm{m}^{3}\right)$ & 1.9 & 4 & 1.4 & 2.2 & 5 & 30 & 30 \\
Modo de compactación & $\mathrm{M}$ & VE & $\mathrm{M}$ & $\mathrm{M}$ & $\mathrm{VE}$ & $\mathrm{VE}$ & $\mathrm{VE}$ \\
\hline
\end{tabular}


S

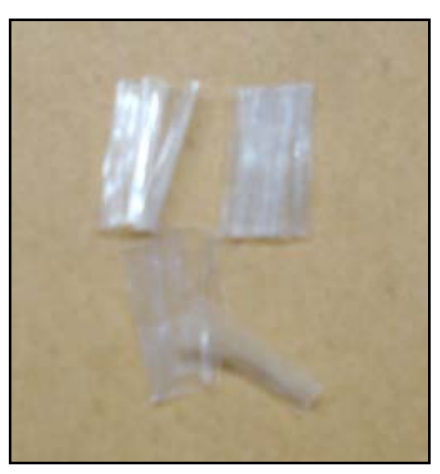

SEc

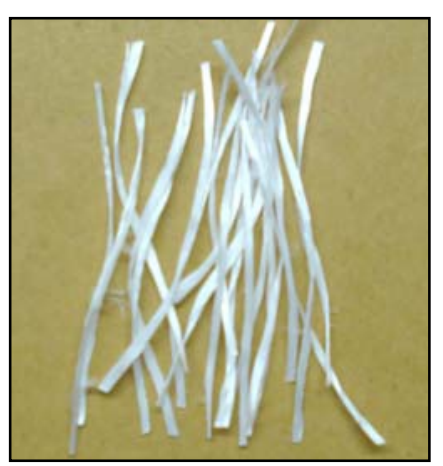

SEa

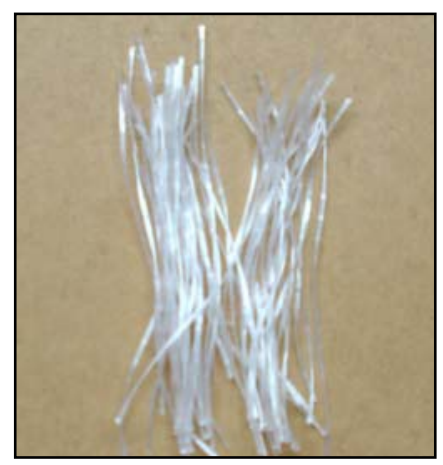

$\mathrm{Aa}$

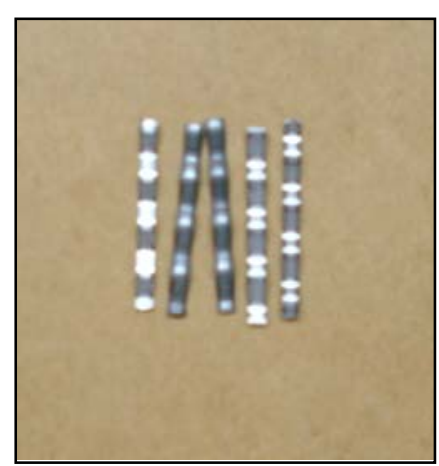

SEb

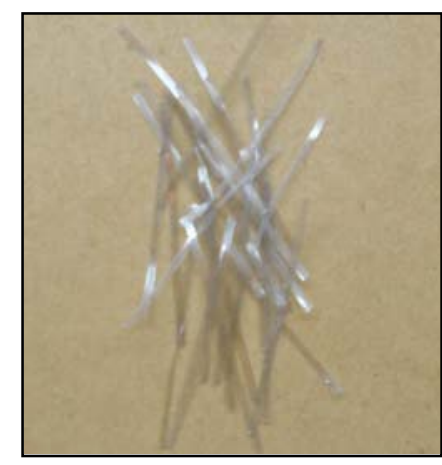

$\mathbf{A b}$

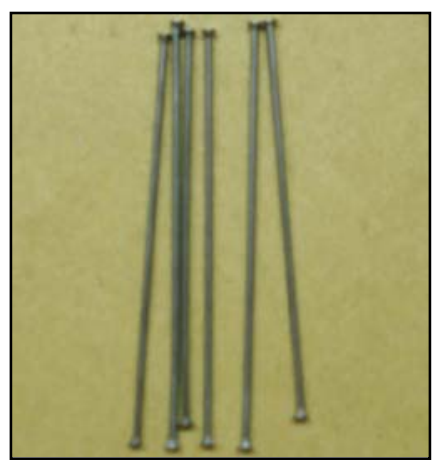

Figura 5.3.1. Fibras utilizadas.

\subsubsection{Detalles experimentales}

Con cada hormigón se moldearon 3 vigas de $75 \times 105 \times 430 \mathrm{~mm}$ y 3 de $150 \times 150 \times 500 \mathrm{~mm}$. Las mismas se ensayaron a flexión y luego se relevaron las fibras en la superficie de fractura de la misma forma en que fuera explicado en el inciso 5.2. Para obtener la densidad de fibras de acero en los otros planos una mitad resultante del ensayo fue cortada en la dirección normal al moldeo y la otra mitad en la dirección longitudinal paralela al moldeo (ver Fig. 5.2.2).

En el caso de las fibras de polipropileno, ante la dificultad de distinguir las fibras en una sección cortada, se ensayaron las mitades a tracción por compresión diametral. De esta manera resulta más sencillo contar las fibras ya que quedan arrancadas en las caras fracturadas. Una de las mitades restantes del ensayo de flexión fue ensayada mediante el ensayo brasileño en la dirección longitudinal paralela al moldeo mientras que la otra fue ensayada en la dirección perpendicular a la misma. 
Las cantidades relevadas en cada cara fueron sumadas para obtener la densidad en cada dirección.

\subsubsection{Resultados y discusión}

En la Tabla 5.3.2 se presentan los resultados de la densidad de fibras según cada uno de los planos relevados. En los hormigones elaborados con fibras sintéticas estructurales, se observó una orientación preferencial en el plano horizontal, pero la misma fue algo menos marcada que en los hormigones con fibras de acero. Estas fibras también tienden a orientarse en la dirección del eje longitudinal de las probetas. La densidad en el plano normal al llenado varió entre el 45 y el $55 \%$ de la densidad en la dirección transversal. En el caso del HRF Sb1 $\left(1.4 \mathrm{~kg} / \mathrm{m}^{3}\right)$ se obtuvo un valor atípico de $96 \%$, mientras que el mismo hormigón con una dosis mayor de fibras $\mathrm{Sb}$ $\left(2.2 \mathrm{~kg} / \mathrm{m}^{3}\right)$ presentó un valor relativo igual a $51 \%$. Como estos hormigones fueron compactados en forma manual, la compactación no tuvo una influencia significativa sobre la orientación de las fibras, las fibras en el hormigón Sb1 (con menor cantidad de fibras) al estar más dispersas no experimentaron el efecto de las paredes del molde y se dispusieron de manera aleatoria. La relación de densidades entre el plano normal y el plano longitudinal osciló entre el 57 y el $88 \%$. Los mayores porcentajes, entre el 82 y el $88 \%$, se presentaron en los hormigones compactados en forma manual (S, $\mathrm{Sb} 1$ y Sb2), en estos casos las fibras no se orientaron tan fuertemente en el plano horizontal. Las dos clases de fibras de acero mostraron un comportamiento similar, verificando la mayor orientación en los planos $T$ y $L$ donde las fibras se disponen en forma horizontal.

Tabla 5.3.2. Densidad de fibras $\left(\mathrm{N} / \mathrm{cm}^{2}\right)$ según el plano relevado.

\begin{tabular}{cccccc}
\hline Plano & $\mathbf{L}$ & $\mathbf{T}$ & $\mathbf{N}$ & $\mathbf{N} / \mathbf{T}$ & $\mathbf{N} / \mathbf{L}$ \\
\hline SEc & 1.21 & 1.54 & 0.69 & 0.45 & 0.57 \\
SEb2 & 0.58 & 0.95 & 0.48 & 0.51 & 0.83 \\
S & 1.03 & 1.52 & 0.84 & 0.55 & 0.82 \\
SEb1 & 0.26 & 0.24 & 0.23 & 0.96 & 0.88 \\
$\mathrm{Aa}$ & 0.15 & 0.25 & 0.10 & 0.39 & 0.67 \\
$\mathrm{Ab}$ & 0.22 & 0.28 & 0.14 & 0.49 & 0.63 \\
SEa & 1.61 & 1.74 & 0.95 & 0.54 & 0.59 \\
\hline
\end{tabular}




\subsubsection{Conclusiones}

En este apartado se evaluó la orientación del refuerzo en HRF con distintos tipos de fibras sintéticas y dos clases de fibras de acero.

Como punto saliente se observó que en hormigones con fibras sintéticas estructurales también puede darse una orientación preferencial en planos horizontales (N). Se verifica que el modo de compactación afecta esta orientación preferencial. En el caso de las fibras de acero el refuerzo se orientó en forma similar independientemente del tipo de fibra utilizada, adquiriendo en ambos casos una orientación 2D.

La gran variedad de fibras sintéticas estructurales y no estructurales que aparecen día a día en el mercado así como las mayores dificultades en el recuento de las mismas comparada con el caso de las fibras de acero, hacen recomendable la profundización en estudios sistemáticos sobre la orientación del refuerzo con este tipo de fibras. 


\subsection{EFECTO DEL MÉTOdO DE LLENADO SOBRE LA ORIENTACIÓN Y DISTRIBUCIÓN DE FIBRAS EN HACRF}

Dado que las fibras modifican el comportamiento del hormigón en estado fresco $y$, a su vez, que las características del hormigón en estado fresco pueden afectar la distribución de fibras, en este apartado se evalúa el efecto de la forma de llenado sobre la orientación del refuerzo en HAC. Las observaciones de las características mesoestructurales del refuerzo se vinculan con la respuesta mecánica del hormigón.

El estudio se realizó en HAC reforzados con fibras de acero de 30 y de $50 \mathrm{~mm}$ de longitud. Se llenaron probetas prismáticas ubicadas en distintas posiciones vertiendo el hormigón en distintas formas, desde el centro o desde un extremo en probetas dispuestas en forma horizontal o desde un extremo del molde ubicado a modo de columna en dirección vertical. Las vigas fueron ensayadas a flexión y posteriormente se evaluó la orientación y distribución de las fibras en las superficies de fractura y sobre cortes en las tres direcciones. Complementariamente se repitió la experiencia con un HAC reforzado con fibras sintéticas estructurales, en este caso sólo se evaluó la respuesta mecánica del HACRF.

\subsubsection{Materiales y mezclas}

Se elaboraron tres hormigones autocompactantes empleando un mismo HAC de base. Se utilizaron arenas y piedra partida, cemento, filler calizo, un aditivo superplastificante de tipo policarboxilato y un aditivo plastificante polifuncional con el fin de aumentar el tiempo abierto de la mezcla. En el primer hormigón (HACRF1) se incorporaron fibras de acero conformadas en los extremos (hooked-end) de $50 \mathrm{~mm}$ de longitud y $1 \mathrm{~mm}$ de diámetro (esbeltez $=50$ ), en el segundo (HACRF2) fibras de acero (F2) del mismo tipo pero de $30 \mathrm{~mm}$ de longitud y $0.38 \mathrm{~mm}$ de diámetro (esbeltez $=80$ ), mientras que el tercer hormigón (HACRF3) se elaboró con fibras sintéticas estructurales (F3) de $54 \mathrm{~mm}$ de longitud. En la Tabla 5.4 .1 se indican las proporciones de los hormigones elaborados. 
Tabla 5.4.1. Proporciones $\left(\mathrm{kg} / \mathrm{m}^{3}\right)$ de los materiales componentes.

\begin{tabular}{cccc}
\hline Materiales & HACRF1 & HACRF2 & HACRF3 \\
\hline Cemento & 343 & \\
Filler & 103 & \\
Agua & 161 & \\
Arena & 965 & \\
Piedra Partida & & 800 & \\
Plastificante & & 2.8 & \\
Superplastificante & & 11.3 & \\
Tipo de Fibra & F1 & F2 & F3 \\
Fibras de acero & 35 & 35 & - \\
Fibras sintéticas & - & - & 2.5 \\
\hline
\end{tabular}

\subsubsection{Detalles experimentales}

Previo al llenado de los elementos, fueron evaluadas las características de autocompactabilidad en estado fresco a través de los ensayos de escurrimiento (midiendo el diámetro final, $D_{f}$ y el tiempo en alcanzar un diámetro de $500 \mathrm{~mm}, T_{50}$ ), escurrimiento con anillo $\mathrm{J}$ (midiendo $D_{f J}$ y $T_{50}$ ) y el ensayo de embudo en $\mathrm{V}$ (midiendo el tiempo de vaciado $T_{V}$ ).

Para cada mezcla se moldearon 12 vigas de $150 \times 150 \times 600 \mathrm{~mm}$ (ver Fig. 5.4.1), siguiendo tres procedimientos de llenado diferentes. Cuatro vigas fueron moldeadas conforme lo indicado por la norma EN 14651, vertiendo el hormigón desde el centro con el molde en posición horizontal, las mismas se identifican por la letra C. Otras cuatro vigas se llenaron desde un extremo del molde luego de que el HACRF atravesara una tubería de $0.15 \mathrm{~m}$ de diámetro y $5 \mathrm{~m}$ de longitud (pendiente $22^{\circ}$ ), estas vigas se identifican por la letra $\mathrm{T}$, simulando un caso de aplicación donde podría favorecerse la orientación y/o distribución diferencial dentro de la probeta. Finalmente se moldearon cuatro vigas dispuestas en posición vertical $(\mathrm{V})$.

Las vigas fueron desmoldadas a las 24 horas y curadas durante 28 días en cámara húmeda $\left(95 \pm 5 \% \mathrm{HR}, 20^{\circ} \mathrm{C}\right)$. 
A los 28 días las vigas fueron ensayadas a flexión con carga centrada de acuerdo con la normativa EN 14651. Se realizaron mediciones de carga y apertura de fisura a través de un dispositivo tipo clip. A partir de este ensayo se determinaron la tensión máxima, la tensión de primera fisura y las resistencias residuales $f_{R 1}, f_{R 2}, f_{R 3} y$ $f_{R 4}$, correspondientes a aperturas de fisura iguales a 500, 1500, 2500 y $3500 \mu \mathrm{m}$.

Para analizar la distribución del refuerzo en el caso de los HAC con fibras de acero se siguió el procedimiento que se detalla a continuación:

Una vez ensayada a flexión cada viga se contó el número de fibras en ambas caras del plano de fractura. En el caso del HACRF1 se hizo además la distinción entre fibras eficaces (aquellas que presentan un enderezamiento de los ganchos de los extremos) y no eficaces (ganchos en su estado original).
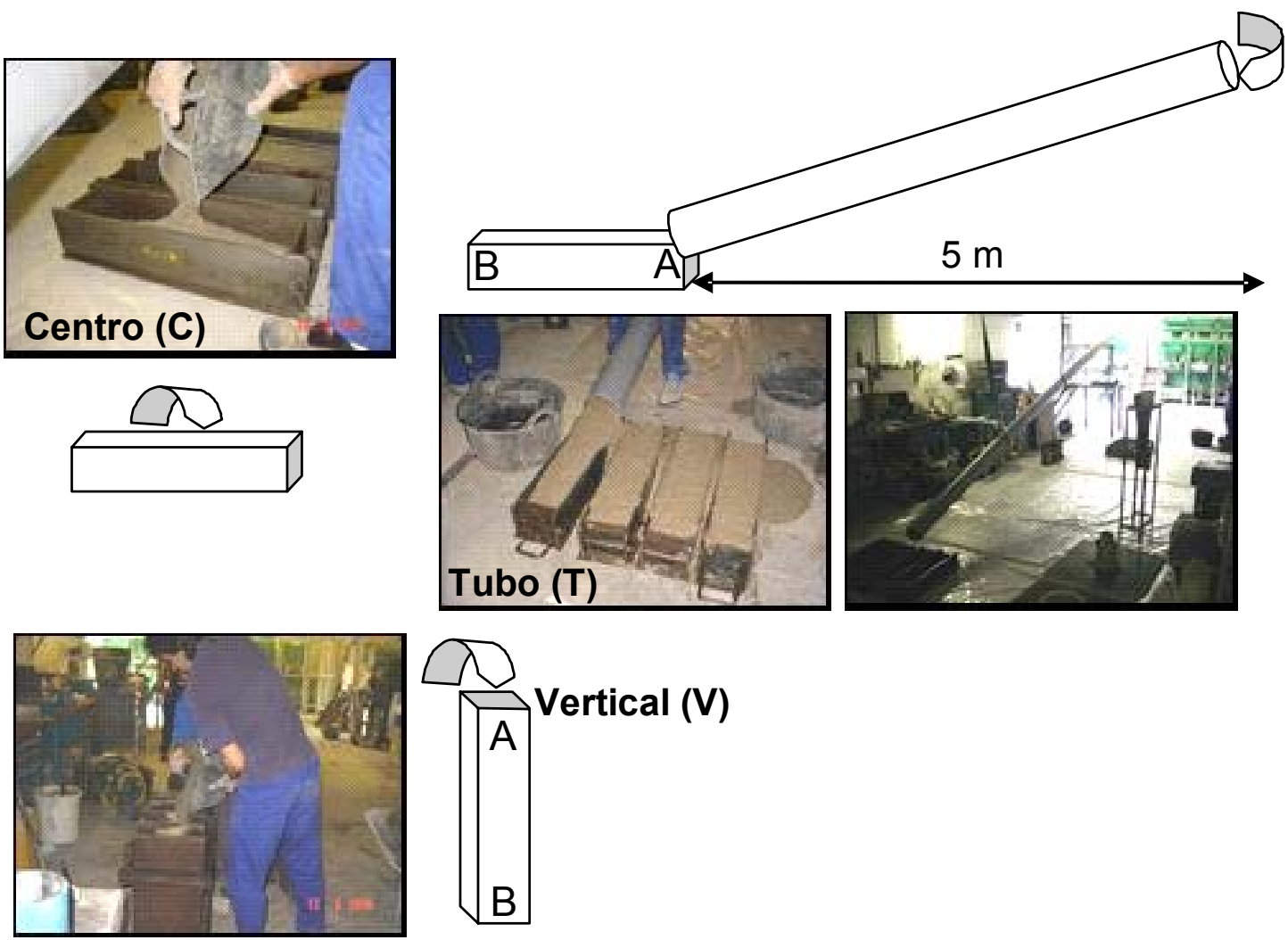

Figura 5.4.1. Tipos de vertido: desde el centro del molde según indica la norma (C), a través de un tubo colocado sobre un extremo del molde $(T)$ y con el molde en posición vertical desde el extremo superior $(\mathrm{V})$. 
Luego en el caso de los HACRF1 y 2, elaborados con fibras de acero, con el propósito de analizar la orientación de las fibras dentro de las vigas para cada uno de los sistemas de moldeo adoptados (C, T, V), se cortaron las mitades según 3 planos: un plano transversal $(\alpha)$, otro longitudinal-perpendicular a la dirección de llenado $(\beta)$ y otro longitudinal-paralelo $(\mathrm{Y})$ a la dirección de llenado (ver Fig. 5.4.2).

En primer lugar de cada mitad de las vigas ensayadas, se cortó una rodaja de $50 \mathrm{~mm}$ en dirección transversal ( $\alpha$ ) a cada lado del plano de fractura, con el fin de evitar el sector donde se pudo haber producido el arrancamiento de las fibras.

En el caso de las vigas $C$ una de las mitades se aserró según el plano $\gamma$ y la otra según el plano $\beta$, considerando que no existe razón para pronosticar una diferencia en la distribución de fibras a ambos lados de la sección de ensayo.

Por el contrario cada una de las mitades de $250 \mathrm{~mm}$ de las vigas $\mathrm{V}$ y $\mathrm{T}$ se aserraron primero siguiendo el plano longitudinal $\gamma$ (paralelo a la dirección de llenado) y a continuación se volvieron a cortar los trozos de hormigón siguiendo el plano $\beta$ (perpendicular a la dirección de llenado). En estas vigas se hizo la distinción entre las dos mitades, llamando A a la mitad por la que comienza el vertido del hormigón (inicio del flujo en vigas $\mathrm{T}$ y extremo superior en las vigas $\mathrm{V}$ ) y $\mathrm{B}$ a la otra mitad (ver Fig. 5.4.1).

Para evaluar la homogeneidad en la distribución de las fibras dentro de cada corte, se delimitaron sectores dependiendo de la incidencia del flujo de llenado (Fig. 5.4.2). En el caso de las vigas $\mathrm{C}$ y $\mathrm{T}$, los cortes correspondientes a los planos a y $\beta$ fueron divididos en 3 zonas, en el primero se evaluó si la cantidad de fibras variaba desde la cara de moldeo con respecto al fondo y en el segundo caso si la cantidad de refuerzo se modificaba a lo largo del eje de la viga. En cambio en el plano $\gamma$ se relevaron 9 zonas para distinguir tanto la variación en el eje longitudinal como en la dirección vertical.

Los cortes correspondientes a las planos $(\gamma$ y $\beta$ ) de las vigas $V$ son paralelos a la dirección de llenado y por lo tanto fueron relevados en 3 sectores teniendo en cuenta el flujo vertical, en este caso la distribución de fibras en ambas direcciones debería ser equivalente. Para verificar si la distribución era homogénea en toda la sección se dividió el corte transversal ( $\alpha$ ) en 9 zonas. 
En las caras aserradas la densidad de fibras se obtuvo haciendo el promedio del recuento del número de fibras en cada uno de los lados del corte y dividiéndolo por el área relevada. La grilla fue numerada de forma tal que el número 1 corresponde al sector más cercano a la cara de moldeo y a la entalla; en el caso de los planos divididos en 9 sectores a los siguientes 2 cuadrantes más cercanos a la entalla les corresponden los números 4 y 7 .

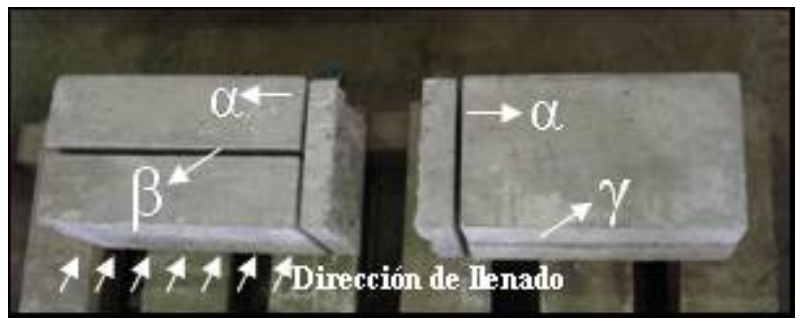

Centro-Tubo

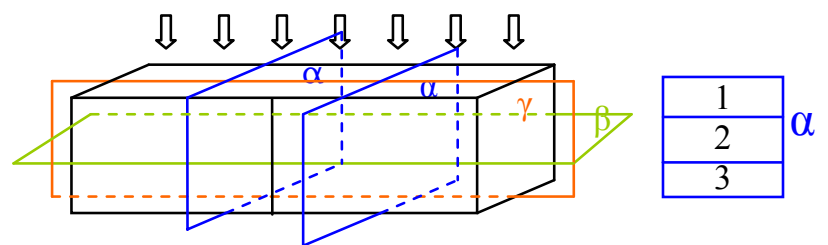

\begin{tabular}{|c|c|c|c|c|c|}
\hline 3 & 2 & 1 & 1 & 2 & 3 \\
\hline 6 & 5 & 4 & 4 & 5 & 6 \\
\hline 9 & 8 & 7 & 7 & 8 & 9 \\
\hline
\end{tabular}

\begin{tabular}{|l|l|l|l|l|l|}
\hline 3 & 2 & 1 & 1 & 2 & 3 \\
\hline
\end{tabular}

Vertical
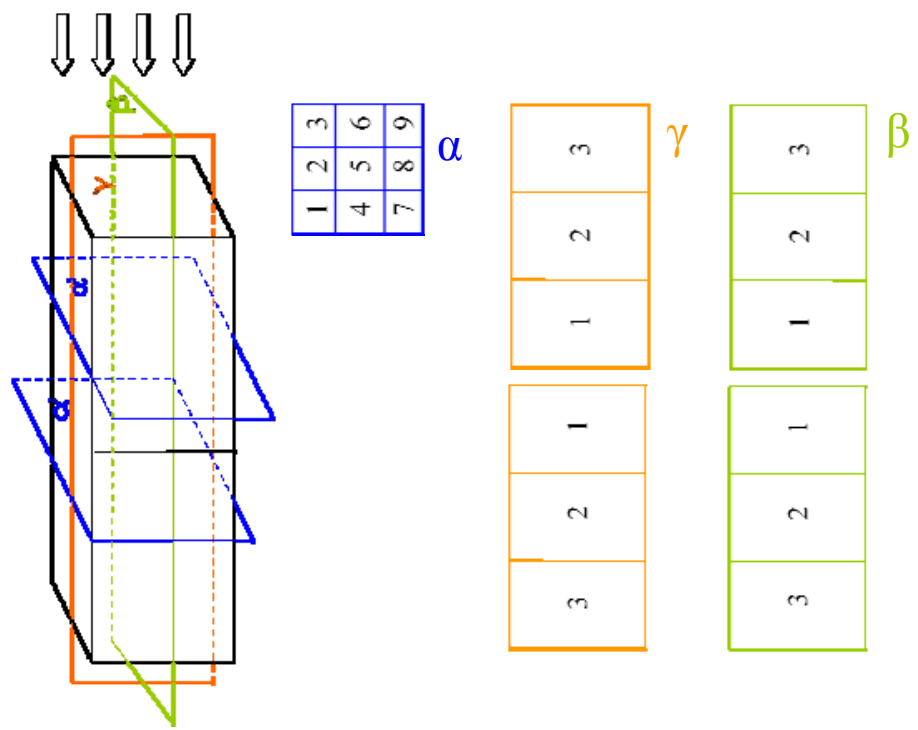

Figura 5.4.2. Direcciones de corte y esquema de relevamiento de fibras. 


\subsubsection{Resultados y discusión}

\subsubsection{Propiedades en estado fresco}

En la tabla 5.4.2 se presentan las características en estado fresco de cada hormigón. Se puede observar en el caso del HACRF3, que la incorporación de fibras sintéticas disminuye la fluidez del hormigón. Los ensayos lo sitúan fuera de los límites propuestos para hormigones autocompactantes (SCCEPG, 2005).

Tabla 5.4.2. Características de los hormigones en estado fresco.

\begin{tabular}{cccccc}
\hline & \multicolumn{2}{c}{ Escurrimiento } & \multicolumn{2}{c}{ Embudo } & \multicolumn{2}{c}{ Escurrimiento J } \\
& Df $(\mathrm{mm})$ & $\mathrm{T}_{50}(\mathrm{~s})$ & $\mathrm{Tv}(\mathrm{s})$ & $\mathrm{Df}(\mathrm{mm})$ & $\mathrm{T}_{50}(\mathrm{~s})$ \\
\hline HACRF1 & 540 & 2.6 & 9.7 & 504 & 4.9 \\
HACRF2 & 590 & 3.2 & 19.5 & 535 & 4.0 \\
HACRF3 & 500 & 5.3 & 9.0 & 460 & - \\
\hline
\end{tabular}

\subsubsection{Propiedades mecánicas}

En este apartado se describen y analizan las propiedades de los hormigones en estado endurecido y la vinculación entre su respuesta mecánica y la densidad de fibras en el plano de fractura.

La Fig. 5.4.3 presenta las curvas individuales carga-apertura de fisura obtenidas en el ensayo de flexión para los tres tipos de vigas $\mathrm{C}$, $\mathrm{T}$ y $\mathrm{V}$ elaboradas con el HACRF1.

Como es posible apreciar este HAC con fibras de $50 \mathrm{~mm}$ presenta un comportamiento post pico con endurecimiento, fundamentalmente en el caso de las vigas $\mathrm{T}$ que muestran un marcado aumento de la resistencia a partir del primer pico. Las vigas moldeadas desde el centro (C), también mostraron curvas con endurecimiento pero con valores post pico significativamente menores a los anteriores lo que se asocia con cambios en la distribución del refuerzo. Por su parte todas la vigas moldeadas en forma vertical (V) presentaron curvas post pico sin endurecimiento, y alcanzaron una tensión límite a partir de la cual las curvas adquieren una forma de meseta con niveles de resistencia residual menores al $40 \%$ de la carga de fisuración. 


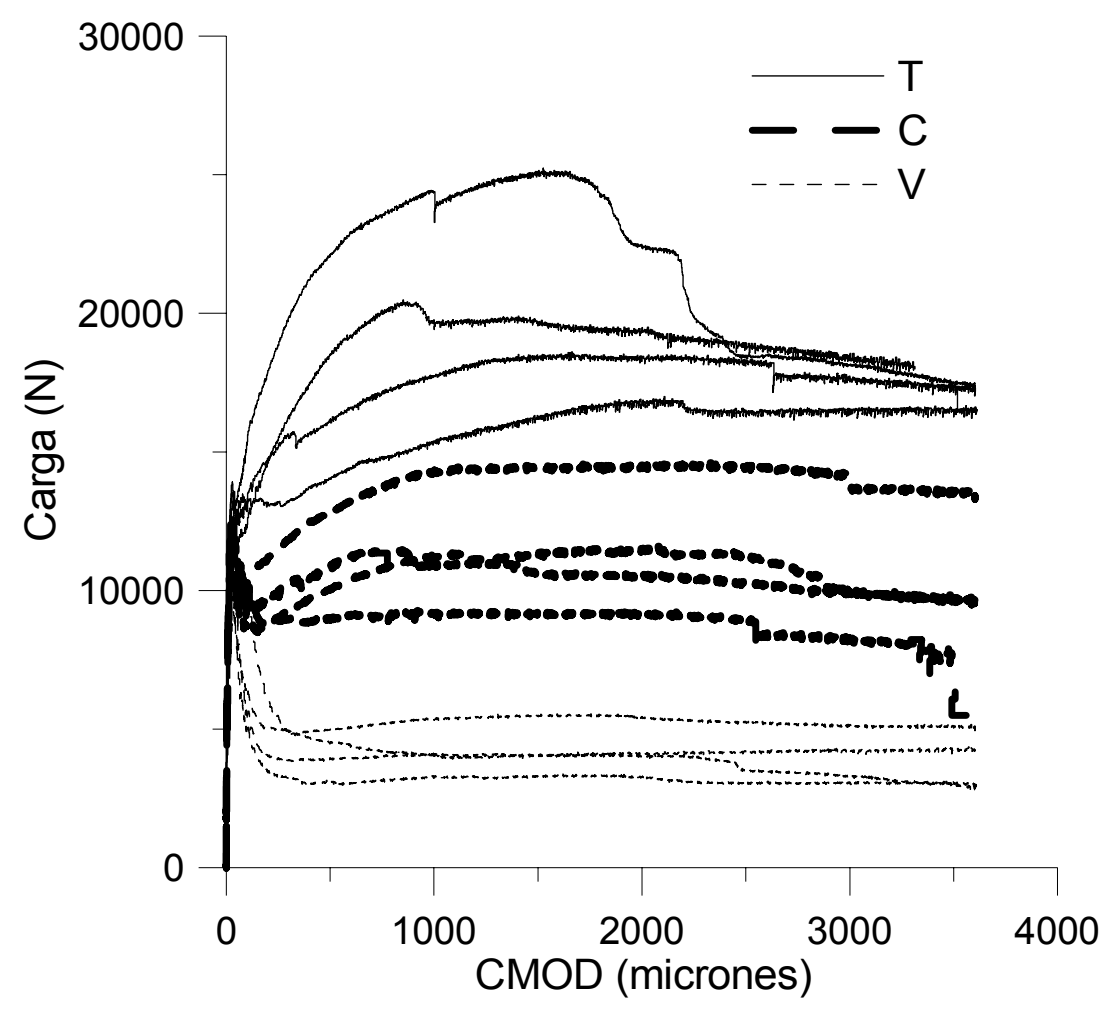

Figura 5.4.3. Gráficos carga-CMOD correspondientes a las vigas elaboradas con HACRF1.

En la Tabla 5.4 .3 se resumen los resultados obtenidos del ensayo de flexión para HACRF1, la tensión máxima $\left(f_{M}\right)$, tensión de primera fisura $\left(f_{L}\right)$ y resistencias residuales $f_{R 1}, f_{R 2}, f_{R 3}$ y $f_{R 4}$. Para analizar la vinculación entre mesoestructura y respuesta mecánica también se incluye la densidad de fibras correspondiente a la superficie de fractura

Tabla 5.4.3. Resultados del ensayo de flexión y densidad de fibras en HACRF1: valores medios y desviación estándar.

\begin{tabular}{cccccccc}
\hline & $\begin{array}{c}\mathbf{f}_{\mathbf{M}} \\
(\mathrm{MPa})\end{array}$ & $\begin{array}{c}\mathbf{f}_{\mathrm{L}} \\
(\mathrm{MPa})\end{array}$ & $\begin{array}{c}\mathbf{f}_{\mathrm{R} 1} \\
(\mathrm{MPa})\end{array}$ & $\begin{array}{c}\mathbf{f}_{\mathrm{R} 2} \\
(\mathrm{MPa})\end{array}$ & $\begin{array}{c}\mathbf{f}_{\mathrm{R} 3} \\
(\mathrm{MPa})\end{array}$ & $\begin{array}{c}\mathbf{f}_{\mathrm{R} 4} \\
(\mathrm{MPa})\end{array}$ & $\begin{array}{c}\text { Densidad } \\
\text { fibras } / \mathrm{cm}^{2}\end{array}$ \\
\hline $\mathrm{C} \mathrm{C}$ & 4.0 & 3.8 & 3.4 & 3.6 & 3.5 & 3.2 & 0.27 \\
& $(0.5)$ & $(0.3)$ & $(0.5)$ & $(0.7)$ & $(0.7)$ & $(0.8)$ & $(0.1)$ \\
$\mathrm{T}$ & 6.4 & 4.2 & 5.6 & 6.3 & 5.7 & 5.5 & 0.39 \\
& $(1.2)$ & $(0.1)$ & $(1.2)$ & $(1.3)$ & $(0.4)$ & $(0.3)$ & $(0.1)$ \\
$\mathrm{V}$ & 3.3 & 3.2 & 1.3 & 1.3 & 1.3 & 1.2 & 0.16 \\
& $(0.2)$ & $(0.25)$ & $(0.3)$ & $(0.3)$ & $(0.3)$ & $(0.3)$ & $(0.02)$ \\
\hline
\end{tabular}




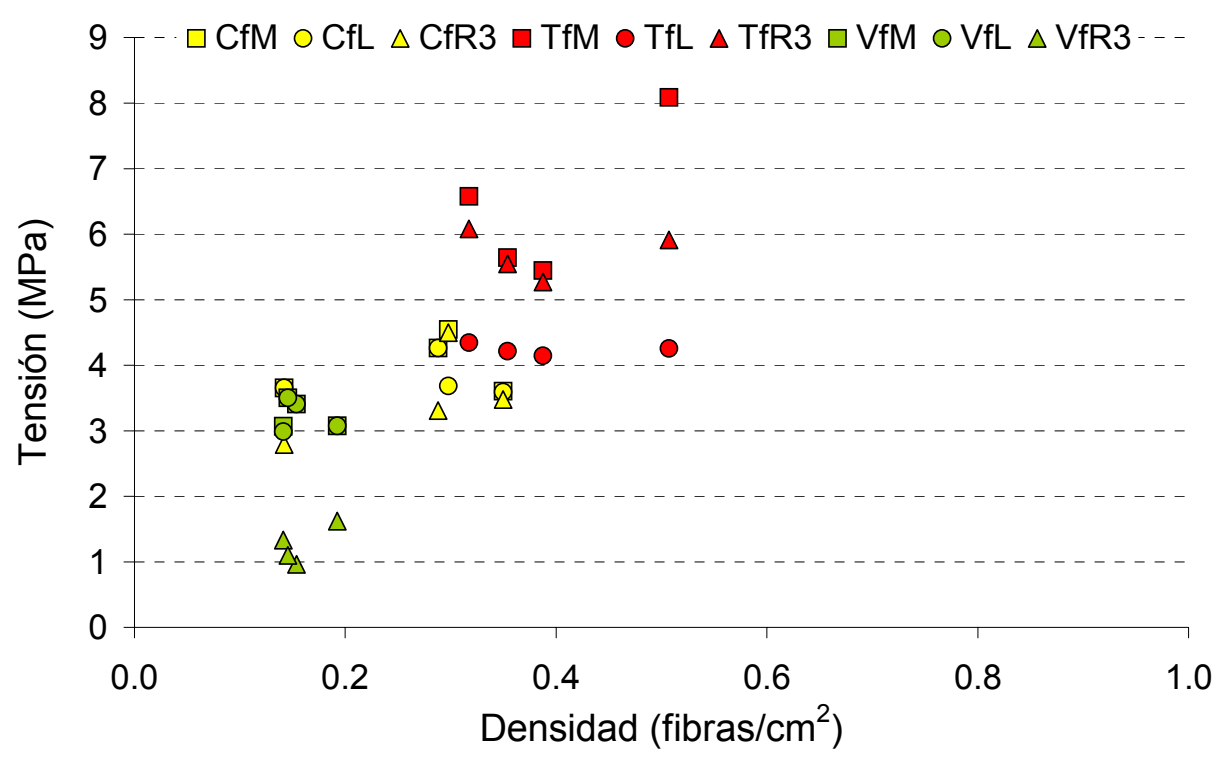

Figura 5.4.4. Variación de los parámetros resistentes con la densidad de fibras HACRF1.

Los valores de resistencia a flexión obtenidos se corresponden con la densidad de fibras medida. En la Fig. 5.4 .4 se representan los valores de la tensión máxima, la tensión de primera fisura y la resistencia residual correspondiente a una apertura de fisura de $2500 \mu \mathrm{m}\left(f_{R 3}\right)$ en función de la densidad de fibras para los grupos de vigas $C$, T y $V$ del HACRF1.

Se observa que la mayor densidad de fibras en el grupo $T$ se corresponde con mayores valores de los parámetros mecánicos lo que puede justificarse considerando que se produce una mayor orientación del refuerzo debido al flujo del hormigón dentro del tubo. Se aprecian menores diferencias en la tensión de primera fisura ya que ésta depende principalmente de la resistencia de la matriz. En el caso de las vigas $V$ existe un número de fibras significativamente menor en la superficie de fractura debido a la orientación desfavorable que produce el llenado, la disminución en la tensión de primera fisura que se observó en este caso se atribuye a una menor consolidación.

Para este caso se hizo la distinción entre fibras eficaces y no eficaces. En la Fig. 5.4.5 es posible apreciar una cierta correlación entre fibras eficaces y totales, siendo la relación para los grupos $\mathrm{C}, \mathrm{T}$ y $\mathrm{V}$ igual a $0.68,0.66$ y 0.50 respectivamente, estos valores están en el orden de los encontrados para hormigones vibrados. 


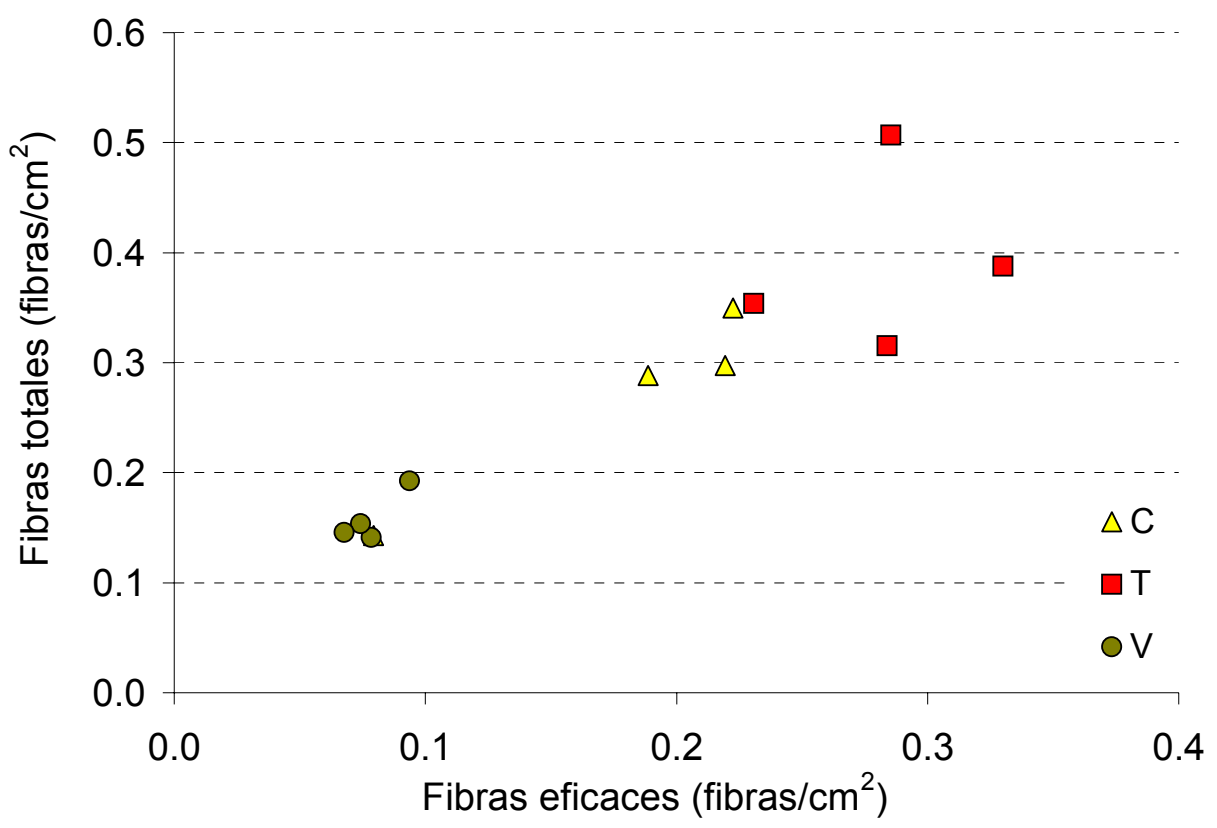

Figura 5.4.5. Fibras eficaces vs fibras totales en HACRF1.

En las Fig. 5.4.6.a y b se observa la correlación entre densidad de fibras eficaces y totales con respecto a $f_{R 2}$ (correspondiente a una apertura de fisura de 1500 $\mu \mathrm{m})$. A diferencia de lo observado en otros trabajos en este caso no se encontraron mayores diferencias entre fibras totales o eficaces, aunque se observó una mejor correlación entre la densidad de fibras totales y la resistencia residual que entre la densidad de fibras eficaces y la resistencia residual.

En la Fig. 5.4 .7 se presentan las curvas carga-CMOD obtenidas a partir de los ensayos de flexión sobre las vigas elaboradas con el hormigón HACRF2.

En el caso de las vigas del HAC con fibras más cortas $(30 \mathrm{~mm})$ no se observa una diferencia tan marcada de comportamiento entre las probetas elaboradas mediante las distintas formas de moldeo como en el caso anterior. Tanto las vigas $\mathrm{C}$ como T se comportan satisfactoriamente en el post pico, se observa en las vigas $T$ una mayor dispersión de los resultados, las vigas $\mathrm{V}$ presentan curvas con endurecimiento. 
a-

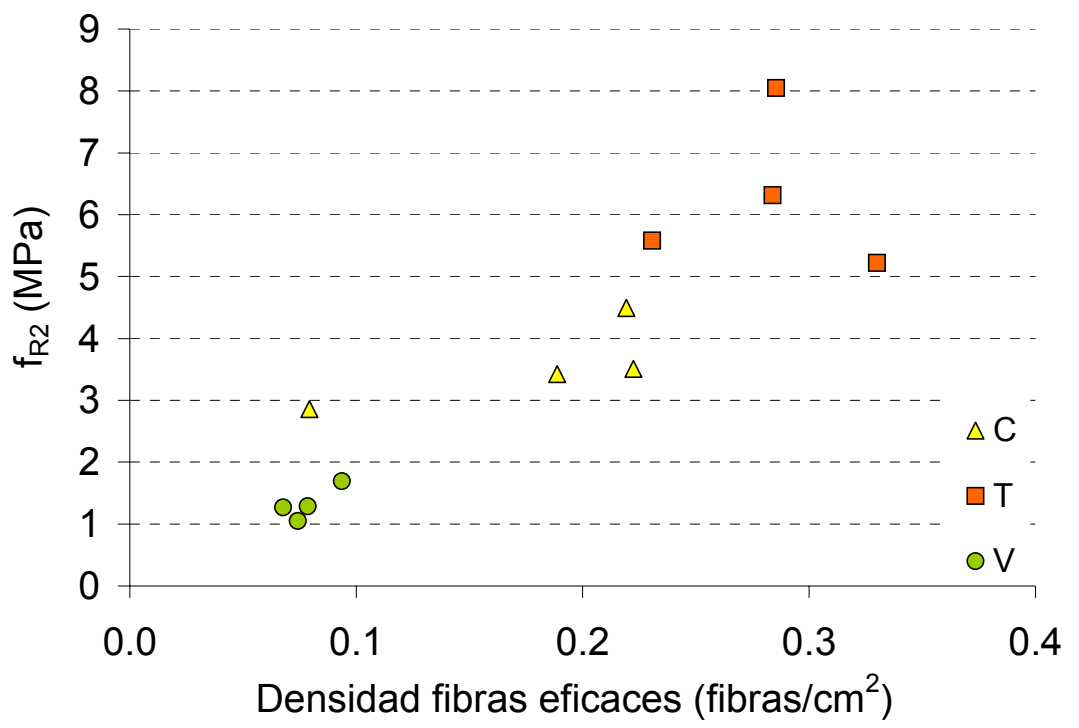

b-

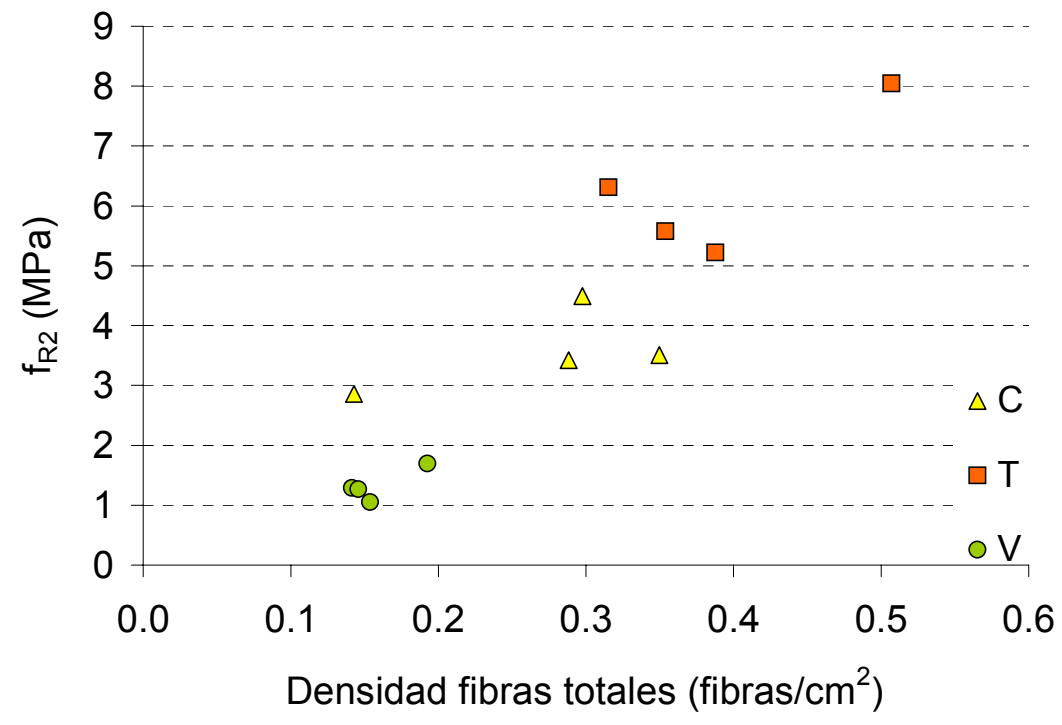

Figura 5.4.6. a- Densidad de fibras eficaces vs $\mathrm{f}_{\mathrm{R} 2} \mathrm{HACRF1.}$

b- Densidad de fibras totales vs $f_{R 2}$ HACRF1.

En la Tabla 5.4.4 se incluyen los resultados del ensayo de flexión y la densidad de fibras en el corte transversal. En este caso sólo fueron contadas las fibras en los cortes, ya que como se comprobará en 5.4.3.3 la densidad de fibras en la superficie de fractura se corresponde con la densidad medida sobre los cortes, aunque es mayor en este último caso. 


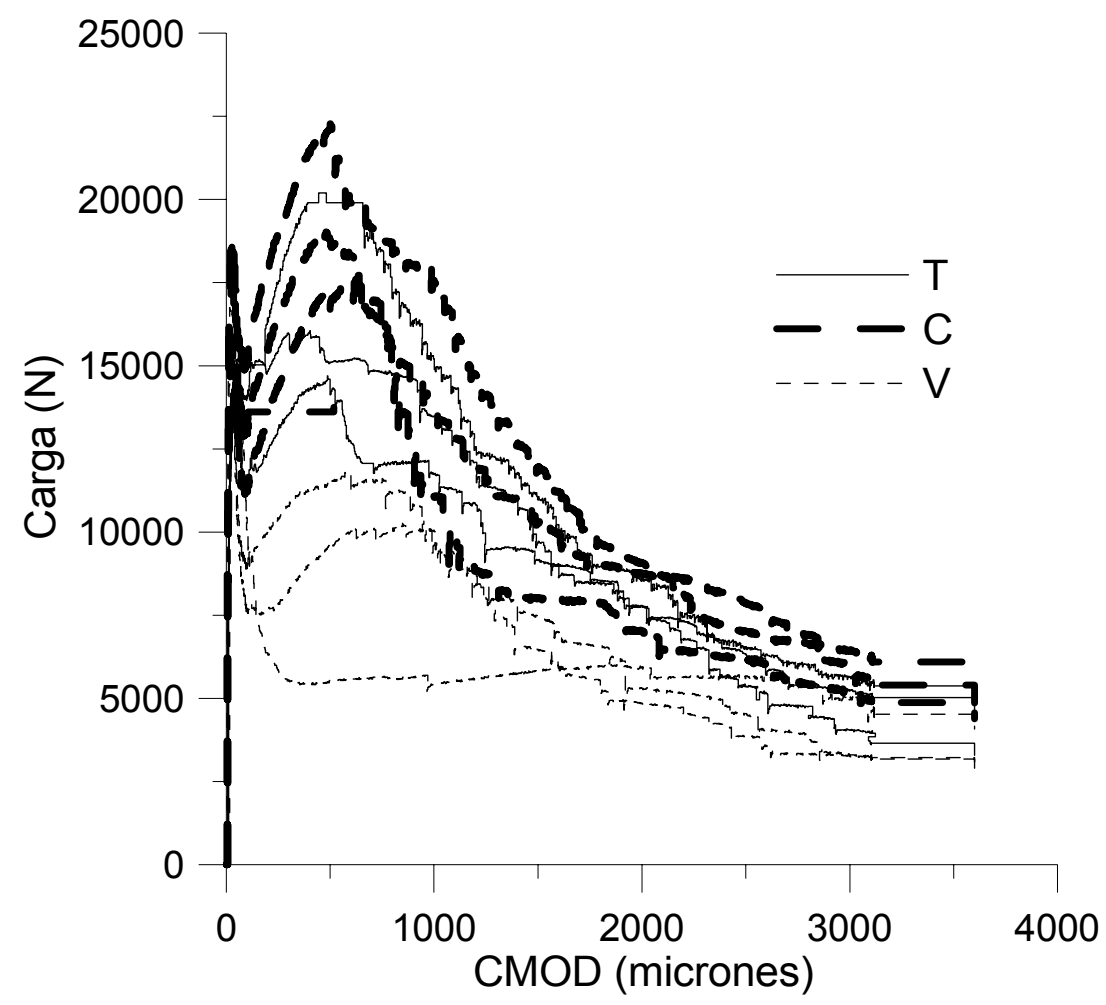

Figura 5.4.7. Gráficos carga-CMOD correspondientes a las vigas elaboradas con HACRF2.

Tabla 5.4.4. Resultados del ensayo de flexión y densidad de fibras en HACRF2: valores medios y desviación estándar.

\begin{tabular}{cccccccc}
\hline & $\begin{array}{c}\mathbf{f}_{\mathrm{M}} \\
(\mathrm{MPa})\end{array}$ & $\begin{array}{c}\mathbf{f}_{\mathrm{L}} \\
(\mathrm{MPa})\end{array}$ & $\begin{array}{c}\mathbf{f}_{\mathrm{R} 1} \\
(\mathrm{MPa})\end{array}$ & $\begin{array}{c}\mathbf{f}_{\mathrm{R} 2} \\
(\mathrm{Mpa})\end{array}$ & $\begin{array}{c}\mathbf{f}_{\mathrm{R} 3} \\
(\mathrm{MPa})\end{array}$ & $\begin{array}{c}\mathbf{f}_{\mathrm{R} 4} \\
(\mathrm{MPa})\end{array}$ & $\begin{array}{c}\text { Densidad } \\
\text { fibras } / \mathrm{cm}^{2}\end{array}$ \\
\hline $\mathrm{C}$ & 5.8 & 5.4 & 5.5 & 3.1 & 2.1 & 1.6 & 0.81 \\
& $(0.6)$ & $(0.3)$ & $(1.0)$ & $(0.7)$ & $(0.3)$ & $(0.3)$ & $(0.05)$ \\
$\mathrm{T}$ & 5.1 & 4.4 & 4.9 & 3.0 & 1.8 & 1.2 & 0.71 \\
& $(1.1)$ & $(0.3)$ & $(1.2)$ & $(0.4)$ & $(0.2)$ & $(0.2)$ & $(0.1)$ \\
$\mathrm{V}$ & 5.1 & 5.1 & 2.9 & 2.0 & 1.5 & 1.0 & 0.57 \\
& $(0.1)$ & $(0.1)$ & $(0.8)$ & $(0.2)$ & $(0.2)$ & $(0.2)$ & $(0.1)$ \\
\hline
\end{tabular}

En la Fig. 5.4 .8 se presenta la variación de los parámetros resistentes con la densidad de fibras para el HACRF2. Se puede observar que las vigas elaboradas con las fibras más cortas son menos eficaces en el control de la fisuración, en todos los casos la resistencia de primera fisura es mayor que la $\mathrm{f}_{R 3}$, las fibras más cortas ofrecen menos resistencia a ser arrancadas de la matriz. También se observa una mayor similitud entre las vigas C y T lo cual corrobora que, en este caso, el moldeo mediante el tubo no favorece significativamente la orientación de las fibras. Nuevamente en las vigas $\mathrm{V}$ la tensión de primera fisura coincide con los valores de tensión máxima. 


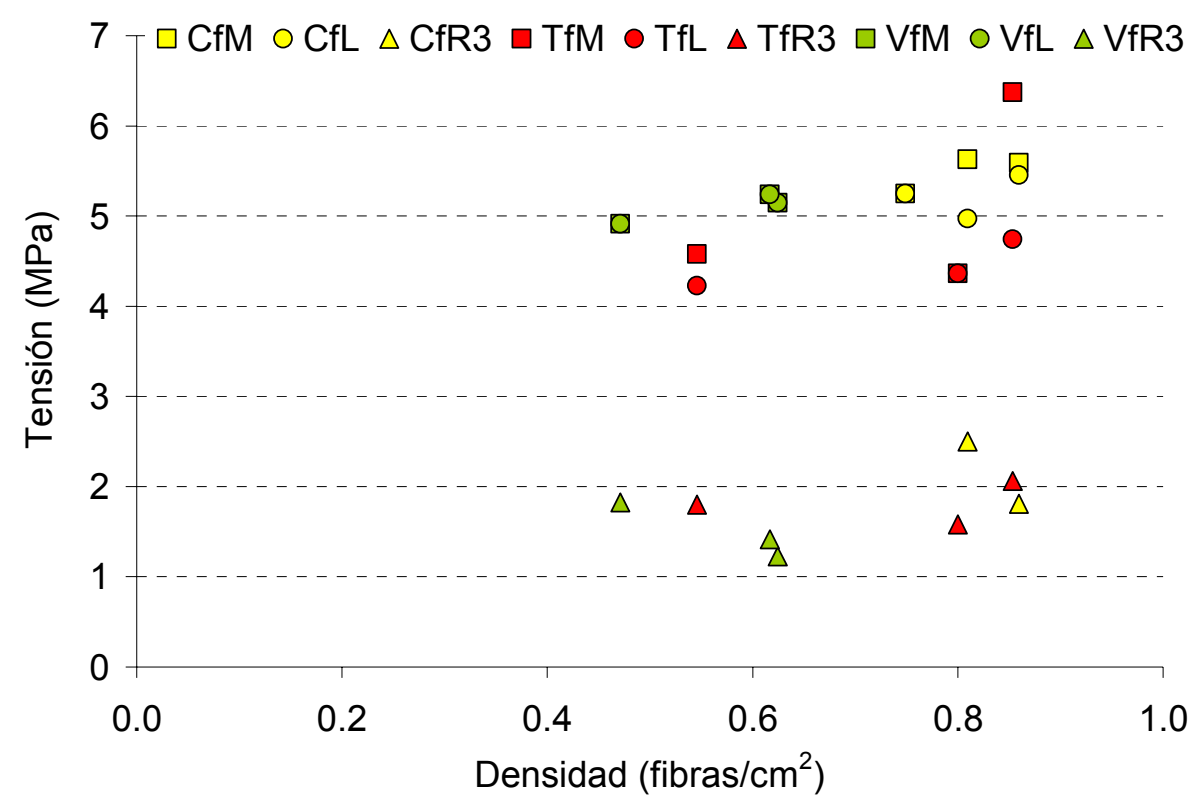

Figura 5.4.8. Variación de los parámetros resistentes con la densidad de fibras HACRF2.

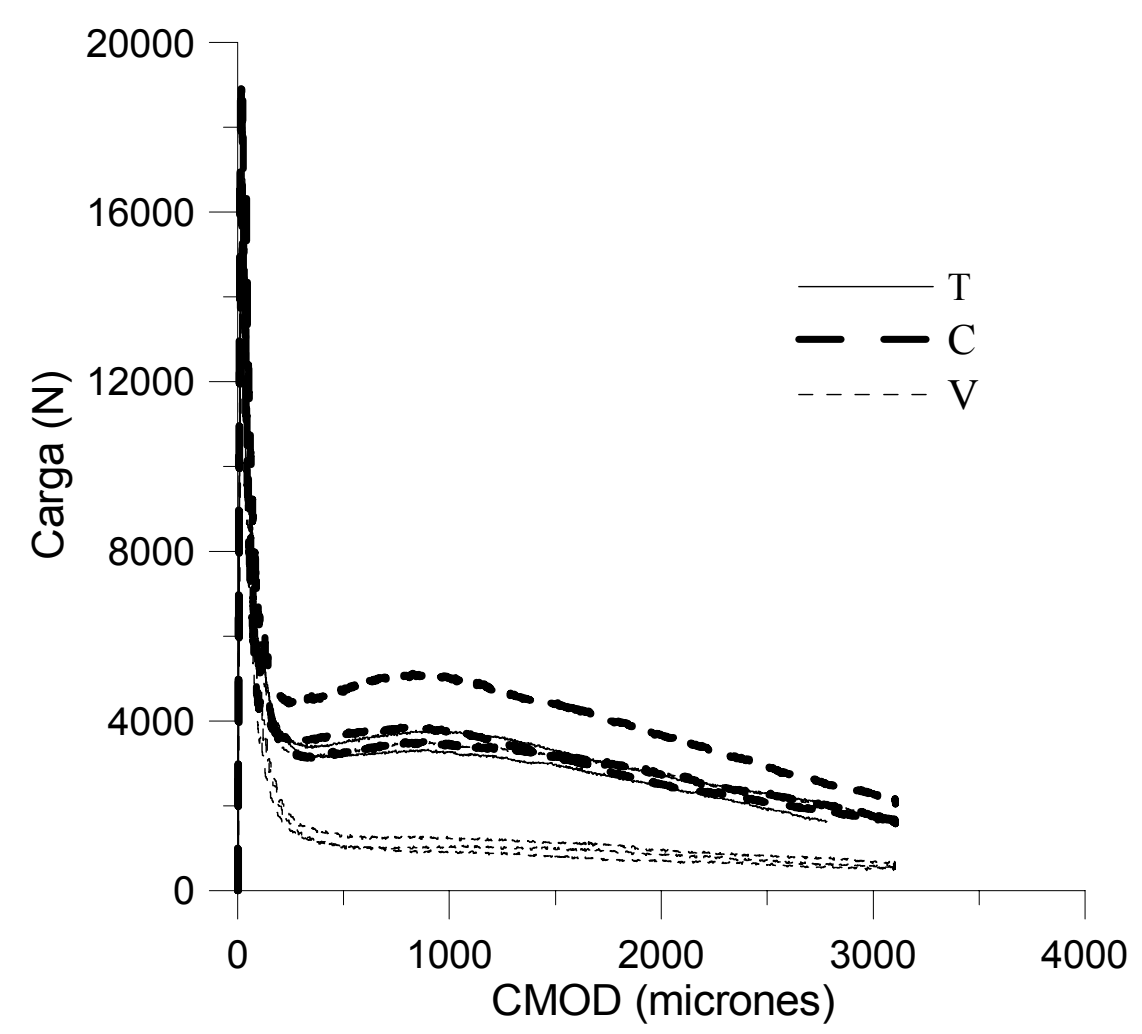

Figura 5.4.9. Gráficos carga-CMOD correspondientes a las vigas elaboradas con HACRF3. 
Finalmente la Fig. 5.4.9 muestra las curvas carga-CMOD para las vigas moldeadas con el HACRF3 que incorpora fibras sintéticas estructurales. Como era previsible el comportamiento post pico no presentó endurecimiento, es decir luego de la primera fisura la capacidad de carga disminuyó en forma continua. Si bien las vigas C y $\mathrm{T}$ se comportan de manera similar, de lo que se puede inferir que no es significativo el efecto pared sobre la orientación de las fibras, en las curvas de las vigas $\mathrm{V}$ la capacidad postpico es claramente diferente, indicando que las fibras se siguen orientando en planos horizontales.

Los resultados de los parámetros de resistencia y tenacidad calculados para cada una de las vigas del HACRF3 incluidos en la Tabla 5.4 .5 confirman lo indicado en el párrafo anterior.

Tabla 5.4.5. Resultados del ensayo de flexión y densidad de fibras en HACRF3: valores medios y desviación estándar

\begin{tabular}{cccccc}
\hline & $\begin{array}{c}\mathbf{f}_{\mathrm{M}} \\
(\mathrm{MPa})\end{array}$ & $\begin{array}{c}\mathbf{f}_{\mathrm{L}} \\
(\mathrm{MPa})\end{array}$ & $\begin{array}{c}\mathbf{f}_{\mathrm{R} 1} \\
(\mathrm{MPa})\end{array}$ & $\begin{array}{c}\mathbf{f}_{\mathrm{R} 2} \\
(\mathrm{MPa})\end{array}$ & $\begin{array}{c}\mathbf{f}_{\mathrm{R} 3} \\
(\mathrm{MPa})\end{array}$ \\
\hline $\mathrm{C}$ & 5.4 & 5.4 & 1.2 & 1.1 & 0.7 \\
& $(0.6)$ & $(0.6)$ & $(0.2)$ & $(0.2)$ & $(0.1)$ \\
$\mathrm{T}$ & 5.2 & 5.2 & 1.1 & 1.0 & 0.7 \\
& $(0.3)$ & $(0.3)$ & $(0.1)$ & $(0.1)$ & $(0.1)$ \\
& 4.9 & 4.9 & 0.4 & 0.3 & 0.2 \\
$\mathrm{~V}$ & $(0.4)$ & $(0.4)$ & $(0.04)$ & $(0.05)$ & $(0.03)$ \\
\hline & & & & &
\end{tabular}

\subsubsection{Estudio de la orientación de las fibras}

Los resultados de resistencia y tenacidad en flexión permiten inferir que de acuerdo con la forma de moldeo y por efecto del flujo varía la distribución y orientación de las fibras.

En la Tabla 5.4.6 (resultados correspondientes al HACRF1) se presentan los resultados de densidad de fibras en cada uno de los planos y en distintos sectores de las probetas. Se puede observar que en las vigas moldeadas verticalmente (V) la distribución fue homogénea, la densidad de fibras fue similar en las tres direcciones de corte $(\alpha, \beta, \gamma)$ siendo igual a 0.35 fibras $/ \mathrm{cm}^{2}$ en los cortes paralelo y perpendicular, y 0.23 fibras $/ \mathrm{cm}^{2}$ en el corte transversal. En las vigas $\mathrm{C}$ las fibras se alinearon preferentemente en el plano horizontal con densidades promedio iguales a 0.42 y 0.43 
fibras $/ \mathrm{cm}^{2}$ en los planos paralelo y transversal respectivamente, mientras que en el plano perpendicular la densidad fue aproximadamente la mitad $\left(0.24\right.$ fibras $\left./ \mathrm{cm}^{2}\right)$. En las vigas $T$, en cambio, la mayor densidad se produjo en el corte transversal $(0.51$ fibras $/ \mathrm{cm}^{2}$ ), con valores similares en los cortes paralelo y perpendicular (0.32 y 0.29 fibras $/ \mathrm{cm}^{2}$ ), como fuera expuesto esta distribución favorece la eficiencia de las fibras en el control de la fisuración durante el ensayo de flexión.

Tabla 5.4.6. Densidad de fibras (fibras $/ \mathrm{cm}^{2}$ ) HACRF1.

\begin{tabular}{cccccc}
\hline \multirow{2}{*}{ Grupo } & \multirow{2}{*}{ Plano $\alpha$} & \multicolumn{2}{c}{ Plano $\gamma$} & \multicolumn{2}{c}{ Plano $\beta$} \\
& & A & B & A & B \\
\hline C & 0.43 & 0.42 & & 0.24 & \\
T & 0.51 & 0.32 & 0.32 & 0.28 & 0.29 \\
V & 0.23 & 0.31 & 0.40 & 0.35 & 0.35 \\
\hline
\end{tabular}

En el HACRF1 se encontraron diferencias al comparar entre la densidad de fibras obtenida en la superficie de fractura con la del corte transversal ubicado a pocos centímetros en la misma dirección. En todos los casos la densidad en los cortes es bastante mayor que la obtenida a partir de la suma del número de fibras que sobresalen hacia ambos lados en las superficies de fractura; las diferencias fueron más evidentes en las vigas $\mathrm{V}$ donde las fibras tienden a posicionarse en dirección paralela al plano de fractura. Es posible que en la superficie fracturada sólo sean visibles las fibras que se encuentran más orientadas en forma perpendicular a la superficie, y que la rugosidad propia del plano de fractura no permita ver la totalidad de las fibras, ya que, al igual que ocurre con los áridos de mayor tamaño, de ser posible la fisura rodeará la fibra y no la atravesará. Este último fenómeno se produciría en especial en fibras donde sólo una pequeña porción de su extremo se encuentra dentro de la zona de fractura. La Fig. 5.4.10 esquematiza este fenómeno.

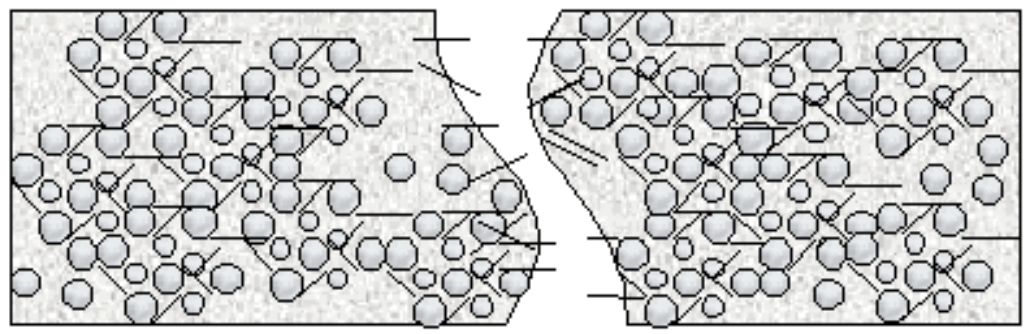

Figura 5.4.10. Esquema de la superficie de fractura. 
En la Tabla 5.4.7 se presentan los resultados correspondientes al HACRF2. Se puede apreciar que también en este caso las fibras adquieren una orientación preferencial en el plano horizontal. Por el contrario se observa poca influencia de la forma de moldeo. Esto puede justificarse considerando que debido a la relación entre la longitud de las fibras y las dimensiones del molde, el efecto pared es de menor magnitud. Se puede observar al comparar las densidades en el plano $\alpha$ para las vigas C y T, 0.81 y 0.71 fibras $/ \mathrm{cm}^{2}$ respectivamente. A su vez la densidad de fibras en el plano $\gamma$ es menor que en el $\alpha$ tanto para las vigas $T$ como las $C$.

Nuevamente la densidad de fibras en el plano $\alpha$ es la menor para las vigas $\mathrm{V}$, evidenciando la orientación en planos normales al moldeo; promediando los planos . $\gamma$ y $\beta$ la densidad es igual a 0.72 .

Tabla 5.4.7. Densidad de fibras (fibras $/ \mathrm{cm}^{2}$ ) HACRF2.

\begin{tabular}{cccccc}
\hline & \multirow{2}{*}{ Plano $\alpha$} & \multicolumn{2}{c}{ Plano $\gamma$} & \multicolumn{2}{c}{ Plano $\beta$} \\
& & A & B & A & B \\
\hline C & 0.81 & 0.48 & & 0.57 & \\
T & 0.71 & 0.50 & 0.44 & 0.47 & 0.35 \\
V & 0.57 & 0.71 & 0.60 & 0.89 & 0.69 \\
\hline
\end{tabular}

\subsubsection{Estudio de la distribución de las fibras}

Para evaluar el grado de homogeneidad en la distribución de fibras en el hormigón autocompactante se analiza a continuación el número de fibras relevadas en distintas zonas a lo largo de cada uno de los planos para los tres grupos de vigas estudiados.

En las Tablas 5.4.8.a y b se presentan para HACRF1 y HACRF2 los resultados del recuento de fibras en diferentes sectores de las vigas. Se indica el número de fibras correspondiente a los planos paralelo al llenado (plano $\gamma$ ), perpendicular al llenado (plano $\beta$ ) y transversal al eje longitudinal de la viga (plano $\alpha$ ). Cada valor corresponde al promedio de las probetas del grupo y el valor entre paréntesis al desvío estándar. Cabe recordar que se identifican con la letra $A$ las mitades más próximas al sector por donde ingresó el hormigón durante el llenado, en el caso de las vigas $\mathrm{V}$ representa el extremo superior. 
Por su parte en las Fig. 5.4.11 se comparan en base a estos resultados, los valores de la densidad de fibras calculada para cada grupo de vigas en los tres planos estudiados.

En las mitades inferiores (B) de las vigas $T$, elaboradas con HACRF1 (Tabla 5.4.8.a), la mayor densidad de fibras en el plano $\gamma$ se presenta en las zonas 3,6 y 9 que se corresponden con el extremo opuesto al de llenado. Esto puede deberse a un efecto pared contra el extremo del molde de mayor magnitud al que se presenta en el extremo A desde donde comienza a fluir el hormigón. En horizontal es mayor el número de fibras en el tercio inferior $(7+8+9)$ de las mitades $A$ con respecto a las $B$ lo que puede evidenciar un proceso de orientación incluso durante el flujo del material de un extremo al otro del molde. Si bien esta tendencia se invierte cuando se considera el sector superior $(1+2+3)$ cabe considerar que este plano sufre los efectos del acabado superficial mediante llana. No obstante debe tenerse en cuenta que también incide la variación propia de la distribución de fibras, ya que al comparar las zonas centrales $(1+4+7)$ en ambas mitades también se observan variaciones, cuando deberían ser similares por tratarse del sector medio de la probeta. En lo que respecta a la distribución de fibras en el plano $\beta$, tanto en las mitades $A$ como $B$ las fibras se disponen en mayor cantidad en el centro de la probeta (zona 1). En los planos transversales $(\alpha)$ la mayor densidad corresponde al tercio superior.

En el caso de las vigas T del HACRF2 (Tabla 5.4.8.b), en el plano $\gamma$, en todos los sectores es mayor la cantidad de fibras en la mitad $A$ que en la mitad $B$, al ser estas fibras más cortas, en relación a las dimensiones del molde, el efecto del flujo del hormigón desde un extremo del molde hacia el otro no es significativo. En el plano transversal $\alpha$, al igual que en el caso anterior la mayor densidad de fibras se encuentra en el sector superior.

En el caso de las vigas $\mathrm{C}$ del HACRF1, si se analiza el plano $\gamma$ (Tabla 5.4.8.a) no se aprecia una tendencia definida de las fibras en cuanto a su distribución, pero se observa menor homogeneidad y mayor cantidad de fibras orientadas en esta dirección en comparación con las vigas T. Esto puede deberse a que con el llenado normalizado el flujo no tiene suficiente recorrido como para alcanzar a orientar las fibras a lo largo del molde. En las zonas $(3+6+9)$ del plano $\gamma$ existe una mayor densidad de fibras, el extremo del molde fuerza a las fibras a orientarse transversalmente. El efecto pared en el fondo del molde y el flujo, favorecen la disposición de las fibras paralela al fondo y 
en dirección longitudinal, como muestran los valores $(7+8+9)$ que comparados son menores a los $(1+2+3)$ y $(4+5+6)$ del plano $\gamma$. En el plano transversal $\alpha$, los valores promedio son similares en los 3 sectores, siendo ligeramente mayor el número de fibras en el sector medio. Dado que las vigas se llenaron desde el centro, es de esperar que en este sector no exista una orientación significativa debido al efecto pared producido por el fondo del molde, lo cual se vería reflejado por una mayor cantidad de fibras en el sector 3. Las fibras orientadas en un plano vertical (relevadas en el plano $\beta$ ) se distribuyen en forma relativamente homogénea a lo largo del eje longitudinal de los prismas, con un leve aumento en el sector medio (sector 1), sector donde el material es vertido $\mathrm{y}$, como se ha comentado, no sufre la influencia del flujo. En todos los casos los valores medios de la densidad de fibras presentan una dispersión mayor que la observada en las vigas moldeadas mediante el tubo, esto puede deberse a que en este último caso la orientación preferencial de las fibras está claramente definida.

En el caso de las vigas $\mathrm{C}$ elaboradas con el hormigón HACRF2 (Tabla 5.4.8.b) las fibras se distribuyen en forma homogénea a lo largo de las probetas, en la Fig. 5.4.11 se puede observar más claramente.

Para analizar la distribución de las fibras en las vigas $\mathrm{V}$ se promediaron los resultados de los planos $\gamma$ y $\beta$; considerando que la influencia de la forma y dirección de llenado es la misma para ambos planos y, por ende, la densidad de fibras debe ser equivalente.

La mitad inferior (B) de las vigas $V$ de HACRF1 (Tabla 5.4.8.a) muestra en todos los sectores densidades ligeramente mayores a las medidas en la parte superior A. En el plano transversal $(\alpha)$ se observó un mayor número de fibras en las celdas perimetrales (el sector 5 tuvo el menor número de fibras) como resultado de la orientación forzada por el efecto de las paredes del molde. Las vigas $\mathrm{V}$ de HACRF2 también presentan en todos los planos una mayor densidad de fibras en la mitad inferior (B). 
Tabla 5.4.8. Distribución del número de fibras en distintos sectores de las vigas (desvío estandar).

a-HACRF1.

\begin{tabular}{|c|c|c|c|c|c|c|c|c|}
\hline Viga & Plano & Zona & $1+4+7$ & $2+5+8$ & $3+6+9$ & $1+2+3$ & $4+5+6$ & $7+8+9$ \\
\hline \multirow{7}{*}{$\mathrm{T}$} & \multirow{3}{*}{$\gamma$} & $A$ & $43(7)$ & $41(7)$ & $42(6)$ & $38(9)$ & $45(5)$ & $43(4)$ \\
\hline & & B & $36(4)$ & $38(9)$ & 51 (11) & 45 (11) & $45(7)$ & $36(4)$ \\
\hline & & & 1 & 2 & & & & \\
\hline & \multirow{3}{*}{$\beta$} & A & $48(7)$ & $30(8)$ & $31(1.5)$ & & & \\
\hline & & B & $41(6)$ & $34(8)$ & $35(4$ & & & \\
\hline & & & 1 & 2 & 3 & & & \\
\hline & $\alpha$ & & $42(11)$ & $35(12)$ & $40(7)$ & & & \\
\hline \multirow{6}{*}{ C } & Plano & Zona & $1+4+7$ & $2+5+8$ & $3+6+9$ & $1+2+3$ & $4+5+6$ & $7+8+9$ \\
\hline & $\gamma$ & & $56(19.5)$ & $49(18)$ & $59(8)$ & $58(6)$ & $57(18)$ & $49(15)$ \\
\hline & & & 1 & 2 & 3 & & & \\
\hline & $\beta$ & & $33(10)$ & 27 (4) & $30(8)$ & & & \\
\hline & & & 1 & 2 & 3 & & & \\
\hline & $\alpha$ & & $31(8)$ & $33(3.5)$ & $30(5)$ & & & \\
\hline \multirow{5}{*}{ V } & Plano & Zona & 1 & 2 & 3 & & & \\
\hline & \multirow[t]{3}{*}{$\gamma, \beta$} & A & $50(16)$ & $43(9)$ & $41(17)$ & & & \\
\hline & & B & $51(20.5)$ & $45(4)$ & $49(6)$ & & & \\
\hline & & & $1+4+7$ & $2+5+8$ & $3+6+9$ & $1+2+3$ & $4+5+6$ & $7+8+9$ \\
\hline & $\alpha$ & & $18(7)$ & $14(4)$ & $19(9)$ & $17(8)$ & $17(3)$ & $18(5)$ \\
\hline
\end{tabular}

b-HACRF2.

\begin{tabular}{|c|c|c|c|c|c|c|c|c|}
\hline Viga & Plano & Zona & $1+4+7$ & $2+5+8$ & $3+6+9$ & $1+2+3$ & $4+5+6$ & $7+8+9$ \\
\hline \multirow{7}{*}{$\mathrm{T}$} & \multirow{3}{*}{$\gamma$} & A & $69(13)$ & $65(7)$ & $77(17)$ & 71(16) & $73(10)$ & $67(8.5)$ \\
\hline & & B & $59(10)$ & $56(8)$ & $57(6)$ & $58(8.5)$ & $52(14)$ & $63(7)$ \\
\hline & & & 1 & 2 & 3 & & & \\
\hline & \multirow[t]{3}{*}{$\beta$} & A & $90(11)$ & $48(10)$ & $87(34)$ & & & \\
\hline & & B & $70(30)$ & $78(22)$ & $82(23)$ & & & \\
\hline & & & 1 & 2 & 3 & & & \\
\hline & $\alpha$ & & $63(14)$ & $46(14)$ & $53(6.5)$ & & & \\
\hline \multirow{6}{*}{ C } & Plano & Zona & $1+4+7$ & $2+5+8$ & $3+6+9$ & $1+2+3$ & $4+5+6$ & $7+8+9$ \\
\hline & $\gamma$ & & $50(8.5)$ & $71(14)$ & 67 (3) & $73(21)$ & $52(4)$ & $62(6)$ \\
\hline & \multirow{3}{*}{$\beta$} & & 1 & 2 & 3 & & & \\
\hline & & & $62(8)$ & 77 (7) & $77(21)$ & & & \\
\hline & & & 1 & 2 & 3 & & & \\
\hline & $\alpha$ & & $51(13)$ & $56(10)$ & $70(14)$ & & & \\
\hline \multirow{5}{*}{ V } & \multirow{4}{*}{$\begin{array}{c}\text { Plano } \\
\gamma, \beta\end{array}$} & Zona & 1 & 2 & 3 & & & \\
\hline & & A & $86(14)$ & $83(2)$ & $81(12.5)$ & & & \\
\hline & & B & $92(14)$ & $106(29)$ & $103(21)$ & & & \\
\hline & & & $1+4+7$ & $2+5+8$ & $3+6+9$ & $1+2+3$ & $4+5+6$ & $7+8+9$ \\
\hline & $\alpha$ & & $42(8)$ & $34(10)$ & $51(13)$ & 48(15) & 41(11) & $38(5)$ \\
\hline
\end{tabular}



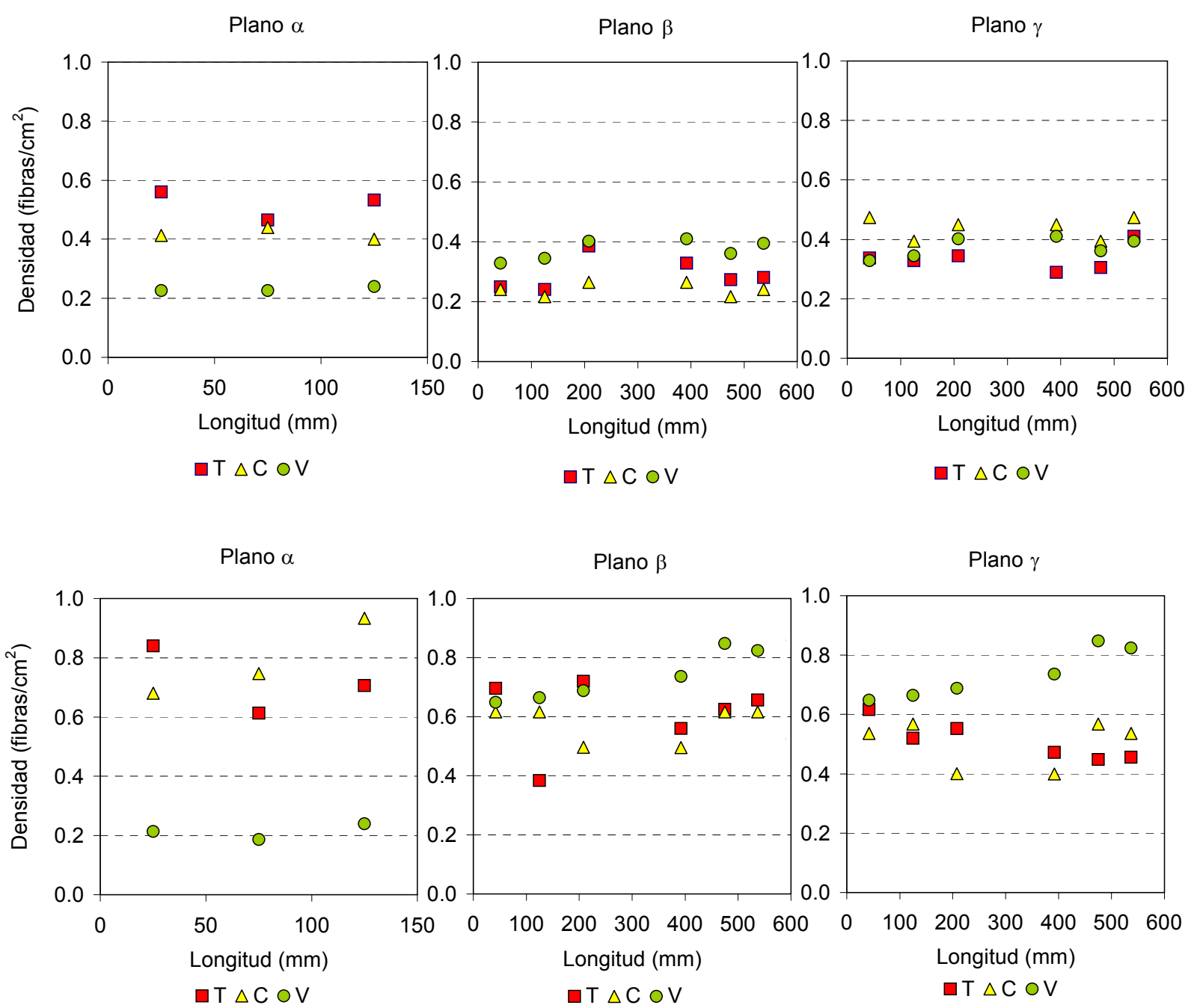

Figura 5.4.11. Densidad de fibras $\left(\mathrm{N} / \mathrm{cm}^{2}\right)$ a lo largo de los plano $\beta$ y $\gamma$, y a lo alto del plano $\alpha$. Los gráficos superiores corresponden a las vigas elaboradas con el hormigón HACRF1 y los inferiores a las vigas elaboradas con el HACRF2.

\subsubsection{Conclusiones}

En este apartado se analizó la influencia de la forma de colocación sobre la orientación y distribución del refuerzo en hormigón autocompactante con fibras y su vinculación con la respuesta mecánica en flexión. A continuación se señalan las conclusiones más relevantes de este estudio:

- En HACRF el refuerzo también adquiere una orientación 2D tal como ocurre en el hormigón vibrado. Las fibras se disponen preferentemente en planos horizontales y la mayor densidad de fibras aparece en la sección transversal. 
- La forma de llenado y las características del molde tienen gran influencia sobre la disposición de las fibras. El grado de influencia del efecto pared es función de la relación entre las dimensiones del molde que contiene al hormigón y las dimensiones de las fibras, si las fibras son cortas en relación con el tamaño del molde, este efecto no adquiere tanta preponderancia.

- En los hormigones con fibras sintéticas también se observaron los efectos de la orientación de las fibras sobre las propiedades mecánicas.

- En el hormigón reforzado con las fibras de acero más largas se observaron diferencias entre las vigas que se llenaron desde el centro (C) y aquellas moldeadas desde un extremo del molde luego que el hormigón atravesara una tubería de $5 \mathrm{~m}$ de longitud $(\mathrm{T})$, donde el flujo orientó significativamente las fibras. Esta diferencia no fue apreciable en las vigas elaboradas con las fibras de acero más cortas o con fibras sintéticas.

- En vigas moldeadas en posición vertical $(\mathrm{V})$ se encontró en los tres hormigones una distribución más homogénea pero desfavorable desde el punto de vista mecánico, además se alcanzó una menor compacidad en el hormigón elaborado con las fibras de acero más largas. 


\subsection{APLICACIÓN DE UN MODELO TEÓRICO PARA EL ESTUDIO DE LA ORIENTACIÓN DE LAS FIBRAS DE ACERO}

El objetivo de este estudio es analizar la orientación de las fibras utilizando un modelo teórico de fácil empleo. Se comparan los resultados del modelo con los resultados experimentales obtenidos en los apartados anteriores tanto sobre hormigones convencionales vibrados como en los hormigones autocompactantes reforzados con fibras de acero.

Considerando la ecuación (1) (Dupont y Vandewalle, 2005) se puede calcular el coeficiente de orientación (CO) como:

$$
\text { Densidad }=\operatorname{COxV}_{f} / A_{f}
$$

donde $V_{f}$ representa el volumen de fibras y $A_{f}$ la sección transversal de una fibra.

Si se tienen en cuenta las dimensiones de la sección transversal, las condiciones de borde y la longitud de las fibras $\left(l_{f}\right)$, se puede determinar en forma teórica el coeficiente de orientación como (Dupont y Vandewalle, 2005):

$$
\mathrm{CO}=\frac{\left[\alpha_{1} \times\left(b-l_{f}\right)\left(h-l_{f}\right)+\alpha_{2} \times\left[\left(b-l_{f}\right) l_{f}+\left(h-l_{f}\right) l_{f}\right]+\alpha_{3} \times l_{f}^{2}\right]}{b h}
$$

siendo $\mathrm{h}$ y $\mathrm{b}$ la altura y base de la sección transversal y $\alpha_{1}=0.5, \alpha_{2}=0.6$ y $\alpha_{3}=0.84$ los factores de orientación correspondientes a los casos en que la fibra puede rotar libremente, cuando existe una condición o cuando existen dos condiciones de borde respectivamente. $\mathrm{CO}=1$ indica que todas las fibras tienen la misma orientación.

En la tabla 5.5 .1 se muestran los resultados del $\mathrm{CO}$ calculados mediante las ecuaciones (1) y (2) considerando tanto la densidad de fibras sobre la superficie de corte y la densidad sobre la cara fracturada, obtenidas en el hormigón HACRF1 de la sección 5.4. Se observa que los valores de CO en el plano de corte para los grupos C y $\mathrm{T}$ superan claramente al valor teórico obtenido mediante la ecuación (2), confirmando que las fibras se orientan en HACRF. Las diferencias entre el $\mathrm{CO}$ en el plano de corte y el plano de fractura pueden asociarse al hecho que las fibras que tienen mayor efecto sobre las propiedades mecánicas son las ubicadas en forma marcadamente perpendicular a la sección de rotura, en el plano de corte el recuento de fibras abarca todas las fibras. 
Las tablas 5.5.2 y 5.5.3 muestran los valores del CO para el HACRF2 (sección 5.4) y para los HRF1, HRF2 y HRF3 (sección 5.2).

Al comparar las relaciones entre el CO calculado mediante la ecuación (2) y el obtenido a través de datos experimentales con la ecuación (1), se observa que la ecuación (2) aproxima mejor el comportamiento del HACRF1 preparado con las fibras más largas que el del HACRF2 (sección 5.4).

En el caso del hormigón convencional vibrado (sección 5.2) las relaciones entre CO teórico y experimental son más próximas a la unidad (tomando en cuenta sólo las fibras largas). Tampoco se observan diferencias significativas entre la aproximación del hormigón vibrado y la del autocompactante, en el hormigón vibrado la relación entre el $\mathrm{CO}$ experimental / CO calculado es en promedio próxima a 0.79 y en el caso del hormigón autocompactante es de 1.17.

Tabla 5.5.1. Coeficiente de orientación (CO) obtenido a partir de las ecuaciones (1) (considerando la densidad de fibras en la cara de corte y en la cara fracturada) y (2) para el HACRF1 (sección 5.4).

\begin{tabular}{ccccc}
\hline HACRF1 & CO (ec2) & CO(ec1-corte) & CO(ec1-fractura) & CO1 $_{\text {corte }} /$ CO2 \\
\hline V & 0.58 & 0.40 & 0.28 & 0.69 \\
$\mathrm{C}$ & 0.58 & 0.75 & 0.55 & 1.29 \\
$\mathrm{~T}$ & 0.58 & 0.89 & 0.61 & 1.53 \\
\hline
\end{tabular}

Tabla 5.5.2. Coeficiente de orientación (CO) obtenido a partir de las ecuaciones (1) (densidad de fibras en la cara de corte) y (2) para el HACRF2 (sección 5.4).

\begin{tabular}{cccc}
\hline HACRF2 & CO (ec1) & CO (ec2) & CO1/CO2 \\
\hline $\mathrm{V}$ & 0.14 & 0.54 & 0.26 \\
$\mathrm{C}$ & 0.20 & 0.54 & 0.37 \\
$\mathrm{~T}$ & 0.18 & 0.54 & 0.33 \\
\hline
\end{tabular}

Según Dupont y Vandewalle (2005) la relación entre CO calculado y experimental fue igual a 1.02 con un coeficiente de variación del $36 \%$, en este caso la ecuación utilizada no fue la (2) sino la (3) que toma en cuenta la presencia de la entalla (en la ecuación 3 ND es la profundidad de la entalla, $\alpha_{4}$ y $\alpha_{5}$ dependen de la relación entre la longitud de las fibras y la profundidad de la entalla). 


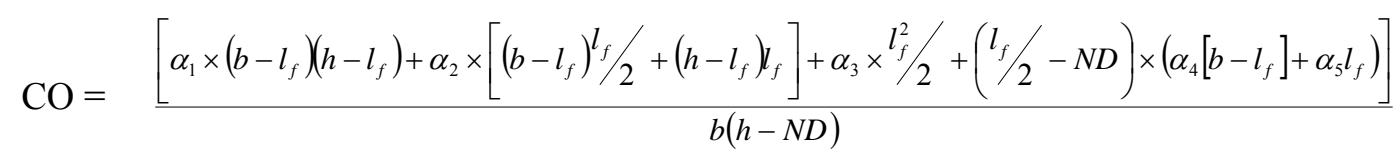

Tabla 5.5.3. Coeficiente de orientación (CO) obtenido a partir de las ecuaciones (1) (densidad de fibras en la cara de fractura) y (2) para los HRF1, 2 y 3 (sección 5.2).

\begin{tabular}{cccc}
\hline HRF & CO (ec1) & CO (ec2) & CO1/CO2 \\
\hline 1-A & 0.43 & 0.53 & 0.81 \\
1-B & 0.37 & 0.55 & 0.67 \\
1-C & 0.39 & 0.55 & 0.71 \\
1-D & 0.45 & 0.57 & 0.79 \\
1-E & 0.36 & 0.56 & 0.64 \\
1-F & 0.50 & 0.56 & 0.89 \\
2-A & 0.40 & 0.53 & 0.75 \\
2-B & 0.50 & 0.55 & 0.91 \\
2-C & 0.47 & 0.55 & 0.85 \\
2-D & 0.50 & 0.57 & 0.88 \\
2-E & 0.42 & 0.56 & 0.75 \\
2-F & 0.44 & 0.56 & 0.79 \\
3-A & 0.61 & 0.58 & 1.05 \\
3-B & 0.50 & 0.62 & 0.81 \\
3-D & 0.70 & 0.65 & 1.08 \\
3-E & 0.75 & 0.66 & 1.14 \\
\hline
\end{tabular}

En síntesis al comparar los resultados obtenidos del modelo con los resultados experimentales se puede concluir que la ecuación teórica utilizada resulta una aproximación pobre a las experiencias realizadas en esta tesis. La variabilidad en la estimación teórica de la densidad de fibras es importante, lo que puede atribuirse a las variaciones propias del hormigón a lo que se suman la orientación del refuerzo por efectos del método de compactación y llenado. Estos últimos dependen de la relación entre el tamaño de las fibras utilizadas y los moldes empleados. 


\subsection{ESTUDIO DE LA HOMOGENEIDAD EN HORMIGÓN AUTOCOMPACTANTE (HAC) y HORMIGÓN AUTOCOMPACTANTE REFORZADO CON FIBRAS (HACRF)}

En este apartado se analiza la homogeneidad de llenado y la tendencia a la segregación de un hormigón autocompactante empleado para el llenado de elementos esbeltos. El tema resulta significativo para este nuevo tipo de hormigón en el cual se debe lograr un diseño de mezcla que asegure una elevada fluidez pero manteniendo una viscosidad suficiente para evitar la segregación de los agregados. Es conocido que las fibras modifican las características de cualquier hormigón en estado fresco, en particular en un HAC las características en estado fresco son determinantes en las propiedades finales del material.

Se elaboraron un HAC sin fibras y dos HACRF obtenidos sobre el mismo hormigón de base luego de adicionar 25 y $50 \mathrm{~kg} / \mathrm{m}^{3}$ de refuerzo con fibras de acero conformadas con los que se llenaron columnas de $0.15 \mathrm{~m}$ de diámetro y $2.5 \mathrm{~m}$ de altura.

\subsubsection{Materiales y mezclas}

Se elaboró un hormigón autocompactante de razón a/c 0.49, fueron utilizadas dos fracciones de arena, dos fracciones de piedra partida, filler calizo y un superplastificante de tipo policarboxilato, en los HACRF se utilizaron fibras de acero conformadas en los extremos de $50 \mathrm{~mm}$ de largo y $1 \mathrm{~mm}$ de diámetro. En la Tabla 5.6 .1 se muestra la dosificación utilizada.

Tabla 5.6.1. Dosificación de los HACs estudiados $\left(\mathrm{kg} / \mathrm{m}^{3}\right)$.

\begin{tabular}{|c|c|c|c|}
\hline Hormigón & HAC-0 & HACRF-25 & HACRF-50 \\
\hline Cemento & & 334 & \\
\hline Filler & & 100 & \\
\hline Agua & & 164 & \\
\hline Arena & & 937 & \\
\hline Piedra Partida & & 775 & \\
\hline Plastificante & & 5.7 & \\
\hline Superplastificante & & 7.0 & \\
\hline Fibras de acero & 0 & 25 & 50 \\
\hline
\end{tabular}




\subsubsection{Detalles experimentales}

Se prepararon $2 \mathrm{~m}^{3}$ de HAC en un camión mixer, el superplastificante y el filler fueron incorporados en el laboratorio. Con este material (identificado como HAC-0) se realizaron los ensayos del hormigón fresco para verificar las condiciones de autocompactabilidad y se llenaron dos columnas de $2.5 \mathrm{~m}$ de altura empleando una cuba de 200 litros de capacidad para el vertido en el interior de las mismas. Posteriormente se llenaron tres cubas de 40 litros de hormigón a las que se le incorporaron fibras de acero en una dosis igual a $25 \mathrm{~kg} / \mathrm{m}^{3}$ (HACRF-25), se mezclaron nuevamente utilizando una mezcladora pequeña, y finalmente el hormigón fue homogeneizado en la cuba para el llenado de los tubos, en forma paralela se verificaron las propiedades del hormigón fresco. Finalmente se repitió el proceso llenando otras cubas con el hormigón de base e incorporando fibras hasta una dosis igual a $50 \mathrm{~kg} / \mathrm{m}^{3}$ (HACRF-50). Como era de prever durante toda esta operatoria (aproximadamente 50 minutos) el material fue modificando sus condiciones de autocompactabilidad, esto se produjo especialmente en el último caso (HACRF-50) lo que quedó reflejado en los ensayos del hormigón fresco.

Para caracterizar la autocompactabilidad se emplearon los ensayos de escurrimiento, midiendo el diámetro final $\left(D_{f}\right)$ y el tiempo en alcanzar un diámetro de $500 \mathrm{~mm}\left(T_{50}\right)$, el escurrimiento con anillo realizando determinaciones similares $\left(D_{J} \mathrm{y}\right.$ $T_{50 J}$ ) y el embudo en $V$, midiendo el tiempo de vaciado ( $\left.T_{V}\right)$ (SSCEPG, 2005).

Sobre el hormigón endurecido se realizó en primer lugar un relevamiento del estado superficial en la zona perimetral de las columnas detectando la formación de burbujas u otros tipos de defectos.

Posteriormente se procedió al aserrado de muestras cilíndricas con el fin de estudiar la variabilidad de las propiedades del hormigón a lo largo de la altura de las columnas. Se extrajeron dos tipos de muestras en cada columna, 7 cilindros de $300 \mathrm{~mm}$ de longitud y 8 rodajas de $20 \mathrm{~mm}$ de espesor intercaladas con los cilindros para evaluar la distribución de agregados y fibras. En la Fig. 5.6.1 se muestra un esquema del aserrado de las columnas para la obtención de las muestras. 

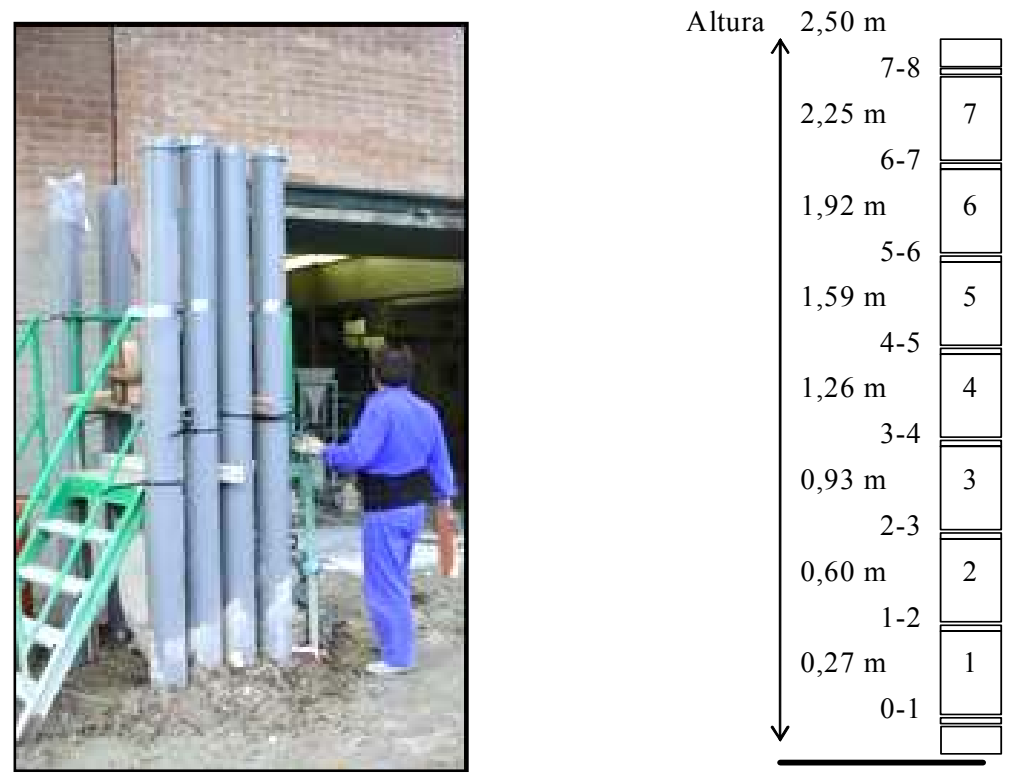

Figura 5.6.1. Esquema de aserrado de los tubos.

Sobre las muestras de $300 \mathrm{~mm}$ de longitud se realizaron las siguientes evaluaciones:

- Relevamiento de defectos en la superficie.

- Medida del peso, altura y diámetro y determinación del peso unitario en estado seco.

- Medida del tiempo de pasaje ultrasónico y determinación de la velocidad del pulso.

- Ensayos de compresión con determinación de la resistencia y el módulo de elasticidad.

Las muestras de $20 \mathrm{~mm}$ de espesor en primer lugar fueron pulidas en una de sus caras a fin de facilitar el escaneado para el conteo y análisis de la distribución de áridos y fibras. Se determinaron:

- La densidad de áridos que fue evaluada como $\mathrm{cm}^{2}$ de agregados por $\mathrm{cm}^{2}$ de sección de hormigón. El análisis se realizó sobre un núcleo de $100 \mathrm{~mm}$ de diámetro. Una vez obtenidas las imágenes de las caras, se diferenciaron los perímetros de dichas partículas y mediante un software de procesamiento de imágenes se calcularon las áreas y perímetros. De este modo se puede analizar la variabilidad en la distribución de los agregados gruesos. En la Fig. 5.6.2 se muestra un relevamiento de la distribución de agregados correspondiente a un corte de HAC-0. 


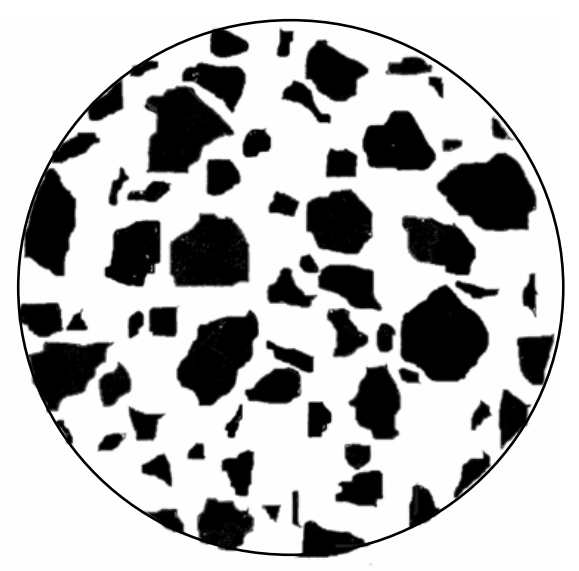

Figura 5.6.2. Distribución de agregados sobre un corte de $20 \mathrm{~mm}$ de espesor.

- La densidad de fibras fue calculada como el número de fibras por $\mathrm{cm}^{2}$ de sección de hormigón. El conteo fue realizado en forma manual diferenciando un núcleo central de $60 \mathrm{~mm}$ de diámetro y un anillo de $30 \mathrm{~mm}$ de espesor adyacente a dicho círculo (anillo central). Se relevó el número de fibras en forma discriminada para tener en cuenta la posibilidad de que la distribución de las mismas no fuera uniforme sobre toda la sección. En la Fig. 5.6 .3 se muestra el esquema empleado para el relevamiento de fibras en una sección de HACRF-25.

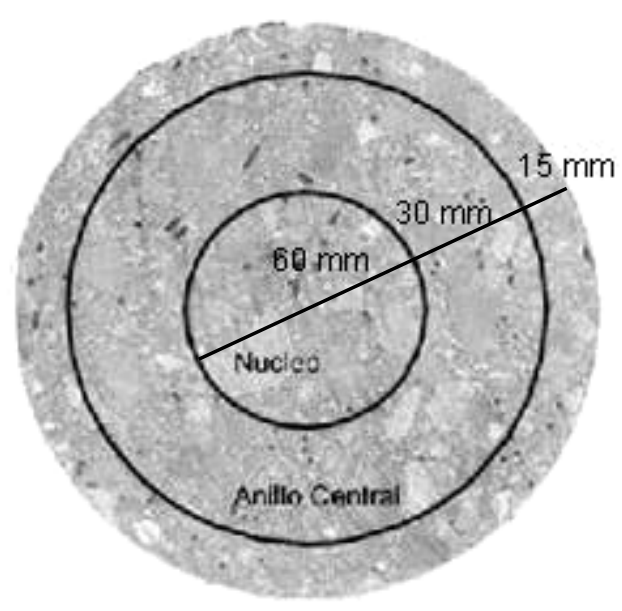

Figura 5.6.3. Esquema de la distribución de fibras en una sección de HACRF-25. 


\subsubsection{Resultados y discusión}

Los ensayos en estado fresco y el llenado de las dos columnas de HAC-0 se realizaron dentro de los primeros quince minutos de elaborado el hormigón, luego se extrajeron muestras de hormigón a las que se les incorporaron $25 \mathrm{~kg} / \mathrm{m}^{3}$ de fibras, se realizaron los ensayos y llenaron otras dos columnas con HACRF-25, aproximadamente media hora después de obtenido el hormigón de base. En tercer lugar se repitió la operatoria con el HACRF-50 la misma finalizó trascurridos aproximadamente 50 minutos. Como era de esperar la fluidez de las mezclas fue decayendo con el correr del tiempo. Para valorar este hecho y diferenciarlo de la pérdida de autocompactabilidad que pudo tener el hormigón por la incorporación de fibras, se extrajo una última muestra de HAC-0 pasados 75 minutos desde el inicio y se repitieron los ensayos ingenieriles. En la Tabla 5.6.2 se muestran los resultados.

Tabla 5.6.2. Resultados de los ensayos sobre el hormigón fresco.

\begin{tabular}{ccccccccc}
\hline \multirow{2}{*}{ Hormigón } & $\begin{array}{c}\text { Tiempo } \\
\text { h:min }\end{array}$ & $\begin{array}{c}\mathbf{D}_{\mathbf{f}} \\
\mathrm{mm}\end{array}$ & $\begin{array}{c}\mathbf{T}_{\mathbf{5 0}} \\
\mathrm{s}\end{array}$ & $\begin{array}{c}\mathbf{D}_{\mathrm{fJ}} \\
\mathrm{mm}\end{array}$ & $\begin{array}{c}\mathbf{T}_{\mathbf{5 0 J}} \\
\mathrm{s}\end{array}$ & $\begin{array}{c}\Delta \mathbf{D} \\
\mathrm{mm}\end{array}$ & $\begin{array}{c}\mathbf{T}_{\mathbf{V}} \\
\mathrm{s}\end{array}$ & $\begin{array}{c}\mathbf{T} \\
{ }^{\circ} \mathrm{C}\end{array}$ \\
\hline HAC-0 & $0: 04$ & 610 & 1.7 & 595 & 2.0 & 15 & 5.8 & 20 \\
HACRF-25 & $0: 30$ & 560 & 1.7 & 530 & 2.8 & 30 & 10.5 & 22 \\
HACRF-50 & $0: 47$ & 390 & - & - & - & - & 12.8 & 22 \\
HAC-0 & $1: 15$ & 310 & - & - & - & - & 13.0 & 22 \\
\hline
\end{tabular}

Los resultados indican que mientras el HAC-0 inicial y el HACRF-25 pueden ser considerados dentro de los rangos aceptables de autocompactabilidad por los ensayos ingenieriles, el HACRF-50 no cumplía tales requisitos posiblemente dado el tiempo transcurrido. Sin embargo resultó de interés verificar si tal variación en las propiedades afectaba la capacidad de llenado. Una observación al respecto es que el peso unitario que creció ligeramente al incorporar fibras en HACRF-25, disminuyó en HACRF-50 seguramente debido a la menor capacidad de autocompactación.

Cabe comentar que las condiciones de llenado utilizadas no fueron las que más favorecen al HAC, ya que los tubos que poseen un diámetro relativamente pequeño $(0.15 \mathrm{~m})$ se llenaron desde su extremo superior, por lo que el desplazamiento del aire fue dificultado por el ingreso del hormigón. La compacidad del HAC se ve favorecida cuando el propio peso y presión que ejerce el hormigón contribuyen a la 
compactación, por lo que en muchos casos se recomienda llenar desde las zonas inferiores hacia las superiores dejando sitios para la salida del aire.

En la Fig. 5.6.4 se muestra el aspecto superficial de las columnas. El mismo resultó aceptable en HAC-0 y HACRF-25 aunque no fue estrictamente homogéneo en todo el perímetro del tubo, mientras en un lado no se ven prácticamente defectos, girando $180^{\circ}$ existen algunas burbujas de aire. Si bien fue aceptable el aspecto de las columnas con HACRF-50, principalmente en la zona superior se encontraron defectos superficiales en mayor número.

Para considerar la variación de las propiedades fisicomecánicas de los hormigones en función de la altura de las columnas en la Fig. 5.6 .5 se representan los resultados de velocidad de pulso ultrasónico, peso unitario del hormigón, resistencia a compresión y módulo de elasticidad. Los puntos indican los valores promedio de dos columnas para distintas alturas y como referencia la línea vertical corresponde al promedio general de cada hormigón.

La velocidad de pulso fue ligeramente mayor en HAC-0, seguida por HACRF25 y por HACRF-50, con valores promedio iguales a $4.96,4.94$ y $4.86 \mathrm{~km} / \mathrm{s}$ respectivamente. Su variabilidad con la altura fue reducida, con diferencias respecto a los valores promedio de sólo $\pm 1, \pm 3$ y $\pm 2 \%$ para tales hormigones. La Fig. 5.6.5 muestra que se produce en general una disminución en la velocidad en la zona superior, en el caso de HACRF-50 se observa también una clara disminución de la velocidad promedio. 


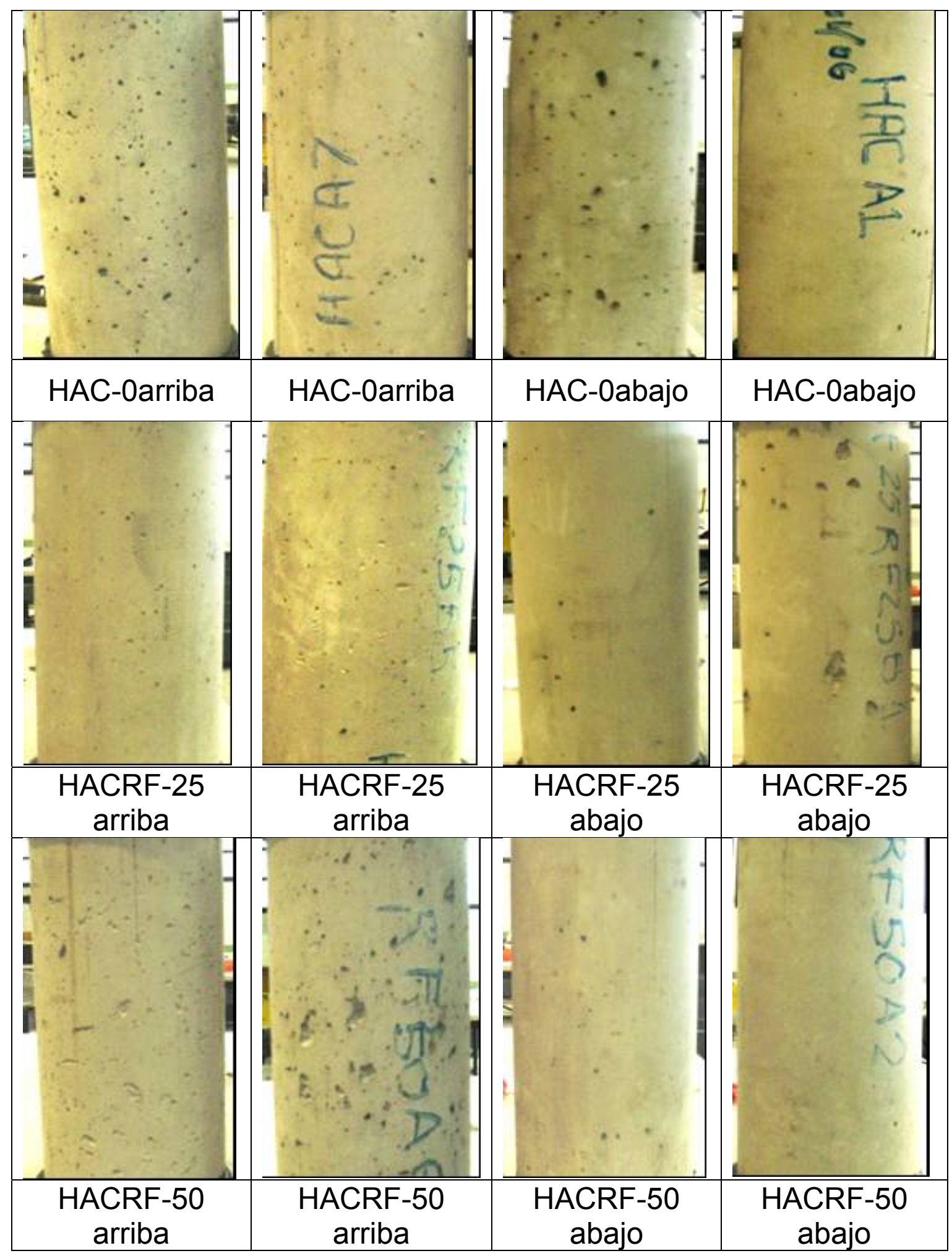

Figura 5.6.4. Aspecto superficial de los tubos. 

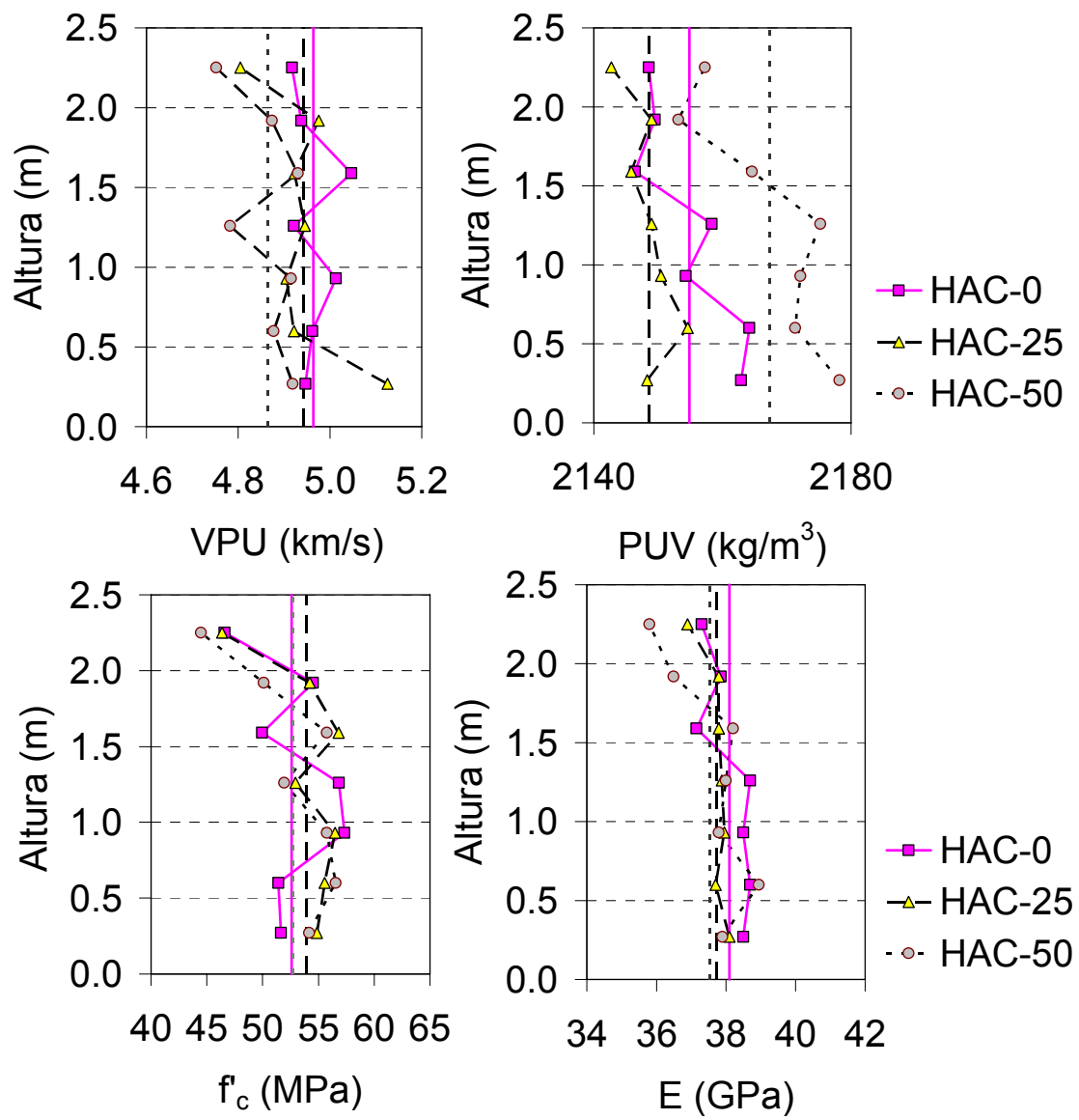

Figura 5.6.5. Variación con la altura de las propiedades fisicomecánicas.

El peso unitario fue algo mayor en HAC-0 que en HACRF-25 que contiene una pequeña cantidad de fibras de acero, lo que indica una mejor compactación. En el caso de HACRF-50 el peso creció por la presencia de las fibras pero disminuyó marcadamente a medida que aumentaba la altura debido a la menor compactación. Este hormigón mostró la mayor variabilidad, sin embargo se destaca que en todos los casos las diferencias a lo largo de la altura fueron menores a $\pm 1 \%$ con relación al valor promedio.

De los ensayos de compresión realizados sobre cilindros de $150 \mathrm{~mm}$ de diámetro por $300 \mathrm{~mm}$ de altura cortados de las columnas, surge que la menor consolidación en el extremo superior provocó una disminución de la resistencia y del módulo de elasticidad, esta variación se produjo en todos los hormigones; los valores medios de resistencia a compresión fueron iguales a 52.6, 56.0 y 54.5 MPa para HAC0, HACRF-25 y HACRF-50 respectivamente. Se aprecia que la resistencia crece con la incorporación de fibras alcanzando valores relativos iguales a 106 y 104 con respecto 
al HAC-0. Estos incrementos son ligeramente menores a los usuales y se atribuyen a una menor compacidad en especial en el caso de HACRF-50. Las disminuciones de resistencia en el extremo superior fueron del 11, 14 y $15 \%$ para HAC-0, HACRF-25 y HACRF-50. El módulo de elasticidad también manifiesta la menor rigidez en la zona superior producto de la menor compacidad, lo que es consistente con los datos de resistencia, velocidad de pulso y peso unitario. Sin embargo la variabilidad no es demasiado grande, en HAC-0 y HACRF-25 no supera el $2 \%$ y en HACRF-50, como era previsible es algo mayor y alcanza el $4 \%$. Es interesante notar que el módulo de elasticidad en lugar de crecer, como es habitual en hormigones con fibras de acero, disminuye 1 y $1.5 \%$ en HACRF-25 y HACRF-50 en relación a HAC-0, verificando en particular en este último una menor consolidación. De todos modos se destaca que las diferencias son muy pequeñas y menores a la propia variabilidad aceptada para estas propiedades en las construcciones de hormigón.

En cuanto al estudio de la mesoestructura del hormigón en la Fig. 5.6.6 se muestran para distintas alturas de las columnas la densidad de agregados (área de agregados/área de hormigón) y el número de los mismos, en la Fig. 5.6.7 se aprecia el relevamiento de agregados en los cortes. Se indican en cada caso los valores promedio de dos columnas para distintas alturas y el promedio general. La densidad de agregados o su número nunca varió más de $\pm 20 \%$ del promedio, esta variación es mayor a la de las propiedades fisicomecánicas y sólo comparable con la disminución de la resistencia en la zona superior, pero no se asocia un efecto de la altura, por lo que se estima que responde a la variabilidad propia del hormigón. Se observa que la variabilidad en la distribución de agregados fue levemente mayor en HAC-0 que en los hormigones con fibras; desde este punto de vista las fibras contribuyen a mejorar la estabilidad del sistema y evitar la segregación. En cambio en HACRF-50 la capacidad de autocompactación se vio marcadamente reducida, aunque, como lo indican los resultados obtenidos, los efectos desfavorables sobre las propiedades fisicomecánicas y la homogeneidad del material no fueron demasiado importantes. 

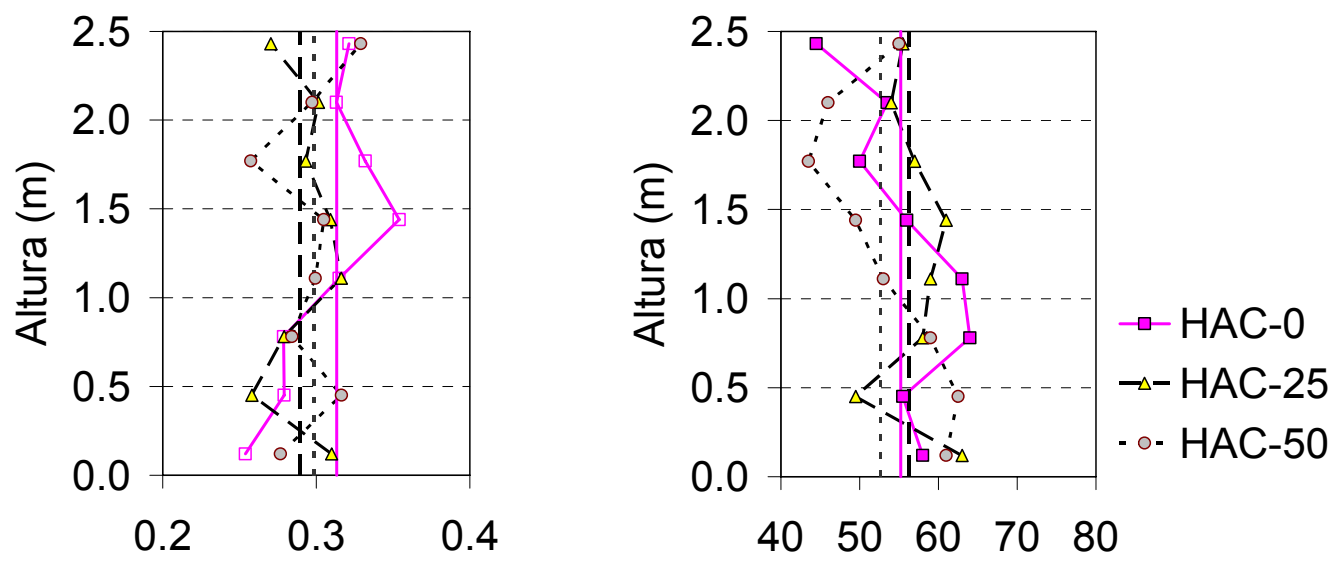

Densidad de agregados $\left(\mathrm{cm}^{2} / \mathrm{cm}^{2}\right)$ Número de agregados $\left(\mathrm{N} / \mathrm{cm}^{2}\right)$

Figura 5.6.6. Variación con la altura de la densidad y número de agregados.

HAC

25

50

0
0.12

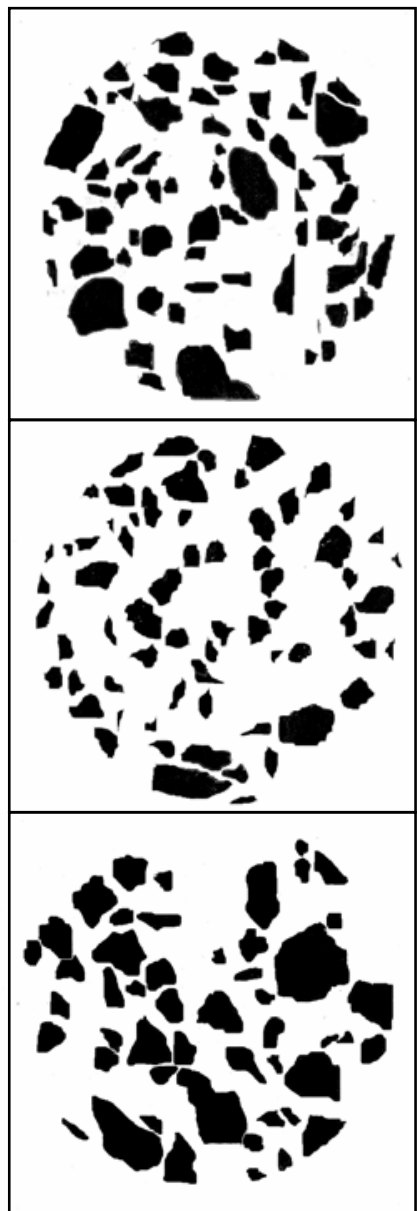

Altura (m) 1.11

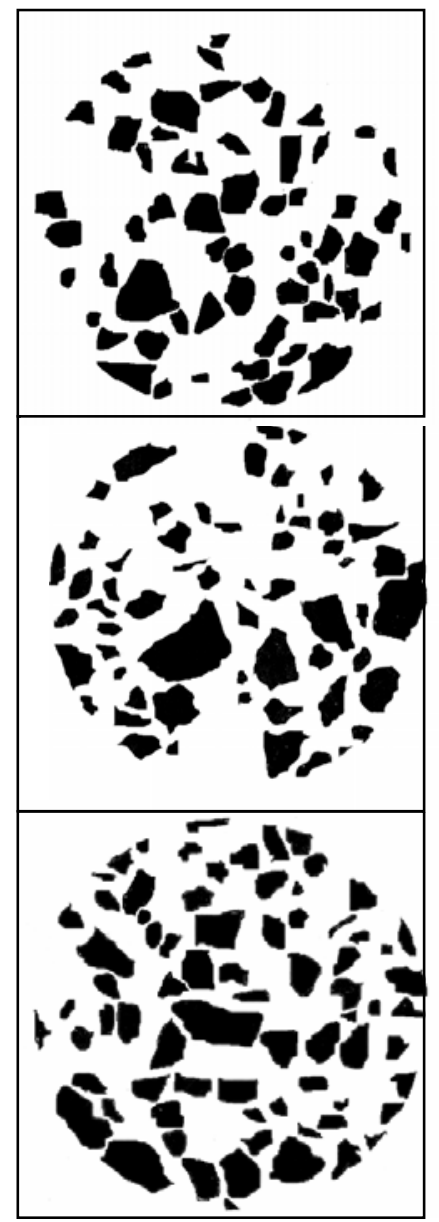

2.43

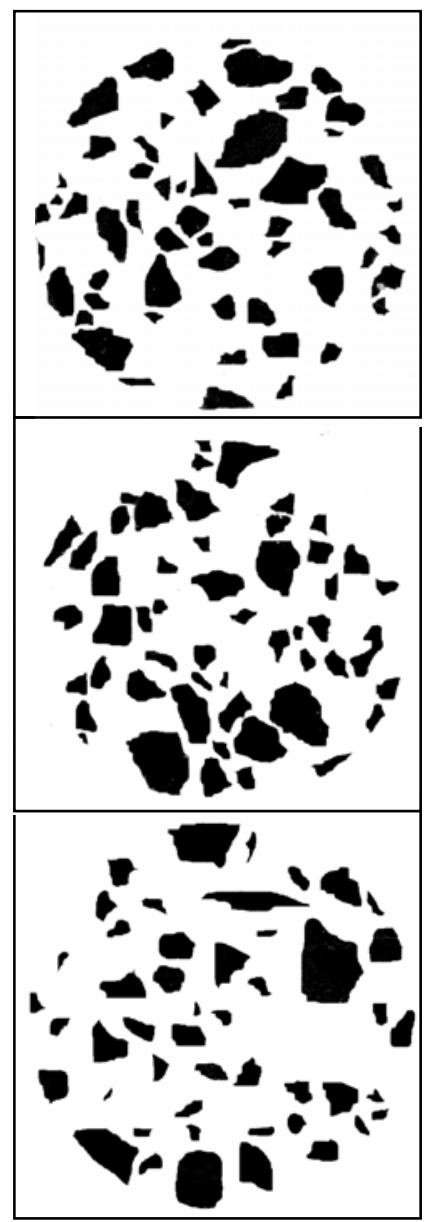

Figura 5.6.7. Relevamiento de agregados sobre cortes a diferentes a alturas. 
En lo referente al análisis de la distribución de fibras se analizó para HACRF-25 y HACRF-50 la variación de la densidad de fibras en los cortes horizontales. En la Fig. 5.6.8 se muestran los resultados obtenidos. La variabilidad en la distribución de fibras a lo largo de las columnas es bastante elevada para ambas dosis de refuerzo con valores del orden de $\pm 50 \%$ con respecto a los promedios. Se puede observar una disminución en la densidad de fibras en la parte superior, particularmente notable para HACRF-50. No hay diferencias significativas entre la densidad promedio de fibras en el núcleo y fuera de él (anillo). Los valores promedio son consistentes con el aumento de refuerzo entre HACRF-25 y HACRF-50.
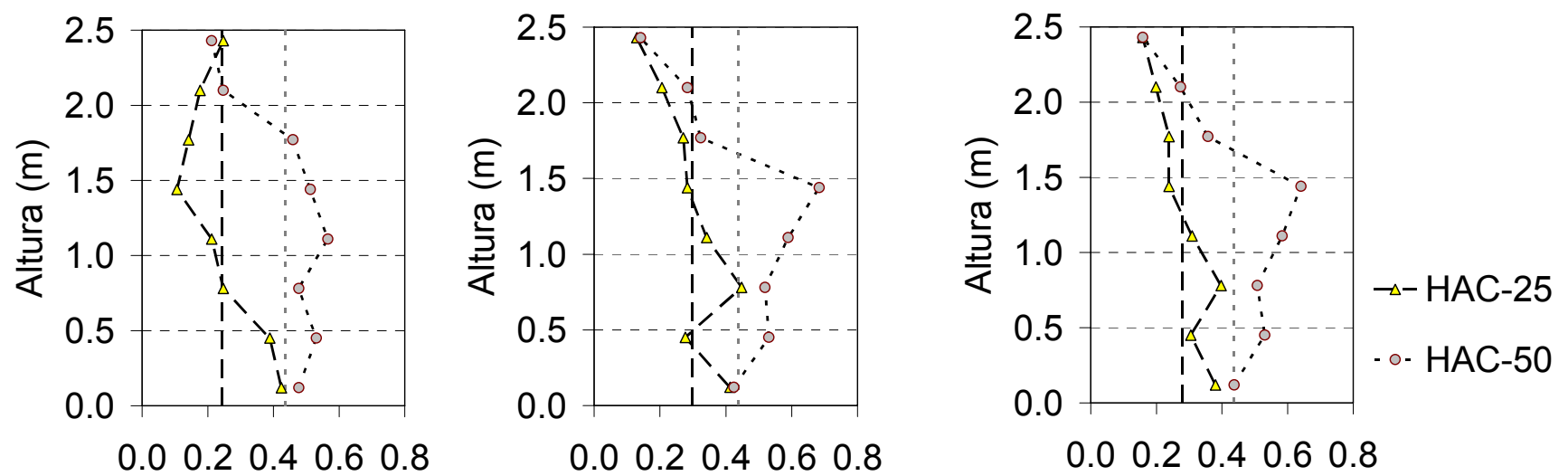

Fibras en el núcleo $\left(\mathrm{N} / \mathrm{cm}^{2}\right)$ Fibras anillo central $\left(\mathrm{N} / \mathrm{cm}^{2}\right)$ Densidad de fibras total $\left(\mathrm{N} / \mathrm{cm}^{2}\right)$

Figura 5.6.8. Variación con la altura de la densidad de fibras.

\subsubsection{Conclusiones}

En este apartado se ha analizado la variabilidad en las propiedades fisicomecánicas de columnas de HAC y HAC reforzado con fibras y su relación con la mesoestructura del material. Las principales conclusiones se indican a continuación.

EI HAC utilizado permitió un llenado adecuado de los prototipos (columnas de $0.15 \mathrm{~m}$ de diámetro y $2.5 \mathrm{~m}$ de altura). El hormigón de base fue apto para incorporar al menos $25 \mathrm{~kg} / \mathrm{m}^{3}$ de fibras de acero sin modificar substancialmente su condición de autocompactante.

La terminación superficial fue aceptable y sólo aparecieron algunas burbujas superficiales. Los casos más críticos ocurrieron al introducir $50 \mathrm{~kg} / \mathrm{m}^{3}$ de fibras pero se destaca que en este caso el hormigón de base había perdido su condición de HAC. 
Las propiedades fisicomecánicas no se modificaron en gran medida a lo largo de la altura de las columnas aunque en general se produjo una disminución de las mismas dentro del tercio superior. La variabilidad de la velocidad de pulso fue como máximo $\pm 3 \%$, el peso unitario tuvo variaciones respecto al promedio de $\pm 1 \%$ incluso en el hormigón con mayor contenido de fibras que había perdido autocompactabilidad. Los efectos de la menor consolidación en el extremo superior afectaron en mayor medida a la resistencia a compresión que en el último tramo acusó reducciones entre el 11 y el $15 \%$. Aunque en esta zona también se verificó una reducción de la rigidez, la variabilidad del módulo de elasticidad no fue demasiado grande, cuando el hormigón cumplió los parámetros de autocompactabilidad no superó el $2 \%$ y como caso extremo llegó al 4 \%.

Los estudios de mesoestructura indican que la distribución de agregados no se modificó siguiendo un patrón determinado a lo largo de la altura. La variabilidad encontrada, aunque mayor que la de las propiedades fisicomecánicas estudiadas, no es significativa y se considera que es propia de cualquier hormigón. Se observó una distribución ligeramente más homogénea en los hormigones con fibras lo que implica que el refuerzo aporta estabilidad y resistencia a la segregación al HAC.

La variación de la densidad de fibras a lo largo de las columnas fue relativamente alta para ambas dosis de fibras consideradas, con variaciones del orden del $50 \%$ respecto al promedio. Se observó un decrecimiento de la densidad en la zona superior, particularmente notable en el caso del HACRF-50. En cuanto a la distribución de fibras en la sección transversal no se observó ninguna particularidad. 


\subsection{ANÁLISIS COMPARATIVO DE LAS VARIABLES QUE INCIDEN SOBRE LA ORIENTACIÓN DE LAS FIBRAS EN HRF Y HACRF}

En este Capítulo se estudió la orientación que adquieren las fibras dentro del hormigón. A partir de estas experiencias se valoró el grado de influencia que ejercen distintos factores sobre la orientación del refuerzo en hormigón convencional (HRF) y en hormigón autocompactante (HACRF). Los factores elegidos son la longitud, el tipo (de acero o sintéticas) y la dosis de fibras, el efecto pared, el efecto del flujo del hormigón dentro de los moldes y para el caso de hormigón convencional el modo de compactación (manual o vibrado).

Tabla 5.7.1. Cuantificación del grado de influencia que ejercen distintas variables sobre la orientación de las fibras.

\begin{tabular}{|c|c|c|c|c|c|c|c|c|}
\hline & \multicolumn{4}{|c|}{ Fibras } & \multicolumn{4}{|c|}{ Colocación y compactación } \\
\hline & \multirow{2}{*}{ Longitud } & \multirow{2}{*}{ Acero } & \multirow{2}{*}{$\begin{array}{l}\text { Tipo } \\
\text { Sintéticas }\end{array}$} & \multirow{2}{*}{ Dosis } & \multirow{2}{*}{\multicolumn{2}{|c|}{ Efecto pared Efecto del flujo }} & \multicolumn{2}{|c|}{ Compactación } \\
\hline & & & & & & & Manual & Vibrado \\
\hline HRF & $\bullet \bullet \bullet \bullet$ & $\bullet \bullet$ & $\bullet$ & $\bullet$ & $\bullet \bullet \bullet \bullet$ & o & $\mathrm{o}$ & $\bullet \bullet \bullet \bullet$ \\
\hline HACRF & $\bullet \bullet \bullet \bullet$ & $\bullet \bullet$ & $\bullet$ & $\mathrm{o}$ & $\bullet \bullet \bullet \bullet$ & $\bullet \bullet \bullet \bullet$ & - & - \\
\hline
\end{tabular}

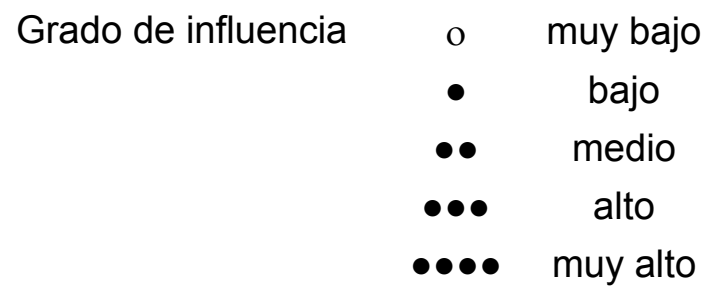

En la Tabla 5.7.1 se observa que los factores que más afectan la orientación de las fibras tanto en hormigón convencional como autocompactante son la longitud de las fibras y el efecto pared, cabe aclarar que ambos factores están estrechamente relacionados ya que el efecto ejercido por las paredes de los moldes varía según las dimensiones de las fibras. Otros factores que ejercen una influencia importante sobre la orientación son el vibrado en los HRF y el flujo del hormigón en los HACRF. Se encontró también que las fibras de acero se orientan en mayor proporción que las sintéticas. La dosis de fibras presentó una baja incidencia sobre la orientación en los HRF pero no se observó ninguna influencia sobre los HACRF, aunque las experiencias realizadas en este último caso fueron escasas. 


\subsection{INFLUENCIA DEL TIPO DE AGREGADO EN LA HOMOGENEIDAD DE UN HORMIGÓN AUTOCOMPACTANTE}

Como fuera indicado el diseño del HAC requiere una cuidadosa combinación de los materiales componentes teniendo en cuenta que las características en estado fresco resultan determinantes de las propiedades finales, en este sentido resulta de interés valorar la homogeneidad del material. El estudio de la mesoestructura es una forma de valorarla.

En este estudio se evaluó la homogeneidad en hormigones elaborados con tres tipos de agregado grueso de uso frecuente en la Provincia de Buenos Aires, piedra partida granítica, piedra partida cuarcítica y canto rodado. Estos agregados presentan diferencias significativas en su forma y textura, influyendo en el comportamiento del hormigón en estado fresco.

\subsubsection{Materiales y mezclas}

Se realizaron tres hormigones variando únicamente el tipo de agregado grueso y manteniendo constante su volumen (31\% del volumen total). Los agregados fueron utilizados en condición saturada a superficie seca, con el objeto de minimizar efectos debidos a la absorción o aporte de agua.

Se emplearon tres tipo de agregado grueso de tamaño máximo $19 \mathrm{~mm}$, piedra partida granítica $(\mathrm{G})$, piedra partida cuarcítica $(\mathrm{Q})$ y canto rodado $(\mathrm{R})$. La piedra partida granítica posee forma irregular, textura rugosa y baja absorción. La piedra partida cuarcítica también tiene textura rugosa, forma irregular, pero la absorción es mucho mayor. Por su parte el canto rodado presenta una textura lisa y partículas redondeadas.

Las propiedades de los agregados se presentan en la Tabla 5.8.1 y las dosificaciones se detallan en la Tabla 5.8.2, los hormigones fueron identificados de acuerdo con el agregado grueso utilizado: $\mathrm{H}-\mathrm{G}, \mathrm{H}-\mathrm{Q}, \mathrm{H}-\mathrm{R}$. 
Tabla 5.8.1. Propiedades del agregado grueso.

\begin{tabular}{cccc}
\hline Piedra & G & $\mathbf{Q}$ & $\mathbf{R}$ \\
\hline Densidad & 2.76 & 2.49 & 2.58 \\
Absorción $(\%)$ & 0.40 & 2.13 & 0.90 \\
PUV $\left(\mathrm{kg} / \mathrm{m}^{3}\right)$ & 1440 & 1300 & 1600 \\
Forma & Irregular & Irregular & Redondeada \\
Textura & Rugosa & Rugosa & Lisa \\
\hline
\end{tabular}

Tabla 5.8.2. Proporciones de los materiales componentes.

\begin{tabular}{cccc}
\hline Hormigón & H-G & H-Q & H-R \\
\hline Cemento $\left(\mathrm{kg} / \mathrm{m}^{3}\right)$ & 331 & 332 & 332 \\
Filler $\left(\mathrm{kg} / \mathrm{m}^{3}\right)$ & 298 & 299 & 299 \\
Agua $\left(\mathrm{kg} / \mathrm{m}^{3}\right)$ & 166 & 166 & 166 \\
Arena $\left(\mathrm{kg} / \mathrm{m}^{3}\right)$ & 745 & 745 & 745 \\
Agregado grueso $\left(\mathrm{kg} / \mathrm{m}^{3}\right)$ & 855 & 770 & 800 \\
Volumen agregado grueso(\%) & 31 & 31 & 31 \\
Superfluidificante $\left(\mathrm{kg} / \mathrm{m}^{3}\right)$ & 5.5 & 4.6 & 4.6 \\
\hline
\end{tabular}

\subsubsection{Detalles experimentales}

Para evaluar la resistencia a la segregación se llenaron tubos en forma de $U$ de $1.90 \mathrm{~m}$ de altura y $0.70 \mathrm{~m}$ de base que fueron cortados en forma transversal de manera de obtener cilindros de aproximadamente $0.40 \mathrm{~m}$ de longitud. En la Fig. 5.8.1 se muestra el esquema de obtención de las muestras de los tubos en $U$, donde se diferencian los cilindros correspondientes a la entrada, base y salida.

Sobre los cilindros de $0.70 \mathrm{~m}$ de diámetro y aproximadamente $0.40 \mathrm{~m}$ de longitud se evaluaron la velocidad de pulso ultrasónico, el peso unitario y, sobre los cortes, el área de los agregados visibles. En la Fig. 5.8.2 se pueden observar las características de los cortes analizados, mientras que las partículas de canto rodado presentan formas redondeadas, las de piedra partida granítica y cuarcítica muestran formas más angulosas. 


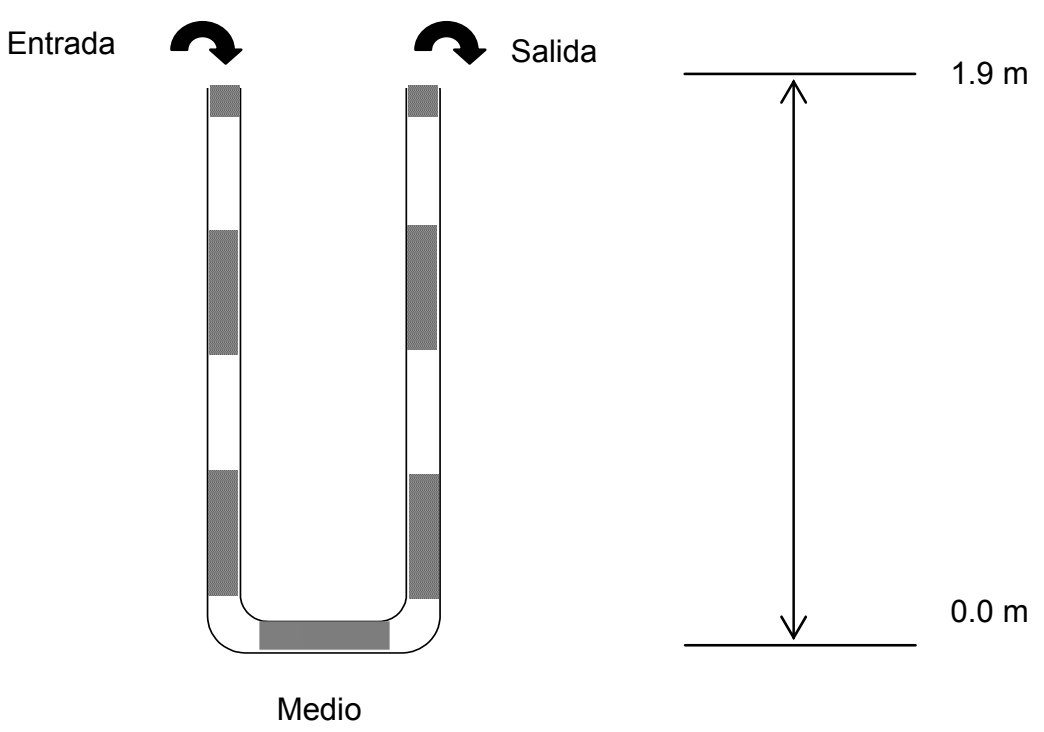

Figura 5.8.1. Esquema del tubo en U.

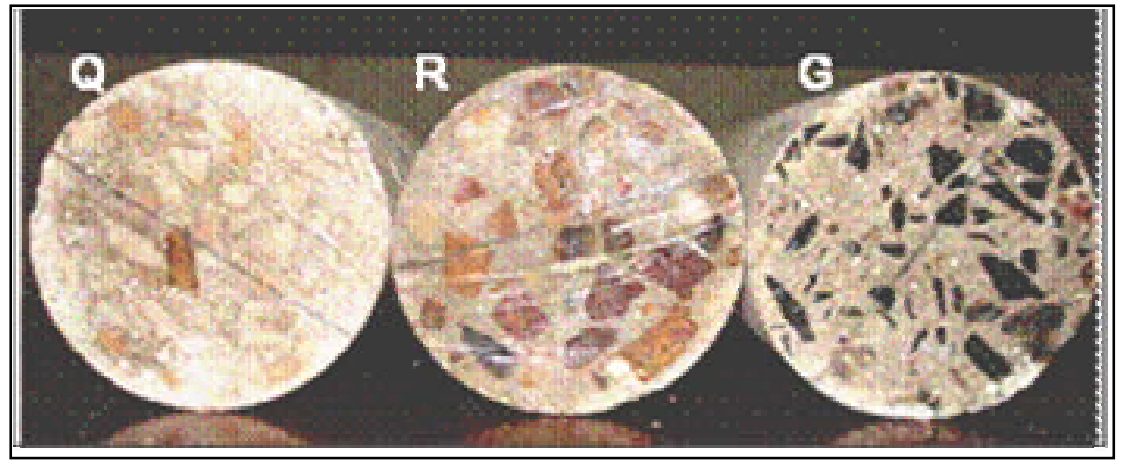

Figura 5.8.2. Cortes transversales de tubos de HAC preparados con diferentes tipos de agregado grueso. La foto de la izquierda corresponde a un tubo elaborado con piedra partida cuarcítica, en el centro con agregados redondeados de rodados silíceos y a la derecha con piedra partida granítica.

\subsubsection{Resultados y discusión}

La Fig. 5.8.3 presenta imágenes del relevamiento de agregados para los tres hormigones en diferentes secciones a lo largo del tubo en U. Por su parte la Fig. 5.8.4 representa la variación de la densidad de agregados.

En la Tabla 5.8.3 se presentan los resultados obtenidos. La densidad de agregados se calcula como la relación entre la suma del área de los agregados y el área del corte analizado. También se informan el número y porcentaje de partículas en cada sección para tres rangos de tamaños: mayores a $15 \mathrm{~mm}$, entre 15 y $10 \mathrm{~mm}$ y 
entre 10 y $5 \mathrm{~mm}$. La densidad promedio de agregados para los tubos elaborados con granito, cuarcita y canto rodado fue igual a $0.28,0.30$ y $0.33 \mathrm{~cm}^{2} / \mathrm{cm}^{2}$ respectivamente, estas diferencias de densidad son poco significativas. A la vez, al observar las densidades determinadas en las distintas secciones a lo largo del tubo tampoco aparecen variaciones importantes, la desviación estándar en el caso del granito y la cuarcita fue del orden de 0.05 y en el rodado de 0.07 .

(1)

Figura 5.8.3. Relevamiento de agregados a lo largo de los tubos en U. 
Como ya fue comentado el hormigón elaborado con canto rodado $(\mathrm{R})$ presentó las mayores variaciones a lo largo del tubo, siendo el sector horizontal y los sectores cercanos a los codos las zonas con mayor variación con respecto al promedio del tubo, en el sector horizontal la densidad de agregados varía entre un 7 y un $23 \%$ y en los sectores cercanos a los codos entre un 29 (salida) y un $34 \%$ (entrada), además la rama de salida presentó menores variaciones que la de entrada. Los hormigones elaborados con cuarcita $(Q)$ y granito $(G)$ presentaron las mayores variaciones en la rama de salida, siendo el hormigón $Q$ el que presentó las menores variaciones a lo largo del tubo.

Tabla 5.8.3. Relevamiento de la densidad y número de agregados en los tubos $U$.

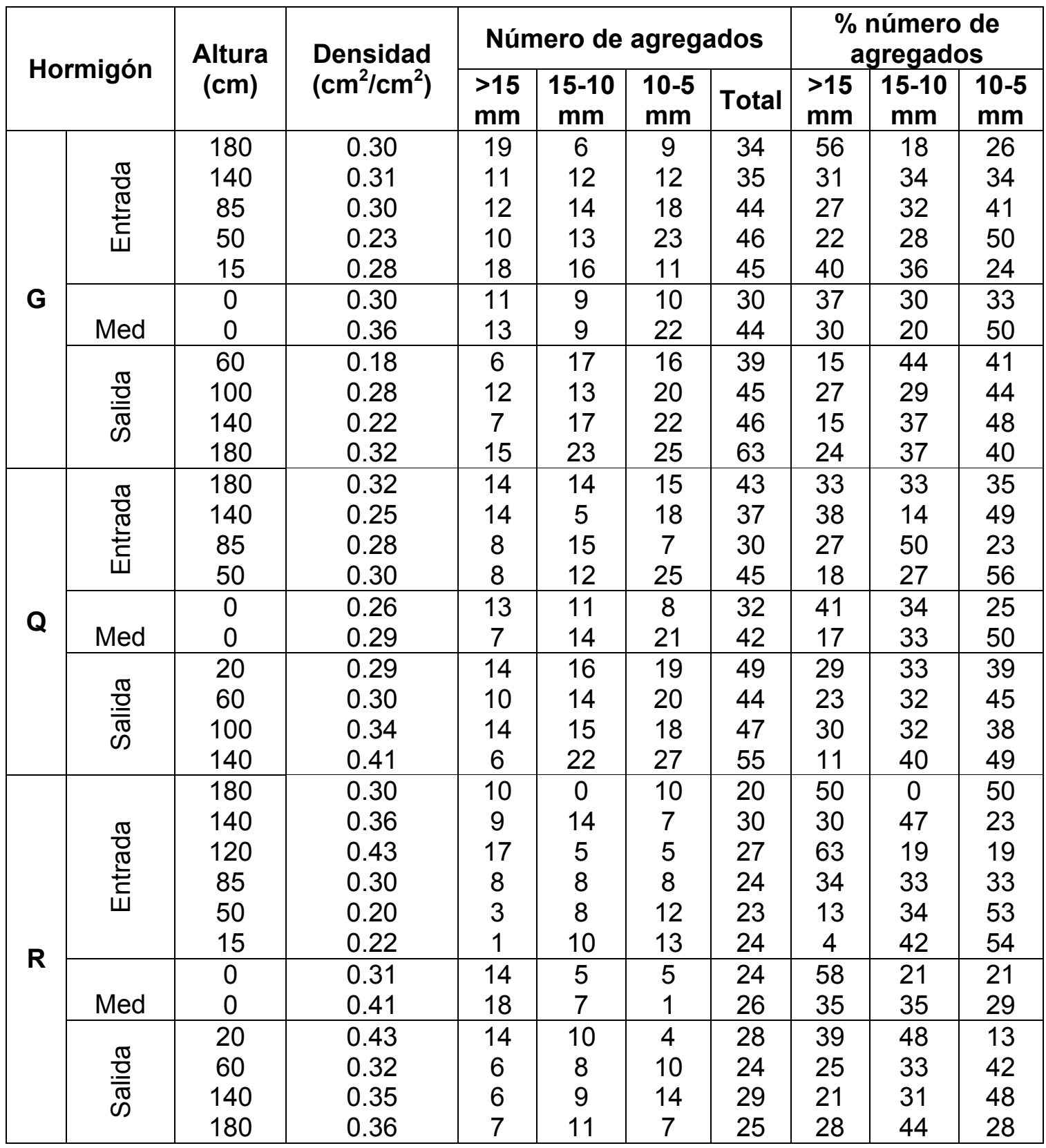




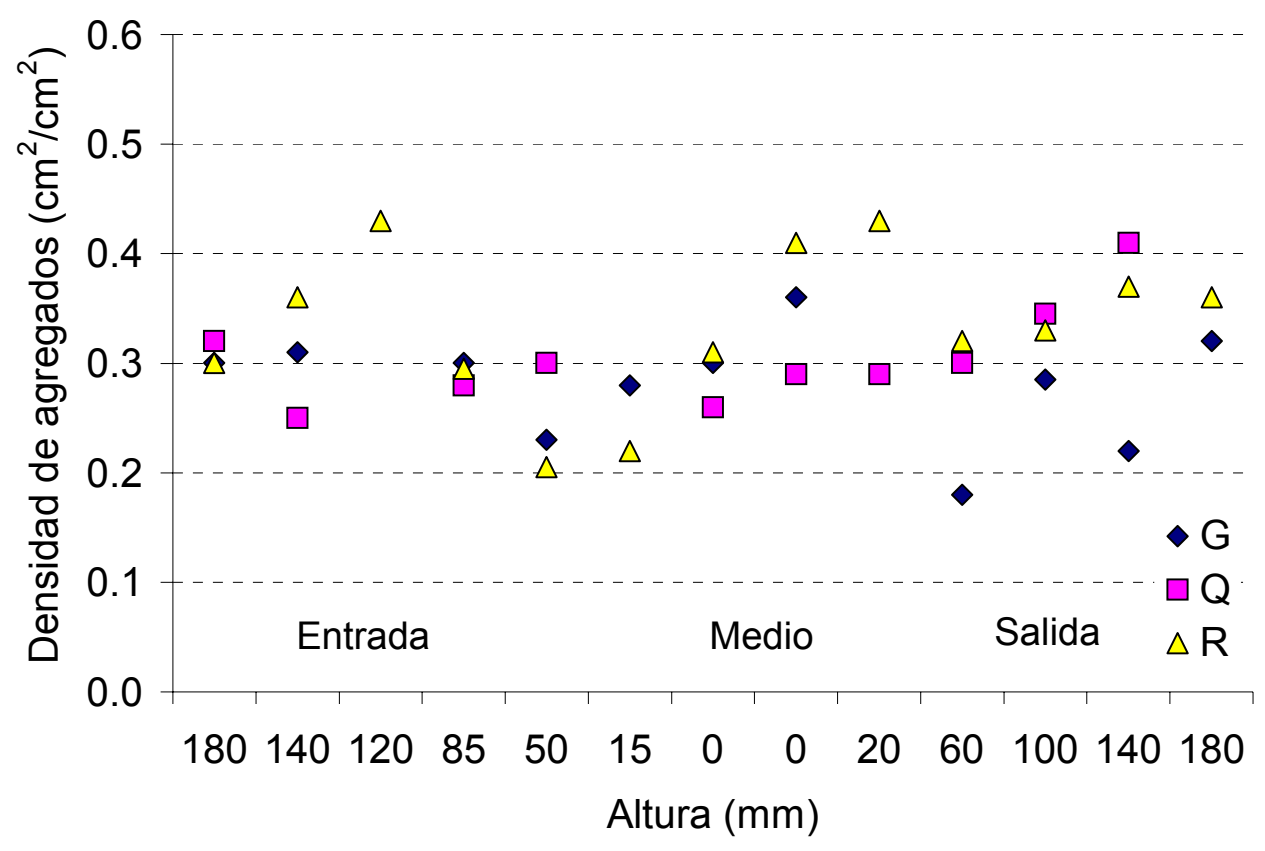

Figura 5.8.4. Variación de la densidad de agregados a lo largo de los tubos en $U$.

En cuanto a la homogeneidad superficial y presencia de burbujas de aire, poros y otros tipos de defectos, en la Fig. 5.8.5 se puede observar el perímetro de tres cilindros obtenidos en la entrada, salida y zona media de cada tubo en U. En las fotos se muestran dos lados opuestos de cada cilindro. Se observa que en uno de los lados de cada tubo existe una mayor cantidad de burbujas de aire, siendo mayor en los tramos por donde ingresó el hormigón y en la zona media (base) del tubo, en estos sectores la salida del aire es entorpecida por el hormigón que va ingresando. Asimismo en el tubo elaborado con canto rodado se observa la mayor cantidad de defectos seguido por el elaborado con cuarcita.

\section{Entrada}

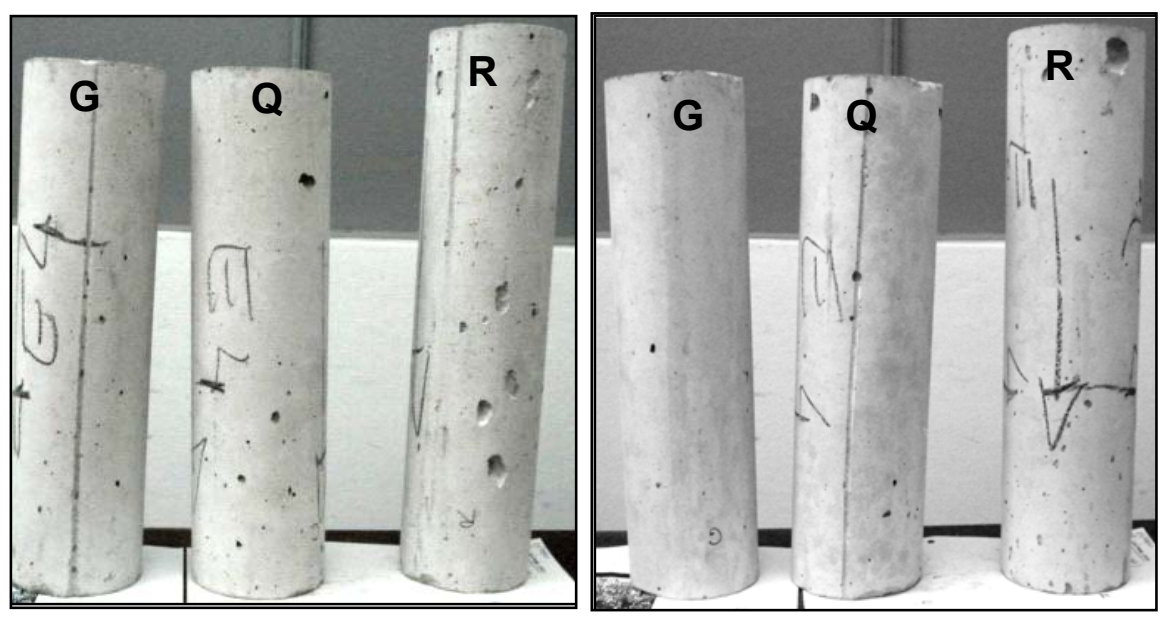


Salida

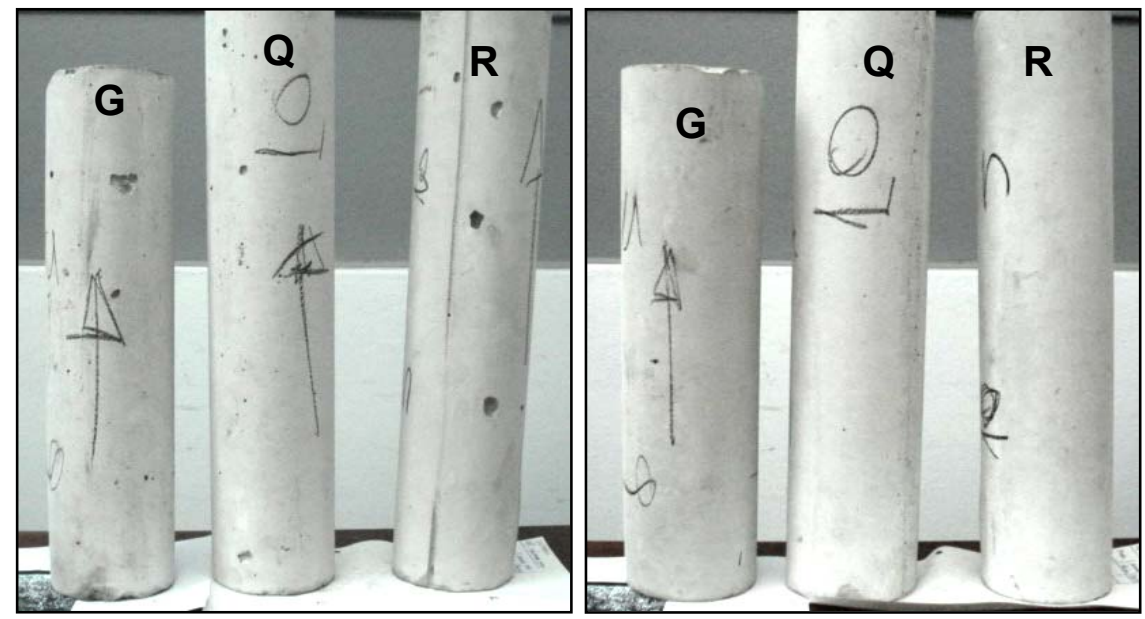

Medio

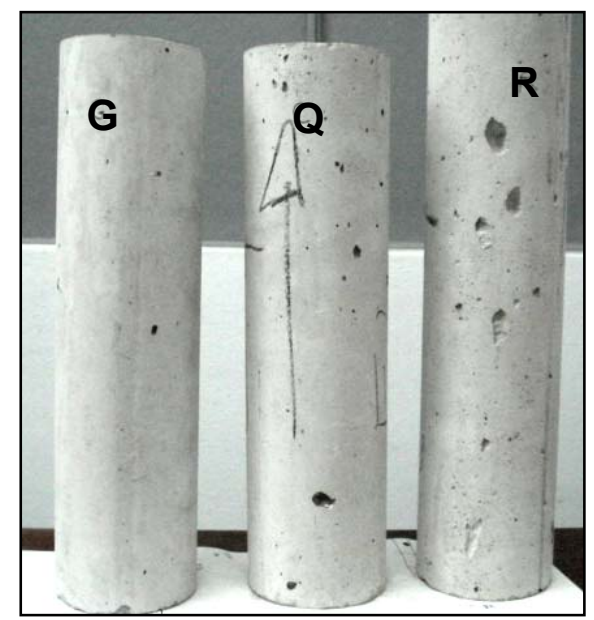

Figura 5.8.5. Aspecto superficial de tres sectores de los tubos en U.

\subsubsection{Conclusiones}

En este apartado se estudió la homogeneidad alcanzada por hormigones autocompactantes elaborados con tres tipos de áridos gruesos de diferentes características, canto rodado, piedra partida granítica y piedra partida cuarcítica. La homogeneidad fue evaluada analizando la distribución de agregados a lo largo de tubos en $U$.

El comportamiento de los tres hormigones no presentó variaciones significativas, el hormigón elaborado con canto rodado tuvo la mayor desviación estándar en la distribución de agregados a lo largo del tubo. En los tres casos las mayores variaciones se encontraron en la rama de salida. Al evaluar el estado superficial de los tubos se observó una mayor cantidad de burbujas de aire sobre uno de los lados, en mayor medida en la rama de entrada y en el tramo horizontal. 


\section{CAPÍTULO VI}

\section{CONCLUSIONES}

\subsection{CONCLUSIONES DE LA TESIS}

El objetivo general de esta tesis fue la búsqueda de una metodología y la propuesta de parámetros para caracterizar la mesoestructura del hormigón y de este modo analizar su influencia en el comportamiento macroscópico del material. En este Capítulo se presentan los aportes originales realizados y las conclusiones alcanzadas, así como algunas recomendaciones para el estudio futuro.

Se propuso un método para caracterizar la mesoestructura del hormigón adoptando como parámetros la densidad de agregados, su perímetro como representativo de las interfaces mortero-agregado grueso, y el número, longitud y ancho de fisuras por unidad de área. Se realizó el relevamiento mediante observación directa y mediante el análisis de imágenes, demostrando que a través de ambas vías se pueden obtener resultados similares.

El estudio de la mesoestructura también se amplió para evaluar la respuesta de hormigones con fibras, en este caso se consideró la densidad de fibras como principal parámetro de caracterización para un determinado tipo de fibra.

Se analizó la variabilidad de los parámetros característicos de la mesoestructura del hormigón, en estudios sobre probetas se encontró que es suficiente relevar dos cortes para obtener resultados representativos. Mediante este método fue posible cuantificar el nivel de daño diferenciando entre probetas de un mismo hormigón sometidas a diferente velocidad de enfriamiento o probetas de hormigones preparados con distintos tipos de agregado expuestas a un mismo ciclo de deterioro. 
El análisis mesoestructural fue aplicado para la caracterización de hormigones dañados. Se seleccionaron como casos de estudio hormigones expuestos a altas temperaturas o bajas condiciones de humedad y hormigones dañados por el desarrollo de la reacción álcali-sílice, encontrando que la densidad y el ancho de fisuras constituyeron los parámetros más significativos para la caracterización de hormigones dañados.

En hormigones dañados por alta temperatura se encontraron diferentes tamaños y densidades de fisuras conforme el tipo de exposición. Se verificó mayor densidad de fisuras en probetas expuestas a $500^{\circ} \mathrm{C}$ (con fisuras principalmente en las interfaces y en menor medida en la matriz) que en las expuestas a $150^{\circ} \mathrm{C}$ (fisuras en las interfaces de menor tamaño). El ancho máximo de fisura experimentó un aumento significativo conforme aumentó la temperatura de exposición. También se cuantificaron las fisuras de hormigones sometidos a procesos de secado en distintos ambientes. Los daños por efecto de la exposición a alta temperatura o al secado se vincularon con los cambios medidos a través de los ensayos no destructivos, mecánicos y de transporte.

Fue confirmada la mayor afectación en la deformabilidad que en la resistencia así como la forma en que el grado de fisuración modifica al mecanismo de rotura en hormigones dañados por alta temperatura. Un aporte original de la tesis fue el estudio de la influencia de la aplicación de cargas de larga duración, demostrando que existen diferencias en el comportamiento de hormigones sanos y dañados. En los hormigones dañados se midieron mayores deformaciones elásticas y menores deformaciones diferidas durante la aplicación de las cargas sostenidas. Comparando la respuesta mecánica de las probetas sometidas a cargas de larga duración con las que permanecieron sin cargar se observó un incremento de un $20 \%$ en la resistencia por consolidación en el hormigón sin dañar, pero esto no sucedió en los hormigones afectados por temperatura.

Otra contribución original fue el estudio de la vinculación entre mesoestructura y propiedades de transporte en hormigones afectados por alta temperatura. La permeabilidad al agua tiene una relación directa con el nivel de daño presente en el hormigón, el coeficiente de permeabilidad creció significativamente a medida que se incrementó la densidad y fundamentalmente el ancho de fisuras. El coeficiente de permeabilidad alcanzó valores del orden de $1000 \times 10^{-11} \mathrm{~m} / \mathrm{s}$ para una densidad de 
fisuras de aproximadamente $0.4 \mathrm{~cm} / \mathrm{cm}^{2}$. Por el contrario se observó que la absorción capilar se maximiza para un dado nivel de defectos. Tanto la velocidad como la capacidad de absorción capilar presentaron un máximo (con una velocidad de absorción capilar de alrededor de $18 \mathrm{~g} / \mathrm{m}^{2} / \mathrm{s}^{1 / 2}$ y capacidad de $8000 \mathrm{~g} / \mathrm{m}^{2}$ ) para una densidad de fisuras entre 0.2 y $0.3 \mathrm{~cm} / \mathrm{cm}^{2}$ y una ancho máximo menor a $0.05 \mathrm{~mm}$ (correspondiente al de los hormigones mantenidos a humedad relativa del $50 \%$ y a los hormigones expuestos a $150^{\circ} \mathrm{C}$ durante 24 horas) y luego disminuyeron para daños mayores (hormigones sometidos a $500^{\circ} \mathrm{C}$ ) con una densidad de fisuras de aproximadamente $0.4 \mathrm{~cm} / \mathrm{cm}^{2}$ y un ancho máximo igual a $0.3 \mathrm{~mm}$. Se observó que la variabilidad en las propiedades de transporte crece en los hormigones deteriorados.

Finalmente en lo que respecta a hormigones afectados por secado y exposición a alta temperatura se demostró que existe una marcada diferencia en el efecto del nivel de daño sobre las propiedades mecánicas y las de transporte. Algunos procesos de fisuración tuvieron poca incidencia sobre la resistencia pero fueron importantes al momento de ponderar la durabilidad del hormigón, como el desarrollado por la contracción por secado.

También se analizó la vinculación entre los defectos a nivel mesoestructural y el comportamiento macroscópico en hormigones afectados por la reacción álcali-sílice, con el aporte original de evaluar el desarrollo de la reacción bajo cargas de larga duración, para considerar el efecto de la cinética de la reacción se ubicaron muestras a 20 y $38^{\circ} \mathrm{C}$. No hubo diferencias en la evolución de las deformaciones bajo carga entre los hormigones con reacción y otros hormigones que no presentaron signos de reacción. Las cargas aplicadas tuvieron una fuerte influencia sobre la formación y propagación de fisuras en hormigones dañados; en las probetas cargadas mas del $67 \%$ fisuras se orientaron en la dirección de las cargas mientras que las que permanecieron sin cargar mostraron una distribución aleatoria de las fisuras.

En el estudio de hormigones afectados por reacción álcali-sílice se encontró que las propiedades mecánicas aumentaron en los grupos que estuvieron sometidos a cargas de larga duración por efecto de la consolidación. Pero en el hormigón afectado fue más notoria la diferencia en el comportamiento entre las probetas que estuvieron cargadas y las que no lo estuvieron debido a la orientación de las fisuras, la resistencia a compresión aumentó un 40 \% aproximadamente en los hormigones sometidos a carga, con respecto a las probetas sin cargar. Se verificaron diferencias en las curvas 
tensión deformación por el desarrollo de fisuras, el hormigón que permaneció sin cargar presentó mayores deformaciones.

En cuanto a las propiedades de transporte el hormigón afectado por la reacción álcali-sílice presentó una elevada permeabilidad al inicio del ensayo, producto del deterioro del hormigón, que disminuyó en forma abrupta al cabo de las primeras horas, esto se atribuye a un proceso de rehidratación del gel presente en las fisuras.

La caracterización a nivel mesoestructural fue aplicada para el análisis de hormigones reforzados con fibras y autocompactantes. Como aportes originales se mostró en el primer caso la estrecha vinculación entre la distribución de fibras y las propiedades post fisuración del material tanto para el caso de hormigón vibrado como autocompactante. El contenido de fibras se relaciona en forma directa con la tensión máxima y con los parámetros representativos del comportamiento post pico de estos hormigones como las tensiones residuales. La distribución de agregados fue de particular aplicación para evaluar la homogeneidad en hormigones autocompactantes.

Se verificó que las fibras se orientan en planos horizontales no sólo en hormigón vibrado sino también en el hormigón autocompactante tanto si se utilizan fibras de acero como sintéticas. La densidad de fibras fue mayor en la sección transversal de las vigas moldeadas en forma normalizada.

El efecto pared influye en forma notable sobre la distribución de las fibras de acero. Esta influencia es función de la relación entre la longitud de las fibras y las dimensiones del molde, para un dado molde las fibras más largas se orientarán en mayor proporción. Estos estudios demuestran la influencia que ejerce el flujo durante el transporte y llenado de los moldes en la disposición de las fibras para el caso de hormigones autocompactantes; para igual dosis de refuerzo, las fibras más largas tuvieron un mejor comportamiento post fisuración, lo que se pudo justificar en base a la orientación de las fibras observada sobre cortes en distintas direcciones.

Los estudios de la mesoestructura permitieron analizar la homogeneidad en elementos esbeltos preparados con hormigones autocompactantes con y sin refuerzo de fibras. La densidad de agregados fue más homogénea en los hormigones con fibras lo que implica que el refuerzo aporta estabilidad y resistencia a la segregación al hormigón. La variación de la densidad de fibras a lo largo de las columnas fue 
relativamente alta del orden del $50 \%$ respecto al promedio; se observó un decrecimiento de la densidad en la zona superior particularmente notable en el hormigón con mayor dosis de fibras, pero no se apreciaron cambios en la distribución de fibras en la sección transversal. En otra aplicación se utilizó la densidad de agregados para analizar la homogeneidad de tubos en forma de $U$ fabricados con hormigones autocompactantes elaborados con distintos tipos de agregados gruesos. Aunque los hormigones no presentaron variaciones significativas, el hormigón con canto rodado tuvo la mayor desviación estándar en la distribución de agregados a lo largo del tubo; las mayores variaciones se encontraron en la zona de salida del hormigón.

\subsection{RECOMENDACIONES DE ESTUDIO FUTURO}

El método adoptado permitió caracterizar la mesoestructura del hormigón verificando su vinculación con el comportamiento macroscópico. Algunas recomendaciones para el estudio futuro que surgen del estudio realizado se presentan a continuación.

Aunque el método desarrollado resultó efectivo insume mucho tiempo por lo tanto sería interesante ahondar en un método más automático para el estudio de la mesoestructura.

Se encontró que la absorción capilar se maximizó para hormigones dañados con anchos de fisuras menores a $0.05 \mathrm{~mm}$. En un futuro sería interesante vincular la mesoestructura con la microestructura para obtener una mayor precisión en cuanto a los defectos que afectan esta propiedad.

Dentro de las propiedades de transporte, y considerando que los defectos no influyen en todos los mecanismos por igual, se recomienda extender la vinculación de la mesoestructura a otros mecanismos de ingreso de importancia para la durabilidad de las estructuras, como la difusión de cloruros.

En lo referente a la influencia de los defectos producto de la contracción por secado sobre el mecanismo de fractura en hormigón, la evaluación de la mesoestructura puede constituir una herramienta muy importante para evaluar y 
comprender los efectos del tipo, distribución y tamaño de agregados presentes en el hormigón.

Es necesario profundizar en los criterios y formas de evaluación de hormigones reforzados con fibras sintéticas. Al realizar el recuento sobre las superficies de fractura no es fácil distinguir si las fibras fueron arrancadas por completo, si se cortaron quedando las fibras a ambos lados de la superficie o si se produjo un proceso de desfibrilación, lo que dificulta definir la cantidad de fibras que efectivamente había en la sección. Se sugiere explorar otras formas de relevar este tipo de fibras para conocer su disposición dentro de los elementos de hormigón. 


\section{REFERENCIAS}

Assié, S., Escadeillas, G. y Waller, V. (2007): Estimates of self-compacting concrete 'potential' durability, Construction and Building Materials, 21, pp. 1909-1917.

Aldea, C.M., Shah, S.P. y Karr, A. (1999a): Effect of Cracking on water and chloride permeability, Journal of Materials in Civil Engineering, 11, 3, pp. 181-187.

Aldea, C.M., Shah, S.P. y Karr, A. (1999b): Permeability of Cracked Concrete, Materials and Structures, RILEM, 32, pp. 381-393.

Ammouche, A., Breysse, D., Hornain, H., Didry, O. y Marchand, J. (2000): A new image analysis technique for the quantitative assessment of microcracks in cementbased materials, Cement and Concrete Research, 30, pp. 25-35.

Barr, B.I.G. (2003a): Round-robin analysis of the RILEM TC 162-TDF uni-axial tensile test: Part 2, Materials and Structures, RILEM, 36, pp. 275-280.

Barr, B.I.G. (2003b): Round-robin analysis of the RILEM TC 162-TDF uni-axial tensile test: Part 3, Materials and Structures, RILEM, 36, pp. 631-635.

Barragán, B.E. (2002): Failure and toughness of steel fiber reinforced concrete, Tesis Doctoral, Universitat Politècnica de Catalunya, España, 151p.

Barragán, B., Di Maio, A., Giaccio, G., Traversa, L. y Zerbino, R. (1998): Características elastoresistentes de hormigones expuestos a altas temperaturas, en Proc. 1 Congreso Internacional Tecnología del Hormigón, Ed. AATH, Buenos Aires, pp. 379-392.

Barragán, B., Di Maio, A., Giaccio, G., Traversa, L. y Zerbino, R. (2000): Effects of High Temperature on Residual Mechanical and Transport Properties of Concrete, en $5^{\text {th }}$ CANMET / ACI International Conference on Durability of Concrete, ACI SP-192, USA, pp. 983-1000.

Barragán, B., Giaccio, G., y Zerbino, R. (2001): Fracture and Failure of Thermally Damaged Concrete Under Tensile Loading, Materials and Structures, RILEM, 34, pp. 312-319. 
Barragán, B.E., Gettu, R., Martín, M.A. y Zerbino, R. (2003): Uniaxial tension test for steel fibre reinforced concrete - A parametric study, Cement and Concrete Composites, 25, 7, pp. 767-777.

Batic, O., Giaccio, G. y Zerbino, R. (2004): On the effect of ASR cracking on the mechanical behavior of concrete in tension and compression, Tang. M. and Deng, Ed., M. Int. Acad. Publishers, World Pub. Corp., 2, pp. 1136-1141.

Bazant, Z. y Kaplan, M. (1996): Concrete at High Temperatures, Longman Group L., UK.

Bhargava, A. y Banthia, N. (2008): Permeability of concrete with fiber reinforcement and service life predictions, Materials and Structures, RILEM, 41, pp. 363-372.

Bonen, D. y Shah, S.P. (2005): Fresh and hardened properties of self-consolidating concrete, Prog. Struct. Engng Mater., 7, pp. 14-26.

Brite-Euram BRPR-CT98-0813 (2002): Quality Assurance guidelines for the use of steel fibres reinforced concrete.

Chen, B. y Liu, J (2004): Residual strength of hybrid-fiber-reinforced high-strength concrete after exposure to high temperatures, Cement and Concrete Research, 34, 6, pp. 1065-1069.

Chen, L., Shao, C., Jan, H., Huang, C. y Tien, Y. (2006): Measuring System for Cracks in Concrete Using Multitemporal 13. Images, Journal of Surveying Engineering, ASCE, 2, pp. 77-82.

Chiang, C.H. y Yang, C.C. (2005): Artificial Neural Networks in Prediction of Concrete Strength Reduction Due to High Temperature, ACI Materials Journal, 102, 2, pp. 93102.

Choi, O.C. y Lee, C. (2003): Flexural performance of ring-type steel fiber-reinforced concrete, Cement and Concrete Research, 33, pp. 841-849.

Choinska, M., Khelidj, A., Chatzigeorgiou, G. y Cabot, G.P. (2007): Effects and interactions of temperature and stress-level related damage on permeability of concrete, Cement and Concrete Research, 37, pp. 79-88.

Cwirzen, A. y Penttala, V. (2005): Aggregate-cement paste transition zone properties affecting the salt-frost damage of high-performance concretes, Cement and Concrete Research, 35, pp. 671-679.

De Schutter, G. y Audenaert, K. (2004): Evaluation of water absorption of concrete as a measure for resistance against carbonation and chloride migration, Materials and Structures, RILEM, 37, pp. 591-596.

Di Maio, A., Giaccio, G. y Zerbino, R. (1999): Relación entre el módulo de elasticidad estático y dinámico de hormigones expuestos a altas temperaturas en $\mathrm{V}$ Cong. 
Iberoamericano de Patologías de las Construcciones, VII Congreso de Control de Calidad, Editorial A. I. de la Fuente, 1, Montevideo, pp. 331-338.

Di Maio, A., Giaccio, G. y Zerbino, R. (2002): Non-destructive Tests for the Evaluation of Concrete Exposed to High Temperatures, Cement, Concrete, and Aggregates, 24, 2, pp. 58-67.

Dupont, D. y Vandewalle, L. (2005): Distribution of steel fibers in rectangular sections, Cement and Concrete Composites, 27, pp. 391-398.

Edgington, J. y Hannant, D.J. (1972): Steel fibre reinforced concrete. The effect on fibre orientation of compaction by vibration, Materials and structures, RILEM, 5, 25, pp. 41-44.

EN 14651 (2005): Test method for metallic fibered concrete - Measuring the flexural tensile strength (limit of proportionality (LOP), residual), 18p.

Ferrara, L. y Meda, A. (2006): Relationships between fibre distribution, workability and the mechanical properties of SFRC applied to precast roof Elements, Materials and Structures, 39, pp. 411-420.

Fu, Y-F., Wong, Y-L., Poon, C-S., Tang, C-A. y Lin, P. (2004): Experimental study of micro/macro crack development and stress-strain relations of cement-based composite materials at elevate temperatures, Cement and Concrete Research, 34, pp. 789-797.

Gerard, B. y Marchand, J. (2000): Influence of cracking on the diffusion properties of cement based materials. Part I: Influence of continuos cracks on the state regime, Cement and Concrete Research, 30, pp. 37-43.

Gettu, R. y Agulló, L. (2004a): Estado del arte del hormigón autocompactable y su caracterización-Parte I, Cemento-Hormigón, 861, pp. 37-47.

Gettu, R. y Agulló, L. (2004b): Estado del arte del hormigón autocompactable y su caracterización-Parte II, Cemento-Hormigón, 862, pp. 9-31.

Gettu, R., Gardner, D.R., Saldivar, H. y Barragán, B.E. (2005): Study of the distribution and orientation of fibers in SFRC specimens, Materials and Structures, RILEM, 38, pp. 31-37.

Giaccio, G. y Giovambattista, A. (1986): Bleeding: Evaluation of its Effects on Concrete Behaviour, Materials and Structures, RILEM, 19, 112, pp. 265-271.

Giaccio, G. y Zerbino, R. (1997): Estructura y mecanismos de deformación y rotura del hormigón: efecto de las alteraciones en las zonas de transición. Primera parte: desarrollo experimental, Ciencia y Tecnología del Hormigón, 5, pp. 35-50.

Giaccio, G. y Zerbino, R. (1998a): Failure Mechanism of Concrete: Combined Effects of Coarse aggregates and Strength Level, Advanced Cement Based Materials, 7, 1, pp. 41-48. 
Giaccio, G. y Zerbino, R. (1998b): Estructura y mecanismos de deformación y rotura del hormigón: efecto de las alteraciones en las zonas de transición. Segunda parte: discusión de conceptos teóricos, Ciencia y Tecnología del Hormigón, 6, pp. 49-69.

Giaccio, G. y Zerbino, R. (2003): Residual properties of concrete exposed to high temperatures, INCONTEST 2003, Coimbatore-6p-17, en CD, India.

Giaccio, G. y Zerbino, R. (2004): Caracterización de hormigones con fibras de acero basada en la recomendación RILEM TC 162-TDF empleando vigas de menor tamaño, en Tecnología de Estructuras de Hormigón, Ed. A. Aguado, L. Agulló, B. Barragán y G. Ramos, Barcelona, pp. 235-247.

Giaccio, G., Zerbino, R., Ponce, J.M. y Batic, O.R. (2008): Mechanical behavior of concretes damaged by alkali-silica reaction, Cement and Concrete Research, 38, pp. 993-1004.

Gonen, T. y Yazicioglu, S. (2007): The influence of compaction pores on sorptivity and carbonation of concrete, Construction and Building Materials, 21, pp. 1040-1045.

Gowripalana, N., Sirivivatnanon, V. y Lim, C.C. (2000): Chloride diffusivity of concrete cracked in flexure, Cement and Concrete Research, 30, pp. 725-730.

Grünewald, S. y Walraven, J. (2001): Parameter-study on the influence of steel fibers and coarse aggregate content on the fresh properties of self-compacting concrete, Cement and Concrete Research, 31, pp. 1793-1798.

Grünewald, S. (2004): Performance-based design of self-compacting fibre reinforced concrete, Tesis Doctoral, Technische Universiteit Delft, Holanda, p. 165.

Hsu, T.C., Slate, F.O., Sturman, G.M. y Winter, G. (1963): Microcracking of Plain Concrete and the Shape of the Stress-Strain Curve, Journal of American Concrete Institute, Proceedings, 60, 2, pp. 209-223.

Hutchinson, T.C., y Chen, Z.Q. (2006): Improved Image Analysis for Evaluating Concrete Damage, Journal of Computing in Civil Engineering, ASCE, 3, pp. 210-216.

Jacobsen, S., Marchand, J. y Homain, H. (1995): SEM observations of the microstructure of frost deteriorated and self-healed concretes, Cement and Concrete Research, 25, 8, pp. 1781-1790.

Khoury, G.A. (2000): Effect of fire on concrete and concrete structures, Prog. Struct. Engineering Materials, 2, pp. 429-447.

Kooiman, A. (2000): Modelling Steel Fibre Reinforced Concrete for Structural Design, Tesis Doctoral, Technische Universiteit Delft, Holanda, p. 170.

Koyata, H. y Comman, C.R. (2005): Workability measurement and developing robust SCC mixture designs, Sec. North Am. Conf. on the Design and Use of Self- 
Consolidating Concrete (SCC) and the Fourth Int. RILEM Symp. on Self-Compacting Concrete, Ed. S. P. Shah, Hanley Wood Pub., Addison, IL, USA, pp. 799-805.

Kurumisawa, K. y Tanaka, K. (2006): Three-dimensional visualization of pore structure in hardened cement paste by the gallium intrusion technique, Cement and Concrete Research, 36, pp. 330-336.

Leemann, A., Münch, B., Gasser, P. y Holzer, L. (2006): Influence of compaction on the interfacial transition zone and the permeability of concrete, Cement and Concrete Research, 36, pp. 1425-1433.

Lepech, M. y Li, V.C. (2001): Water permeability of cracked cementitious composites, Advanced Civil Engineering Materials Research Laboratory, Department of Civil and Environmental Engineering, University of Michigan, USA.

Li, M., Qian, C. X. y Sun, W. (2004): Mechanical Properties of high-strength concrete after fire, Cement and Concrete Research, 34, 6, pp. 1001-1005.

Lu, S., Landis, E.N. y Keane, D.T. (2006): X-ray microtomographic studies of pore structure and permeability in Portland cement concrete, Materials and Structures, RILEM, 39, pp. 611-620.

Mehta, P.K. y Monteiro, P.J.M. (1993): Concrete: Structure, Properties and Materials, Prentice Hall, NJ.

Mehta, P.K. y Aitcin, P.C. (1990): Effect of coarse aggregate characteristics on mechanical properties of high-strength concrete, ACI Materials Journal, 87, 2, pp. 103107.

Mindess, S. y Young, J.F. (1981): Concrete, Ed. Prentice-Hall, ISBN 0-13-167106-5.

Mindess, S., Young, J. y Darwin, D. (2003): Concrete, $2^{\text {nd }}$ Ed. Prentice Hall, N. J.

Neithalath, N. (2006): Analysis of Moisture Transport in Mortars and Concrete Using Sorption-Diffusion Approach, ACI Materials Journal, 103, 3, pp. 209-217.

Nemati, K.M. (2000): Preserving microstructure of concrete under load using the Wood's metal technique, International Journal of Rock Mechanics and Mining Sciences, 37, pp. 133-142.

Nemati, K.M. y Stroeven, P. (2001): Stereological analysis of micromechanical behavior of concrete, Materials and Structures, RILEM, 34, pp. 486-494.

Níelsson, I. y Wallevik, O.H. (2003): Rheologycal evaluation of some empirical test methods-Preliminary results, Proc. 3rd Int. RILEM Symp. Reykjavik, Iceland, Ed. O. Wallevik and I. Nielsson, (RILEM Pub. PRO 33), pp. 59-68.

Ostertag, C.P., Yi, C. y Monteiro, P.J.M. (2007): Effect of Confinement on Properties and Characteristics of Alkali-Silica Reaction Gel, ACl Materials Journal, 104, 3, pp. 276-282. 
Ozyurt, N., Mason, T.O. y Shah, S.P. (2006): Non-destructive monitoring of fiber orientation using AC-IS: An industrial-scale application, Cement and Concrete Research, 36, 9, pp.1653-1660.

Ozyurt, N., Mason, T.O. y Shah, S.P. (2007): Correlation of fiber dispersion, rheology and mechanical performance of FRCs, Cement and Concrete Composites, 29, pp. 7079.

Pasini, F., Garcia, T., Gettu, R. y Agulló, L. (2004): Experimental study of the properties of flowable fiber reinforced concretes, BEFIB 04, Proc. Sixth Int. RILEM Symp., 1, pp. 279-288.

Persson, B. (2004): Fire resistance of self-compacting concrete, SCC, Materials and Structures, RILEM, 37, pp. 575-584.

Phan, T. y Carino, N. (2000): Fire Performance of High Strength Concrete: Research needs, en Proc. Advanced Technology in Structural Engineering, ASCE/SEI Structures Congress 2000, Philadelphia, EE.UU.

Pradhana, B., Nageshb, M. y Bhattacharjeec, B. (2005): Prediction of the hydraulic diffusivity from pore size distribution of concrete, Cement and Concrete Research, 35, pp. 1724-1733.

Prudencio, L. Jr., Austin, S., Jones, P., Armelin, H. y Robins, P. (2006): Prediction of steel fibre reinforced concrete under flexure from an inferred fibre pull-out response, Materials and Structures, RILEM, 39, pp. 601-610.

Rapoport, J., Aldea, C.M., Shah, S.P., Ankenman, B. y Karr, A. (2002): Permeability of Cracked Steel Fiber-Reinforced Concrete, Journal of materials in civil engineering, 14, 4, pp. 355-358.

Redon, C., Chermant, L., Chermant, J.L. y Coster, M. (1999): Automatic image analysis and morphology of fibre reinforced concrete, Cement and Concrete Composites, 21, pp. 403-412.

RILEM TC50-FMC (1985): Determination of the fracture energy of mortar and concrete by means of three-point bend tests on notched beams, Materials and Structures, 18, 106, pp. 285-290.

RILEM TC162-TDF (2002): Test and design methods for steel fibre reinforced concrete, Materials and Structures, 35, pp. 579-582.

Ringot, E. y Bascoul, A. (2001): About the analysis of microcracking in concrete, Cement and Concrete Composites, 23, pp. 261-266.

Saouma, V. y Perotti, L. (2006): Constitutive Model for Alkali-Aggregate Reactions, ACI Materials Journal, 103, 3, pp. 194-202. 
Sarja, A. (2003): Durability design of concrete structures-Committee report 130-CSL 2nd International RILEM Workshop on Life Prediction and Aging Management of Concrete Structures Paris, France, Materials and Structures, 33, pp. 14-20.

SCCEPG Guidelines (2005): The European Guidelines for Self-Compacting Concrete Specification, Production and Use.

http://www.efnarc.org/pdf/SCCGuidelinesMay2005.pdf

Shah, S. P. (1991): Do fibers increase the tensile strength of cement-based matrices? ACI Material Journal, 88, 6, pp. 595-602.

Shah, S.P. y Chandra, S. (1968): Critical stress, Volumen change and Microcracking, ACl Journal, Title $\mathrm{N}^{\circ}$ 65-57, pp. 770-780.

Sicard, V., Francois, R., Ringot, E. y Pons, G. (1992): Influence of creep and shrinkage on cracking in high strength concrete, Cement and Concrete Research, 22, 1, pp. 159-168.

Soroushian, P. y Elzafraney, M. (2004): Damage effects on concrete performance and microstructure, Cement and Concrete Composites, 26, pp. 853-859.

Soroushian, P. y Lee, C.D. (1990): Distribution and Orientation of Fibers in Steel Fiber Reinforced Concrete, ACI Materials Journal, 87, 5, pp. 433-439.

Soylev, T.A. y François, R. (2003): Quality of steel-concrete interface and corrosion of reinforcement steel, Cement and Concrete Research, 33, pp. 1407-1415.

Stähli, P. y van Mier, J.G.M. (2007): Manufacturing, fibre anisotropy and fracture of hybrid fibre concrete, Engineering Fracture Mechanics, 74, pp. 223-242.

Tasdemir, C. (2003): Combined effects of mineral admixtures and curing conditions on the sorptivity coefficient of concrete, Cement and Concrete Research, 33, 10, pp. 16371642.

Taus, V., Di Maio, A. y Traversa, L. (2005): Sorptivity: Parameter for the Evaluation of Cover Concrete Quality, Proc. Fourth International Conference $\mathrm{ACl}$, Ed. Helene, P., Pazini Figueiredo, E., Holland, T., Bittencourt, R., Olinda, Brazil, pp. 121-134.

Toutanji, H. y Bayasi, Z. (1998): Effects of manufacturing techniques on the flexural behavior of steel fiber-reinforces concrete, Cement and Concrete Research, 28, 1, pp. $115-124$.

Wang, K., Jansen, D.C., Shah, S.P. y Karr, A.F. (1997): Permeability study of cracked concrete, Cement and Concrete Research, 27, 3, pp. 381-393.

Woo, L.Y., Wansom, S., Ozyurt, N., Mu, B., Shah, S.P., y Mason, T.O. (2005): Characterizing fiber dispersion in cement composites using AC-Impedance Spectroscopy, Cement and Concrete Composites, 27, pp. 627-636. 
Yurtdas, I., Burlion, N. y Skoczylas, F. (2004): Experimental characterization of the drying effect on uniaxial mechanical behaviour of mortar, Materials and Structures, RILEM, 37, pp. 170-176.

Zhang, B. (1998): Relationship between pore structure and mechanical properties of ordinary concrete under bending fatigue, Cement and Concrete Research, 28, 5, pp. 699-711.

Zhang, C., Wang, A., Tang, M., Wu, B. y Zhang, N. (1999): Influence of aggregate size and aggregate size grading on ASR expansion, Cement and Concrete Research, 29, pp. 1393-1396.

Zhu, W., Gibbs, J.C. y Bartos, P.J.M. (2001): Uniformity of in situ properties of selfcompacting concrete in full-scale structural elements, Cement and Concrete Composites, 23, pp. 57-64. 


\section{Anexo I Capítulo IV}

Tabla I.1. Resultados individuales de los ensayos no destructivos (inciso 4.3).

\begin{tabular}{|c|c|c|c|c|c|c|c|c|c|c|}
\hline Grupo & Probeta & $\begin{array}{c}\text { Peso } \\
\text { (g) }\end{array}$ & $\begin{array}{l}\text { Perímetro } \\
\text { (cm) }\end{array}$ & $\begin{array}{l}\text { Diámetro } \\
\text { (cm) }\end{array}$ & $\begin{array}{l}\text { Longitud } \\
(\mathrm{cm})\end{array}$ & $\begin{array}{c}\text { PUV } \\
\left(\mathrm{g} / \mathrm{cm}^{3}\right)\end{array}$ & $\begin{array}{l}\text { t VPU } \\
\text { ( } \mu \text { seg) }\end{array}$ & $\begin{array}{c}\text { VPU } \\
(\mathrm{km} / \mathrm{seg})\end{array}$ & LS & $\begin{array}{c}\mathrm{Ed} \\
(\mathrm{GPa})\end{array}$ \\
\hline \multirow[t]{6}{*}{ Control } & HP13 & 12408 & 47.9 & 15.2 & 30.1 & 2.26 & 699 & 4.31 & 399 & 33.5 \\
\hline & HP16 & 12532 & 48.1 & 15.3 & 30.2 & 2.25 & 710 & 4.25 & 397 & 32.5 \\
\hline & HP18 & 12562 & 48 & 15.3 & 30 & 2.28 & 705 & 4.26 & 400 & 34.2 \\
\hline & HP21 & 12437 & 48 & 15.3 & 30 & 2.26 & 704 & 4.26 & 399 & 33.3 \\
\hline & HP28 & 12516 & 48 & 15.3 & 30.2 & 2.26 & 712 & 4.24 & 398 & 33.2 \\
\hline & HP30 & 12423 & 47.9 & 15.2 & 30 & 2.27 & 705 & 4.26 & 400 & 34 \\
\hline \multirow[t]{2}{*}{150} & HP3 & 12767 & 48 & 15.3 & 30.2 & 2.31 & 702 & 4.3 & 400 & 35 \\
\hline & HP11 & 12793 & 48.1 & 15.3 & 30.5 & 2.28 & 703 & 4.34 & 399 & 34.7 \\
\hline \multirow[t]{3}{*}{ (1) } & HP12 & 12491 & 48 & 15.3 & 30.1 & 2.26 & 722 & 4.17 & 399 & 33.6 \\
\hline & HP22 & 12540 & 48 & 15.3 & 30.2 & 2.26 & 699 & 4.32 & 399 & 33.8 \\
\hline & HP26 & 12447 & 48 & 15.3 & 30.2 & 2.25 & 715 & 4.22 & 399 & 33.6 \\
\hline \multirow[t]{2}{*}{150} & HP3 & 12318 & 48 & 15.3 & 30.2 & 2.22 & 814 & 3.71 & 380 & 24.5 \\
\hline & HP11 & 12362 & 48.1 & 15.3 & 30.5 & 2.2 & 820 & 3.72 & 378 & 23.9 \\
\hline \multirow[t]{3}{*}{ (2) } & HP12 & 12057 & 48 & 15.3 & 30 & 2.19 & 816 & 3.68 & 378 & 23 \\
\hline & HP22 & 12083 & 48 & 15.3 & 30.1 & 2.19 & 822 & 3.66 & 378 & 23.1 \\
\hline & HP26 & 12007 & 48 & 15.3 & 30.2 & 2.17 & 806 & 3.75 & 378 & 23 \\
\hline \multirow[t]{2}{*}{500} & HP25 & 12500 & 48.1 & 15.3 & 30 & 2.26 & 700 & 4.29 & 393 & 30.2 \\
\hline & HP24 & 12399 & 48.1 & 15.3 & 30.2 & 2.23 & 696 & 4.34 & 391 & 29.2 \\
\hline \multirow[t]{3}{*}{ (1) } & HP8 & 12467 & 48 & 15.3 & 30.1 & 2.26 & 704 & 4.28 & 393 & 30.3 \\
\hline & HP20 & 12505 & 48 & 15.3 & 30.2 & 2.26 & 694 & 4.35 & 395 & 31.5 \\
\hline & HP14 & 12394 & 48 & 15.3 & 30.3 & 2.23 & 697 & 4.35 & & \\
\hline \multirow[t]{2}{*}{500} & HP25 & 12091 & 48.1 & 15.3 & 30 & 2.19 & 1005.5 & 2.98 & 328 & 11.6 \\
\hline & HP24 & 12007 & 48.1 & 15.3 & 30.2 & 2.16 & 1002 & 3.01 & 333 & 12.4 \\
\hline \multirow[t]{3}{*}{ (2) } & HP8 & 12092 & 48 & 15.3 & 30.1 & 2.19 & 1001.3 & 3.01 & 335 & 12.8 \\
\hline & HP20 & 12096 & 48 & 15.3 & 30.2 & 2.18 & 1003 & 3.01 & 340 & 13.8 \\
\hline & HP14 & 12043 & 48 & 15.3 & 30.2 & 2.17 & 1009.5 & 3 & 326 & 11.5 \\
\hline \multirow[t]{8}{*}{ CS } & HP7 & 12286 & 48 & 15.3 & 30.2 & 2.22 & 732 & 4.13 & 388 & 27.6 \\
\hline & HP2 & 12364 & 48 & 15.3 & 30 & 2.25 & 745 & 4.03 & 390 & 28.5 \\
\hline & HP9 & 12549 & 48 & 15.3 & 30.2 & 2.27 & 730 & 4.14 & 390 & 29.2 \\
\hline & HP5 & 12393 & 48 & 15.3 & 30.1 & 2.25 & 722 & 4.17 & 390 & 28.7 \\
\hline & HP31 & 12177 & 48 & 15.3 & 30 & 2.21 & 737 & 4.07 & 390 & 28.1 \\
\hline & HP29 & 12343 & 48 & 15.3 & 30 & 2.24 & 738 & 4.07 & 389 & 28 \\
\hline & HP23 & 12205 & 48 & 15.3 & 29.9 & 2.23 & 742 & 4.03 & 390 & 28.1 \\
\hline & HP27 & 12440 & 48 & 15.3 & 30 & 2.26 & 732 & 4.1 & 391 & 29.2 \\
\hline \multirow[t]{8}{*}{$\mathrm{CH}$} & HP1 & 13029 & 48.1 & 15.3 & 30 & 2.36 & 650 & 4.62 & 410 & 41.5 \\
\hline & HP4 & 12947 & 47.9 & 15.2 & 30.2 & 2.35 & 650 & 4.65 & 410 & 41.9 \\
\hline & HP6 & 12943 & 48.1 & 15.3 & 30.2 & 2.33 & 680 & 4.44 & 405 & 38.2 \\
\hline & HP10 & 12843 & 48.2 & 15.3 & 30.3 & 2.29 & 670 & 4.52 & 395 & 32.2 \\
\hline & HP17 & 12991 & 48.2 & 15.3 & 30.2 & 2.33 & 670 & 4.51 & 385 & 27.6 \\
\hline & HP19 & 12947 & 47.9 & 15.2 & 30 & 2.36 & 650 & 4.62 & & \\
\hline & HP32 & 12879 & 48.1 & 15.3 & 30.2 & 2.32 & 660 & 4.58 & 400 & 35.2 \\
\hline & HP33 & 12880 & 48 & 15.3 & 30.2 & 2.33 & 670 & 4.51 & 400 & 35.3 \\
\hline
\end{tabular}

(1) Antes de la exposición a altas temperaturas.

(2) Después de la exposición a altas temperaturas. 
Tabla I.2. Ensayos no destructivos (inciso 4.4)

\begin{tabular}{|c|c|c|c|}
\hline & Probeta & $\begin{array}{c}\text { Peso } \\
\text { g }\end{array}$ & $\begin{array}{l}\text { VPU } \\
\mathrm{km} / \mathrm{s}\end{array}$ \\
\hline \multirow{5}{*}{$\begin{array}{c}20 \\
\text { cargadas }\end{array}$} & 1 & 12880 & 4.314 \\
\hline & 4 & 13019 & 4.373 \\
\hline & 6 & 12807 & 4.518 \\
\hline & 7 & 12881 & 4.539 \\
\hline & 8 & 12848 & 4.479 \\
\hline \multirow{5}{*}{$\begin{array}{l}20 \text { sin } \\
\text { cargar }\end{array}$} & 2 & 12801 & 4.478 \\
\hline & 9 & 12932 & 4.539 \\
\hline & 10 & 12648 & 4.385 \\
\hline & 11 & 12928 & 4.526 \\
\hline & 14 & 12858 & 4.401 \\
\hline \multirow{5}{*}{$\begin{array}{c}150 \\
\text { cargadas }\end{array}$} & 17 & 12483 & 3.512 \\
\hline & 18 & 12589 & 3.630 \\
\hline & 19 & 12584 & 3.787 \\
\hline & 24 & 12624 & 3.716 \\
\hline & 27 & 12561 & 3.744 \\
\hline \multirow{4}{*}{$\begin{array}{l}150 \text { sin } \\
\text { cargar }\end{array}$} & 16 & 12603 & 3.783 \\
\hline & 21 & 12759 & 3.826 \\
\hline & 25 & 12704 & 3.781 \\
\hline & 26 & 12610 & 3.812 \\
\hline \multirow{5}{*}{$\begin{array}{c}500 \\
\text { cargadas }\end{array}$} & 28 & 12457 & 1.620 \\
\hline & 34 & 12597 & 2.876 \\
\hline & 35 & 12673 & 1.570 \\
\hline & 37 & 12567 & 2.744 \\
\hline & 40 & 12511 & 2.517 \\
\hline \multirow{4}{*}{$\begin{array}{l}500 \text { sin } \\
\text { cargar }\end{array}$} & 29 & 12590 & 1.721 \\
\hline & 32 & 12418 & 2.810 \\
\hline & 36 & 12541 & 2.720 \\
\hline & 39 & 12594 & 2.515 \\
\hline
\end{tabular}


Tabla I.3. Ensayos no destructivos (inciso 4.5).

\begin{tabular}{|c|c|c|c|c|c|c|c|c|}
\hline Grupo & Prob. & $\begin{array}{l}\text { Perímetro } \\
\text { (cm) }\end{array}$ & $\begin{array}{c}\text { Diámetro } \\
\text { (cm) }\end{array}$ & $\begin{array}{l}\text { Peso } \\
\text { (g) }\end{array}$ & $\begin{array}{c}\text { Longitud } \\
\text { (cm) }\end{array}$ & $\begin{array}{c}\mathrm{PUV} \\
\left(\mathrm{g} / \mathrm{cm}^{3}\right)\end{array}$ & $\begin{array}{c}\text { tVPU } \\
(\mu \mathrm{s})\end{array}$ & $\begin{array}{c}\text { VPU } \\
(\mathrm{km} / \mathrm{s})\end{array}$ \\
\hline C20 c & 13 & 48.4 & 15.4 & 13152 & 29.9 & 2.36 & 720 & 4.15 \\
\hline $20 c$ & 15 & 48.2 & 15.3 & 13446 & 30.4 & 2.39 & 740 & 4.11 \\
\hline $20 c$ & 16 & 48.3 & 15.4 & 13114 & 29.9 & 2.36 & 716 & 4.18 \\
\hline $20 c$ & 18 & 48.1 & 15.3 & 13206 & 30.4 & 2.36 & 744 & 4.09 \\
\hline $20 c$ & 21 & 48.7 & 15.5 & 13564 & 30.5 & 2.36 & 749 & 4.07 \\
\hline $20 d$ & 22 & 48 & 15.3 & 12851 & 29.9 & 2.34 & 807 & 3.71 \\
\hline $20 d$ & 25 & 48.1 & 15.3 & 13257 & 29.9 & 2.41 & 675 & 4.43 \\
\hline $20 d$ & 26 & 48.1 & 15.3 & 12813 & 29.6 & 2.35 & 840 & 3.52 \\
\hline $38 \mathrm{c}$ & 14 & 48.1 & 15.3 & 12953 & 30.5 & 2.31 & 760 & 4.01 \\
\hline $38 \mathrm{c}$ & 19 & 48.1 & 15.3 & 12904 & 30.4 & 2.31 & 765 & 3.97 \\
\hline $38 \mathrm{c}$ & 23 & 48.3 & 15.4 & 12973 & 30.3 & 2.31 & 750 & 4.04 \\
\hline $38 d$ & 17 & 48.2 & 15.3 & 12728 & 29.6 & 2.33 & 860 & 3.44 \\
\hline $38 d$ & $20 d$ & 48.4 & 15.4 & 13230 & 30.7 & 2.31 & 1087 & 2.82 \\
\hline $38 d$ & 24 & 48.1 & 15.3 & 13064 & 30 & 2.37 & 955 & 3.14 \\
\hline 20 & 35 & 48.4 & 15.4 & 13395 & 30.4 & 2.36 & 875 & 3.47 \\
\hline 20 & 31 & 48.2 & 15.3 & 13284 & 30.6 & 2.35 & 900 & 3.40 \\
\hline 38 & 33 & 49.2 & 15.7 & 13064 & 30.5 & 2.22 & 986 & 3.09 \\
\hline 38 & 34 & 48.2 & 15.3 & 13026 & 30.4 & 2.32 & 935 & 3.25 \\
\hline T20c & 54 & 48.1 & 15.3 & 13367 & 30.4 & 2.39 & 704 & 4.32 \\
\hline $20 c$ & 57 & 48 & 15.3 & 13301 & 29.9 & 2.43 & 665 & 4.50 \\
\hline $20 c$ & 60 & 48.2 & 15.3 & 13643 & 30.1 & 2.45 & 668 & 4.51 \\
\hline $20 c$ & 61 & 48.1 & 15.3 & 13425 & 30.4 & 2.40 & 665 & 4.57 \\
\hline $20 c$ & 64 & 47.9 & 15.2 & 13274 & 30.4 & 2.39 & 646 & 4.71 \\
\hline $20 d$ & 55 & 48 & 15.3 & 13257 & 29.8 & 2.43 & 840 & 3.55 \\
\hline $20 d$ & 63 & 48.3 & 15.4 & 13517 & 30.05 & 2.42 & 653 & 4.60 \\
\hline $20 d$ & 58 & 48.2 & 15.3 & 13109 & 29.8 & 2.38 & 648 & 4.60 \\
\hline $38 \mathrm{c}$ & 59 & 48.2 & 15.3 & 12975 & 30.3 & 2.32 & 690 & 4.39 \\
\hline $38 \mathrm{c}$ & 62 & 48 & 15.3 & 12923 & 30.4 & 2.32 & 674 & 4.51 \\
\hline $38 \mathrm{c}$ & 56 & 48.2 & 15.3 & 13105 & 30.5 & 2.32 & 682 & 4.47 \\
\hline $38 d$ & 53 & 47.4 & 15.1 & 12612 & 30 & 2.35 & 658 & 4.56 \\
\hline $38 d$ & 65 & 48.3 & 15.4 & 13251 & 30.4 & 2.35 & 665 & 4.57 \\
\hline $38 d$ & 66 & 48.2 & 15.3 & 13271 & 30.4 & 2.36 & 659 & 4.61 \\
\hline 20 & 71 & 48.1 & 15.3 & 13160 & 30.3 & 2.36 & 653 & 4.64 \\
\hline 20 & 75 & 48 & 15.3 & 13298 & 30.5 & 2.38 & 647 & 4.71 \\
\hline 20 & 77 & 48.2 & 15.3 & 13303 & 30.4 & 2.37 & 656 & 4.63 \\
\hline 38 & 72 & 48 & 15.3 & 13140 & 29.9 & 2.40 & 660 & 4.53 \\
\hline 38 & 74 & 48 & 15.3 & 13134 & 30.5 & 2.35 & 670 & 4.55 \\
\hline
\end{tabular}




\section{Anexo II Capítulo V}

Tabla II.1. Resultados individuales de VPU, PUV, $f_{c}^{\prime}$ y E en cada tubo (inciso 5.6).

\begin{tabular}{|c|c|c|c|c|c|c|c|}
\hline \multirow{3}{*}{ Propiedades } & & \multicolumn{6}{|c|}{ Hormigón } \\
\hline & & \multicolumn{2}{|c|}{ HAC-0 } & \multicolumn{2}{|c|}{ HACRF-25 } & \multicolumn{2}{|c|}{ HACRF-50 } \\
\hline & $\mathrm{H}(\mathrm{m})$ & Tubo A & Tubo B & Tubo A & Tubo B & Tubo A & Tubo B \\
\hline \multirow{7}{*}{ VPU $(\mathrm{km} / \mathrm{s})$} & 0.27 & 4.93 & 4.97 & 5.01 & 5.24 & 4.84 & 5.00 \\
\hline & 0.60 & 4.95 & 4.97 & 4.93 & 4.91 & 4.88 & 4.87 \\
\hline & 0.93 & 5.04 & 4.98 & 4.86 & 4.95 & 4.95 & 4.89 \\
\hline & 1.26 & 4.89 & 4.95 & 4.95 & - & 4.76 & 4.80 \\
\hline & 1.59 & 5.01 & 5.09 & 4.92 & - & - & 4.93 \\
\hline & 1.92 & 4.94 & - & 4.97 & 4.98 & 4.85 & 4.89 \\
\hline & 2.25 & 4.95 & 4.89 & 4.85 & 4.76 & 4.82 & 4.69 \\
\hline \multirow{7}{*}{$\mathrm{f}^{\prime} \mathrm{c}(\mathrm{MPa})$} & 0.27 & 53.0 & 50.2 & 57.8 & 55.2 & 56.2 & 55.3 \\
\hline & 0.60 & 56.1 & 46.7 & 62.3 & 52.3 & 54.7 & 61.8 \\
\hline & 0.93 & 58.6 & 56.0 & 60.6 & 55.8 & 56.9 & 57.8 \\
\hline & 1.26 & 55.8 & 57.9 & 56.1 & - & 57.5 & 49.1 \\
\hline & 1.59 & 46.0 & 53.9 & 60.2 & - & - & 59.2 \\
\hline & 1.92 & 54.5 & - & 60.8 & 51.1 & 49.9 & 53.3 \\
\hline & 2.25 & 48.0 & 45.2 & 45.2 & 50.1 & 37.7 & 54.2 \\
\hline \multirow{7}{*}{$E(G P a)$} & 0.27 & 38.5 & & 38.1 & & & 37.9 \\
\hline & 0.60 & 38.7 & & 37.7 & & & 38.95 \\
\hline & 0.93 & 38.5 & & 37.95 & & & 37.8 \\
\hline & 1.26 & 38.7 & & 37.9 & & & 38.0 \\
\hline & 1.59 & 37.2 & & 37.8 & & & 38.2 \\
\hline & 1.92 & 37.85 & & 37.8 & & & 36.5 \\
\hline & 2.25 & 37.3 & & 36.9 & & & 35.8 \\
\hline \multirow{7}{*}{$\operatorname{PUV}\left(\mathrm{kg} / \mathrm{m}^{3}\right)$} & 0.27 & 2170 & 2156 & 2152 & 2145 & 2173 & 2183 \\
\hline & 0.60 & 2160 & 2168 & 2165 & 2145 & 2175 & 2168 \\
\hline & 0.93 & 2161 & 2147 & 2166 & 2135 & 2174 & 2170 \\
\hline & 1.26 & 2154 & 2162 & 2149 & - & 2183 & 2168 \\
\hline & 1.59 & 2132 & 2161 & 2146 & - & - & 2165 \\
\hline & 1.92 & 2149 & - & 2153 & 2145 & 2152 & 2155 \\
\hline & 2.25 & 2148 & 2149 & 2149 & 2136 & 2167 & 2148 \\
\hline
\end{tabular}


Tabla II.2. Resultados individuales del relevamiento de agregados en cada tubo (inciso 5.6).

\begin{tabular}{cccccccc}
\hline & \multicolumn{9}{c}{ HAC-0 } & \multicolumn{2}{c}{ HACRF-25 } & \multicolumn{2}{c}{ HACRF-50 } \\
& $\mathbf{h}(\mathbf{m})$ & Tubo A & Tubo B & Tubo A & Tubo B & Tubo A & Tubo B \\
\hline & 0.12 & 0.26 & 0.25 & 0.32 & 0.30 & 0.31 & 0.25 \\
& 0.45 & 0.26 & 0.30 & 0.27 & 0.25 & 0.36 & 0.27 \\
Densidad & 0.78 & 0.26 & 0.30 & 0.23 & 0.33 & 0.27 & 0.30 \\
agregados $\left(\mathrm{cm}^{2} / \mathrm{cm}^{2}\right)$ & 1.11 & 0.28 & 0.35 & 0.32 & - & 0.29 & 0.31 \\
& 1.44 & 0.34 & 0.37 & 0.31 & - & 0.27 & 0.34 \\
& 1.77 & 0.34 & 0.32 & 0.29 & - & 0.20 & 0.31 \\
& 2.10 & 0.38 & 0.24 & 0.29 & 0.32 & 0.30 & 0.30 \\
& 2.43 & 0.32 & - & 0.29 & 0.26 & 0.36 & 0.30 \\
\hline & & & & & & & \\
$N^{\circ}$ agregados $\left(\mathrm{N}^{2} / \mathrm{cm}^{2}\right)$ & 1.11 & 57 & 69 & 59 & - & 53 & 53 \\
& 0.12 & 60 & 56 & 58 & 68 & 63 & 59 \\
& 0.45 & 62 & 49 & 55 & 44 & 66 & 59 \\
& 1.44 & 53 & 59 & 61 & - & 46 & 53 \\
& 1.77 & 64 & 36 & 57 & - & 44 & 43 \\
& 2.10 & 61 & 46 & 64 & 44 & 46 & 46 \\
& 2.43 & 43 & 46 & 52 & 59 & 55 & - \\
\hline
\end{tabular}


Tabla II.3. Resultados individuales del relevamiento de fibras (inciso 5.6).

\begin{tabular}{cccccc}
\hline & & \multicolumn{2}{c}{ HACRF-25 } & \multicolumn{2}{c}{ HACRF-50 } \\
& Altura (cm) & Tubo A & Tubo B & Columna A Columna B \\
\hline & 0.12 & 0.42 & & 0.32 & 0.64 \\
Fibras núcleo & 0.45 & 0.35 & 0.42 & 0.50 & 0.57 \\
$\left(\mathrm{~N}^{\circ}\right.$ & 0.78 & 0.25 & 0.25 & 0.78 & 0.18 \\
fibras $\left./ \mathrm{cm}^{2}\right)$ & 1.11 & 0.18 & 0.25 & 0.71 & 0.42 \\
& 1.44 & 0.11 & & 0.78 & 0.25 \\
& 1.77 & 0.14 & & 0.74 & 0.18 \\
& 2.10 & 0.11 & 0.25 & 0.32 & 0.18 \\
Fibras anillo & 0.43 & 0.11 & 0.39 & 0.25 & 0.18 \\
\hline exterior & 0.12 & 0.41 & & 0.26 & 0.59 \\
$\left(\mathrm{~N}^{\circ}\right.$ & 0.78 & 0.24 & 0.32 & 0.51 & 0.55 \\
fibras $\left./ \mathrm{cm}^{2}\right)$ & 1.11 & 0.12 & 0.57 & 0.53 & 0.51 \\
& 1.44 & 0.28 & & 0.74 & 0.44 \\
& 1.77 & 0.27 & & 0.73 & 0.64 \\
& 2.10 & 0.21 & 0.20 & 0.46 & 0.19 \\
Fibras Total & 2.43 & 0.11 & 0.15 & 0.17 & 0.20 \\
$\left(\mathrm{~N}^{\circ}\right.$ & 0.12 & 0.42 & & 0.27 & 0.12 \\
\hline fibras $\left./ \mathrm{cm}^{2}\right)$ & 0.45 & 0.27 & 0.34 & 0.50 & 0.56 \\
& 1.11 & 0.31 & 0.49 & 0.59 & 0.42 \\
& 1.44 & 0.13 & 0.49 & 0.73 & 0.43 \\
& 1.77 & 0.24 & & 0.74 & 0.54 \\
\hline & 2.10 & 0.19 & 0.21 & 0.53 & 0.19 \\
& 2.43 & 0.11 & 0.21 & 0.19 & 0.19 \\
& & & & & 0.13 \\
\hline
\end{tabular}




\section{Nomenclatura}

A: Àrea $\left(\mathrm{cm}^{2}\right)$.

$A_{f}$ : Sección transversal de una fibra $\left(\mathrm{mm}^{2}\right)$.

Abs: Absorción de agua (\%).

b: Ancho (mm, cm).

Co: Coeficiente de orientación de las fibras.

CoV: Coeficiente de variación (\%).

D: Coeficiente de difusión.

$D_{1}$ : Coeficiente de difusión de iones en solución libre.

$D_{0}$ : Coeficiente de difusión de iones en el material homogéneo.

$D_{\mathrm{f}}$ : Diámetro final correspondiente al ensayo de escurrimiento $(\mathrm{mm})$.

$D_{\mathrm{fJ}}$ : Diámetro final correspondiente al ensayo de escurrimiento con anillo $\mathrm{J}(\mathrm{mm})$.

$\mathbf{D}_{\mathrm{BZ}, 2}^{\mathrm{f}}, \mathbf{D}_{\mathrm{Bz}, 3}^{\mathrm{f}}$ : Áreas bajo la curva tensión-deformación (ensayo de flexión)

correspondiente al aporte de las fibras.

E: Módulo de elasticidad (GPa).

Ed: Módulo de elasticidad dinámico (GPa).

$\mathbf{f}^{\prime}{ }_{c}$ : Resistencia a compresión (MPa).

$\mathbf{f}_{\mathrm{cd}}$ : Resistencia a tracción por compresión diametral (MPa).

$\mathbf{f}_{\text {crít: }}$ Tensión crítica $(\mathrm{MPa})$.

$\mathbf{f}_{\text {eq2 }}$ : Tensión media hasta una deformación $\delta_{2}=\delta_{\mathrm{L}}+0.65 \mathrm{~mm}(\mathrm{MPa})$.

$f_{\text {eq3 }}$ : Tensión media hasta una deformación $\delta_{3}=\delta_{\mathrm{L}}+2.65 \mathrm{~mm}(\mathrm{MPa})$.

$\mathbf{f}_{\text {inic: }}$ Tensión de iniciación (MPa).

$\mathbf{f}_{\mathrm{L}}$ : Tensión de primera fisura (MPa).

$\mathbf{f}_{\mathrm{M}}$ : Tensión última $(\mathrm{MPa})$.

$\mathbf{f}_{\text {net: }}$ Resistencia a tracción sobre vigas entalladas (MPa).

$\mathbf{f}_{\mathrm{R} 1}$ : Tensión residual para una apertura de fisura de $500 \mu \mathrm{m}(\mathrm{MPa})$.

$\mathbf{f}_{\mathrm{R} 2}$ : Tensión residual para una apertura de fisura de $1500 \mu \mathrm{m}(\mathrm{MPa})$.

$\mathbf{f}_{\mathrm{R} 3}$ : Tensión residual para una apertura de fisura de $2500 \mu \mathrm{m}(\mathrm{MPa})$.

$\mathbf{f}_{\mathrm{R} 4}$ : Tensión residual para una apertura de fisura de $3500 \mu \mathrm{m}(\mathrm{MPa})$.

$\mathrm{f}_{\mathrm{R} 1-\delta}$ : Tensión residual para una flecha de $470 \mu \mathrm{m}(\mathrm{MPa})$.

$\mathbf{f}_{\mathrm{R2}-\delta}$ : Tensión residual para una flecha de $1320 \mu \mathrm{m}(\mathrm{MPa})$.

$\mathbf{f}_{\mathrm{R3}-\delta}$ : Tensión residual para una flecha de $2170 \mu \mathrm{m}(\mathrm{MPa})$.

$\mathbf{f}_{\mathrm{R4}-\delta}$ : Tensión residual para una flecha de $3020 \mu \mathrm{m}$ (MPa). 
K: Coeficiente de permeabilidad al agua $(\mathrm{m} / \mathrm{s})$.

h: Altura (mm, cm).

$\mathbf{h}_{\mathrm{sp}}$ : Altura de la probeta descontando la entalla $(\mathrm{mm}, \mathrm{cm})$.

J: velocidad de transferencia de la masa a través de una sección unitaria.

I: Longitud ( $\mathrm{mm}, \mathrm{cm})$.

$\mathbf{I}_{\mathrm{f}}$ : Longitud de una fibra $(\mathrm{mm})$.

L: Luz entre apoyos ( $\mathrm{mm}, \mathrm{cm})$.

$\mathbf{L}_{v}$ : Longitud total de fibras en un volumen unitario de hormigón (mm).

ND: Profundidad de la entalla $(\mathrm{mm})$.

$\mathbf{N}^{\mathbf{p}}{ }_{\mathrm{A}}$ : Número de fibras por unidad de área paralela a la dirección de llenado $\left(\mathrm{N} / \mathrm{cm}^{2}\right)$.

$\mathbf{N}_{\mathrm{A}}{ }_{\mathrm{A}}$ : Número de fibras por unidad de área perpendicular a la dirección de llenado $\left(\mathrm{N} / \mathrm{cm}^{2}\right)$.

OF: Factor de orientación de fibras.

P: Carga $(\mathrm{kg})$.

Ps: Peso seco a estufa (g).

Psss: Peso saturado a superficie seca (g).

Psum: Peso sumergido (g).

PUV: Peso por unidad de volumen $\left(\mathrm{kg} / \mathrm{m}^{3}\right)$.

Q: Caudal $\left(\mathrm{m}^{3} / \mathrm{s}, \mathrm{g} / \mathrm{s}\right)$.

s: Velocidad de succión capilar $\left(\mathrm{g} / \mathrm{m}^{2} / \mathrm{s}^{1 / 2}\right)$.

t: Tiempo (s).

$\mathbf{T}_{50}$ : Tiempo correspondiente a un diámetro de $500 \mathrm{~mm}$ en el ensayo de escurrimiento (s).

$\mathbf{T}_{50 \mathrm{j}}$ : Tiempo correspondiente a un diámetro de $500 \mathrm{~mm}$ en el ensayo de escurrimiento con anillo J (s).

$\mathbf{T}_{\mathrm{v}}$ : Tiempo correspondiente al ensayo de embudo en $\mathrm{V}(\mathrm{s})$.

$V_{\mathrm{f}}$ : Volumen de fibras.

VPU: Velocidad de Pulso Ultrasónico $(\mathrm{km} / \mathrm{s})$.

w: Grado de orientación.

$\Delta \mathbf{P}$ : Variación de presión $\left(\mathrm{kg} / \mathrm{cm}^{2}\right)$.

$\delta$ : Densidad.

$\delta_{\mathrm{L}}$ : Flecha correspondiente a la primera fisura $(\mathrm{mm})$.

$\Delta \mathbf{c} / \Delta \mathbf{x}$ : Gradiente de concentración.

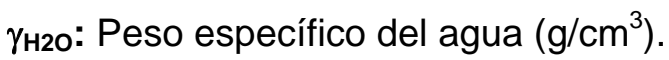

$\sigma:$ Desviación estándar.

$\mu$ : Coeficiente de Poisson. 